Rechtsmedizin $2013 \cdot 23: 287-358$

DOI 10.1007/s00194-013-0903-8

๑) Springer-Verlag Berlin Heidelberg 2013

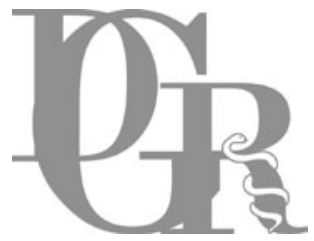

UNIVERSITÄT

DES

SAARLANDES

\section{Jahrestagung der Deutschen Gesellschaft für Rechtsmedizin}

Saarbrücken,

17. - 21. September 2013

Inhalt

288

V1-141

Vorträge der 92. Jahrestagung der Deutschen Gesellschaft für Rechtsmedizin

Abstracts of the 92nd Annual Conference of the

German Society of Legal Medicine

$327 \quad P_{1}-85$

Poster der 92. Jahrestagung der Deutschen Gesellschaft für Rechtsmedizin

Posters of the 92nd Annual Conference of the

German Society of Legal Medicine

355

Autorenindex

Index of authors 


\section{Vorträge der 92. Jahrestagung der Deutschen Gesellschaft für Rechtsmedizin}

\section{V1 \\ Kritische Analyse ausgewählter Aspekte des Patientenrechte- gesetzes (PatRG)}

\author{
M. Parzeller', B. Zedler \\ 'Institut für Rechtsmedizin, Goethe-Universität, Frankfurt am Main, \\ Deutschland
}

Fragestellung. Nach umfangreichen Beratungen trat am 26.02.2013 das Patientenrechtegesetz (Gesetz zur Verbesserung der Rechte von Patientinnen und Patienten - PatRG) als Artikelgesetz ohne Übergangsfrist in Kraft. Die Vorgaben des PatRG sind nicht nur für den behandelnden Arzt, sondern auch für den medizinischen Sachverständigen in Arzthaftungsverfahren von Relevanz.

Methoden. Unter Berücksichtigung bisherigen Rechts und des Richterrechts in Arzthaftungssachen wurde der Behandlungsvertrag als „,neuer besonderer Vertragstyp “ (Gesetzentwurf der Bundesregierung, BR-Drs. $312 / 12$ S. 12, 17) in das BGB eingefügt. Die zivilrechtlichen Regelungen des PatRG (\$630a-h BGB) werden vorgestellt und einer kritischen Bewertung unterzogen.

Ergebnisse. $\$ 630$ a BGB regelt die vertragstypischen Pflichten der medizinischen Behandlung, wobei nicht nur ärztliche Behandelnde in die Regelungen einbezogen sind. Probleme ergeben sich bei der Bestimmung der geschuldeten Behandlung, z. B. im Hinblick auf Neuland. Methoden. $₫ 630 c$ BGB regelt $u$. a. die therapeutische Informationspflicht des Behandelnden, wobei teilweise die Trennschärfe zur Selbstbestimmungsaufklärung nach $\$$ 630e BGB unklar bleibt. Rechtliche Probleme stellen sich u. a. bezüglich der Informationspflicht des Behandelnden nach $\$ 630$ o BGB über Behandlungsfehler auf Nachfrage des Patienten oder zur Abwendung gesundheitlicher Gefahren oder beim Recht auf unverzügliche Einsichtnahme in die vollständige Patientenakte. Regelungen zur Beweislast (bei voll beherrschbarem Risiko, bei der Einwilligung und Aufklärung, bei Dokumentationsmängeln, bei mangelnder Befähigung und bei grobem ärztlichem Behandlungsfehler) wären eher in der ZPO als in $₫ 630$ h BGB zu erwarten gewesen und sind teilweise unvollständig.

Schlussfolgerungen. Der Gesetzgeber geht teilweise von einer sehr idealistischen Vorstellung aus, wenn er glaubt, dass die Lektüre des Gesetzeswortlautes ohne Kenntnis der Rechtsprechung den Patienten in die Lage versetzt, seine Rechte zu erkennen. Allerdings dürfte durch diese Kodifizierung bislang praktizierten Richterrechts und weiterer Verschärfungen zu Lasten der Behandelnden in Zukunft mit einem Anstieg von haftungsrechtlichen Verfahren nach medizinischen Behandlungen zu rechnen sein.

\section{V2}

\section{Behandlungsfehler - Aspekte aus Sicht einer Klinikärztin}

\section{E. Türk}

\section{'Asklepios Klinik Harburg, Kardiologie, Hamburg, Deutschland}

Die Begutachtung in Fällen mutmaßlicher ärztlicher Behandlungsfehler ist eine zentrale Aufgabe rechtsmedizinischer Sachverständiger. Dabei steht sowohl in der gerichtlichen Würdigung als auch in der rechtsmedizinischen Begutachtung meist die Frage eines ärztlichen oder pflegerischen Fehlverhaltens im Vordergrund. Das Verhalten von sog. „patientenfernen“ Entscheidungsträgern, etwa der kaufmännischen Leitung einer Klinik, die dem Kostensparen zunehmend eine höhere Priorität einräumen als der Patientensicherheit, ist dagegen bislang kaum Gegenstand strafrechtlicher Verfolgung. Eine stärkere Berücksichtigung dieser organisatorischen Entscheidungen in der rechtsmedizinischen Begutachtung könnte dazu beitragen, eine besse- re medizinische Versorgung auch auf der Ebene der „patientenfernen“ Entscheidungsträger zu gewährleisten.

Der vorliegende Vortrag soll anhand von Beispielen aus der eigenen Praxis die Bedeutung der „Täter hinter den Tätern“ verdeutlichen und einige Hinweise für die rechtsmedizinische Begutachtungspraxis liefern.

\section{V3}

Anwendung einer neuen Methode zur Messung der postmortalen Pupillenweite: Intra- und Interraterreliabilität

\section{S. Anders', L. Fleischer', S. Susanne', K. Püschel', A. Gehl'}

'Universitätsklinikum Hamburg-Eppendorf, Institut für Rechtsmedizin, Hamburg, Deutschland, ${ }^{2}$ Universitätsklinikum Hamburg-Eppendorf, Institut für Medizinische Biometrie und Epidemiologie, Hamburg, Deutschland

Fragestellung. Bei der Anwendung der Komplexmethode zur Eingrenzung des Todeszeitpunkts kommt die Messung der Pupillenweite zur Anwendung bzw. deren Änderung nach pharmakologischer Beeinflussung. Die Messungen wurden unter Verwendung von Pupillometern oder Zentimetermaßen etabliert, jedoch sind erstere nicht ubiquitär verfügbar und letztere nur wenig exakt ablesbar. In der vorliegenden Studie soll eine neue Methodik zur Messung der postmortalen Pupillenweite etabliert und hinsichtlich ihrer Reliabilität evaluiert werden.

Methoden. Die postmortale Pupillen- und Irisgröße sowie deren Verhältnis zueinander wurden nach digitalfotographischer Dokumentation der Augen mit Hilfe des Freeware-Programms ImageJ bestimmt. Hierbei nahmen 4 Rater jeweils 3 Messungen an Fotographien von (a) drei unterschiedlichen Verstorbenen $\mathrm{zu} 14^{-15}$ verschiedenen Postmortalzeitpunkten (insgesamt 44 Aufnahmen) und (b) 27 unterschiedlichen Verstorbenen zu je einem Postmortalzeitpunkt vor. Die Intra- und Interraterreliabilität wurden für die Messserien (a) und (b) berechnet. Ergebnisse. Sowohl bei (a) mehrfacher Messung des gleichen Falles als auch (b) einmaliger Messung verschiedener Fälle wiesen die Messergebnisse eine Intra- und Interraterreliabilität von $>0,9$ auf.

Schlussfolgerungen. Als technische Vorraussetzung zur Anwendung der vorgestellten Methode sind lediglich ein Computer und eine Digitalkamera notwendig. Das verwendete Programm steht im Internet kostenfrei zur Verfügung. Die Ergebnisse zeigen, dass ein hohes Maß an Reproduzierbarkeit der Ergebnisse bei Mehrfachuntersuchungen durch denselben Rater sowie bei Messwiederholungen durch einen anderen Rater gegeben ist. Zudem ist durch die Archivierbarkeit der digitalen Fotographien eine Überprüfbarkeit der Untersuchungsergebnisse jederzeit gegeben. Somit erscheint die vorgestellte Methode zur Anwendung für forensische Zwecke als sehr gut geeignet.

\section{V4}

\section{Das Schütteltrauma - wer war's?}

J. Sperhake', C. Kreye', J. Matschke²

'Institut für Rechtsmedizin, Universitätsklinikum Hamburg-Eppendorf, Hamburg, Deutschland, ${ }^{2}$ Institut für Neuropathologie, Universitätsklinikum Hamburg-Eppendorf, Hamburg, Deutschland

Einleitung. Das Schütteltrauma ist die häufigste Form des nichtakzidentellen Schädel-Hirn-Traumas im Säuglingsalter. In der Literatur existieren nur wenige Studien, die sich mit epidemiologischen Aspekten der Täterschaft befassen. Systematische Analysen sind aber nur schwer durchführbar, da es nur wenige Geständnisse gibt.

Fragestellung. Wie ist das Geschlechterverhältnis der Täter beim Schütteltrauma?

Methoden. Schütteltraumafälle aus 13 Jahren (1997-2009) wurden analysiert, mit denen das Hamburger Institut für Rechtsmedizin gutachterlich befasst war (Obduktion und/oder klinische Untersuchung und/ oder Aktengutachten). Die Daten wurden aus den archivierten Hand- 


\begin{tabular}{|c|c|c|c|c|c|c|c|}
\hline Fall & Jahr & $\begin{array}{l}\text { Lebens- } \\
\text { alter } \\
\text { (Jahre) }\end{array}$ & Geschlecht & $\begin{array}{l}\text { Todesursache lt. } \\
\text { Todesbescheinigung }\end{array}$ & $\begin{array}{l}\text { Todesursache/ } \\
\text { Tatsächliche Diagnose }\end{array}$ & $\begin{array}{l}\text { Falsche Todesfest- } \\
\text { stellung durch }\end{array}$ & Überlebt \\
\hline 1 & 1998 & 89 & w & $\begin{array}{l}\text { Unterkühlung als Folge } \\
\text { von Herzversagen bei } \\
\text { Demenzsyndrom }\end{array}$ & $\begin{array}{l}\text { Koronarsklerose mit } \\
\text { Schwielenaneurysma }\end{array}$ & Hausarzt & ca. $5 \mathrm{~h}$ \\
\hline 2 & 2007 & 78 & $\mathrm{~m}$ & $\begin{array}{l}\text { Todesbescheinigung } \\
\text { nicht ausgestellt }\end{array}$ & Offenbar SHT nach Sturz & Rettungssanitäter & Jahre \\
\hline 3 & 2011 & 58 & w & $\begin{array}{l}\text { Tablettenintoxikation als } \\
\text { Folge von Depressionen, } \\
\text { chronischem Schmerz- } \\
\text { syndrom }\end{array}$ & $\begin{array}{l}\text { Opiat-Benzodiazepin- } \\
\text { Intoxikation }\end{array}$ & Ltd. Notarzt & Jahre \\
\hline
\end{tabular}

akten des Institutes und aus den Ermittlungsunterlagen der Staatsanwaltschaft entnommen. Ein besonderes Augenmerk lag dabei auf der Frage, ob ein Geständnis oder eine Verurteilung vorlagen. War dies nicht zu klären, wurde analysiert, unter wessen Aufsicht das Kind zuletzt gewesen sein soll.

Ergebnisse. Insgesamt 54 Fälle, bei denen aus rechtsmedizinischer Sicht ein Schütteltrauma hochwahrscheinlich bis gesichert war, wurden für die Studie im Hinblick auf die Täterschaft ausgewertet. In 10 Fällen gab es entweder Geständnisse oder die Beweislage führte zu einer Verurteilung vor Gericht ( 9 Männer, eine Frau). In 24 Fällen ohne Geständnis oder Verurteilung wurde deutlich, unter wessen Aufsicht das Kind zuletzt gestanden haben soll: In 9 Fällen soll es mit einem Mann allein gewesen sein, in 4 Fällen mit einer Frau (Mutter) und in 20 Fällen sowohl mit Mutter und deren Partner. In 11 Fällen blieb die Frage, wer bei dem Kind war, ungeklärt.

Schlussfolgerungen. Es ist anzunehmen, dass sich die meisten jungen Säuglinge ganz überwiegend in der Obhut der Mutter befinden. Das Überwiegen von Männern, sowohl bei den Geständnissen als auch bezüglich der Frage, wer die letzte Aufsicht hatte, spricht daher für ein Überwiegen von männlichen Tätern beim Schütteltrauma.

\section{V5}

\section{"Scheintod" - AEIOU?}

S. Kraus' W. Keil'

'Institut für Rechtsmedizin, München, Deutschland

Einleitung. Fehlerhafte Leichenschauen führen vereinzelt zu falschen Feststellungen des Todes. Dadurch wird nach wie vor das Phänomen „Scheintod“ aufrechterhalten. Verlässliche Daten zu Häufigkeiten und Ursachen von „Scheintodfällen“ sind nur sehr eingeschränkt verfügbar. Vor Jahrzehnten ist in der Rechtsmedizin die AEIOU-Regel eingeführt worden. Es stellt sich die Frage, ob diese Faustregel vor dem Hintergrund veränderter gesellschaftlicher Bedingungen und einer sich wandelnden medizinischen Versorgung noch ihre Berechtigung hat.

Methoden. Es wurden die im Versorgungsgebiet des Münchner Instituts für Rechtsmedizin in den Jahren 1998 bis 2011 begutachteten Fälle mit falscher Todesfeststellung ausgewertet. Darüber hinaus wurde in Bezug auf Deutschland bzw. Europa eine Literatur- und Internetrecherche durchgeführt, um Häufigkeiten, Fallkonstellationen bzw. Ursachen derartiger Fälle besser einzuschätzen.

Ergebnisse. Die im Münchner Institut bearbeiteten Fälle sind in Tab. 1 zusammengestellt. Im Fall 1 hatte die 89-Jährige mehrere Stunden im Nachthemd im Treppenhaus gelegen. Der Tod wurde aufgrund der „Leichenkälte“ dokumentiert. Im Fall 2 spielte die „Kältestarre“ eine Rolle für die Fehleinschätzung. Auch im Fall 3 wurde der Tod aufgrund einer „spürbaren Starre“ (offenbar infolge längerer Liegezeit, Auskühlung und Austrocknung) festgestellt. Das Fehlen der Totenflecken wurde jeweils nicht berücksichtigt $\bullet$ Tab. 1.
Schlussfolgerung. Die eigenen Begutachtungen von Fällen falscher Todesfeststellungen und die Recherchen erbrachten keine fehlerhaften Todesfeststellungen, die mit Alkohol, Anämie, Elektrizität (Blitzschlag) oder Urämie in Zusammenhang zu bringen sind. Insofern erscheint die AEIOU-Regel die Verhältnisse der Realität dieser tragischen Fälle nicht widerzuspiegeln.

\section{V6}

\section{Die Evidenz des Bildlichen in der Forensik}

\section{F. Ramsthaler', M. Kettner', M.A. Verhoff ${ }^{2}$}

'Universität des Saarlandes, Institut Rechtsmedizin, Homburg, Deutschland, ${ }^{2}$ Universität Gießen, Institut für Rechtsmedizin, Gießen, Deutschland

Die forensische Medizin hat sich seit Anbeginn unterschiedlichster Techniken bedient, um Befunde „ins Bild“ zu setzen. Dabei dienen die gewonnenen (heutzutage zumeist digitalen?) Bilder nicht nur der Illustration und Präsentation von Beobachtungen, sondern auch der Dokumentation und Speicherung von Befunden. Eine weitere, auf den ersten Blick nicht so naheliegende Funktion wird deutlich, wenn man bildgebende Verfahren als technische Modalität der Erzeugung von Abbildern basierend auf Messparametern real existierender Objekte begreift, bei denen die gewonnenen, bzw. durch das Gerät erzeugten Daten erst in eine visuelle Form überführt werden müssen, um als kommunizierbarer Befund in Diagnostik und darauf basierenden forensischen Beurteilungen verwendet werden zu können. In der Forensik werden Derivate der Bildgebung zudem nicht selten in rekonstruktive Kontexte eingebettet, wo sie als Visualisierungen einer validen und objektiven Spurenerkennung und -sicherung verwendet werden.

Die Bedeutung bildgebender Befunde ist nicht zu unterschätzen, weil diese dem Betrachter schlagkräftige, oft umgehend einleuchtende visuelle Argumente liefern, die als Grundlage für gutachterliche und folglich juristische Entscheidungen dienen können.

Die Befürworter einer komplementären Kopplung von klassischer Morphologie und digitaler Bildgebung in der forensischen Fallarbeit führen das Argument an, dass Bildgebung eine objektivere Dokumentation forensisch relevanter Beobachtungen ermöglicht, die unabhängig von der Subjektivität des Beobachters und unabhängig vom Wissen und der Erfahrung des Beurteilers Befunde „archiviert". Besonders in Fällen, die ihre Relevanz zu einem wesentlichen Anteil aus der Erzeugung einer bildlichen Evidenz beziehen (z. B. Altersschätzung von intrakraniellen Hämatomen nach Schütteltrauma), stellt sich angesichts der methodenabhängigen „Unschärfe“ eines jeden Bildbefundes die wissenschaftlich im Detail komplexe und forensisch weitreichende Frage nach der tatsächlichen Objektivität und Vollständigkeit der durch Bildgebung bereitgestellten Information, z. B. im Vergleich zu einem makromorphologischen Obduktionsbefund, einem Laborergebnis oder einem hergestellten Präparat.

Die in der klinischen Diagnostik analog geführten Debatten um den Umgang mit moderner Bildgebung belegen, dass neue bildgenerierende 
Systeme auch Befundergebnisse hervorbringen können, deren diagnostische oder therapeutische Relevanz nicht in jedem Fall gesichert ist Der in diesem Kontext zirkulierende Begriff des UBO (,unidentified bright object") kann daher durchaus als Hinweis dafür gelten, dass jenseits aller Vorzüge und Vorteile bei der Erkenntnisgewinnung durch moderne Bildgebung mögliche Fehlerquellen und Fehlinterpretationen nicht außer Acht gelassen werden dürfen. Wie jede andere auf objektivierbaren Befunden basierende diagnostische oder therapeutische Entscheidung muss auch das auf Bildgebung fundierende Fachurteil den Ansprüchen einer evidenzbasierten Grundstruktur genügen.

Nachfolgender Vortrag soll anhand „bildlicher“ Beispiele aus Klinik und Forensik die Möglichkeiten und Grenzen moderner Bildgebung aus der Perspektive einer evidenzbasierten Forensik aufzeigen. Ziel der Ausführungen ist unter anderem, zu belegen, dass seit dem Einzug der Digitalisierung in den Bilderzeugungs- und Bildpräsentationstechniken Bilder zunehmend als epistemische Desiderate fungieren, die ohne weiteres als komplementäre visuelle Analytika definierbar sind, weil sie bestimmte Aussagen über Objektstrukturen ermöglichen, die verfahrensspezifisch (z. B. Schnittbildverfahren) überhaupt erst hervorgebracht werden. Der Erkenntnisgewinn begründet sich somit in der bildlichen Darstellung als Conditio sine qua non für eine zusätzliche Erkenntnis. Die Bedeutung der modernen Bildgebung für die Forensik ergibt sich folglich aus der Tatsache, dass mit ihrer Hilfe nicht nur bekanntes und a-priori vorhandenes Wissen illustriert oder bestätigt werden kann, sondern auch aus ihrer Zielsetzung, zusätzliche objektive Erkenntnisse zu generieren, die ohne die Bildgebung verborgen geblieben wären.

\section{V7}

Neues aus der Technical Working Group Post-mortem Angiography Methods (TWGPAM): Multizenterstudie zur Validierung der "multiphase post-mortem CT angiography“

S. Grabherr', J. Grimm' ', A. Heinemann'2, G. Guglielmi', K. Wozniak', F. Eplinius5, F. Dedouit ${ }^{6}$, F. Fischer', G. Rutty ${ }^{8}$, B. Morgan ${ }^{9}$, H. Wittig ${ }^{10}$, P. Mangin', R. Dirnhofer'

'Institut für Rechtsmedizin Lausanne-Geneva, Forensische Medizin/Bildgebung, Lausanne, Schweiz, ${ }^{2}$ Universitätsklinikum Hamburg- Eppendorf, Institut für Rechtsmedizin, Hamburg, Deutschland, ${ }^{3}$ University of Foggia, Department of Radiology, Foggia, Italien, ${ }^{4}$ Uniwersytet Jagiellonski, Department of Forensic Medicine, Kraków, Polen, ${ }^{5}$ Unversität Leipzig, Institut für Rechtsmedizin, Leipzig, Deutschland, ${ }^{6}$ Hôpital Rangueil, Department of Radiology, Toulouse, Frankreich, ${ }^{7}$ Universität München, Institut für Rechtsmedizin, München, Deutschland, ${ }^{8}$ University of Leicester, East Midlands Forensic Pathology Unit, Leicester, Vereinigtes Königreich, ${ }^{2}$ University of Leicester, Department of Radiology, Leicester, Vereinigtes Königreich, ${ }^{10}$ Universität Basel, Institut für Rechtsmedizin, Basel, Schweiz

Einleitung. Durch detaillierte Darstellung des Gefäßsystems kann die postmortale CT-Angiographie die diagnostische Sensitivität der Leichenuntersuchung erhöhen. Dies wurde bereits in mehreren Publikationen beschrieben. Trotzdem sind die meisten Methoden bis heute eher zu Forschungszwecken als in der Routine eingesetzt worden. Um dies zu ändern, ist es wichtig, standardisierte Methoden und entsprechendes technisches Equipment zu entwickeln, welche den Einsatz in der täglichen Routine ermöglichen. Mit diesem Ziel vor Augen wurde im Februar 2012 eine internationale Arbeitsgruppe gegründet, welche sich TWGPAM (Technical Working Group Postmortem Angiography Methods) nennt. Sie besteht derzeit aus Vertretern von neun teilnehmenden rechtsmedizinischen Instituten aus sechs verschiedenen europäischen Ländern.

Methoden. Im Rahmen der TWGPAM wurde eine Multizenterstudie gestartet, welche die Durchführung einer standardisierten Methode namens MPMCTA („multi-phase post-mortem CT angiography“) validiert und dabei ihre Vorteile und Grenzen beschreibt. Eine ähnliche
Studie, welche 50 Fälle aus dem Institut für Rechtsmedizin in Lausanne als Studienkollektiv beinhaltet, wurde 2013 publiziert und dient als Vorbild für die laufende Multizenterstudie. Hierfür haben die TWGPAMMitglieder insgesamt 500 rechtsmedizinische und klinisch-pathologische Fälle mittels MPMCTA und Autopsie untersucht. Ein Team bestehend aus zwei Rechtsmedizinern und einem Radiologen führt derzeit die Datenaufnahme in den einzelnen Instituten durch. Alle Befunde aus CT, CT-Angiographie und Autopsie werden in eine Excel-Tabelle eingetragen, um sie später zu vergleichen und statistisch auszuwerten. Ergebnisse. Wie bereits die Vorstudie zeigte, kann die MPMCTA wichtige Befunde darstellen, welche mittels einer konventionellen Autopsie nicht zu erheben sind. Es gibt jedoch auch Diagnosen, welche erst nach einer Autopsie gestellt werden können. Die Multizenterstudie soll diese Befunde nennen, und die bestehende Technik validieren. Auf diese Art kann die MPMCTA in der Rechtsmedizin als standardisierte Technik akzeptiert und im Alltag einsetzbar werden.

Schlussfolgerung. Diese Studie ist einer der ersten Meilensteine im Rahmen der TWGPAM. Das weitere Vorgehen und zukünftige Entwicklungen der Arbeitsgruppe sollen vorgestellt werden, um die Gesellschaft zu informieren.

\section{V8}

\section{Fehlklassifikationsraten bei Rippenfrakturen: PMCT-Routinebefund} und PMCT-Second look sowie Sektion im Vergleich

\section{A. Heinemann', M. Kammal', A. Köwing', H. Vogel', K. Püschel'}

'Institut für Rechtsmedizin, Hamburg, Deutschland

Fragestellung. Das PMCT wird seit 2010 in Hamburg im Rahmen eines Routine-Indikationskatalogs vor gerichtsmedizinischen Sektionen eingesetzt. Dabei ergibt sich die Problematik, für das Ergebnisprotokoll bei Widersprüchen zwischen Sektion und PMCT je nach Status eines Befundes eine der beiden Methoden als Validierung zu definieren oder bei unauflösbaren Widersprüchen diese explizit zu thematisieren. In einer retrospektiven Studie wurde diese Problematik am Beispiel von Rippenfrakturen analysiert.

Material und Methoden. Es wurden die 134 Legalsektionen ausgewertet, die 2010 am IfR in Kombination mit einer Ganzkörper-PMCT durchgeführt wurden. Rippenfrakturbefunde als Ergebnis der Sektion und/ oder des PMCT-Erstbefundes (Fachradiologe) wurden einander gegenübergestellt und hinsichtlich der Häufigkeit, der Lokalisation, der Art und des Entstehungszeitpunkts (alt/frisch) verglichen. In den Vergleich wurde weiter eine Second-look-Validierung aller PMCT-Erstbefunde zum Rippenfrakturstatus (Fachradiologe) einbezogen.

Ergebnisse. Es wurden 54 Fälle mit mindestens einer Rippenfraktur (nachgewiesen mit mindestens einer Methode) ausgewertet, es ergab sich bei $n=24$ Rippen die Gesamtzahl von 1296 Einzelbefunden. Durch die Sektion wurden insgesamt $n=566$, durch die PMCT-Erstbefunderhebung $n=491$ und durch die PMCT-Zweitbefunderhebung $n=587$ Frakturen diagnostiziert. Ein Vergleich von PMCT-Erst- und -Zweitbefund ergab eine Falschklassifikationsrate von 9,2\% (o,6\% falsch-negativ, $8,6 \%$ falsch-positiv), der Vergleich von Sektion und PMCT-Second look eine Rate von $11,5 \%$. Fehlklassifikationen korrelierten mit der Lokalisation und der Art der Fraktur.

Schlussfolgerung. Eine PMCT-Ganzkörperbefundung stellt hohe Anforderungen an den Routine-Gutachter, mit einer Fehlerrate ist zu rechnen. Bei Widersprüchen zum Sektionsbefund auch nach PMCT-Second look ist bei (aus Sicht der Sektion) „falsch-negativen“ PMCT-Befunden - in Abhängigkeit von der Lokalisation - ggf. an Sektionsartefakte, bei „falsch-positiven“ an inkomplette Frakturtypen zu denken. 


\section{V9}

\section{Lungenbelüftung bei Neugeborenen und Totgeburten: Vergleich von CT-Dichte, Schwimmprobe und Histologie}

\section{F.T. Fischer', S. Lochner', L. Bechstein'², F. Mück², M. Scherr', J. Grimm ${ }^{3,4}$ 'Rechtsmedizin LMU München, Forensische Radiologie, München, Deutschland, ${ }^{2}$ Institut für Klinische Radiologie, LMU, München, Deutsch- land, 'Universität Lausanne, Institut für Rechtsmedizin, Lausanne, Schweiz, ${ }^{4}$ Universität Lausanne, CHUV, Department für Radiologie, Lausanne, Schweiz}

Einleitung. Die Lungenbelüftung gilt als Zeichen des "Gelebthabens“, solange keine iatrogenen Maßnahmen oder Fäulnis den Befund der Schwimmprobe verfälschen. Als aktueller Standard für die Beurteilung der Belüftung gelten hier Schwimmprobe und Histologie. Die CT ist durch die Möglichkeit der Messung der Strahlendichte gut geeignet, um die Proportion von Gas und Gewebe zu bestimmen. Ziel der Studie ist der Vergleich von CT und Schwimmprobe zur Beurteilung der Belüftung gemessen an der Histologie.

Methode. Von 38 verstorbenen Neugeborenen wurden 17 konsekutive Fälle von fraglichen Lebendgeburten verglichen mit 21 sicher gelebt habenden postpartal Verstorbenen. Alle wurden mittels CT, Schwimmprobe/Sektion und Histologie untersucht. Im CT wurde die durchschnittliche Strahlendichte in HU für beide Lungen gemessen, bei der Sektion Schwimmproben nach festgelegtem Standard durchgeführt. Die Histologie wurde fachärztlich pathologisch befundet.

Ergebnisse. Die Gruppe der sicher gelebt Habenden zeigte durchschnittlich $-207 \mathrm{HU}$ (SD $104 \mathrm{HU}$ ). Nach den Ergebnissen der CT fanden sich in 10 Fällen nicht belüftete Lungen mit im Schnitt 46 HU (SD 11 HU) und 7 belüftete Lungen mit durchschnittlich -147 HU (SD $201 \mathrm{HU}$ ), der Cut-off value lag bei -35 HU (ROC-Analyse). Die Schwimmprobe korrelierte mit dem CT-Ergebnis in 15 von 17 Fällen (88\%). Die Histologie korrelierte mit der CT in 17 von 17 Fällen (100\%). In Einzelfällen zeigte sich in der Histologie ein atypischer Lungenbefund, der nicht als reguläre Entfaltung bewertet werden konnte, gleichzeitig wiesen diese deutlich höhere CT-Dichten auf.

Schlussfolgerung. Die Messung der Lungenbelüftung anhand der Strahlendichte im CT scheint der Schwimmprobe überlegen. Es ist zu erwägen, die Schwimmprobe als Screeningmethode für die Lungenbelüftung durch eine postmortale CT vorläufig zu ergänzen und nach weiterer Validierung ggf. zu ersetzen. In Einzelfällen ist eine kritische Zusammenschau von Histologie und CT zur genauen differenzierten Beurteilung erforderlich. Die Schwimmprobe könnte in Einzelfällen ein falsch-positives Ergebnis hinsichtlich eines Gelebthabens liefern.

\section{V10 \\ Postmortales digitales Röntgen des Schädels - der Radiologe und Rechtsmediziner im Vergleich}

S. Heinze1,2, F. Müller', L. Hettler', G. Kastenholz², R. Urban', R.-J. Schröder', D. Breitmeier ${ }^{7}$

'Johannes Gutenberg-Universität Mainz, Institut für Rechtsmedizin, Mainz, Deutschland, ${ }^{2}$ St. Marienkrankenhaus, Radiologische Klinik, Ludwigshafen, Deutschland

Einleitung. Trotz der steigenden Relevanz der Bildgebung sowie der zunehmenden Bedeutung insbesondere der Computertomographie als Entscheidungs- und Befundungshilfe in der Rechtsmedizin stellt die Forensische Radiologie bisher kein eigenständiges Spezialgebiet mit entsprechender Weiterbildung dar.

Zielsetzung. Im Rahmen einer retrospektiven Auswertung von 700 postmortalen Röntgenuntersuchungen des Schädels, die vor jeder Sektion routinemäßig im Institut für Rechtsmedizin der Universitätsmedizin Mainz mittels des digitalen Röntgensystems Definium AMX 700 von GE Healthcare ${ }^{\circ}$ angefertigt werden, sollen die Stärken und Schwächen sowie die unterschiedlichen Interessenschwerpunkte in der
Interpretation der Röntgenbilder beider Fachrichtungen in der Begutachtung der o. g. Röntgenuntersuchungen evaluiert werden.

Methoden. Die digitalen Röntgenaufnahmen der Sektionsfälle des Jahres 2011 sowie der ersten Hälfte des Jahres 2012 wurden mittels eines eigens für die Studie erstellten standardisierten Erhebungsbogens namens „Schädel“ untersucht. Zunächst wurden die Röntgenaufnahmen im Rahmen der Obduktion durch den 1. Obduzenten und im Anschluss separat durch einen Radiologen in Unkenntnis des Sektionsergebnisses befundet. Zusätzlich wurde anschließend das Sektionsergebnis in dem Bogen erfasst. Im Nachgang an die rechtsmedizinische und radiologische Befundung wurden die Aufnahmen hinsichtlich Qualität der Aufnahmen, knöcherne Strukturen, Frakturen/Luxationen, körperfremdes Material, Schädelkavum und Kopf-/Halsweichteile unter Verwendung des Auswertebogens untersucht.

Ergebnisse. Die Ergebnisse der zwei Fachbereiche werden sowohl untereinander als auch mit den Sektionsergebnissen verglichen und statistisch ausgewertet.

Schlussfolgerung. Die teils erwarteten, aber auch überraschenden Ergebnisse von und zwischen den beiden Fachdisziplinen in Relation zum Sektionsergebnis werden im Vortrag diskutiert und evidenzbasierte, statistische Schlussfolgerungen dargestellt.

\section{V11}

\section{Postmortales digitales Röntgen des Thorax - der Radiologe und} Rechtsmediziner im Vergleich

\section{S. Heinze ${ }^{1,2}$, L. Hettler', F. Müller', G. Kastenholz'2, R.-J. Schröder', R. Urban', D.} Breitmeier'

'Johannes Gutenberg-Universität Mainz, Institut für Rechtsmedizin, Mainz, Deutschland, ${ }^{2}$ St. Marienkrankenhaus, Radiologische Klinik, Ludwigshafen, Deutschland

Einleitung. Trotz der steigenden Relevanz der Bildgebung sowie der zunehmenden Bedeutung insbesondere der Computertomographie als Entscheidungs- und Befundungshilfe in der Rechtsmedizin stellt die Forensische Radiologie bisher kein eigenständiges Spezialgebiet mit entsprechender Weiterbildung dar.

Zielsetzung. Im Rahmen einer retrospektiven Auswertung von 700 postmortalen Röntgenuntersuchungen des Thorax, die vor jeder Sektion routinemäßig im Institut für Rechtsmedizin der Universitätsmedizin Mainz mittels des digitalen Röntgensystems Definium AMX 700 von GE Healthcare ${ }^{\circledR}$ angefertigt werden, sollen die Stärken und Schwächen sowie die unterschiedlichen Interessenschwerpunkte in der Interpretation der Röntgenbilder beider Fachrichtungen in der Begutachtung der o. g. Röntgenuntersuchungen evaluiert werden.

Methoden. Die digitalen Röntgenaufnahmen der Sektionsfälle des Jahres 2011 sowie der ersten Hälfte des Jahres 2012 wurden mittels eines eigens für die Studie erstellten standardisierten Erhebungsbogens namens „Thorax“ untersucht. Zunächst wurden die Röntgenaufnahmen im Rahmen der Obduktion durch den 1. Obduzenten und im Anschluss separat durch einen Radiologen in Unkenntnis des Sektionsergebnisses befundet. Zusätzlich wurde anschließend das Sektionsergebnis in dem Bogen erfasst. Im Nachgang an die rechtsmedizinische und radiologische Befundung wurden die Aufnahmen hinsichtlich Qualität der Aufnahmen, knöcherne Strukturen, Frakturen/Luxationen, körperfremdes Material, Weichteile und Lunge im Speziellen unter Verwendung des Auswertebogens untersucht.

Ergebnisse. Die Ergebnisse der zwei Fachbereiche werden sowohl untereinander als auch mit den Sektionsergebnissen verglichen und statistisch ausgewertet.

Schlussfolgerung. Die teils erwarteten, aber auch überraschenden Ergebnisse von und zwischen den beiden Fachdisziplinen in Relation zum Sektionsergebnis werden im Vortrag diskutiert und evidenzbasierte, statistische Schlussfolgerungen dargestellt. 


\section{V12}

\section{Postmortale Validierung von MRT-Befunden in Hirngewebe}

N. Krebs', , C. Langkammer', T. Ehammer', K.-O. Lövblad ${ }^{4}$, G. Komatz', S. Rope$l^{3}$, K. Yen ${ }^{6}$, E. Scheurer ${ }^{1,2}$

'Ludwig Boltzmann Institut, Klinisch-Forensische Bildgebung, Graz, Österreich, ${ }^{2}$ Medizinische Universität, Graz, Österreich, ${ }^{3}$ Medizinische Universität, Universitätsklinik für Neurologie, Graz, Österreich, ${ }^{4}$ Universitätsspital, Abteilung für Radiologie, Genf, Schweiz, ${ }^{5} \mathrm{CT} / \mathrm{MR}$-Center Graz Geidorf, Graz, Österreich, ${ }^{6}$ Universitätsklinikum, Institut für Rechtsmedizin und Verkehrsmedizin, Heidelberg, Deutschland

Fragestellung. Zerebrale CT- und MRT-Befunde Lebender können in der Regel nicht direkt validiert werden. Daher drängt sich die Frage nach dem morphologischen Korrelat radiologischer Befunde auf. Inwieweit stimmen radiologische Befunde mit makroskopischen überein? Methoden. Nach Ausschluss von Leichen mit Fäulnis oder bereits diagnostizierten Hirnmassenblutungen wurden 6 Subjekte (1 weiblich, 5 männlich, Median: 68 Jahre, 37-92 J.) mit einem kürzlich stattgehabten, stumpfen Kopftrauma sowie 11 Verstorbene ohne Kopftrauma (3 weiblich, 8 männlich, Median: 64 Jahre, 48-81 J.) mittels 3T-MRT gescannt: T1-gewichtete Sequenz, T2-gew. Turbo Spin Echo S., T2*-gew. Gradienten Echo S., Protonendichte-gew. S., FLAIR S., diffusionsgew. temperaturangepasste S. Im Rahmen der Obduktion wurde das Hirn in toto entnommen, für mindestens 3 Wochen formalinfixiert und in $1 \mathrm{~cm}$ dicke, axiale Scheiben geschnitten. Die MRT-Bilder wurden geblindet und unabhängig voneinander von 2 Radiologen befundet, von einem weiteren einer Entscheidungsauswertung unterzogen und mit den makroskopischen Befunden verglichen.

Ergebnisse. Die Auswertung der MRT-Daten erbrachte insgesamt $30 \mathrm{Be}-$ funde, die makroskopische Untersuchung lediglich 16. Indirekte Hinweise für ein stumpfes Kopftrauma wie parenchymale Einblutungen und subarachnoidale Blutungen wurden in guter Übereinstimmung gefunden, während die MRT-Befundung zusätzlich Mikroangiopathien und multiple Sklerose (MS) assoziierte Läsionen detektierte. Unterschiede ergaben sich auch bei der Auswertung von Mikroblutungen, die auf den MRT-Bildern in verminderter Anzahl zu erkennen waren.

Schlussfolgerungen. Die Studie bestätigt die Überlegenheit der radiologischen Auswertung in der Detektion von klinischen Befunden wie Mikroangiopathien oder MS-assoziierten Veränderungen. Die makroskopische Befundung zeigte hingegen mehr relevante Befunde für die Rekonstruktion eines Traumas. Die geringere Sensitivität der MRT für die Detektion von Mikroblutungen ist evtl. auf die Schwierigkeit, diese von Blutgefäßen zu unterscheiden, zurückzuführen. Direkte Validierungsstudien zeigen die Stärken und Schwächen unterschiedlicher diagnostischer Verfahren für klinische und rechtsmedizinische Indikationen auf. Zerebrale MRT-Untersuchungen könnten in Zukunft die Ergebnisse der Obduktion vervollständigen.

\section{V13}

\section{Korrelation von Messwerten des Dual-Energy-CT der Leber mit der} histologischen Klassifikation der Steatosis hepatis

\author{
S. Franckenberg', B. Fliss', M.J. Thali', S.G. Ross' \\ 'Universität Zürich, Institut für Rechtsmedizin, Abteilung Forensische \\ Medizin und Bildgebung, Zürich, Schweiz
}

Fragestellung. Mit unserer Studie wollen wir untersuchen, ob es eine Korrelation der Dichtemessung von Lebergewebe im Dual-Energy-CT mit der histologischen Klassifizierung bei Steatosis hepatis gibt.

Material und Methoden. Wir untersuchten 40 frisch verstorbene (keine Gasbildung im CT sichtbar), zur Obduktion an das Institut für Rechtsmedizin überführte Leichname ohne Lebertrauma. Die postmortale Bildgebung wurde maximal 12 Stunden vor der Obduktion mit einem Dual-Energy-CT von Siemens durchgeführt. Die Befundung der Daten erfolgte durch einen Radiologen. Anlässlich der Obduktion wurden je von der rechten und der linken Leberhälfte Proben für die histologische Aufarbeitung in Formalin asserviert. Anschließend wurde eine HEFärbung der Leberschnitte durchgeführt. Die Beurteilung der Histologie erfolgte geblindet durch zwei Rechtsmediziner.

Ergebnisse und Schlussfolgerungen. Wir stellen die ersten Ergebnisse der Korrelation der Dichtemessung von Lebergewebe im Dual-EnergyCT mit der histologischen Klassifizierung bei Steatosis hepatis vor.

\section{V14}

\section{Schädel-Hirn-Traumen ohne äußere Verletzungsbefunde - Studie} an Obduktionsfällen

\section{Führer', I. Sinicina', W. Keil'}

'Institut für Rechtsmedizin der LMU München, München, Deutschland

Einleitung. Bei der Leichenschau bilden Zeichen stumpfer Gewalt an der Kopfhaut wesentliche Hinweise auf zu erwartende innere Befunde im Sinne von Schädelprellungen bzw. Schädel-Hirn-Traumen. Lokalisation und Qualität von Weichteilverletzungen des Kopfes sind auch Kriterien für den Rückschluss auf mögliche Fremdeinwirkungen. Das Vorliegen derartiger äußerer Befunde ist nicht selten Anlass für gerichtliche Obduktionen. Die Zielstellung unserer Studie ist, Fälle zu demonstrieren, bei denen relevante innere Verletzungen des Kopfes vorhanden sind, obwohl bei der äußeren Besichtigung kein Verletzungsbefund erhoben werden kann.

Methoden. Seit dem Jahr 2011 wird im Institut für Rechtsmedizin München eine prospektive Studie durchgeführt, die Obduktionsfälle ohne äußere Kopfverletzungen betrifft. Dabei fanden sich bisher 16 Fälle - 8 Männer, 8 Frauen im Alter von 20 bis 88 Jahren - mit kräftigen flächenhaften Unterblutungen der Kopfschwarte und des Schädeldachperiosts.

Ergebnisse. Histologische Untersuchungen erbrachten, dass sogar Einblutungen in der Schicht der Kopfhaut bei fehlendem makroskopischem Befund vorhanden sein können. Fünfmal wurden zudem Schädeldachbrüche diagnostiziert, darunter einmal in Verbindung mit Kontusionsblutungen der Stirnlappen und einmal mit einer Subarachnoidalblutung. Bei einem Fall bestand eine subdurale Blutung. Verletzungsursachen waren Stürze ( $\mathrm{n}=9)$, Anschlagen an Gegenstände $(\mathrm{n}=1)$ und Schläge $(n=2)$, in 4 Fällen war kein ursächliches Geschehen nachvollziehbar. Im Fall eines 47-Jährigen handelte es sich um ein zunächst unerkanntes Tötungsdelikt mit offensichtlich intensiver Schlageinwirkung gegen den Kopf. Todesursächlich war das Schädel-Hirn-Trauma. Aufgrund der unauffälligen Auffindungssituation wurde zunächst von einem natürlichen Tod ausgegangen.

Schlussfolgerung. Die Ergebnisse verdeutlichen, dass trotz des Fehlens von sichtbaren Verletzungen Kopfschwartenhämatome bis hin zu schweren Schädel-Hirn-Traumen bestehen können, die erst durch Obduktion nachweisbar sind. Auf die Möglichkeit der postmortalen CTDiagnostik ist im Zusammenhang mit derartigen Fällen hinzuweisen. 


\section{V15}

\section{Postmortale biochemische Untersuchungen nach Schädel-Hirn- Trauma}

\section{B. Ondruschka', D. Pohlers' ${ }^{2}$, G. Sommer ${ }^{3}$, K. Schobef, ${ }^{4,}$, D. Teupser ${ }^{5}$, H. Franke, J. Dreßler}

'Universität Leipzig, Institut für Rechtsmedizin, Leipzig, Deutschland, ${ }^{2}$ Klinikum Chemnitz, Zentrum für Diagnostik, Chemnitz, Deutschland, ${ }^{3}$ Universität Leipzig, Innovationszentrum für Computerassistierte Chirurgie, Leipzig, Deutschland, ${ }^{4}$ Flugmedizinisches Institut der Luftwaffe, Abteilung Rechtsmedizin und Flugunfallmedizin, Fürstenfeldbruck, Deutschland, ${ }^{5}$ Ludwig-Maximilians-Universität München, Institut für Laboratoriumsmedizin, München, Deutschland, ${ }^{6}$ Universität Leipzig, Rudolf-BoehmInstitut für Pharmakologie und Toxikologie, Leipzig, Deutschland

Fragestellung. Postmortale Liquor- und Serumanalysen relevanter Biomarker können Hinweise auf die Todesursache und Überlebenszeiten der Verstorbenen in Fällen tödlicher Gewalteinwirkungen liefern. Bis jetzt sind derartige Untersuchungen im rechtsmedizinischen Spektrum jedoch vorwiegend der Klärung funktioneller Todesursachen vorbehalten. Daher sollen der Gliazellmarker S1ooB und die neuronenspezifische Enolase (NSE) auf ihre Validität als postmortale Biomarker für Schädel-Hirn-Traumen (SHT) untersucht werden.

Methoden. In 17 SHT-Fällen (mittleres Alter: 58 Jahre) und 23 Kontrollen mit unterschiedlichen Todesursachen (mittleres Alter: 59 Jahre) und postmortalen Intervallen (PMI) bis zu 5 Tagen wurden die Markerkonzentrationen im Serum und Liquor mit dem Elecsys Immunoassay (Roche Diagnostics) bestimmt. Weiterhin erfolgte die Ermittlung des Hämolyse-Index als Maß für die Probenqualität.

Ergebnisse. Im Serum wurden in Abhängigkeit von der Traumaüberlebenszeit ein signifikanter Anstieg und Wiederabfall der S1ooB-Konzentrationen festgestellt $(\mathrm{p}<\mathrm{O}, 01)$. Die Konzentrationen von $\mathrm{S} 100 \mathrm{~B}$ und NSE liegen im Liquor bei einer Überlebenszeit $>15$ min oberhalb festgelegter Cut-off-Werte $(\mathrm{p}<\mathrm{o}, \mathrm{o1})$. Die NSE-Konzentrationen im Liquor $(\mathrm{p}<\mathrm{o}, \mathrm{o1})$ und die S1ooB-Konzentrationen sowohl im Liquor als auch im Serum $(p<0,05)$ waren bei den TBI-Fällen signifikant höher als bei isolierten Rumpftraumen. Die Länge des PMI hatte keinen Einfluss auf die Probenqualität ( $r=0,05$ für Liquor, $r=0,13$ für Serum). Eine längere Leichenliegezeit führte jedoch im Serum zu einem passiven Anstieg der Markerkonzentrationen ( $r=0,50$ für $\mathrm{S} 100 B, r=0,56$ für NSE). Anhand dieser Befunde sind nur bis zu einem 48-stündigen PMI valide Ergebnisse zu erwarten.

Schlussfolgerungen. Anhand der Ergebnisse wird deutlich, dass postmortal-biochemische Verfahren für rechtsmedizinische Untersuchungen an Unfallopfern geeignet sind. Deren spezifische Verwendbarkeit in der forensischen Diagnostik und der Einfluss der fortschreitenden postmortalen Hämolyse werden diskutiert.

\section{V16}

\section{Statistische Erfassung stumpfer Gewalt}

\section{Siegenthaler', B. Kneubüh?}

'Institut für Rechtsmedizin, Zentrum für forensische Physik/Ballistik, Bern, Schweiz

Fragestellung. Aus dem Fallarchiv des Instituts für Rechtsmedizin Bern sollen aus mehreren Jahren die Fälle stumpfer Gewalt zusammengetragen und statistisch ausgewertet werden. Es sollen dadurch Zusammenhänge zwischen Tatwerkzeug, Energieaufwand, Opfer, Täter und Verletzung hergestellt werden.

Methoden. Im Fallarchiv wurden aus den Jahren 2000 bis 2007 etwa 1500 Fälle stumpfer Gewalt gefunden, davon waren bei ca. 500 die Umstände der stumpfen Gewalteinwirkung ausreichend genau dokumentiert, um zuverlässige Informationen über Tatwerkzeug, Opfer, Täter und Verletzung zu erhalten. Zusätzlich konnten einigen Ereignissen eine Energie sowie anderen ein Energiebereich zugeordnet werden. Diese Informationen wurden erfasst und statistisch ausgewertet.

Ergebnisse. Für die Verletzungen ist eine extreme Vielfalt an Werkzeugen verantwortlich. Es wurden Statistiken über den Ort und die Art der Verletzung, deren Schwere und die benötigte Behandlung gemacht. Zusammenhänge zwischen Länge und Masse des Tatwerkzeuges und der Verletzung sowie zwischen Energie und Verletzung wurden hergestellt. Schlussfolgerung. Im Bereich stumpfe Gewalt gibt es noch einige Wissenslücken. Es fehlt z. B. das Wissen über die Auswirkung der Schwerpunktslage und der Geometrie eines Schlaginstrumentes auf die durchschnittliche Schlagenergie eines Menschen. Dieser Einfluss soll in einem weiteren Schritt untersucht werden.

\section{V17}

Das Saarland als ideales Forschungsgebiet? Standortbewertung am Beispiel des interdisziplinären Verkehrsunfallforschungsprojekts "Motorisierte Zweiradunfälle 2010/2011"

J.-P. Stock', T. Rahlmeyer', S. Köhl', B. Wilhelm², W. Knopp', J. Priester' ${ }^{2}$, M. Kühn ${ }^{3}$, T. Pohlemann', A. Schuff

'Universitätsklinikum des Saarlandes, Klinik für Unfall-, Hand- und Wiederherstellungschirurgie, Homburg, Deutschland, ${ }^{2}$ Ingenieurbüro Dr. Priester, Saarbrücken, Deutschland, ${ }^{3}$ UDV, Unfallforschung der Versicherer, Berlin, Deutschland, ${ }^{4}$ Rechtsmedizin am Klinikum Saarbrücken, Saarbrücken, Deutschland

Hintergrund. Im Rahmen eines Unfallforschungsprojekts wurden von Juni 2010 bis Dezember 2011 im Saarland Unfälle mit Beteiligung von motorisierten Zweirädern analysiert. Ziel war es, Korrelationen zwischen Unfallmechanismus, der getragenen Schutzkleidung und den aus dem Unfallgeschehen resultierenden Verletzungen zu ermitteln. Zudem wurde bei diesem Pilotprojekt untersucht, inwieweit das Saarland als Standort einer langfristigen interdisziplinären Verkehrsunfallforschung geeignet ist.

Methodik. In einer prospektiven Erhebung wurden erstmals Verkehrsunfälle in der Fläche eines gesamten Bundeslandes erfasst und analysiert. Die Datenerhebung erfolgte durch ein interdisziplinäres Team, das „on scene in time“ noch an der Unfallörtlichkeit technische und medizinische Parameter erfasste. In die Unfallanalyse wurden auch die Ergebnisse der nachträglichen Patientenbefragung sowie der Auswertung der klinischen Behandlungsakten einbezogen. Zur Beurteilung, ob das Saarland als Forschungsgebiet einer langfristigen Unfallanalyse geeignet ist und sich dort gewonnene Erkenntnisse auf die gesamte Bundesrepublik übertragen lassen, wurden beide Gebiete im Bezug auf die Unfallforschung in über 120 Einzelparametern miteinander verglichen.

Ergebnisse. Das Saarland erweist sich insbesondere in den Basiskenngrößen „Bevölkerungsstruktur“, „Flächenanteil Verkehr, Gewerbe/ Industrie und Wohnen“, „Witterungsverhältnisse“ und „Fahrzeugbestand" als besonders repräsentativ. Auch ein Vergleich der Unfallstatistiken weist nur vereinzelt größere Abweichungen auf. Die Betrachtung der saarländischen Klinikstruktur und Organisation des Rettungswesens ergibt zudem eine günstige Standortverteilung im zu erwartenden Unfallschwerpunktgebiet sowie eine geringe Patientenabwanderungstendenz aus dem Erhebungsgebiet heraus. Die zentrale Organisation der übrigen, zur Umsetzung einer Unfallforschung notwendigen Institutionen ermöglicht eine effektive Zusammenarbeit. Die durch ein vergleichsweise dichtes Autobahnnetz und eine günstigere Staubilanz gekennzeichnete Verkehrsinfrastruktur kommt der praktischen Umsetzung ebenfalls entgegen.

Schlussfolgerung. Aufgrund der guten Repräsentativität im Bezug auf Gesamtdeutschland und den günstigen infrastrukturellen Standorteigenschaften ist das Saarland als ideales Erhebungsgebiet einer interdisziplinären Verkehrsunfallforschung anzusehen. 
V18

Unfall oder Gewaltdelikt? Retrospektive Analyse von Gesichtsverletzungen durch stumpfe Gewalt

\section{Duckwitz', M. Bohnert}

'Institut für Rechtsmedizin, Würzburg, Deutschland

Fragestellung. Die Beurteilung von Verletzungen des Gesichts durch stumpfe Gewalt ist eine häufige Aufgabe in der rechtsmedizinischen Routine und in nicht wenigen Fällen ist keine eindeutige Unterscheidung von Fremdbeibringung oder Unfallgeschehen möglich. Vor diesem Hintergrund wurden die Verletzungen im Gesicht bei Unfällen und Misshandlungsdelikten miteinander verglichen, um ggf. statistisch unterfütterte Aussagen bei Begutachtungsfällen treffen zu können.

Methoden. Die Obduktionen und Lebenduntersuchungen am Würzburger Institut für Rechtsmedizin der vergangenen 10 Jahre wurden retrospektiv im Hinblick auf Verletzungen des Gesichts bei Unfällen und Körperverletzungsdelikten analysiert. Erfasst wurden dabei 94 Opfer von Gewalttaten und 598 Unfallopfer. Es wurden dabei 3 Untersuchungsgruppen gebildet: ein Gesamtkollektiv, eine Gruppe speziell ohne Insassenverkehrsunfälle und ein Kollektiv generell ohne Verkehrsunfälle.

Ergebnisse. Männer waren häufiger Opfer von Unfällen als Frauen $(m: w=2,8: 1)$. Bei Gewaltdelikten war das Verhältnis ausgeglichen $(\mathrm{m}: \mathrm{w}=1: 1)$. Die Analyse der Ausprägung verschiedener Verletzungen ergab, dass mehrere gleichzeitig auftretende Verletzungen eher für ein Gewaltdelikt sprechen (Verkehrsunfälle ausgenommen). Zudem zeigte sich, dass Sturzereignisse weniger Verletzungen aufweisen als Misshandlungen. Verletzungen der Nasenweichteile und der Ober- und Unterkiefermundschleimhäute traten sowohl bei Unfällen als auch bei Gewalttaten in allen Kollektiven am häufigsten auf. Frakturen der Mandibula, Maxilla, des Os nasale und Zahnverletzungen zeigten keine signifikant unterschiedlichen Ausprägungen. Mundschleimhautverletzungen insbesondere des Oberkiefers, Verletzungen der Nasenweichteile, der Ohrmuschel und der Haut hinter den Ohren kamen signifikant häufiger bei Delikten als bei Sturzgeschehen vor. Obwohl ein deutliches statistisches Übergewicht der Unfallzahlen im Vergleich zu Gewalttaten vorlag, zeigte sich, dass unter allen Ohrenverletzungen mehr als die Hälfte durch eine Gewalttat verursacht wurden.

Schlussfolgerungen. Gesichtsverletzungen durch stumpfe Gewalt, welche als typisch für Kindesmisshandlungen gelten, treten auch in Fällen von Gewalt gegen Erwachsene signifikant häufiger bei Gewaltdelikten auf. Somit könnten solche Befundkonstellationen auch in dieser Altersgruppe als Prädiktor für Gewalttaten dienen.

\section{V19}

\section{Tödliche Arbeitsunfälle im Kölner Sektionsgut 2004 bis 2012} Umstände, Todesursachen, Vermeidbarkeit

\section{S. Bartschat', H.K. Al Beraiki', M.A. Rothschild' \\ 'Uniklinik Köln, Institut für Rechtsmedizin, Köln, Deutschland}

Einleitung. In Deutschland kamen in den letzten 10 Jahren laut Statistik der Bundesanstalt für Arbeitsschutz und Arbeitsmedizin pro Jahr durchschnittlich rund 280 Menschen durch Arbeitsunfälle zu Tode, wobei sich eine rückläufige Tendenz abzeichnet.

Methoden. Im Institut für Rechtsmedizin Köln wurden in den Jahren 2004 bis 2012 insgesamt 88 Fälle von Arbeitsunfällen obduziert. Der Großteil der Arbeitsunfälle ereignete sich dabei in der Baubranche: Rund $46,6 \%$ der Unfälle fanden im Zusammenhang mit Baumaßnahmen statt.

Ergebnisse. In der Regel waren die jeweiligen Unfälle auf mehrere Ursachen zurückzuführen (z. B. Verhalten, Organisation, Arbeitsstätte), jedoch war in den meisten Fällen (58\%)der wichtigste unfallverursachende Faktor im Verhalten des Verunfallten selbst am Arbeitsplatz oder der Kollegen zu suchen. Insbesondere der unterlassene bzw. unsachgemäße oder unbefugte Gebrauch von Arbeitsmitteln sowie der Aufenthalt im Gefahrenbereich und/oder Benutzung unzulässiger Verkehrswege spielten eine Rolle. 40\% der Unfallopfer kamen dabei bei Abstürzen zu Tode, welche vorwiegend vom Dach oder auch von Geräten erfolgten. Bei knapp einem Viertel der Fälle waren Körperkompressionen die zu Tode führenden Unfallvorgänge. Die Blutalkoholkonzentration wurde bei 55,7\% der Fälle bestimmt, die Beeinflussung durch Betäubungsmittel in rund einem Drittel untersucht. Dabei stellte sich heraus, dass in vier Fällen zum Unfallzeitpunkt eine Alkoholisierung bestand, während die Unfallopfer in fünf Fällen unter Einfluss von Betäubungsmitteln standen.

\section{V20}

\section{Giftgasexposition im Röntgenbild}

\section{H. Vogel}

\section{'Institut für Rechtsmedizin, Hamburg, Deutschland}

Hintergrund und Fragestellung. Syrien verfügt über Kampfgase. Ihr Einsatz ist als kritisch („rote Linie“) bezeichnet worden. Diskutiert wird, ob Kampfgase durch die Regierung und/oder die Aufständischen eingesetzt wurden. Angeführt werden Untersuchungen von Granatfragmenten und von Geschädigten. Aufgezeigt werden soll, welche Befunde im Röntgenbild nach Kampfgasexposition auftreten.

Material und Methoden. Analysiert wurden die Angaben aus den Medien zu den vorhandenen/eingesetzten Kampfgasen. Den verschiedenen Kampfgasen wurden eigene Befunde zugeordnet, die von Opfern aus dem Kampfgaseinsatz im Krieg zwischen dem Irak und dem Iran stammten. Einbezogen wurden die Röntgenbefunde von Unfällen mit chemischen Substanzen, deren Wirkung zu ähnlichen/gleichen Erkrankungen führte wie Kampfgase, und Berichte aus dem Ersten Weltkrieg. Berücksichtigt wurden auch Berichte über den Einsatz von Kampfgasen durch die AUM-Sekte in Japan.

Ergebnisse. Schwefellost und Stickstofflost wirken als Kontaktgifte. Bei der Akutexposition sind an der Haut Blasen zu beobachten. In der Bronchoskopie zeigt sich eine Irritation der inneren Oberfläche der Bronchien. Wird nativ diagnostisch eine Verdichtung sichtbar, weist dies auf eine schlechte Prognose hin. Der Tod tritt mit großer Wahrscheinlichkeit ein. Spätfolgen sind ein Emphysem der Lunge, möglicherweise auch ein Hochdruck im kleinen Kreislauf. Acetylcholinesterasehemmer (Insektizide) führen zu einem Lungenödem. Wird die Exposition überlebt, ist die Lunge in der Regel schwer geschädigt. Besondere Aufmerksamkeit verdienen die „Maskenbrecher“, eine Bezeichnung aus dem Ersten Weltkrieg, die durch Kontakt über die Haut in den Körper eindringen, Atemnot erzeugen und zur Abnahme der Gasmaske führen.

Schlussfolgerung. Röntgenbilder von Lebenden lassen in Grenzen zu, auf den Einsatz von Kampfgasen zu schließen. Sie bieten sich an für den Nachweis ihres Einsatzes. Für die Behandlung des Opfers erlauben sie Aussagen zur Prognose.

\section{V21}

Analyse von 11 Todesfällen aus Afghanistan - seltene Verletzungskomplexe im rechtsmedizinischen Alltag

J. Cortis', S. Banaschak', M.A. Rothschild"

Institut für Rechtsmedizin der Uniklinik Köln, Köln, Deutschland

Einleitung. In der Rechtsmedizin in Deutschland stellt die Untersuchung tödlicher kriegsbedingter Verletzungen eine Seltenheit dar. Das Verletzungsmuster, das durch ballistische Einwirkungen einschließlich Explosionen entsteht, differiert deutlich von dem, was im Rahmen des rechtsmedizinischen Alltags beobachtet wird. Ziel dieser Analyse ist es, die Schwere solcher kriegsbedingt tödlichen Verletzungen und das damit einhergehende Verletzungsmuster darzustellen. 
Material und Methoden. Zwischen 2006 und 2013 wurden insgesamt 11 Todesfälle im Institut für Rechtsmedizin der Uniklinik Köln obduziert, welche sich in Afghanistan ereigneten. Die einzelnen Todesfälle wurden auf die jeweiligen Verletzungskomplexe hin analysiert. Des Weiteren wurden die Todesumstände im Hinblick auf die Verletzungen ausgewertet.

Ergebnisse. Unter den 11 Todesfällen aus Afghanistan waren 2 Frauen und 9 Männer im Alter zwischen 21 und 48 Jahren (im Mittel 27,7 Jahre). Sieben von ihnen waren Bundeswehrsoldaten, 2 Journalisten, eine Frau gehörte einer Gruppe von ärztlichem Personal/Dolmetschern an und bei einem Mann handelte es sich um ein Entführungsopfer. Es fanden sich unter den Todesfällen 2 Suizide mit einer Schusswaffe, 4 Todesfälle durch Explosions-/Sprengstofftraumata sowie 5 Todesfälle durch fremd beigebrachte Schussverletzungen. Bei den Suizidenten fand sich je 1 Kopfschuss. Die Opfer der Explosionen zeigten je eine massive Körperzerstörung einschließlich Weichgewebs-, Knochen- und Organzerstörungen. Bei den fremdbeigebrachten Todesfällen durch Schusswaffen fanden sich je mindestens 1 bis maximal 9 Schussverletzungen sowie einmal zusätzlich eine Pfählungsverletzung.

\section{V22}

Bergbauunfälle in Polen - Identifizierungsmaßnahmen und Darstellung der Verletzungen der Opfer aus dem Sektionsgut des Instituts für Gerichtmedizin und Toxikologie der Schlesischen Medizinischen Universität in Katowice

\section{K. Rygol', C. Chowaniec}

'Schlesische Medizinische Universität Katowice, Institut für Rechtsmedizin und Toxikologie, Katowice, Polen

Einleitung. Bei der Bearbeitung von Massenkatastrophen nehmen Bergbauunfälle insbesondere wegen der speziellen Risiken in der Bergbauindustrie eine Sonderstellung ein. Als Gefahren sind u. a. Verschüttungen bei Schachteinstürzen, Vergiftungen durch Gase, Kohlenstaubexplosionen, Verbrennungen und Schädigungen der Arbeiter durch Wassereinbrüche zu nennen.

Methoden. In den Jahren 2002, 2006 und 2009 kam es in Jastrzębie, Ruda Śląska und Katowice zu schweren Bergbauunfällen mit insgesamt 72 Verletzten und 53 Toten. Im Einzelnen werden die durchgeführten rechtsmedizinischen Maßnahmen zur Identifizierung, Todeszeitbestimmung und Feststellung der Todesursachen dargestellt.

Ergebnisse. Bei den Bergbauunfällen verstarben im Jahr 2002 zehn Personen, 2006 waren es 23 Tote und im Jahr 2009 verunglückten 20 Arbeiter tödlich. In 50 Fällen verstarben die Opfer unmittelbar nach dem Unfall, 3 Menschen starben im Krankenhaus kurz nach dem Vorfall. In 21 Fällen war eine Kohlenstaubexplosion todesursächlich, in 15 Fällen verstarben die Menschen durch eine Verschüttung bei Schachteinstürzen und in 17 Fällen kam es zu Verbrennungen nach Methanexplosionen.

Schlussfolgerung. Bei den Verletzten wurden die gesundheitlichen Unfallfolgen entsprechend den Vorgaben aus dem Strafgesetzbuch abgeschätzt.

\section{V23}

Retrospektive Analyse der Leberverletzungen im Sektionsgut des Instituts für Rechtsmedizin Frankfurt/Main im Zeitraum 2002 bis 2011

\section{H. Held', S. Plenzig', A. Schnabel', H. Bratzke'}

'Institut für Rechtsmedizin Frankfurt/Main, Frankfurt/Main, Deutschland

Methoden. Es wurde eine retrospektive Analyse des Sektionsgutes des Instituts für Rechtsmedizin in Frankfurt am Main über einen Zeitraum von 10 Jahren (2002-2011) hinsichtlich traumatischer Leberschäden durchgeführt. Hierbei ergab sich eine Gesamtzahl von 503 Fällen (ent- spricht $8,8 \%$ des Sektionsguts). Ziel war es, die Frage zu beantworten, ob sich aus unterschiedlichen Gewalteinwirkungen ein Trend zu verschiedenen Schweregraden der Leberverletzung und ihrer Lokalisation ableiten lässt.

Ergebnisse. Zunächst wurde die Zahl der Lebertraumata für die jeweiligen Jahre erfasst und diese dann entsprechend des zugrundeliegenden Unfallmechanismus aufgeschlüsselt. Hierbei zeigte sich, dass mehr als die Hälfte $(52,8 \%$; 266 Fälle) der Leberverletzungen infolge eines Verkehrsunfalls eingetreten waren. Bahnleichen, welche gesondert untersucht wurden, wiesen in 42 Fällen eine Leberverletzung auf, bei Stürzen aus großer Höhe zeigte sich in 88 Fällen ein Lebertrauma. Daneben gab es insgesamt 48 Fälle von scharfer Gewalteinwirkung mit nachfolgender Leberverletzung und 22 Fälle bei denen eine Schussverletzung zugrunde lag. In weiteren 36 Fällen waren andere Ursachen Grund für die Leberverletzung (u. a. ärztliche Fehlpunktion, Reanimation, andere stumpfe Gewalteinwirkung).

Schlussfolgerung. Im Vergleich der einzelnen Gruppen zeigte sich, dass Bahnleichen einen deutlich höheren Anteil an schwersten Lebertraumen aufwiesen, wohingegen sich bei Verkehrsunfällen und Stürzen aus der Höhe keine signifikanten Unterschiede im Schweregrad der erlittenen Verletzung zeigten. Bei weiterer Aufschlüsselung der Gruppe der Verkehrsunfälle zeigte sich, dass Leberverletzungen, welche infolge eines Frontalzusammenstoßes erlitten wurden, bei Kradfahrern insgesamt schwerwiegender waren. Im direkten Vergleich wiesen $\mathrm{Kfz}$ Beifahrer zudem weniger schwere Verletzungen der Leber auf als KfzFahrer.

\section{V24}

Massenspektrometrische Analyse organspezifischer Proteinmuster an Projektilen zur Identifizierung der durch diese penetrierten Organe

S. Dammeier', S. Nahnsen', J. Junker ${ }^{3}$, O. Kohlbacher ${ }^{3}$, H.-D. Wehner', F. Wehner', M. Ueffing

'Universitätsklinikum Tübingen, Medizinisches Proteomzentrum, Tübingen, Deutschland, ${ }^{2}$ Eberhard Karls Universität, Quantitative Biology Center, Tübingen, Deutschland, ${ }^{3}$ Eberhard Karls Universität, Zentrum für Bioinformatik, Tübingen, Deutschland, ${ }^{4}$ Universitätsklinikum Tübingen, Rechtsmedizin, Tübingen, Deutschland

Fragestellung. $\mathrm{Zu}$ den Standardaufgaben der Forensik bei Schussverletzungen gehört die Rekonstruktion des Tatherganges. Während ein Großteil der Fragen durch die Analyse der Schusskanäle geklärt werden kann, fällt die Zuordnung einzelner Projektile zu bestimmten Schusskanälen eher schwieriger aus, vor allem, wenn mehrere Schüsse, womöglich aus verschiedenen Waffen, abgegeben wurden. In diesem Kontext gilt es bei Fällen mit Todesfolge in erster Linie die Frage zu beantworten, welcher Schuss tödlich war. Wir überprüfen hier, inwieweit es durch moderne proteomanalytische Methoden möglich ist, die eindeutige Zuordnung der sicher gestellten Projektile zu den Schusskanälen anhand organspezifischer Proteinsignaturen, die auf den Projektilen verbleiben, vorzunehmen.

Methoden. Als Modellsystem dienten Rinderorgane, die mit diversen Projektilen penetriert wurden. Die auf den Projektilen befindlichen Rückstände wurden proteomanalytisch mit Hilfe Flüssigkeitschromatographie-gekoppelter Orbitrap-Massenspektrometrie untersucht. Die entstandenen Spektren wurden systematisch bioinformatisch durch Hauptkomponentenanalyse und unter Verwendung von Support Vector Machines ausgewertet.

Ergebnisse. Es wurden 4 lebenswichtige Organe (Leber, Lunge, Herz, Niere) und Skelettmuskel als häufig betroffenes ubiquitäres Gewebe von mindestens 3 unterschiedlichen Tieren mit diversen Projektilen penetriert und diese dann proteomanalytisch untersucht. Die statistische Analyse von 65 Datensätzen mit mehr als 300.000 detektierten Peptidsignaturen führte zu einem Clustering der Daten gemäß der eingesetzten Organe mit einer Genauigkeit von mehr als 95\% inklusive Kreuzvalidie- 
rung. Die so generierten Proteinlisten und Entscheidungsbäume wurden auf humane Proteine übertragen und in einem konkreten Mordfall angewendet. Durch die Methode konnte in diesem Fall eine eindeutige Zuordnung der sichergestellten Projektile zu den Schusskanälen und den penetrierten Organen erfolgen.

Schlussfolgerungen. Durch den Einsatz von moderner Proteomanalyse in der Forensik lassen sich organspezifische Proteinmuster auf Projektilen identifizieren, die konkret die Zuordnung zu Schusskanälen - und damit einen wesentlichen Aspekt der Rekonstruktion des Tatherganges und gegebenenfalls der Beweisführung - verbessern.

\section{V25 \\ Verletzungspotenzial einer in Deutschland verbotenen Schlag- waffe im Vergleich zum herkömmlichen Stock}

\section{S. Axmann', L. Siegenthaler', B.P. Kneubueh" \\ 'Institut für Rechtsmedizin Bern, Zentrum für Forensische Physik/Ballistik, Bern, Schweiz}

Fragestellung. Bei der Verwendung einer Schlagwaffe ist die auf das Ziel übertragene Energie für das Ausmaß der entstehenden Verletzung entscheidend. Die kinetische Energie, welche durch das Auftreffen der Schlagwaffe übertragen werden kann, ergibt sich aus deren Auftreffgeschwindigkeit und der in den Schlag eingebrachten Gesamtmasse. Das Augenmerk dieser Arbeit richtet sich auf die aufzubringende Schlagenergie eines Nunchaku im Vergleich mit einem Stock selbiger Masse, Länge und Trägheitsmoment. Weil die Masse des Schlaginstruments beim Vorgang der Gewalteinwirkung konstant bleibt, kann die zu übertragende Energie nur durch eine Erhöhung seiner Auftreffgeschwindigkeit gesteigert werden. Ein Nunchaku zeichnet sich gegenüber einem Stock durch seine zwei oder mehr flexibel miteinander verbundenen Griffstücke aus. Ist es auf Grund dieser Beweglichkeit des Nunchaku möglich, eine höhere Auftreffgeschwindigkeit als unter Verwendung eines Stocks zu erreichen und somit eine größere Verletzung zu erzeugen?

Methoden. Die Bestimmung der mittels verwendeter Schlagwaffen übertragbaren Energie erfolgte anhand von Schlägen gegen einen Pendelbock, wobei die kinetische Energie beim Aufschlag über die Auslenkung der Pendelschaukel ermittelt wurde. Die Messung der Auftreffgeschwindigkeit wurde unter Zuhilfenahme einer Hochgeschwindigkeitskamera realisiert.

Ergebnisse. Die Schlagversuche ermöglichten die Bestimmung des Verletzungspotenzials eines Nunchaku im direkten Vergleich mit dem eines herkömmlichen Stocks.

Schlussfolgerung. Die Konstruktion des Nunchaku trägt zur Dynamik und zur Energieabgabe beim Schlag bei.

\section{V26}

\section{Molekulargenetische Identifizierung von Leichen in Main-/ Unterfranken und dem Rhein-Main-Gebiet}

\section{A. Kurz', R. Zehner', M. Apfelbacher', M. Bohnert'}

'Institut für Rechtsmedizin Würzburg, Forensische Molekularbiologie, Würzburg, Deutschland, ${ }^{2}$ Institut für Rechtsmedizin Frankfurt, Forensische Biologie, Frankfurt am Main, Deutschland

Einleitung. Bei der Identifizierung von Verstorbenen mit späten Leichenerscheinungen sowie Unbekannten haben sich neben der Daktyloskopie und der Erhebung des Zahnstatus zunehmend molekulargenetische Methoden in der forensischen Fallarbeit etabliert. Ein wichtiger Faktor, der über das Gelingen der molekulargenetischen Identifizierung einer Leiche entscheiden kann, ist die Auswahl von adäquatem Vergleichsmaterial.

Fallbericht. Ein bemerkenswerter Fall mit zunächst falsch-negativem Ergebnis aus dem eigenen Labor sowie die Publikation von Schwark und Kollegen (2012; Rechtsmedizin), in der die Erfahrungen mit verschiedenen Vergleichsmaterialien im Rahmen von molekulargenetischen Identifizierungen diskutiert werden, gaben den Anstoß, eine vergleichende Statistik über molekulargenetische Identifizierungen von Leichen in der Region Main-/Unterfranken sowie dem Rhein-MainGebiet zu erstellen.

Schlussfolgerung. Die Analyse der Befunde sowie die Berücksichtigung möglicher regionaler Besonderheiten sollen Empfehlungen für die Vorgehensweise bei der Gewinnung von Vergleichsmaterial ermöglichen. Die entsprechenden Daten sowie einige exemplarische Identifizierungsfälle werden vorgestellt.

\section{V27}

\section{Untersuchung von Punktheteroplasmie in Thrombozyten}

\section{S. Hörer', C. Nowotni', T. Sänger', S. Lutz-Bonengel' \\ 'Institut für Rechtsmedizin, Freiburg, Deutschland}

Einleitung. Mit steigender Sensitivität der Analysemethodik erhöht sich die Anzahl an detektierter Punktheteroplasmie in der mitochondrialen DNA. Bisher ist ungeklärt, ob die vorgefundenen Heteroplasmien ausschließlich auf Mutationen im mitochondrialen Genom, oder auch auf die gleichzeitige Amplifikation eines Pseudogens zurückzuführen sind. Methoden. Dieser Fragestellung wird in der vorliegenden Studie mittels der Untersuchung der kernlosen Thrombozyten aus 10 Personen nachgegangen, welche jeweils eine Heteroplasmie in der nichtkodierenden mitochondrialen Kontrollregion aufweisen. Die Thrombozyten wurden aus Blutproben isoliert und mittels FACS in 96 Well-Platten vereinzelt abgelegt. WSA, Vollblut und Einzelthrombozyten wurden im folgenden durch PCR und anschließender Sequenzierung auf Heteroplasmie hin untersucht.

Ergebnisse. Bei der Untersuchung ergaben sich keine Hinweise darauf, dass die Ursache für die hier vorgefundenen Heteroplasmien im Vorkommen von Pseudogenen begründet ist. Weitere Ergebnisse werden vorgestellt.

\section{V28}

Entfernung von DNA-Kontaminationen zellulären Ursprungs durch Wasserstoffperoxid-Plasmasterilisation

\section{Vennemann', F. Bittner ${ }^{1,2}$, K. Läer}

'Medizinische Hochschule Hannover, Institut für Rechtsmedizin, Hannover, Deutschland, ${ }^{2}$ Hogeschool Van Hall Larenstein, Leeuwarden, Deutschland

Einleitung. Seit einiger Zeit bildet die Behandlung mit Ethylenoxid (EO) die Standardtechnik zur Dekontamination von Verbrauchsmaterialien, die in forensisch-molekularbiologischen Laboren zum Einsatz kommen. Allerdings birgt das Verfahren enorme gesundheitliche Risiken, die von möglichen EO-Rückständen an Material oder in der Umgebungsluft ausgehen. Daher wurde das Verfahren aus anderen Bereichen, wie beispielsweise der Sterilisation thermolabiler Gegenstände der medizinischen Diagnostik und Therapie, in den letzten Jahren weitgehend durch weniger gesundheitsgefährdende Prozesse verdrängt. Eines dieser alternativen Verfahren ist die Niedrigtemperatur-Plasmasterilisation mittels Wasserstoffperoxid.

Zielsetzung. Ziel dieser Studie war die Prüfung der Eignung des Verfahrens für die Entfernung von DNA-Kontaminationen von Verbrauchsmaterialien.

Methoden. Verschiedene forensische Verbrauchsmaterialien, darunter Tupfer, Reaktionsgefäße und Pipettenspitzen, wurden gezielt kontaminiert und anschließend in einem Sterrad 10oS-Gerät sowie dem Sterrad 10o-NX-Gerät (beides Johnson und Johnson) mittels Wasserstoffperoxid-Plasma dekontaminiert. Der Erfolg des Dekontaminationsschrittes wurde mittels quantitativer PCR und STR-Analyse überprüft. 
Schlussfolgerung. Nachdem in vorangegangenen Projekten vor allem die Entfernung genomischer DNA geprüft wurde, sollen nun die Daten zur Dekontamination von zellulärem Material, darunter Speichel, Hautschuppen und Blut, präsentiert und diskutiert werden.

\section{V29}

Sampletype i-sep ${ }^{\oplus}$ System - effiziente Probenaufbereitung zur Gewinnung partikelfreier DNA-Lysate in der Gerichtsmedizin

\section{H. Schnerr', C. Kunz ${ }^{2}$, J. Edelmann ${ }^{2}$ \\ 'Biotype Diagnostic GmbH, Dresden, Deutschland, ${ }^{2}$ Universität Leipzig, Institut für Rechtsmedizin, Leipzig, Deutschland}

Einleitung. Die Wichtigkeit zur Verbesserung der Qualität und Quantität isolierter DNA aus forensischem Material ist unstrittig. Dabei bildet die Extraktion der genomischen DNA den ersten Schritt, der neben der Auswahl des Spurenmaterials maßgeblich den Erfolg der gesamten Testung bestimmt. Nach Zerstörung der Zellstruktur muss die freigesetzte DNA von den unlöslichen Zellbestandteilen und dem Spurenträger abgetrennt werden, um die DNA weiter aufzureinigen. Die Effizienz der Probenpräparation und die Ausbeute an isolierter DNA lassen sich dadurch optimieren, dass das DNA-Lysat quantitativ gewonnen wird und gleichzeitig die manuellen Arbeitsschritte auf ein Minimum reduziert werden. Dies gilt für Standardproben in der Routine ebenso wie für schwierige Proben, z. B. Mischspuren nach Sexualdelikten.

Methoden. Das vorgestellte System zur Isolierung von Nukleinsäuren beruht auf einem neuentwickelten Konzept, welches die Inkubation mit anschließender Abtrennung der flüssigen Reaktionsprodukte vom Probenträger in einem Reaktionsgefäß ermöglicht. Die Beschaffenheit der jeweiligen Membran erlaubt entweder die einmalige Abtrennung einer Flüssigkeit oder die schrittweise Abtrennung mehrerer Flüssigkeiten; eine wichtige Voraussetzung für die Durchführung der differenzielle Extraktion, aber auch der DNA-Gewinnung aus Paraffinproben (FFPE-Material: „formalin-fixed, paraffin-embedded“). Die Probenpräparation erfolgt dabei in einem geschlossenen System ohne den Transfer des Spurenträgers, ohne zusätzliche Pipettierschritte, ohne Verwechslungsgefahr, aber mit hoher Arbeitssicherheit.

Schlussfolgerung. Die Ergebnisse präsentieren eine Studie zur Charakterisierung einer schnellen und einfachen sequenziellen DNA-Präparation aus Mischproben, eine zeitsparende DNA-Präparationsmethode aus Paraffinproben und eine Schnellmethode für die DNA-Gewinnung aus Körperflüssigkeiten und Gewebe für den direkten Einsatz in der DNA-Amplifikation.

\section{V30 \\ Co-Extraktion und Analyse von DNA und RNA aus biologischen Spuren im Schusswaffeninneren zur Opferindividualisierung und simultaner Gewebetypisierung}

C. Lux' , C. Schyma', B. Madea', C. Courts'

'Institut für Rechtsmedizin, Universität Bonn, Deutschland, ${ }^{2}$ Institut für Rechtsmedizin, Universität Bern, Schweiz

Einleitung. Spuren von Backspatter, die aus dem Inneren von Feuerwaffen nach suizidalen oder homizidalen aufgesetzten oder extremen Nahschüssen gewonnen werden, können eine wertvolle Quelle forensischer Evidenz darstellen. Erste systematische Untersuchungen der Persistenz und Überdauerungsfähigkeit solcher Spuren, insbesondere von Opfer-DNA im Waffeninneren liegen vor. Ziel dieser Studie war, die Nukleinsäureanalytik für solche Spuren auf RNA auszuweiten und eine gleichzeitige Extraktion und parallele Analyse von DNA zur Individualisierung von Opfern und RNA zur Typisierung von Geweben zu ermöglichen.

Methoden. Zunächst wurden hierfür geeignete RNA-Kandidaten zur Gewebeidentifikation ausgewählt und mittels quantitativer PCR em- pirisch bestätigt. Anhand der Spuren aus experimentellen Schüssen auf ballistische Modelle wurde dann ein Co-Extraktionsverfahren für DNA und RNA etabliert und die Analysierbarkeit von RNA aus solchen backspatter-Spuren nachgewiesen. In einer dritten Phase wurden Proben aus Schusswaffen, die in echten Fällen gegen biologische Ziele eingesetzt worden waren, entnommen und mit dem Verfahren analysiert. Ergebnisse und Schlussfolgerung. In dieser Studie zeigen wir erstmals die Möglichkeit der Co-Extraktion von DNA und RNA aus Spuren aus dem Waffeninneren auf und demonstrieren die parallele Durchführbarkeit und Aussagenkomplementarität der beiden Analyseverfahren.

\section{V31}

Untersuchung zum Nachweis von DNA-Profilen an verschossenen Patronenhülsen

\section{J. Sanft', J. Strien' ${ }^{1}$, R. Köllner ${ }^{2}$, G. Mall ${ }^{1}$}

IInstitut für Rechtsmedizin Jena, Jena, Deutschland, ${ }^{2}$ Kriminalpolizeiinspektion Gotha, Gotha, Deutschland

Einleitung. Nach tätlichen Auseinandersetzungen mittels Schusswaffen können häufig verschossene Patronenhülsen gesichert werden. Diese können auf trassologische Spuren sowie auf Reste von DNA der Person, welche die Patronen geladen hat, untersucht werden. Somit kann möglicherweise der Täter anhand von DNA identifiziert werden. Bisher wurde allgemein angenommen, dass durch die Hitze, welche beim Verschießen entsteht, die eventuell vorhandene DNA an der Patrone zerstört wird.

Methoden. Wie vorangegangene Arbeiten bereits zeigen, kann an verschossenen Patronen bzw. deren Hülsen trotz Wärmeentwicklung noch DNA nachgewiesen werden. Diese Arbeiten haben systematisch artifiziell hergestellte Spuren auf das Vorhandensein von DNA nach Abschuss ohne Körpertreffer untersucht. Hierfür wurde auf Patronen biologisches Material aufgebracht, verschossen und zur DNA-Untersuchung abgerieben.

Ergebnisse. Unsere Untersuchung zeigt, inwieweit an Patronenhülsen ohne vorherige Präparation, alleinig durch die gewöhnliche Handhabung, noch DNA nachgewiesen werden kann. In die Analyse wurden verschiedene Waffen unterschiedlichen Kalibers mit der dazugehörigen Munition einbezogen. Bei den verwendeten Waffen/Munition handelt es sich um solche, welche in der Vergangenheit und sicherlich auch in der Zukunft als Tatmittel eingesetzt wurden und werden und somit immer wieder in den Fokus der Ermittlungen geraten.

\section{V32}

Optimization and validation of $18 \mathrm{X}$-STR loci in the Egyptian population and testing their value in solving kinship deficiency cases

\section{S. Elakkary', C. Augustin \\ 'Institut für Rechtsmedizin Hamburg, Hamburg, Deutschland}

Introduction. Qiagen Investigator Argus X-12 kit is currently the only commercially available kit for X-STRs analysis. Before its potential for use in forensic setting could be estimated, it should be examined with different populations. Additionally, more STR loci and haplogroups should be examined to have a better view of the most informative combination.

Methods and results. 250 and 243 samples of Egyptian males were typed using Argus X-12 kit as well as an in-house prepared multiplex that was first described by Edelmann et al [1] respectively. Six closely linked X-STR loci; DXS10159, DXS10161, DXS10162, DXS10163, DXS10164 and DXS10165 were co-amplified with the in-house prepared multiplex. These 6 loci are located in centromere region between 56 and $64 \mathrm{Mb}$ distant from Xp telomere at Xp11.21-Xq11.1. We present allele and haplotype-frequency as well as statistical parameters of forensic interest for the 18 X-STR loci tested. Moreover, use of both multiplexes, complementary 
to each other and to autosomal and Y-STRs, to solve complex kinship deficiency cases was evaluated. New microvariant and rare alleles have been detected in DXS10134, DXS10101, DXS10135, DXS10146, DXS10079 and DXS10148. Some samples showed allele drop out in DXS10148 and DXS10146 for which new primers were designed. With the newly designed primers, alleles of those samples could be typed and latter on sequenced where certain structural polymorphisms were detected. The primer sequences as well as structural polymorphisms observed are described. Furthermore, two samples tested with Argus X-12 kit showed allele drop out at DXS10101 locus. These two samples were then amplified with Mentype Argus X 8 kit where they showed normal alleles at this locus. This genotyping discrepancy was confirmed and explained by DNA sequence analysis at DXS10101 locus.

Conclusions. Both multiplexes would be useful in forensic applications and show potential for improved analysis of complex kinship testing. Some modification might have to be considered regarding DXS10146, DXS10148 and DXS10101 loci included in Investigator Argus X-12 kit in order to overcome allele drop outs in these loci.

1. Edelmann J, Hering S, Augustin C, Kalis S, Szibor R (2010) Validation of six closely linked STRs located in the chromosome X centromere region. Int J Legal Med 124:83-7

\section{V33}

\section{„Dreh dich, dreh dich, DNA!" - Zentrifugal-mikrofluidische Reak-} tionsplattform zur Anwendung in der forensischen Genetik

\section{J. Naue ${ }^{1,2}$, M. Keller ${ }^{3}$, S. Lutz-Bonengel', D. Mark ${ }^{3,4}$, K. Pietsch', N. Schlauderer', G. Segelbacher ${ }^{6}$, O. Strohmeier ${ }^{3,4}$, F. von Stetten ${ }^{3,4}$, U. Schmidt \\ 'Universitätsklinikum Freiburg, Institut für Rechtsmedizin, Freiburg, Deutschland, ${ }^{2}$ Universität Freiburg, Fakultät für Biologie, Freiburg, Deutsch- land, ${ }^{3}$ Universität Freiburg, Institut für Mikrosystemtechnik - IMTEK, Frei- burg, Deutschland, ${ }^{4} \mathrm{HSG}-\mathrm{IMIT}$, Institut für Mikro- und Informationstechnik, Freiburg, Deutschland, ${ }^{5}$ Chemisches und Veterinäruntersuchungsamt Freiburg, Freiburg, Deutschland, ${ }^{6}$ Universität Freiburg, Professur für Wild- tierökologie und Wildtiermanagement, Freiburg, Deutschland}

Einleitung. Die Automatisierung von Assays spielt auch im Bereich der forensischen Genetik eine immer größere Rolle. Mit Hilfe mikrofluidischer Technologien können kleinste Volumina kontrolliert in Kanälen und Kammern bewegt werden, weshalb sie sich für die Automatisierung biochemischer Assays anbieten. Eine robuste mikrofluidische Assaysteuerung unter Ausnutzung von Zentrifugalkräften erforderte bisher Rotationen von etwa 1600 rpm.

Methoden. In der hier vorgestellten Studie wurde ein auf der Real-time-PCR basierendes Screeningassay zur Detektion häufiger in Europa vorkommenden Tierfamilien entwickelt und auf einer zentrifugalmikrofluidischen Reaktionsplattform etabliert. Diese sog. „LabDisk“ kann auf einem gewöhnlichen Rotor-Gene-Thermocycler mit einer Rotationsgeschwindigkeit von $400 \mathrm{rpm}$ betrieben werden. Das Assay basiert auf einer universellen Voramplifikation zweier mitochondrialer Genabschnitte ( $12 \mathrm{~S}$ rRNA und Cytochrom b), sowie einer tierfamilienspezifischen Hauptamplifikation. Hierfür wird die Probe nach der Voramplifikation durch den zentrifugal-thermopneumatischen Effekt automatisch in 14 Endkavitäten aliquotiert, wo die spezifischen „nested“ PCRs sowie Kontrollreaktionen stattfinden. Im Anschluss wird eine Schmelzkurvenanalyse zur Überprüfung der PCR-Produkte durchgeführt. Da im Gegensatz zu einer entsprechenden In-tube-Reaktion eine enzymatische Entfernung der Voramplifikationsprimer nicht möglich ist, wird ihre Inaktivierung $u$. a. durch Verwendung von sog. Blockingprimern erreicht. Zusätzliche Pipettierschritte, notwendige Aufreinigungsschritte oder der Transfer in verschiedene Reaktionsgefäße entfallen, wodurch Kontaminationsquellen im Assayablauf ausgeschaltet werden.

\section{V34}

"Secondary transfer" epithelialer Abriebspuren von Stoff auf Stoff wie sauber wäscht die Waschmaschine?

\section{T. Kamphausen', S. Fandel', M. Poetsch'}

'Institut für Rechtsmedizin Essen, Essen, Deutschland

Einleitung. Die Bedeutung molekulargenetischer Nachweisverfahren zur Beurteilung von Spuren an einem Tatort hat in den vergangenen Jahren stetig zugenommen. Die verwendeten molekulargenetischen Assays für Spuren-DNA werden immer sensitiver, so dass auch immer kleinere - mitunter verschleppte, also möglicherweise nicht mit dem Tatgeschehen in Zusammenhang stehende - Mengen an DNA nachgewiesen werden können. Neben der Übertragung einer Spur von der Haut des Täters auf eine Oberfläche, dem sog. „primary transfer", muss also auch mit einer Verschleppung von DNA von einem Gegenstand zum anderen (sog. ,secondary transfer“) gerechnet werden.

Methoden. Im Rahmen dieser Studie wurden eine Reihe solcher „secondary transfers" von Stoff zu Stoff künstlich simuliert und mit Hilfe des routinemäßig verwandten Promega ${ }^{\star}$ ESX-17-PCR Multiplex-Kits die Qualität und Quantität der dabei entstandenen DNA-Antragungen bestimmt. Darüber hinaus wurde erstmals die Übertragung von DNA-Antragungen im Rahmen unterschiedlicher Waschvorgänge in standardisierten Verfahren untersucht. Dazu wurden verschiedene Hautabriebe auf Stoff von jeweils zwei männlichen und zwei weiblichen Probanden in einem DIN-genormten Testwaschverfahren mit normierter Waschflotte und normierter Waschmittelzusammensetzung in Kooperation mit dem Deutschen Textilforschungszentrum NordWest gewaschen und nach Trocknung molekulargenetisch untersucht. Die Ergebnisse dieser Simulation eines Waschmaschinenwaschganges wurden mit den Ergebnissen verschiedener „Handwaschtechniken“ verglichen.

Schlussfolgerung. Es zeigten sich deutliche Unterschiede zwischen den einzelnen Waschtechniken in Bezug auf die zu erwartende Gesamtmenge und Qualität der übertragenen DNA, die im Einzelnen vorgestellt und diskutiert werden.

\section{V35}

Charakterisierung kardialer Sequenzveränderungen als Grundlage einer gezielten genetischen Beratung

\section{T. Jenewein', S. Biel', R. König', S. Kauferstein}

'Institut für Rechtsmedizin, Goethe Universität, Frankfurt am Main, Deutschland, '2Institut für Humangenetik, Goethe Universität, Frankfurt am Main, Deutschland

Einleitung. Der plötzliche Herztod ist häufig das erste und einzige Anzeichen einer primär elektrischen Herzerkrankung. In den letzten Jahren wurden Mutationen in Genen identifiziert, die mit diesen Herzerkrankungen in Verbindung gebracht werden konnten. Die Interpretation dieser genetischen Untersuchungen ist sehr komplex, da die klinischen Auswirkungen der gefundenen Sequenzvarianten bzw. Mutationen oft unbekannt sind.

Ergebnisse. Für die Aufklärung von Fällen eines plötzlichen Herztodes bzw. für eine individuelle Therapie von Patienten und Familienangehörigen ist es wichtig, genetische Testergebnisse gezielt interpretieren zu können. Daher kommt der funktionellen Charakterisierung der gefundenen Sequenzveränderungen eine große Bedeutung $\mathrm{zu}$, wie der vorgestellte Fall des plötzlichen Herztodes eines 17 Jahre alt gewordenen Mädchens zeigen soll. 


\section{V36}

\section{Aufklärung der genetischen Ursachen eines lebensbedrohlichen} Kammerflimmerns

\section{S. Biel', T. Jenewein', N. Kiehne', G. Thieß, S. Kauferstein' \\ 'Institut für Rechtsmedizin Frankfurt am Main, Frankfurt am Main, Deutschland, ${ }^{2}$ Bundeskriminalamt, Wiesbaden, Deutschland, ${ }^{3} \mathrm{TU}$ Darm- stadt, Darmstadt, Deutschland}

Einleitung. Der spannungsabhängige Kaliumkanal hERG sorgt für die schnelle Repolarisation eines kardialen Aktionspotenzials und spielt somit eine wichtige Rolle innerhalb des Reizleitungssystem des Herzens. Mutationen in dem für hERG kodierenden Gen $\mathrm{KCNH}_{2}$ können zu Herzrhythmusstörungen wie dem Long-QT-Syndrom führen und dadurch lebensbedrohlich werden.

Ergebnisse. Durch unsere Untersuchungen konnte eine neue Mutation in $\mathrm{KCNH}_{2}$ nachgewiesen werden, welche sich in einem hoch konservierten Bereich befindet. Die von uns durchgeführten elektrophysiologischen Messungen haben gezeigt, dass ein Austausch an dieser Stelle Auswirkungen auf die Kanalfunktionalität hat.

\section{V37}

\section{Monoamine Oxidase A (MAOA) und plötzlicher Kindstod revisited}

\section{Poetsch', M. Groß', T. Bajanowski'}

'Universitätsklinikum Essen, Institut für Rechtsmedizin, Essen, Deutschland

Einleitung. Die X-chromosomale Monoamine Oxidase A, ein Enzym mit einer Schlüsselrolle im serotonergen und noradrenergen System, enthält einen funktionalen Promotorpolymorphismus, dessen unterschiedliche Allele die Expression des Gens beeinflussen. In SIDS Kindern kommen laut einer Studie aus 2012 die zu einer geringeren Expression führenden Allele signifikant häufiger vor, insbesondere bei Jungen. Methoden. Da bereits diverse Assoziationen zwischen dem plötzlichen Kindstod und genetischen Veränderungen in kleineren Studien beschrieben wurden, die durch nachfolgende Untersuchungen nicht bestätigt werden konnten, haben wir diesen Promotorpolymorphismus sowie kodierende und nichtkodierende SNPs aus dem MAOA-Gen in 261 Kindern (entsprechend $368 \mathrm{X}$-Chromosomen) aus der BMBF-Studie „Plötzlicher Kindstod“ untersucht.

Ergebnisse. Ein signifikanter Zusammenhang zwischen dem Auftreten bestimmter Allele des Promotorpolymorphismus konnte weder mit der Gruppe der SIDS Kinder insgesamt, noch mit einzelnen Untergruppen (in Abhängigkeit vom Geschlecht oder dem Sterbealter) festgestellt werden. Auch durch ein Poolen mit den Probanden der früheren Studie veränderte sich dieses Ergebnis nicht.

Schlussfolgerung. Assoziationen einzelner genetischer Veränderungen mit dem Auftreten von SIDS sollten also immer an möglichst großen Fallzahlen untersucht und in weiteren Studien überprüft werden.

\section{V38}

\section{World skeletal data bases: the perspective from America}

\section{R. Jantz', S. Ousley' \\ 'University of Tennessee, Anthropology, Knoxville, USA}

Introduction. America faces a number of challenges in the forensic identification of skeletal remains. The population is large, heterogeneous and constantly changing. Its population originates from many different parts of the world, and they have also created "hybrid" subpopulations. These kinds of problems may not be unique to America, but are greater in magnitude than other parts of the world.

Methods. In order to develop identification criteria, about 25 years ago we began systematically collecting skeletal information from identified forensic cases in the U.S. in order to build a comparative/reference database. About the same time the Anthropology Department, University of Tennessee began its donated body program, which had the dual purposes of studying human decomposition and assembling a documented skeletal collection.

Results. Extensive measurements exist on ca. 3000 crania, and for over ten years we have been collecting 3-dimensional coordinate data as well. We have learned that 2oth century Americans have undergone remarkable changes since the 19th century. Americans from the late 20 th century are taller than Americans of the late 19th century, and have crania that are higher, narrower and more sexually dimorphic. Modern White Americans are strongly differentiated from 19th century White Americans, as well as 19th century Europeans. We have begun assembling skeletal data from 19th century and modern Germans and other European populations to address the question of whether secular changes seen in Americans have also occurred in Europe. At present we have data from 19th Century Germans (Berlin), Croats, and French, Czechs, and 2oth Century Portuguese and Czechs. Analysis of the data currently available shows that 19th century European groups and 19th century U.S. Whites form a cluster, while 2oth century U.S. Whites and 2oth century Portuguese are differentiated from the 19th century cluster. As we move forward our plan is to collect additional data from more 19th and 2oth century groups, either from skeletons directly, or from CT scans.

Conclusions. These additional data will allow us to clarify the nature of secular changes and present day population variation, and to develop criteria for estimating sex and ancestry appropriate to Europe.

\section{V39}

\section{Prä- und perimortale Traumata an einem Karnerkollektiv}

\section{F. Holz', K. Kreutz' ${ }^{2}$, C.G. Birngruber', M. Obert ${ }^{3}$, F. Ramsthalef, M. A. Verhoff'}

'Universität Gießen, Institut für Rechtsmedizin, Gießen, Deutschland, ${ }^{2}$ Institut für Forensische Anthropologie, Wettenberg, Deutschland, ${ }^{3}$ Universität Gießen, Neuroradiologie, Gießen, Deutschland, ${ }^{4}$ Universität des Saarlandes, Institut für Rechtsmedizin, Homburg/Saar, Deutschland

Einleitung. Beinhäuser (Syn. Ossarien, Karner) wurden zur Aufbewahrung menschlicher Knochen verwendet, die bei Wiederbelegungen oder Abräumungen von Gräbern freigelegt wurden. Hierbei wurden jedoch nicht ganze Skelette sondern meist nur Schädel und große Knochen gesichert und diese im Ossarium in pragmatischer Weise gelagert, oft in Form einer platzsparenden Schichtung. Wird z. B. bei Bauarbeiten ein Karner eröffnet, dessen Existenz in Vergessenheit geraten war, führt das häufig zu einer Information der Polizei und in der Folge zu einer Untersuchung durch die Rechtsmedizin. Nach Ausschluss einer strafrechtlichen Relevanz können anthropologische Untersuchungen zu den Fragen der Populationszusammensetzung, Krankheiten oder Verletzungen erfolgen. Insbesondere bei der Beurteilung der Verletzungen ist forensisch-osteologische Expertise hilfreich, was zu einer sekundären Involvierung der Rechtsmedizin führen kann.

Methoden. Bei Ausgrabungen zur Sanierung einer Kapelle wurde in einem Kellergewölbe unerwartet ein Ossarium freigelegt. Es handelte sich vorwiegend um teils fragmentierte, teils komplett erhaltene menschliche Lang- und Schädelknochen. Recherchen ergaben, dass sich die Nutzung des Karners in dieser Form auf einen Zeitraum vom 15. bis 19. Jahrhundert beschränkt haben musste.

Ergebnisse. Die anthropologische Analyse der Schädel ergab eine Mindestzahl von 750 Individuen, davon 229 Frauen, 393 Männer und 81 Kinder. Bei der überwiegenden Anzahl der Individuen fanden sich makroskopisch erkennbare Veränderungen durch Krankheiten oder Traumata.

Schlussfolgerung. In dem Vortrag werden ausgewählte prä- und perimortale Verletzungen an den vorliegenden Schädelknochen dargestellt, z. T. unter Einsatz von Computertomogrammen. Außerdem werden die Aufgaben und Möglichkeiten der Rechtsmedizin bei der Untersuchung von größeren Knochenfunden, hier speziell eines Ossariums berichtet und diskutiert. 
V40

Morphologische Variabilität des Sternums als Merkmal zur radiologischen Identifikation

\section{H. Wittig', S. Grünewald', V. Dittmann}

'Institut für Rechtsmedizin, Basel, Schweiz

Einleitung. Die Identifikation unbekannter Leichen gehört zu den Kernaufgaben der Rechtsmedizin. In vielen Fällen werden dazu radiologische Bilder (Röntgen, CT, MRT) als Vergleichsmaterial herangezogen, wobei der Schwerpunkt wegen der hohen Variabilität auf odontologischen Befunden und der Morphologie der Nasennebenhöhlen liegt. In Fällen, bei denen das Vergleichsmaterial lediglich Röntgenbefunde von Rumpf oder Extremitäten umfasst, ist eine Identifikation ohne individualisierendes chirurgisches Fremdmaterial oder krankhafte Skelettveränderungen häufig nur sehr eingeschränkt möglich. In einem Identifikationsfall konnte die verstorbene Person anhand eines Thorax-CT identifiziert werden, das auf koronaren Schichten eine fünfteilige, mosaikartige Ossifikation des Corpus sterni zeigte.

Methoden. Spaltbildungen und Foramina sind durchaus bekannte Phänomene, die sich aus der embryonalen Entwicklung des Sternums ergeben. Eine Literaturrecherche zur Häufigkeit derartiger Veränderungen erbrachte nur wenige Resultate, die eine biostatistische Untermauerung des Identifikationsbefundes ermöglicht hätten. Davon ausgehend wurde das eigene Untersuchungsmaterial von derzeit über 400 postmortalen Computertomographien hinsichtlich der Variabilität des Sternums untersucht.

Ergebnisse. Bereits eine erste orientierende Bestandsaufnahme von 100 Brustbeinen erbrachte eine erstaunliche Variabilität, deren Vielfalt und Variationsbreite hier vorgestellt werden sollen. Neben Umriss- und Querschnittsformen, Spalt- und Lochbildungen wurden auch Längen- und Breitenrelationen der Sternumteile Manubrium, Corpus und Proc. xiphoideus mit berücksichtigt.

Schlussfolgerung. Ziel der Untersuchungen ist die Validierung der Brustbeinmorphologie als brauchbares radiologisches Identifikationsmerkmal.

\section{V41}

\section{Sidescansonar zur Ortung von Wasserleichen nach jahrelanger Liegezeit}

\section{Mueller', J. Schoepfer', W. Keil}

${ }^{1}$ tauchdienste, München, Deutschland, ${ }^{2}$ Rechtsmedizin München, München, Deutschland

Einleitung. Die Suche nach Wasserleichen ist häufig schwierig und war in der Vergangenheit in vielen Fällen ergebnislos. Mit Hilfe der modernen Sonartechnik können Leichen nach jahrelanger Liegezeit im Wasser geortet werden und die Möglichkeit der Bergung und anschließenden rechtsmedizinischen Untersuchung ist gegeben.

Methoden. Das vorher eingegrenzte Suchgebiet wird mit einem am Boot geschleppten Schallgeber (Sidescansonar) flächendeckend gescannt. Durch die Auswertung der Echodaten ergeben sich Hinweise für Auffälligkeiten am Seegrund, die nach Wahrscheinlichkeiten den Konfigurationen menschlicher Körper bzw. ihrer Überreste zugeordnet werden. Die infrage kommenden Lokalisationen sind je nach Bedingungen mit unterschiedlichen visuellen Methoden zu überprüfen (Unterwasserroboter, Schleppkamera oder Taucher). Von 2011 bis 2012 wurden mit dieser Methode in 4 Fällen Leichen bzw. Leichenteile in bayerischen Seen geortet und geborgen. Nach polizeilichen Erkenntnissen handelte es sich um Unfälle.

Ergebnisse. Die Einzelheiten gehen aus $\bullet$ Tab. 1 hervor. Die vier, teils skelettierten Körper waren augenscheinlich am Gewässergrund komplett vorhanden, wurden jedoch nicht vollständig geborgen. Unterhautfettgewebe und Muskulatur hatten sich überwiegend zu Fettwachs umgewandelt. Einzelne innere Organe sowie Blutgefäße waren noch sehr

\begin{tabular}{|c|c|c|c|c|c|}
\hline $\begin{array}{l}\text { Wasser- } \\
\text { liegezeit } \\
\text { (Jahre) }\end{array}$ & $\begin{array}{l}\text { Vermisst } \\
\text { seit }\end{array}$ & Tiefe $(m)$ & $\begin{array}{l}\text { Lebens- } \\
\text { alter } \\
\text { (Jahre) }\end{array}$ & $\begin{array}{l}\text { Ge- } \\
\text { schlecht }\end{array}$ & Vorfall \\
\hline 8 & $08 / 2004$ & 19 & 69 & $\mathrm{~m}$ & $\begin{array}{l}\text { Untergehen } \\
\text { bei Rettungs- } \\
\text { versuch eines } \\
\text { Hundes }\end{array}$ \\
\hline 9 & $05 / 2003$ & 18 & 52 & w & $\begin{array}{l}\text { Untergehen } \\
\text { beim Schwim- } \\
\text { men }\end{array}$ \\
\hline 10 & $07 / 2001$ & 48 & 49 & $\mathrm{~m}$ & $\begin{array}{l}\text { Kentern beim } \\
\text { Segeln }\end{array}$ \\
\hline 27 & $02 / 1985$ & 52 & 52 & $\mathrm{~m}$ & $\begin{array}{l}\text { Einbrechen au } \\
\text { Eisfläche }\end{array}$ \\
\hline
\end{tabular}

gut zu beurteilen. Es bestand ausnahmslos ein auffallend guter Erhaltungszustand der Hirnhäute und des Gehirns, sodass Massenblutungen ausgeschlossen werden konnten. Anhaltspunkte für gröbere $\mathrm{Ge}-$ walteinwirkungen ergaben sich nicht. Anhand der Obduktionsbefunde und der jeweiligen Zahnstaten konnten alle vier Leichen identifiziert werden - Tab. 2.

Schlussfolgerung. Bislang galt die Suche nach lange im Wasser vermissten Personen als wenig erfolgversprechend. Die Fälle zeigen, dass bei entsprechender Vorgehensweise weit mehr als Zufallsfunde möglich sind. Die Ortung der Leichen und die Aufklärung der Vermisstenfälle hat nicht nur in rechtlicher, sondern auch in ethischer Hinsicht große Bedeutung.

\section{V42}

Morphologische Ursachen von Differenzen der Ossifikationsstadien der medialen Klavikulaepiphyse zwischen Sonographie, Computertomographie und Makroskopie

\section{Gonsior', F. Ramsthaler', A. Gehß', M.A. Verhoff'}

'Universität Gießen, Institut für Rechtsmedizin, Gießen, Deutschland, 2Universität des Saarlandes, Institut für Rechtsmedizin, Homburg/Saar, Deutschland, 'Universitätsklinikum Eppendorf, Institut für Rechtsmedizin, Hamburg, Deutschland

Einleitung. In der forensischen Altersschätzung nimmt die Beurteilung des Ossifikationsstatus der medialen Klavikulaepiphyse bei der Frage nach der Vollendung des 18. bzw. 21. Lebensjahres eine entscheidende Rolle ein. Goldstandard ist hierbei die Computertomographie. Vorwiegend aus Gründen des Strahlenschutzes wird jedoch versucht, strahlungsfreie Methoden wie die Sonographie zu etablieren.

Methoden. In der vorgestellten Studie wurde erstmals die Verknöcherung der medialen Klavikula sowohl sonographisch, computertomographisch sowie teilweise makroskopisch beidseits an denselben Probanden vergleichend beurteilt. Dazu wurden fünf männliche Verstorbene im Alter zwischen 15,8 und 28,8 Jahren untersucht.

Ergebnisse. Im Vergleich zwischen der hochauflösenden Sonographie (Frequenz: $12-15 \mathrm{MHz}$ ) und der Dünnschicht-Computertomographie (Schichtdicke: o,6 $\mathrm{mm}$ ) lag für rechtes und linkes Schlüsselbein getrennt betrachtet in 7 von 1o Fällen eine Diskrepanz zwischen den Ergebnissen dieser beiden Methoden vor. Sechsmal wurde das nach Schulz et al. (2008) sonographisch beurteilte Ossifikationsstadium der medialen Klavikula höher, in einem Fall niedriger als in der Computertomographie eingestuft. Lediglich bei einem der untersuchten Probanden führten die Sonographie und die Computertomographie auf beiden Körperseiten zu übereinstimmenden Ergebnissen. 


\section{V43}

Altersbestimmung von lebenden Personen anhand von Merkmalen der Weisheitszähne - Messung der Zahnkeimlänge in Kombination mit dem Mineralisations- und Eruptionsstadium

\section{S. Schmitter', C. Erfurt ${ }^{7}$ \\ 'Institut für Rechtsmedizin Dresden, Forensische Medizin, Dresden, Deutschland}

Einleitung. Gelangen Gutachtenaufträge zur forensischen Altersschätzung Jugendlicher und junger Erwachsener an das Institut für Rechtsmedizin Dresden, handelt es sich in der Regel um Ausländer, die nicht mehr im Besitz von gültigen Personaldokumenten sind und die ihr Lebensalter gegenüber deutschen Behörden im Rahmen von Asyl- oder Strafverfahren nicht mit notwendiger Zuverlässigkeit angeben können. Im Rahmen der praktischen forensisch-odontologischen Altersschätzung stellen die Weisheitszahnmineralisation und -eruption die Hauptkriterien in den relevanten Altersgruppen dar. Der zeitliche Ablauf beider Merkmale wurde im Rahmen zahlreicher Forschungsarbeiten für die einzelnen Ethnien gut untersucht. Dennoch ist eine Erweiterung des forensisch-odontologischen Methodenspektrums zur Präzisierung der Altersschätzung Lebender wünschenswert.

Methoden. Im Rahmen einer retrospektiven Studie wurde daher als zusätzliches Merkmal zur Beurteilung des Alters von lebenden Personen die Zahnkeimlänge der Weisheitszähne herangezogen, um festzustellen, ob deren Messung in Kombination mit dem Mineralisations- und Eruptionsstadium als weiterer Parameter in der forensischen Altersdiagnostik, insbesondere zur Abgrenzung der juristisch relevanten Altersgrenzen von 18 bzw. 21 Jahren genutzt werden kann.

Ergebnisse. Es erfolgte eine Auswertung von insgesamt 454 digitalen Orthopantomogrammen von Kindern und Jugendlichen im Alter von 13,5 bis 23,8 Jahren.

Schlussfolgerung. Anhand der gewonnenen Daten wurde ein verallgemeinert lineares Modell mit dem quantitativ errechneten Alter als Zielvariable und dem Längenmesswert am Weisheitszahn sowie dessen Eruptions- und Mineralisationsstadium als Erklärungsvariablen erstellt.

\section{V44 \\ Lebensaltersschätzung anhand des Razemisierungsgrades von Asparaginsäure in Elastin aus elastischem Knorpel der Epiglottis \\ C. Matzenauer ${ }^{1}$, A. Reckert', S. Ritz-Timme \\ 'UKD, Institut für Rechtsmedizin, Düsseldorf, Deutschland}

Einleitung. Zur biochemischen Lebensaltersschätzung anhand der intravitalen Razemisierung von Asparaginsäureresten in langlebigen Proteinen hat sich Dentin als Untersuchungsmaterial der Wahl bewährt. Allerdings sind Zähne nicht immer zur Analyse verfügbar. Es wurde untersucht, ob elastischer Knorpel der Epiglottis über das langlebige Strukturprotein Elastin zur Lebensaltersschätzung eingesetzt werden kann.

Material und Methodik. Insgesamt 65 Gesamtgewebeproben von elastischem Knorpel der Epiglottis (Lebensalter: 16 bis 92 Jahre) und 45 aufgereinigte Elastinproben (Lebensalter: 24 bis 96 Jahre) wurden untersucht. Die Kehldeckel wurden histologisch auf bindegewebigen Umbau und Degradation elastischer Fasern untersucht. Zur Analyse wurden die Proben gewaschen, die Proteine hydrolysiert, die Aminosäuren derivatisiert und die Proben gaschromatographisch analysiert. Die Elastinaufreinigung erfolgte mittels Kollagenaseverdaus. Die Aufreinigungsqualität wurde anhand von Aminosäurenanalysen überprüft. Ergebnisse. In den Gesamtgewebeproben zeigte sich ein langsamer Anstieg des Razemisierungsgrades von Asparaginsäure (AAR) mit dem Lebensalter, wobei der Zusammenhang zwischen Lebensalter und DAsparaginsäuregehalt bei jungen Individuen deutlich enger war als bei älteren Personen. In den aufgereinigten Elastinproben fand sich eine deutlich raschere Zunahme der AAR-Werte mit steigendem Lebens- alter; diese entsprach der typischen Kinetik der Razemisierung von Asparaginsäure in Elastin aus anderen Geweben. Bei gutem Aufreinigungsergebnis (Hydroxyprolingehalt $<3 \%$ ) war der Zusammenhang zwischen AAR und Lebensalter vergleichsweise eng $(\mathrm{r}=0,915)$.

Diskussion. Die in den Gesamtgewebeproben gefundene altersabhängige Razemisierung belegt, dass im Knorpelgewebe von Kehldeckeln permanente oder langlebige Proteine vorhanden sind. Allerdings war der Anstieg der AAR-Werte mit dem Lebensalter gering, was auf einen vergleichsweise geringen Gehalt langlebiger Proteine hinweist.

Schlussfolgerung. In aufgereinigtem Elastin stiegen die AAR-Werte mit dem Lebensalter deutlich schneller an; bei gutem Aufreinigungsergebnis war der Zusammenhang ausreichend eng für Lebensaltersschätzungen. Die Methode stellt eine Alternative für biochemische Lebensaltersschätzungen dar, wenn Zähne nicht verfügbar sind.

\section{V45}

\section{Todeszeitschätzung unter Verwendung eines Schweinemodells}

S. Niederegger', J. Schermer' ${ }^{2}$, J. Höfig², G. Mall ${ }^{2}$

'Institut für Rechtsmedizin, Forensische Entomologie, Jena, Deutschland, ${ }^{2}$ Institut für Rechtsmedizin, Jena, Deutschland

Einleitung. Schweinekadaver mit einem Gewicht von rund $25 \mathrm{~kg}$ werden vor allem in der forensischen Entomologie häufig als Substitution für menschliche Leichen verwendet, da sie während des Zerfalls ähnliche Insektenpopulationen aufweisen. Auch für andere Untersuchungen können sie verwendet werden, sofern die Tiere nicht ausgewachsen sind und die typische Schwarte noch nicht ausgebildet ist. Beim Hausschwein sind diese Voraussetzungen in der Mastzucht bis zu einem Gewicht von 35-40 kg gegeben.

Methoden. Die Todeszeitbestimmung ausschließlich anhand von Zerfallserscheinungen ist nach wenigen Tagen bereits sehr schwierig, wenn nicht sogar nahezu unmöglich. Erfolgte zudem ein Vergraben der Leiche kommen durch die Charakteristik des Bodens unzählige Einflussparameter hinzu, die nicht systematisch für alle Varianten erfasst werden können. Als Faustregel wird der Casparsche Satz herangezogen. Fall. Ende Juli 2012 wurde in einer Gartenanlage die Leiche einer männlichen Person mit einer Körpergröße von $180 \mathrm{~cm}$ und einem Gewicht von $60 \mathrm{~kg}$ gefunden. Die Leiche war in einem Holzschuppen in lehmigem Erdboden vergraben. Diverse Zeugenaussagen eröffneten ein Zeitfenster von 2 bis 8 Wochen für die mögliche Todeszeit.

Ergebnisse. Zur Simulation der Veränderungen, denen eine menschliche Leiche unter den gegebenen Voraussetzungen unterworfen ist, wurde der $35 \mathrm{~kg}$ schwere Kadaver eines frisch getöteten Schweins verwendet. Wöchentliche Ausgrabungen und Analysen des Schweinekadavers gestattete schließlich durch Vergleich die Eingrenzung der Todeszeit auf mehr als zwei aber weniger als drei Wochen.

\section{V46}

Beurteilung der DNA-Profilierbarkeit fäulnisveränderter Leichen basierend auf einem neuentwickelten quantitativen Bewertungssystem für Fäulnis

\section{Courts', Y. Hofmann', E. Sauer', B. Madea', C. Schyma}

${ }^{1}$ Institut für Rechtsmedizin, Bonn, Deutschland, ${ }^{2}$ Institut für Rechtsmedizin, Bern, Schweiz

Einleitung. Die DNA-basierte Identifizierung ansonsten unkenntlicher Faulleichen ist eine routinemäßige Aufgabe der forensischen Genetik. Mit fortschreitender Fäulnis verringert sich jedoch stetig die DNA-Integrität bis zu dem Punkt, ab dem eine Analyse nicht mehr möglich ist. Wann dieser Zeitpunkt erreicht ist, kann derzeit nur grob geschätzt werden, da eine systematisch-empirische Untersuchung der Assoziation von DNA-Profilierbarkeit mit verschiedenen Fäulniszeichen sowie 
mit dem für die Extraktion verwendeten Gewebetyp bislang nicht vorliegt.

Methoden. In der vorgestellten Studie wurde für ein Kollektiv von 69 fäulnisveränderten Leichen zunächst der Grad der Fäulnis mithilfe eines neuentwickelten quantitativen 12-stufigen binären Bewertungssystems klassifiziert. Die DNA-Profilierbarkeit von Lungenabstrichen, Aorta-, Leber-, Nieren-, Gehirn- und Muskelproben wurde anschließend evaluiert indem zunächst alle Proben mit einer selbstentwickelten Pentaplex-PCR analysiert wurden. Für repräsentativ ausgewählte Fälle wurde zusätzlich eine STR-Multiplex-PCR durchgeführt. Abschließend wurden die Ergebnisse zur Profilierbarkeit der DNA mit dem Grad der Fäulnis korreliert, und ein Vorhersagemodell für den zu erwartenden Erfolg bei der STR-Typisierung von DNA aus Geweben einer Faulleiche wird vorgeschlagen

\section{V47}

Molekulargenetische Identifizierung bei längerer Leichenliegezeit

U. Schmidt', J. Naue', D. Geisenberger', F. Neuhuber ${ }^{2}$

'Institut für Rechtsmedizin, Forensische Molekularbiologie, Freiburg, Deutschland, ${ }^{2}$ Fachbereich Gerichtsmedizin, Forensische Molekularbiologie, Salzburg, Österreich

Methoden. Für DNA-Analysen zur molekulargenetischen Identifizierung von fäulnisveränderten Leichen erfolgt häufig die aufwendige Aufbereitung von Knochen oder Zähnen. Einige Studien haben die Eignung alternativer Ausgangsmaterialien untersucht, die eine raschere und leichtere Extraktion von DNA erlauben, z. B. Organgewebe (Aorta, Niere, Leber).

Ergebnisse. Die Erfahrung aus der Fallarbeit zeigt, dass vor allem aus Hirngewebe häufig noch sehr gut erhaltene DNA extrahiert werden kann, was sich insbesondere in der erfolgreichen Amplifikation auch längerer STR-Fragmente niederschlägt. Zur systematischen Überprüfung dieser Beobachtung wurden bis zu 15 verschiedene Ausgangsmaterialien von Leichen mit unterschiedlich weit fortgeschrittener Fäulnis hinsichtlich ihrer Eignung für die DNA-Analyse verglichen.

\section{V48}

Evidenzbasierte Strategie zur Normalisierung quantitativer PCRDaten in der forensischen miRNA-Analyse

\section{E. Sauer', B. Madea', C. Courts \\ IInstitut für Rechtsmedizin, Bonn, Deutschland}

Einleitung. Die mikro-RNA(miRNA)-basierte Analyse von Körperflüssigkeiten und der Zusammensetzung komplexer Tatortspuren wurde vor einiger Zeit als potenzielles nutzbringendes Werkzeug in die forensische Genetik eingeführt. Die Verwendung von miRNAs hat hierbei einige Vorteile gegenüber mRNA; eine reliable miRNA-Detektion und -Quantifizierung mittels quantitativer PCR (qPCR) setzt allerdings grundsätzlich eine solide, forensisch relevante Normalisierungsstrategie voraus.

Methoden. In der vorliegenden Studie wurde eine sorgfältig ausgewählte Gruppe potenzieller Referenzgene auf ihre Eignung als endogene Kontrollen für die forensische miRNA-qPCR-Normalisierung untersucht. Unter Verwendung standardisierter aktueller Protokolle und spezialisierter Computeralgorithmen wurden Assay-Performance und -Varianzen in venösem Blut, Speichel, Sperma, Vaginalsekret und Menstruationsblut sowie Mischungen analysiert.

Ergebnisse. Basierend auf diesen empirischen Ergebnissen empfehlen wir die Normalisierung gegen eine Signatur derjenigen Referenzgene mit der jeweils stabilsten Expression und geringsten zu erwartenden Variation.

Schlussfolgerung. Aufgrund des fehlenden Konsenses bezüglich der Durchführung und Interpretation von qPCR-Experimenten in der
miRNA-Analytik folgen Darstellung und Dokumentation der Studie den sogenannten MIQE-Richtlinien (DOI: 10.1373/clinchem.2008), die die „minimale Information für Publikationen von quantitativen Realtime-PCR-Experimenten“ definieren.

\section{V49}

\section{Qualitätssicherung und Akkreditierung in der Forensischen Ento- mologie}

\section{J. Amendt ${ }^{1}$, H. Fremdt ${ }^{7}$}

'Institut für Forensische Medizin, Forensische Biologie, Frankfurt am Main, Deutschland

Einleitung. Die Insektenkunde hat sich als probates Mittel zur Beantwortung forensischer Fragestellungen etabliert. Um ihre Gerichtstauglichkeit auch in Zeiten der Akkreditierung sicherzustellen, ist der nächste Schritt zwangsläufig die Standardisierung der Methode. Diese fußt auf drei Grundpfeilern: 1. der fachgerechten Asservierung, Weitergabe und Dokumentation des insektenkundlichen Materials, 2. der Harmonisierung der Auswertung und Interpretation der Befunde, sowie 3. der Erstellung des forensisch-entomologischen Gutachtens.

Methoden. Immer wieder wird selbst bei offenkundigen Tötungsdelikten aus unterschiedlichsten Gründen gar nicht oder schlecht asserviert. Hier gilt es zu erreichen, dass Insekten effizient und mit überschaubarem Aufwand gesammelt werden. Zu diesem Zweck müssen Anweisungen, die die Methoden der Asservierung darlegen, für jeden zugänglich sein, sodass sowohl Biologen als auch Rechtsmediziner und Polizeibeamte gutachtentaugliches Untersuchungsmaterial asservieren. Auch eine standardisierte Temperaturdokumentation ist dabei zwingend notwendig. Bei der weiteren Behandlung und Untersuchung des oftmals lebenden Materials sind die Lagerungs- bzw. Aufzuchtbedingungen zu dokumentieren, die anschließende Bestimmung der Tiere und die Auswertung der Entwicklungsdaten muss gängigen Qualitätsstandards folgen. Zur Sicherstellung der Kompetenz müssen Ringversuche entwickelt werden, die aber schwieriger zu organisieren sind als z. B. die Versuche in der DNA-Analytik - wie ist etwa garantiert, dass jedes Labor mit der gleichen Qualität an insektenkundlichen Spuren versorgt wird? Nicht zu unterschätzen ist schließlich die schriftliche Ausarbeitung, also die Erstellung des entomologischen Gutachtens. Es muss eine klar formulierte Fragestellung beinhalten, aufzeigen, wer das untersuchte Material wo und wie gesammelt und wann an den Gutachter gegeben hat, die (bei einer Leichenliegezeiteingrenzung unerlässlichen) Temperaturdaten präsentieren und aufzählen, welche Insektenarten in welchem Entwicklungsstadium vorgefunden wurden. Zudem müssen die für die Altersberechnung der Insekten verwendeten Referenzdaten und -quellen genannt sein.

\section{V50}

Generierung von Entwicklungsdiagrammen für die forensisch relevante Schmeißfliege Calliphora vicina in Deutschland mittels quantiler Regression

\section{Baqué ${ }^{1,2}$, N. Filmann ${ }^{3}$, J. Amendt ${ }^{1}$}

'Institut für Rechtsmedizin, Forensische Entomologie, Frankfurt/Main, Deutschland, 'Institut für Aquatische Ökotoxikologie, Frankfurt/Main, Deutschland, ${ }^{3}$ Institut für Biostatistik und Mathematische Modellierung, Frankfurt/Main, Deutschland

Einleitung. Zur Bestimmung des minimalen postmortalen Intervalls mittels forensisch entomologischer Methoden werden Entwicklungsdaten nekrophager Schmeißfliegenarten herangezogen. Die wichtigsten Komponenten in der Ermittlung des Alters eines larvalen Individuums stellen hierbei die sich verändernden Parameter Körperlänge und -gewicht dar. Da sich die Erkenntnis immer mehr durchsetzt, dass bei der Bewertung und Evaluierung dieser morphologischen Entwick- 


\begin{tabular}{|lll|}
\hline Tab. 3 | V53 & & \\
\hline & CN- $(\mathbf{m g} / \mathbf{l})$ & CO-Hb (\%) \\
\hline & Median (Range) & Median (Range) \\
\hline Wohnungsbrände & $0,8(0,0-7,1)$ & $39,7(12,8-90,2)$ \\
\hline Pkw-Brände & $3,5(1,8-5,3)$ & $44,3(29,1-59,6)$ \\
\hline
\end{tabular}

lungsparameter einfache lineare Modelle nicht ausreichend sind, müssen additive oder gemischte Modelle Anwendung finden.

Methoden. Es wurden zweimal 600 Larven der forensisch relevanten Schmeißfliege Calliphora vicina bei $15^{\circ} \mathrm{C}, 20^{\circ} \mathrm{C}$ und $25^{\circ} \mathrm{C}$ untersucht. Dreimal täglich wurden 5 Larven willkürlich abgesammelt und Länge, Gewicht und Larvenstadium notiert. Die statistische Analyse wurde mittels eines linearen quantilen gemischten Modells in R durchgeführt. Ergebnisse. Für jede Temperatur konnten für die Larvenstadien 1-3 die 10\% und 90\%-Quantilfunktion des Larvenalters bestimmt werden. Für das „vierte“ Larvenstadium (Wanderphase), in dem nach Einstellung der Nahrungsaufnahme ein Schrumpfen der Made stattfindet, zeigten sich die Regressionsfunktionen als nicht adäquat und verdeutlichen die Schwierigkeit, dieses Stadium genauer einzugrenzen. Hier ist ein additives gemischtes Modell, das die Nichtlinearität des Stadiums berücksichtigt, denkbar. Für die fressaktiven Stadien konnte dagegen das Larvenalter für die untersuchten Temperaturen anhand von Stadium und Länge ermittelt und graphisch gut dargestellt werden.

Schlussfolgerung. Erstmals werden mittels gemischter quantiler Regression Entwicklungsdiagramme einer deutschen Calliphora-vicinaPopulation generiert, die als Referenzwerte bei der Erstellung eines forensisch entomologischen Gutachtens herangezogen werden können.

\section{V51}

Kandidatengene für die molekulare Altersbestimmung der Puppen von Lucilia sericata und Calliphora vicina (Diptera: Calliphoridae)

\section{B.K. Zajac', J. Amendt', R. Zehner ${ }^{\text {? }}$ \\ 'Institut für Rechtsmedizin, Forensische Entomologie, DNA, Frankfurt am Main, Deutschland}

Fragestellung. Das Alter von Schmeißfliegenpuppen kann durch die relative Änderung der Expression von entwicklungsrelevanten Genen bestimmt werden. Erste Studien zeigen allerdings eine mangelnde Genauigkeit - das Alter kann lediglich auf etwa 2-3 Tage genau eingegrenzt werden. Um diese Variationsbreite zu reduzieren, suchen wir neue Gene, die sich aufgrund ihres Expressionsmusters während der Metamorphose für die molekulare Altersbestimmung besser eignen. Im Fokus stehen dabei Puppen der in Deutschland forensisch bedeutsamsten Schmeißfliegenarten Calliphora vicina und Lucilia sericata.

Methoden. Aus Studien über die entwicklungsabhängige Expression von Gen-Clustern bei Drosophila melanogaster wurden Gene ausgewählt. Da zwischen D. melanogaster und den hier untersuchten Schmeißfliegen nur schwache Sequenzhomologien bestehen, war es nötig, basierend auf dem 2012 veröffentlichten Transkriptom von L. sericata neue Primer zur Amplifikation dieser Gene zu entwerfen. Hierzu wurde eine Reverse Transkriptase-PCR mittels ACPTMPrimern und eine anschließende Amplifikations-PCR zur Kontrolle der Primer-Spezifität entwickelt.

Ergebnisse. Die Ergebnisse zeigen gut etablierte PCR-Systeme, die die Grundlage der entworfenen qPCR-Assays für die laufenden Untersuchungen bei L.-sericata- und C.-vicina-Puppen darstellen. Die ausgewählten Loci zeigen im Verlauf der Metamorphose von L. sericata differente Muster der Expression. Eine Kombination dieser und bereits etablierter Loci kann die Altersschätzung an L.-sericata-Puppen präzisieren. Bei der Untersuchung der Expression der zweiten Schmeißfliegenart C. vicina zeigt sich jedoch, dass die hier entwickelten qPCRAssays nur für wenige der auf Basis des L.-sericata-Transkriptoms ausgewählten Gene nutzbar sind.
Schlussfolgerung. Vermutlich sind die Sequenzhomologien zwischen den untersuchten Arten geringer als erwartet. Um qPCR-Assays zu entwickeln, die gleichermaßen für beide Arten anwendbar sind, bietet sich somit eine Erfassung des C.-vicina-Transkriptoms an.

\section{V52}

Die sog. Fechterstellung bei Brandleichen - Wirklichkeit oder Fehleinschätzung?

\section{T. Riepert', T. Hassel', M. Sariyar ${ }^{2}$, R. Urban}

'Universitätsmedizin, Institut für Rechtsmedizin, Mainz, Deutschland, ${ }^{2}$ Universitätsmedizin, Institut für Medizinische Biometrie, Epidemiologie und Statistik, Mainz, Deutschland

Fragestellung. Im rechtsmedizinischen Alltag wird bei einer Brandleiche die auffällige Stellung der Gelenke, die auf eine hitzebedingte Schrumpfung der Muskulatur und Sehnen zurückgeführt wird, in der Regel als „Fechterstellung“ bezeichnet. Unsere Untersuchungen galten der Frage, ob diese Bezeichnung der Wirklichkeit entspricht oder andere Typisierungen notwendig erscheinen.

Methode. In einer retrospektiven Studie wurden 60 fortlaufende Fälle von Verstorbenen mit dritt- und/oder viertgradigen Verbrennungen aus dem Obduktionsgut der Jahre 1994 bis 2013 des Instituts für Rechtsmedizin Mainz untersucht, bei denen zusätzlich zum Obduktionsprotokoll eine fotographische Dokumentation vorlag und der Leichnam im Wesentlichen vollständig erhalten war. Bei der Auswertung wurde auf die Stellung der Gelenke an Hals, Schultern, Ellenbogen, Hüfte und Knie besonderes Augenmerk gelegt.

Ergebnisse. Die im Fechtsport als „Fechtstellung“ bezeichnete Anfangsund Endstellung besteht im Wesentlichen in einer Seitwärtshaltung des Kopfes zum Waffen führenden Arm, leichter Streckung und Seitwärtshaltung dieses Arms in die Horizontale, Wegführung des anderen Arms in die Gegenrichtung, leichter Beugung der Beine, Stellung der Füße im rechten Winkel zueinander um gut eine Fußlänge entfernt, der Fuß unter dem Waffen führenden Arm nach vorne gerichtet. Diese klassische, asymmetrische Fechtstellung wurde bei unserer Auswertung in voller Ausprägung praktisch nicht gesehen. Die vorläufige Analyse ergab ein uneinheitliches Bild. Insgesamt überwogen zur Sagittalebene symmetrische Körperstellungen mit Betonung der Beugung in Ellenbogen-, Hüft- und Kniegelenken.

Schlussfolgerungen. Eine mögliche feingliedrige Klassifikation sollte der Bezeichnung „Fechterstellung“ eine eher untergeordnete Bedeutung zukommen lassen und diese Bezeichnung nur den Fällen vorbehalten bleiben, in denen eine Fechterstellung tatsächlich vorliegt.

\section{V53}

\section{Postmortale Cyanidkonzentration bei Bränden}

S. Stoll', G. Roider', S. Kraus', W. Keil'

'Institut für Rechtsmedizin München, München, Deutschland

Einleitung. HCN ist ein relevanter toxischer Rauchgasbestandteil. Während die CO-Messung zur Routine der forensisch-toxikologischen Analytik gehört, werden die $\mathrm{CN}-$-Konzentrationen vergleichsweise selten bestimmt. HCN entsteht bei der Verbrennung C- und N-haltiger Materialien unter $\mathrm{O}_{2}$-Mangel. Voraussetzung sind höhere Temperaturen wie sie bei Vollbränden erreicht werden. Natürliche Materialien sind beispielsweise Federn, Wolle und Seide, synthetische Stoffe stellen z. B. Polyurethane und Polyamide dar. Im Kunststoff Polyacrylnitril liegt in einer Seitenkette bereits die CN-Gruppierung vor. Auf die Entstehungsweisen von $\mathrm{HCN}$ wird eingegangen.

Methoden. In den Jahren 2011 und 2012 fanden sich im Obduktionsgut des Instituts für Rechtsmedizin München insgesamt 29 Brände, davon 27-mal Wohnungen und 2-mal Pkws betreffend. Sowohl CN- als auch 
CO wurden mittels (spektro)photometrischer Methoden im Herzblut mit folgenden Ergebnissen bestimmt (• Tab.3).

Bei allen Bränden wurde $\mathrm{CN}$ - festgestellt; lediglich in einem Fall mit mehrstündiger Überlebenszeit bei intensivmedizinischer Behandlung war kein $\mathrm{CN}$ - nachweisbar. Die $\mathrm{CN}--$ Konzentrationen lagen häufig im toxischen, gelegentlich im letalen Bereich. Die CN--Werte wurden in Relation zum Brandgut nach Aktenlage ausgewertet. Auffallend sind die hohen $\mathrm{CN}$--Konzentrationen bei den beiden Pkw-Bränden, die sich auf häufig im Automobilbau verwendete Kunststoffe zurückführen lassen.

Schlussfolgerung. Die Untersuchungsergebnisse unterstreichen die Notwendigkeit der $\mathrm{CN}$--Analyse in der forensisch-toxikologischen Routine.

\section{V54}

\section{Suizide durch thermische Gewalt in der Schweiz im Zeitraum 2000-2010}

\section{S. Gauthier', T. Reisch², N. Nigg-Trawally', C. Bartsch}

'Institut für Rechtsmedizin der Universität Zürich, Forensische Medizin und Bildgebung, Zürich, Schweiz, ${ }^{2}$ PZM Psychiatriezentrum Münsingen, Fachklinik für Allgemeine Psychiatrie, Münsingen, Schweiz

Einleitung. Suizide durch thermische Gewalt sind in den Industrienationen generell sehr selten. In Nordamerika und Europa liegt die Rate derer, die sich durch Selbstverbrennung suizidieren, bei etwa 1-1,5\% aller Suizide, während diese Methode im Nahen Osten, in Afrika oder Südasien aus unterschiedlichen Gründen einen Anteil von ca. 11\% der vollendeten Suizide ausmacht.

Methoden. Im Rahmen eines vom Schweizerischen Nationalfonds finanzierten Forschungsprojekts wurden schweizweit alle in den Instituten für Rechtsmedizin untersuchten Todesfälle nach Suizid für den oben genannten 11-Jahres-Zeitraum mit Hilfe eines hierfür erarbeiteten Erhebungsbogens dokumentiert und statistisch nach unterschiedlichen Kriterien ausgewertet.

Ergebnisse. Von insgesamt knapp 5000 Suizidtodesfällen fanden sich 120 Suizide $(2,4 \%)$ durch thermische Gewalt. Die am häufigsten gewählte Suizidmethode unter denen durch thermische Gewalteinwirkung Verstorbenen war mit 41,6\% die Selbstverbrennung, gefolgt von Suizid durch Kälte (30\%) und Stromeinwirkung (17,5\%). Im Gesamtuntersuchungsgut fanden sich insgesamt doppelt so viele Männer $(67,7 \%)$ wie Frauen $(32,3 \%)$, bei den Suiziden durch thermische Gewalteinwirkung war die Geschlechtsverteilung hingegen nur leicht zugunsten der Männer verschoben (55\% Männer : 45\% Frauen). Die Altersverteilung im Gesamtkollektiv lag zwischen 11 und 101 Jahren bei einem Median von knapp 50 Jahren, der Median bei Suiziden durch thermische Gewalteinwirkung lag etwas darunter (47 Jahren). In $73 \%$ aller Fälle handelte es sich um Schweizer Staatsangehörige, bei mehr als der Hälfte der Suizidenten (56\%) wurden psychische Probleme als Auslöser für den Suizid vermutet.

Schlussfolgerung. Die Ergebnisse der vorliegenden Schweizer Studie ermöglichen erstmals einen detaillierten Überblick über rechtsmedizinisch untersuchte Suizidtodesfälle durch thermische Gewalt aus dem genannten 11-Jahres-Zeitraum und werden zur internationalen Situation in Beziehung gesetzt, wobei die häufigste Methode, die Selbstverbrennung, im Zentrum steht.
V55

Der erweiterte Suizid als kriminalistische und psychiatrische Herausforderung

\section{B. Hartung', C. Lange-Asschenfeldt'², W. Huckenbeck', F. Hellen²}

${ }^{1}$ Heinrich-Heine-Universität, Institut für Rechtsmedizin, Düsseldorf, Deutschland, ${ }^{2}$ Heinrich-Heine-Universität, Klinik für Psychiatrie und Psychotherapie, Düsseldorf, Deutschland

Einleitung. Eine besonders schwerwiegende Form des Suizides stellt der „erweiterte Suizid“ bzw. „Mitnahmesuizid“ dar. Ziel der Arbeit war es, die einschlägigen Risikofaktoren zu identifizieren und mit dem aktuellen Stand der Wissenschaft abzugleichen, um ggf. behandelnde Ärzte und Ermittlungsbehörden hinsichtlich der Gefahr eines erweiterten Suizids zu sensibilisieren.

Methoden. Aus dem Einzugsgebiet der Rechtsmedizin Düsseldorf wurden für den Zeitraum der Jahre 2006 bis 2011 die Sektionsprotokolle $(n=3132)$ hinsichtlich des Vorliegens eines solchen Ereignisse überprüft, wobei abschließend vom Vorliegen von insgesamt 10 solcher Ereignisse auszugehen ist. Die Abgrenzung von „gemeinsamem Suizid“, „erweitertem Suizid“ und „Tötung mit anschließendem Suizid“ war im Einzelfall komplex. Als Risikofaktoren für die Tatbegehung konnten im Konsens mit der Literatur männliches Geschlecht, höheres Lebensalter, intime Täter-Opfer-Beziehung, Zugang zu Schusswaffen sowie narzisstische und/oder emotional instabile Persönlichkeitsmerkmale sowie Aggressivität herausgearbeitet werden.

Ergebnisse. Mutmaßliche Hauptmotive waren Trennungswunsch der Partnerin und drohender sozialer Abstieg. Der Tod der Opfer trat ganz überwiegend durch die Folgen einer Schussverletzung oder durch die Einwirkung scharfer Gewalt ein.

Schlussfolgerung. Die Autoren empfehlen die Verwendung des Begriffes der „erweiterten Tötung“ anstelle des „erweiterten Suizides“, um einerseits der Opferperspektive Rechnung zu tragen und anderseits die begangene Straftat des Tötungsdeliktes in den Vordergrund zu stellen.

\section{V56}

Soziale Netzwerke als Kommunikationsplattform zur Vorbereitung eines gemeinschaftlichen Suizides - ein Fallbericht

R. Wolff-Maras', Y. Schulz'2, F. Ast', U. Preiß', J.P. Weller', M. Klintschar', T. Germerott ${ }^{?}$

IInstitut für Rechtsmedizin, Medizinische Hochschule Hannover, Hannover, Deutschland, ${ }^{2}$ Karl-Jaspers-Klinik, Klinik für Forensische Psychiatrie u. Psychotherapie, Bad Zwischenahn, Deutschland

Einleitung. Soziale Netzwerke sind, insbesondere für jüngere Menschen, ein wesentlicher Bestandteil der modernen Kommunikation, über die Informationen des alltäglichen Lebens einer breiten Masse mitgeteilt sowie Treffen und Veranstaltungen organisiert werden können. Jedoch werden diese Netzwerke in Einzelfällen auch zur Suizidankündigung und Planung gemeinschaftlicher Suizide genutzt. Darüber hinaus existieren auch sogenannte Suizidforen, in denen ein Austausch über „effektive" Suizidmethoden und Suizidversuche erfolgt.

Fallbericht. Vorgestellt wird ein Fall eines gemeinsam begangenen Suizides dreier junger Frauen, die sich über ein soziales Netzwerk zu einem gemeinschaftlichen Suizid in Norddeutschland verabredeten. Bereits beim ersten Chat wurde mit Vorbereitungen für den gemeinsamen Suizid begonnen und Arbeitsaufträge untereinander verteilt. Die Zeitspanne zwischen der ersten Kontaktaufnahme und dem gemeinsamen Suizid betrug weniger als eine Woche. Todesursache war in allen drei Fällen eine Kohlenmonoxidintoxikation. Die drei Frauen hatten in einem mit einer Folie abgedichteten Igluzelt Holzkohle in drei EinwegAluminiumgrillschalen abgebrannt.

Schlussfolgerung. Die vorgestellte Kasuistik verdeutlicht, dass über soziale Netzwerke eine schnelle und einfache Kontaktaufnahme zu Gleichgesinnten über das reale soziale Umfeld hinaus ermöglicht wird. 
Hierbei kann sich auch eine Gruppendynamik im Sinne einer Bestärkung des Suizidwunsches entwickeln und somit zur Umsetzung eines Suizidversuches beitragen.

\section{V57}

Das Bild der Rechtsmedizin in Österreich - die Auswertung einer wissenschaftlichen Studie

\section{S. Kainz', E. Scheurer, ${ }^{1,2}$, P.J. Schick ${ }^{1,3}$, R. Riener-Hofer ${ }^{1}$}

'Ludwig Boltzmann Institut für Klinisch-Forensische Bildgebung, Graz, Österreich, ${ }^{2}$ Medizinische Universität, Graz, Österreich, ${ }^{3}$ Karl-Franzens-Universität, Institut für Strafrecht, Strafprozessrecht und Kriminologie, Graz, Österreich

Einleitung. Das Ludwig Boltzmann Institut für Klinisch-Forensische Bildgebung in Graz (LBI-CFI) betreibt seit 2008 die erste und bisher einzige klinisch-forensische Ambulanz in Österreich. Es gibt jedoch Bestrebungen, klinisch-forensische Untersuchungen österreichweit $\mathrm{zu}$ ermöglichen.

Fragestellung. Verändern diese neuen Entwicklungen das Bild der Rechtsmedizin in der Öffentlichkeit? Mit dem Begriff „Gerichtsmedizin" werden vorwiegend postmortale Untersuchungen in Verbindung gebracht; Medienberichte in Zusammenhang mit Tötungsdelikten tragen das ihre dazu bei. Die vom LBI-CFI durchgeführte Studie „Standortbestimmung der Gerichtsmedizin in Österreich" hat aufgezeigt, welches Bild sich die „Endabnehmer“ - nämlich die Strafverfolgungsbehörden - vom Fach und vom Leistungsangebot der Rechtsmedizin machen.

Methoden. Von Seiten des Ludwig Boltzmann Instituts wurde ein anonymisierter Fragebogen mit insgesamt 21 Fragen ausgearbeitet, der in Form einer österreichweiten Online-Befragung (in Zusammenarbeit mit dem Bundesministerium für Justiz) von Staatsanwältinnen/Staatsanwälten und Richterinnen/Richtern zu beantworten war. Ziel der gestellten Fragen war es, eine Standortbestimmung der Rechtsmedizin, und insbesondere des Stellenwertes der klinischen Rechtsmedizin in Österreich durchzuführen. Im September 2012 wurde von Seiten des Bundesministeriums für Justiz eine österreichweite Intranetschaltung unter Verweis auf den Link zur Studie veröffentlicht. Ab diesem Zeitpunkt hatten die Richterinnen/Richter und Staatsanwältinnen/ Staatsanwälte 9 Wochen lang die Möglichkeit, den Fragebogen zu beantworten.

Ergebnisse und Schlussfolgerung. Insgesamt haben 139 Personen an der Studie teilgenommen. Die gewonnenen Ergebnisse sind für die zukünftige Zusammenarbeit zwischen Strafverfolgungsbehörden und Rechtsmedizin in Österreich von Relevanz.

\section{V58}

\section{Anatomie am konkreten Fall - ein innovatives Lehrkonzept durch Kooperation zwischen Anatomie und Rechtsmedizin}

T. Riepert', I. Spiwoks-Becker², R. Urban', R. Nitsch'², T. Sebestény ${ }^{2}$

'Universitätsmedizin, Institut für Rechtsmedizin, Mainz, Deutschland, ${ }^{2}$ Universitätsmedizin, Institut für Mikroskopische Anatomie und Neurobiologie, Mainz, Deutschland

Einleitung. Über zwei Semester wurde an der Universitätsmedizin Mainz ein neu konzipiertes Lehrkonzept etabliert, welches auf einer Kooperation von Anatomie und Rechtsmedizin im 2. bzw. 3. vorklinischen Semester beruht.

Ziele. Folgende Ziele des Vorhabens wurden verfolgt: 1) Vorklinik und Klinik zu verzahnen, entsprechend den Vorgaben der Approbationsordnung, 2) Interesse an klinischen Fragestellungen zu fördern, 3) den Studierenden bereits in der Vorklinik die topographische Anatomie des menschlichen Körpers im unfixierten Zustand zu demonstrieren, 4) den Studierenden einen direkten Bezug zur Arbeitswelt zu erschließen, 5) das Problemlösungsdenken der Studierenden zu fördern.

Methoden. Zunächst wird allen Studierenden (über 450) eine einführende Vorlesung angeboten, in der die Besonderheiten einer rechtsmedizinischen Obduktion (Ablauf, Schweigepflicht, Fragestellungen, Asservierung usw.) erläutert werden. Im Laufe des Semesters werden kleinen Gruppen von jeweils acht Studierenden einer Obduktion zugeführt, wobei die Möglichkeit besteht, an der Vorbesprechung mit den Beamten der Ermittlungsbehörden und an der abschließenden Fallabnahme durch die Institutsleitung teilzunehmen und so den Gesamtfall und die möglichen Aspekte der Problemlösung zu diskutieren. Während der Obduktion erläuterten Mitarbeiter der Anatomie und der Rechtsmedizin die wesentlichen Befunde und beantworteten die Fragen der Studierenden.

Ergebnisse. Fast alle Studierenden (etwa 90\%) nutzten das freiwillige Angebot. Die schriftlichen Evaluationen am Abschluss der beiden Semester ergaben einen ausgesprochen positives Bild („highlight“) und lagen deutlich über dem Durchschnitt anderer vorklinischer Angebote. Studierende höherer Semester beklagten, dass nicht auch ihnen schon in der Vorklinik diese Möglichkeit gegeben wurde. Allerdings war die Organisation aufwändig (terminliche Absprachen, geeignete Fälle, räumliche Entfernung zwischen Anatomie und Rechtsmedizin, zeitlicher Aufwand für die Betreuer) und die Beurteilung durch die Studierenden auch sehr von den betreuenden Dozenten abhängig.

Schlussfolgerung. Zusammenfassend konnten die angegebenen Ziele erreicht werden. Wir streben eine Weiterführung des Projekts, auch unter Einbeziehung von Studierenden der Zahnmedizin, an. Das Vorhaben wurde gefördert durch MAICUM (Mainzer Curriculum Medizin - 9729045).

\section{V59}

Die ärztliche Leichenschau - ausgewählte Differenzialdiagnostik für Praxis und Lehre

\section{U. Hammer', A. Büttner?}

'Institut für Rechtsmedizin der Universitätsmedizin, Gerichtsärztlicher Dienst, Rostock, Deutschland

Fragestellung. Wir verfolgen das Ziel, die Lehrplanstruktur im Fach Rechtsmedizin für Mediziner, Polizisten und Juristen über eine relevanzgewichtete Differenzialdiagnostik von Leichenschaubefunden zu optimieren, dass ausgehend von Standardsituationen bei der ärztlichen Leichenschau, von häufigen Befundkonstellationen und von Tatort- $/$ Ereignisortsituationen besonders praxisrelevant unterrichtet werden kann.

Methoden. Im Rückblick auf Obduktionen, Leichenschauen am Ereignisort/Tatort und Krematoriumsleichenschauen in Rostock und Schwerin zeigen wir Leichenschaubefunde, die übersehen werden können oder deren Interpretation aufgrund ähnlicher Morphologie schwierig sein kann. Dazu wurden 50 differenzialdiagnostische Oppositionen ausgewählt, die häufig vorkommen, deren Fehleinordnung von rechtlicher Relevanz sein würde oder zu Fehldiagnosen bezüglich der Todesursache führte.

Ergebnisse und Schlussfolgerungen. Eine Relevanzwichtung führte zu einer breit illustrierten Basis von Leichenschaubefunden, auf die sich variabel Lehrplanstrukturen aufsetzten ließen, die an die Erfordernisse des Studiengangs Medizin ebenso leicht anzupassen waren, wie an polizeiliche, juristische oder forensisch-naturwissenschaftliche Studiengänge. 


\section{V60}

\section{Forschung im Krematorium}

\section{B. Wulff', O. Seibel', C. Edler', A. Heinemann', K. Püschel' 'Institut für Rechtsmedizin, Hamburg, Deutschland}

Einleitung. Aktuell liegt die Kremierungsrate in Deutschland bei 50-80\% der etwa 852.000 Sterbefälle (2011). Die gesetzlich geregelte 2. Leichenschau vor der Kremierung zur letztmöglichen Sicherung der Befunde an der Leiche wird von universitär angebundenen Rechtsmedizinern oder anderen speziell weitergebildeten Ärzten, z. B. aus dem Öffentlichen Gesundheitswesen, geleistet.

Fragestellung. Zur Krematoriumsleichenschau werden in Justiz, Polizei und gerichtlicher Medizin zumeist strafrechtliche Aspekte im Hinblick auf die Todesart diskutiert. Wir möchten vorstellen, dass dort auch epidemiologisch bedeutsame Daten zur Versorgungsforschung und Qualitätssicherung bei hoch spezialisierten ärztlichen Eingriffen erhoben werden können.

Material und Methoden. Zu folgenden 4 Forschungsprojekten wurden in Hamburger Krematorien Daten und Befunde an der Leiche erhoben, durch Befragung der Hausärzte bzw. der Hinterbliebenen ergänzt und nach deren Einverständnis zur Sektion bzw. zum wissenschaftlichem Eingriff ausgewertet:

- kontinuierliches Dekubitus-Monitoring,

- Qualitätskontrolle bei Endoprothesen,

- Mundgesundheit unter besonderer Berücksichtigung von Zahnimplantaten in Abhängigkeit von der Altersgruppe und den Vorerkrankungen,

- Osteoporosebehandlung mit Bisphosphonaten.

Einzelbeispiele werden vorgestellt.

Ergebnisse. Auch bei niedriger Prävalenz einer Gesundheitsstörung bzw. einer medizinischen Intervention in der Gesamtbevölkerung können mithilfe des großen Kollektivs der im Krematorium untersuchten Verstorbenen wissenschaftlich relevante Fallzahlen erreicht werden, sofern dafür allerdings erhebliche Ressourcen für den zusätzlichen Zeitaufwand des ärztlichen Leichenschauers, die Kommunikation mit Bestattern, ärztlichen Kollegen und insbesondere den Hinterbliebenen eingesetzt werden.

Schlussfolgerung. Forschung im Krematorium kann wichtige Hinweise für die Weiterentwicklung der medizinischen Versorgung, aber auch sozial- und gesellschaftspolitische Impulse geben. Sie eröffnet für das Fach Rechtsmedizin darüber hinaus die Möglichkeit, breitgefächerte Forschungskooperationen einzugehen.

\section{V61}

\section{Drogentote in Hamburg - welche Rolle spielt Methadon?}

\section{S. Iwersen-Bergmann', H. Jungen', H. Andresen-Streichert' ${ }^{1}$, A. Mueller', A. Heinemann ${ }^{7}$ \\ 'Institut für Rechtsmedizin, Toxikologie, Hamburg, Deutschland}

Fragestellung. Tödliche Drogenintoxikationen nehmen in Hamburg, wie auch bundesweit, erfreulicherweise ab. In Hamburg sehen wir jedoch bei den tödlichen Intoxikationen seit 3 bis 4 Jahren einen sehr deutlichen Anstieg der methadonbedingten Todesfälle. Aus Gründen des Datenschutzes ist es nicht möglich zu erfahren, ob sich ein Verstorbener in einem Methadon-Substitutionsprogramm (MSP) befand. Der Hamburger Datenschutzbeauftragte erteilte wegen der Dringlichkeit des Problems eine Sondergenehmigung zur Auswertung des Anteils methadonsubstituierter Patienten an den tödlichen Intoxikationen. Darüber hinaus wurde unsere Methode zum Nachweis von Disacchariden im Urin retrospektiv auf die Untersuchungsgruppe angewandt, die geeignet ist um einen intravenösen Methadonkonsum nachzuweisen. Methoden. Namen und Geburtsdaten, der als Drogentote (2007-2012) kategorisierten Personen $(n=341)$ wurden an die kassenärztliche Vereinigung (KV) übermittelt. Die Meldedaten der substituierenden Ärzte für das Substitutionsregister wurden von der KV daraufhin überprüft und der Substitutionsstatus zurückgemeldet.

Ergebnisse. Die aktuelle Auswertung der Substitutionsraten bezieht sich lediglich auf die Intoxikationen mit Methadonbeteiligung $(\mathrm{n}=112)$. $48 \%$ der an einer Methadon(Misch-)Intoxikation Verstorbenen befanden sich zum Todeszeitpunkt in einem MSP, weitere $21,4 \%$ waren schon einmal zeitlich zurückliegend in einem MSP, zum Zeitpunkt des Todes jedoch nicht mehr. 30,3\% waren nie substituiert. Mittelwerte der bei den tödlichen Methadonintoxikationen erhobenen Methadonkonzentrationen im Venenblut zeigten bei einer erheblichen Streubreite der Befunde deutliche Unterschiede bei Nichtsubstituierten (o,32 mg/L) und Substituierten (1,02 mg/L). Die Untersuchungen zum Zuckernachweis sind derzeit noch nicht abgeschlossen, werden jedoch zur Tagung präsentiert.

Schlussfolgerungen. Die deutlich niedrigeren Methadonmittelwerte in der Gruppe der in der Vorgeschichte Nichtsubstituierten unterstreichen die Wichtigkeit des Faktors "Opiattoleranz" bei der Bewertung von Drogentodesfällen. Der hohe Anteil der methadonbedingten Todesfälle macht deutlich, dass der Sensibilisierung der substituierenden Ärzte und auch der Substituierten für die Gefahren des missbräuchlichen Methadonkonsums erhebliche Relevanz zukommt.

\section{V62}

\section{Eine neue Methodik zur Einstufung von neuen „Research Chemicals" als CB1-affine Substanz}

\section{A. Paulke', C. Wunder', S.W. Toennes', K. Sommer', J. Achenbach ${ }^{2}$ E. Proschak ${ }^{2}$}

'Institut für Rechtsmedizin, Forensische Toxikologie, Frankfurt, Deutschland, ${ }^{2}$ Institut für Pharm. Chemie, AK Proschak, Frankfurt, Deutschland

Einleitung. Die große Vielfalt und hohe Variabilität neuer synthetischer Rauschmittel, die gerne unter dem Begriff „Legal Highs“ subsumiert werden, gestaltet eine zuverlässige Einschätzung von Wirkungsweise und Toxizität extrem schwierig. Um die Potenz dieser Substanzen dennoch abschätzen zu können, dienen ihre Rezeptoraffinitäten, ausgedrückt in Form von pKi-Werten, als Anhaltspunkte. Um diese zu erhalten, sind normalerweise aufwändige In-vitro-Assays notwendig, mit deren Hilfe jede Substanz für jeden Rezeptor getestet werden muss. Methode. Für den Fall neuer synthetischer Cannabinoide („Spice“), deren pKi noch nicht ermittelt wurden, wurden nun mit Hilfe eines computergestützten Verfahrens (QSAR, „quantitative structure activity relationship") deren Rezeptoraffinitäten für den CB1-Rezeptor vorhergesagt. Hierzu wurden 1771 bekannte Cannabinoide virtuell in einen EDV-kompatiblen Zahlencode, den sog. Deskriptor, transformiert. Mit einem aus der frei zugänglichen Datenbank ChEMBL erhaltenen Datensatz wurde nun durch mathematische Verfahren (IDW, „inverse distance weighting") die Rezeptoraffinität für die einzelnen Cannabinoide durch Interpolation vorhergesagt. Die Güte der Vorhersagen wurde durch Kreuzvalidierung bestimmt.

Ergebnisse. Die Grenzen des Verfahrens spiegeln sich in den Validierungsergebnissen wieder: Für einige Cannabinoide wurden pKi-Werte, die sehr nah an den Literaturdaten liegen, erhalten (Beispiel: AM-729: pKi 7,6 vs. 7,5), für andere zeigten sich teilweise große Abweichungen (Beispiel: JWH-o15: pKi 6,8 vs. 6,0). Die Ursache hierfür liegt zum Großteil in der Qualität der dem Verfahren zugrunden liegenden Daten der ChEMBL-Datenbank, die durch unterschiedliche experimentelle Verfahren mit hohen Streubreiten erhalten wurden. Durch Verwendung eines homogenen Datenpools ließ sich dieser Fehler jedoch sehr wahrscheinlich minimieren.

Diskussion. Die Vorteile des In-silico-Verfahrens zur Affinitätsabschätzung für neue Substanzen liegen in der Kostengünstigkeit, Schnelligkeit und Flexibilität, es ist auf nahezu beliebige Molekülvariationen anwendbar. Der Nachteil liegt in der Nichtunterscheidung zwischen Stereoisomeren und der prinzipiell eingeschränkten Aussagekraft der 
Rezeptoraffinitäten, die keine Aussage über die intrinsische Aktivität erlauben.

\section{V63}

Identifizierung von Amisulprid, Diazepam, Temazepam, Oxazepam und Dosulepin in Urin mittels LC-MS/MS „neutral loss scan“ und „enhanced product ion scan“

\section{Montenarh', M. Hopf', P. Schmidt', A. Ewald' \\ 'Institut für Rechtsmedizin, Toxikologie, Homburg, Deutschland}

Fragestellung. In früheren Arbeiten wurde eine LC-MS/MS-Methode für die Identifikation von 150 Substanzen in Serum, Plasma, Vollblut, Leichenblut, Lebergewebe, Mageninhalt, Haaren und Urin entwickelt. In Urinproben zeigten die zu untersuchenden Substanzen eine geringe Wiederfindung auf Grund hoher Extraktionsverluste. Daher sollte in dieser Arbeit zur Weiterentwicklung auf die Extraktion sowie die vorhergehende Glucuronid- bzw. Sulfatabspaltung verzichtet werden und die Glucuronide sowie Sulfate der Substanzen mit Hilfe eines „neutral loss scan“ mit anschließendem „enhanced product ion scan“(EPI scan) zur eigentlichen Substanz führen.

Methode. Die Urinproben wurden 1:4 mit HPLC-Wasser verdünnt. Die Trennung sowie die Identifikation wurde mit einem Shimadzu prominence LC 20 System (Waters SunFire C18 Säule, 2,1×150 mm, 3,5 $\mu \mathrm{m}$ ) gekoppelt mit einem ABSCIEX 3200 Q-TRAP Massenspektrometer im positiven ESI-Modus (ESI+) durchgeführt. Für die Identifikation der Substanzen wurde ein "neutral loss scan" mit anschließendem "enhanced product ion scan" (EPI scan; Kollisionsenergie, $35 \mathrm{eV}$, Kollisionsenergiespanne, $15 \mathrm{eV}$ ) durchgeführt. Zum Abgleich der erhaltenen Spektren wurde die hauseigene Spektrendatenbank für Serumproben herangezogen.

Ergebnisse und Diskussion. Amisulprid, Diazepam und Temazepam werden als Glucuronide im Urin ausgeschieden und konnten mit Hilfe des „neutral loss scans“ für Glucuronide und anschließendem Abgleich mit den durch den „enhanced product ion scan" erhaltenen Spektren identifiziert werden. Dosulepin und Oxazepam ließen sich mit dem „neutral loss scan“ für Sulfate und dem Abgleich der erhaltenen Spektren identifizieren. Diese Ergebnisse stimmen mit den in der Literatur bekannten Metaboliten für diese Substanzen überein.

Schlussfolgerung. Nicht alle der 150 Substanzen, die sich in unserer hauseigenen Spektrendatenbank befinden, werden zu Glucuroniden bzw. Sulfaten metabolisiert und als solche im Urin ausgeschieden. Für Amisulprid, Diazepam, Temazepam, Oxazepam und Dosulepin war die hier beschriebene Methode erfolgreich, für weitere Substanzen werden Studien folgen.

\section{V64}

Ein Todesfall im Zusammenhang mit synthetischen Cannabinoiden

\section{N. Schäfer', M. Kettner', B. Peters', D. Bregel', S. Kneisel', V. Auwärter', P. Schmidt', A. Ewald}

'Institut für Rechtsmedizin, Universität des Saarlandes, Homburg, Deutschland, ${ }^{2}$ Institut für Rechtsmedizin, Freiburg, Deutschland

Einleitung. Ein 36 Jahre alter Mann verstarb nach frustranen Reanimationsbemühungen, nachdem er zuvor in Gegenwart von Bekannten eine Kräutermischung namens „Mary Joy Annihilation“ geraucht hatte und hiernach kollabiert war und generalisierte Krampfanfälle gezeigt hatte. In der Wohnung des Verstorbenen wurden Reste eines Joints sichergestellt. Bei der gerichtlichen Leichenöffnung zeigten sich neben einer stenosierenden Koronarsklerose (Dreigefäßerkrankung) und einer myokardialen Muskelbrücke unspezifische Zeichen einer Intoxikation. Unter der Verdachtsdiagnose wurden die toxikologischen Untersuchungen beauftragt.
Methoden. Aliquote des Venenbluts, des Mageninhalts, der Gallenflüssigkeit, der homogenisierten Gewebe (Hirn, Lunge, Niere, Leber) und der pulverisierten Haare wurden flüssig-flüssig extrahiert. Fettgewebe wurde mit Acetonitril homogenisiert und extrahiert. Alle Extrakte wurden mittels LC-MS/MS gemessen. Die Reste des Joints wurden in Ethanol mazeriert und mittels GC-MS im Scanmodus gemessen. Aliquote des Venenblutes wurden zusätzlich mittels GC-MS im Scan- und SIM-Modus analysiert.

Ergebnisse. Die chemisch-toxikologische Untersuchung des Venenbluts erbrachte den Nachweis von o,1 ng/ml JWH-o18, o,3 ng/ml JWH-122, $1,4 \mathrm{ng} / \mathrm{ml}$ AM-2201, 1,5 ng/ml MAM-2201, ca. $6 \mathrm{ng} / \mathrm{ml}$ UR-144 und $250 \mathrm{ng} / \mathrm{ml}$ Amphetamin. Die Cannabinoide wurden auch in anderen Körperflüssigkeiten und Geweben gefunden. Zudem wurde JWH-210 in Haaren und Fettgewebe detektiert. Der Joint enthielt dieselben Cannabinoide, welche auch im Venenblut nachgewiesen wurden, mit Ausnahme von JWH-o18.

Schlussfolgerungen. Eine akute Beeinflussung durch synthetische Cannabinoide und Amphetamin kann angenommen werden. Aufgrund der teilweise viel höheren Potenz und Bindungsstärke der synthetischen Cannabinoide an CB1-Rezeptoren im Vergleich zu THC und des zeitlichen Zusammenhangs zwischen Konsum und Todeseintritt können sie zumindest als zum Todesgeschehen beitragender Faktor betrachtet werden, insbesondere in Kombination mit dem in relativ hoher Konzentration bestimmten Amphetamin. Der Nachweis von JWH-210 in Fettgewebe und Haaren und die Abwesenheit in Blut und Joint belegen eine länger zurückliegende Aufnahme dieser Substanz.

\section{V65}

\section{Pragmatischer Ansatz zur Auffindung von SPICE- und weiteren} Legal-high-Metaboliten mittels LC-MS/MS

\section{V.Spencer', L. Kröner ${ }^{2}$}

${ }^{1}$ Institut für Rechtsmedizin, Toxikologie, Gießen, Deutschland, ${ }^{2}$ Laboratoriumsmedizin, Köln, Deutschland

Einleitung. Die Verbreitung der synthetischen Cannabinoide und Amphetamine stellt nach wie vor ein Problem in der Drogenanalytik dar. In bestimmten Kreisen, wie Justizvollzugsanstalten, ist die Konsumentendichte relativ hoch. Eine Abstinenzkontrolle soll praktischerweise aus dem Urin erfolgen. Gerade für die oben genannten Substanzen bilden sich aus dieser Anforderung folgende Probleme:

- Urinanalytik erfordert Metabolite der Wirksubstanzen, diese sind zunächst weder bekannt noch als Standard käuflich.

- Wegen der rasant wachsenden Zahl identifizierter Wirkstoffe läuft das Nachweislabor der Entwicklung hinterher.

- Die hohen Beschaffungskosten der Reinsubstanzen führen zwangsläufig in die Unwirtschaftlichkeit.

Material und Methoden. Im Urin sind hauptsächlich/ausschließlich die Metabolite der Wirksubstanzen zu finden. Da viele Gruppen der Legal-high-Substanzen sich strukturell sehr ähnlich sind, ist davon auszugehen, dass ihre monohydroxylierten Phase-1-Metabolite sich ebenfalls ähneln und somit gleiche Fragmente im MS-Spektrum liefern. Darauf basierend wurde ein Methodenansatz entwickelt, der unabhängig von der Muttersubstanz die Fragmente der Phase-1-Metabolite in der LCMS/MS detektiert. Das Prinzip beruht darauf, in der Theorie vorherzusagen, wie die Phase-1-Metabolite fragmentieren und das Masse/ Ladungsverhältnis dieser Fragmente in der Ionenfalle zu detektieren. Weist man nun die typischen Fragmente eines möglichen monohydroxylierten Metaboliten nach, kann man dies als hinweisgebend auf den Konsum einer Legal-high-Substanz werten.

Ergebnis. mit diesem pragmatischen Ansatz zur Auffindung von SPICE- und weiteren Legal-high-Metaboliten lassen sich die oben angesprochenen Probleme lösen:

- Die Metabolite werden theoretisch erdacht und vom positiv getesteten Konsumenten in seiner Urinprobe bereitgestellt. 
- Sobald eine neue Droge auf den Markt gelangt, kann man analytisch sofort darauf reagieren.

- Es entfällt die Notwendigkeit zum Kauf von Reinsubstanzen.

Diskussion. Da man unabhängig von schwer zugänglichen Reinsubstanzen ist, lassen sich zeitnah zum Erscheinen neuer Substanzen die Methoden anpassen. Die Ergebnisse müssen allerdings zurückhaltend interpretiert werden, da strukturelle Ähnlichkeiten eine sichere Zuordnung erschweren.

\section{V66}

Charakterisierung der Designer-Benzodiazepine Pyrazolam und Flubromazepam: Analytik, Metabolismus und Pharmakokinetik

\section{B. Moosmann', M. Hutter', L.M. Huppertz', V. Auwärter}

'Institut für Rechtsmedizin, Forensische Toxikologie, Freiburg, Deutschland

Einleitung. Bis zum Jahr 2012 waren die über das Internet angebotenen „legalen“ Alternativen zu verschreibungspflichtigen Benzodiazepinen auf die in verschiedenen Ländern zugelassenen und von Pharmaunternehmen vermarkteten Arzneimittel Phenazepam und Etizolam beschränkt. Nachdem diese Substanzen allerdings in immer mehr Ländern dem Betäubungsmittelgesetz unterstellt wurden, wurden nun die ersten Designer-Benzodiazepine, Pyrazolam und Flubromazepam, im Internet angeboten. Im Gegensatz zu den anderen Benzodiazepinen liegen bei diesen Substanzen jedoch keine Informationen über ihre pharmakologischen Eigenschaften, ihren Metabolismus und das analytische Nachweisfenster in biologischen Matrices vor. Infolgedessen wurden zwei Experimente durchgeführt um erste Daten für beide Substanzen zu erhalten.

Material und Methoden. Für die Charakterisierung der Substanzen wurden methodisch NMR, LC-MS/MS, Q-ToF-MS und GC-MS angewendet. Zur Erlangung erster pharmakokinetischer Daten nahm ein Freiwilliger 1 mg Pyrazolam bzw. 4 mg Flubromazepam ein. Im Anschluss wurden Serum- und Urinproben erhoben und mittels LC-MS/ MS und Q-ToF-MS auf die jeweilige Substanz und etwaige Metaboliten hin untersucht.

Ergebnisse und Diskussion. Pyrazolam war in allen entnommenen Serumproben (1-50 h, LOD: $1 \mathrm{ng} / \mathrm{ml})$ und in den bis zu 6 Tagen nach der Einnahme gewonnenen Urinproben nachweisbar. Die ungefähre Eliminationshalbwertszeit im Serum betrug 17 h. Die höchste Konzentration im Serum von $51 \mathrm{ng} / \mathrm{ml}$ wurde $3 \mathrm{~h}$ nach der Einnahme gemessen. Des Weiteren zeigte Pyrazolam keinen nachweisbaren Metabolismus. Flubromazepam war für 19 Tage im Serum (LOD: $1 \mathrm{ng} / \mathrm{ml}$ ) mit einer ungefähren Eliminationshalbwertszeit von $106 \mathrm{~h}$ und einer maximalen Konzentration von $78 \mathrm{ng} / \mathrm{ml}(\mathrm{tmax}=6 \mathrm{~h})$ nachweisbar. Nur geringe Mengen an Flubromazepam wurden unverstoffwechselt renal ausgeschieden und die monohydroxylierte Substanz konnte als Hauptmetabolit identifiziert werden.

Schlussfolgerung. Aufgrund der Unterstellung von Phenazepam und Etizolam unter das Betäubungsmittelgesetz, stellt das Auftreten von Designer-Benzodiazepinen den nächsten logischen Schritt auf dem Markt für „Legal highs“ dar. Durch die breite Verfügbarkeit über das Internet sollten diese Drogen insbesondere bei Verdacht einer KOMittel-Beibringung und in Fällen, in denen ein positiver immunchemischer Test nicht mit den üblichen MRM-Methoden bestätigt werden kann, in Betracht gezogen werden.

\section{V67}

Drei Fälle ungewöhnlicher letaler CO-Intoxikationen mit jeweils zwei Opfern

\section{H. Wollersen', V. Spencer', F. Erdmann', R. Dettmeyer ${ }^{2}$}

'Institut für Rechtsmedizin, Toxikologie und Blutalkohol, Giessen, Deutschland, ${ }^{2}$ Institut für Rechtsmedizin, Giessen, Deutschland

Einleitung. Akzidentelle CO-Intoxikationen werden z. B. bei Bränden, bei defekten Öfen oder bei dem Indoor-Gebrauch von Grillöfen beschrieben. Darüber hinaus erfolgt die Aufnahme von CO auch in suizidaler Absicht z. B. durch Inhalation von Autoabgasen. Im Folgenden werden 3 Fälle mit außergewöhnlichen CO-Quellen und jeweils 2 Opfern vorgestellt. Die Aufnahme erfolgte in einem Fall akzidentell in zwei Fällen in suizidaler Absicht.

Kasuistiken. Im ersten Fall wurden zwei Brüder tot in einem Zelt gefunden, welches in einem Wohnraum aufgebaut war, dessen Fenster geöffnet gewesen sei. Im Zelt fanden sich 11 „gelbe Säcke“, deren Öffnungen mit einem Plastikschlauch versehen waren, welche mit Tesafilm verklebt gewesen seien. Im zweiten Fall wurde in einem Wohnhaus nach einem Brand eine Art Scheiterhaufen gefunden, welcher aus mehreren Schichten Kohlebrikett sowie etwa zehn 5-kg-Säcken Thermit errichtet worden war. Darauf hätten sich die Leichen eines Ehepaares befunden. Im dritten Fall wurden zwei Männer tot in einem Transporter zusammen mit einem Gaskühlschrank gefunden.

Diskussion. In allen drei Fällen wurden im Femoralvenenblut CO-HbKonzentrationen von mehr als 80\% detektiert. Darüber hinaus fanden sich keine toxikologisch relevanten Substanzen. Im ersten Fall ist bisher ungeklärt, wie das Kohlenmonoxid vom älteren Bruder in die gelben Säcke verbracht wurde. Der jüngere Bruder betrat das Zimmer, öffnete vermutlich das Fenster, und verstarb ebenfalls an einer CO-Intoxikation. Im zweiten Fall verstarb das Ehepaar in suizidaler Absicht, nachdem sie im Haus eine Art Scheiterhaufen aus Kohlebriketts und Thermit errichtet hatten. Im dritten Fall führte der unsachgemäße Gebrauch eines Gaskühlschranks in einem Transporter zu akzidentellen, tödlichen CO-Intoxikationen.

Schlussfolgerung. Die dargestellten Fälle zeigen, dass es neben den bekannten CO-Quellen bei Unfällen auch weniger geläufige und speziell in suizidaler Absicht arrangierte CO-Quellen gibt.

\section{V68}

Problemstellungen bei der Analytik von Antiepileptika aus biologischen Matrices

\section{J. Schürenkamp', S. Schmüser', A. Gasse', H. Pfeiffer', H. Köhler'}

'Institut für Rechtsmedizin Münster, Toxikologie, Münster, Deutschland

Einleitung. Die Bestimmung von Antiepileptika stellt aufgrund der Heterogenität der Arzneistoffklasse insbesondere hinsichtlich unterschiedlicher Säure-Base-Eigenschaften, Polaritäten und Stabilitäten eine Herausforderung dar. In der Literatur werden zumeist unspezifische Proteinfällungen, Flüssig-Flüssig-Extraktionen oder Festphasenextraktionen mit apolaren Wechselwirkungen bzw. spezifische Extraktionen für einzelne Antiepileptika-Untergruppen beschrieben.

Methoden. Die entwickelte Extraktionsmethode nutzt zur Isolierung von Antiepileptika erstmalig einen polymerbasierten Anionenaustauscher. Die Kapazität der Extraktionssäule wurde hinsichtlich Probenvolumen, Matrices und Analytmenge überprüft. In Abhängigkeit vom Probenvolumen und Kalibrationsbereich der jeweiligen Analyten wurde ein optimales Bettvolumen ausgewählt. Nach dem Waschen werden die Säulen aufgrund der Instabilität einiger Analyten nicht mit Luft sondern mit Stickstoff getrocknet. Zudem wird zur Stabilisierung vor dem Einengen des Eluats Ethylenglykol zugesetzt. Die Messung des Extraktes mittels LC-MS/MS erfolgt je nach Analyt im ESI-positiv- bzw. ESI-negativ-Modus. Eine Kombination aus optimierter flüssigchroma- 
tographischer Trennung und Setzen von MRM-Zeitfenstern ermöglicht das Messen mit beiden Ionisationsmodi bei einer Injektion.

Ergebnisse. Mit der entwickelten Methodik können Antiepileptika mit stark unterschiedlich physikalisch-chemischen Eigenschaften mit nur einer Extraktions- bzw. Detektionsmethode identifiziert und quantifiziert werden. Die empfindliche Messmethodik der LC-ESI-MS/MS ermöglicht den Einsatz von nur $100 \mu$ l Probenmaterial. Die Methode wurde vollständig nach den Kriterien der GTFCh validiert und erfolgreich auf authentisches Probenmaterial angewendet.

Schlussfolgerung. Es wurde eine empfindliche, schnelle Methode zur Bestimmung der heterogenen Arzneistoffklasse der Antiepileptika aus biologischen Matrices entwickelt.

\section{V69}

\section{Missbrauch von Pregabalin - Ergebnisse der toxikologischen Analyse von Post-mortem-Proben im Zeitraum Quartal 4/2011 bis Quartal 1/2013}

\section{S. Lottner-Nau', B. Övgüer', L.D. Paul', M. Graw', H. Sachs', G. Roider' \\ ${ }^{1}$ Institut für Rechtsmedizin, München, Deutschland, ${ }^{2}$ Forensisch Toxikologi- sches Centrum München, München, Deutschland}

Einleitung. Pregabalin (Lyrica ${ }^{\circledR}$ ), ein Analogon der Gamma-Aminobuttersäure (GABA), ist zur Behandlung von neuropathischen Schmerzen, generalisierten Angststörungen sowie als Zusatztherapie bei Epilepsie zugelassen. Im Jahr 2009 gehörte Pregabalin zu den 12 umsatzstärksten patentgeschützten Arzneimitteln in Deutschland. In den letzten Jahren wurde in Deutschland vermehrt über Missbrauch von Pregabalin berichtet. In den USA ist Pregabalin sogar als Substanz mit Abhängigkeitspotenzial aufgeführt. Um einen möglichen Missbrauch zu überprüfen, wurde Pregabalin in die routinemäßige toxikologische Analyse von Post-mortem-Fällen aufgenommen.

Material und Methode. Im Rahmen der toxikologischen Analyse wurde Oberschenkelvenenblut untersucht. Konnte kein peripheres Blut asserviert werden, wurde die toxikologische Untersuchung in alternativen Asservaten (z. B. Herzblut) durchgeführt. Mittels LC-MS/MS wurden die Proben im FTC nach Proteinfällung und weiterer Aufarbeitung analysiert.

Ergebnisse und Diskussion. Pregabalin wurde im Zeitraum Quartal 4/2011 bis $1 / 2013$ in insgesamt 5,9\% $(n=75)$ der untersuchten Fälle $(n=1271)$ nachgewiesen. In lediglich 2 Fällen wurde ausschließlich Pregabalin gefunden. In 97,3\% der Fälle mit einem Nachweis von Pregabalin wurden weitere Substanzen wie beispielsweise Opiate/Opioide, Benzodiazepine sowie Antidepressiva detektiert. In der Gruppe der Drogen-/Betäubungsmittelkonsumenten $(n=257)$ wurde in $20,6 \%(n=53)$ der Fälle Pregabalin gefunden. Ein Nachweis von Pregabalin in der Gruppe der Opiat/Opioid-Abhängigen $(n=230)$ erfolgte in $23,0 \%(n=53)$ der Fälle. Listet man die Pregabalin-Fälle in dieser Gruppe quartalsmäßig auf, ist ein Anstieg von 4,5\% im Quartal 4/2011 auf etwa 30\% in den letztuntersuchten Quartalen erkennbar.

Schlussfolgerung. Pregabalin wird hauptsächlich bei der toxikologischen Analyse von Opiat/Opioid-Abhängigen nachgewiesen, wobei sich eine deutliche Steigerung des Missbrauchs erkennen lässt.

\section{V70}

\section{Der fehlplatzierte Beatmungstubus im postmortalen CT}

\section{S. Ross ${ }^{1,2}$, A. Persson ${ }^{3}$, M. Thali', S. Franckenberg', P. Flach ${ }^{1}$}

${ }^{1}$ Institut für Rechtsmedizin, Forensische Bildgebung, Zürich, Schweiz, ${ }^{2}$ Institut für Rechtsmedizin, Forensische Bildgebung, Bern, Schweiz, ${ }^{3}$ Universität Linköping, CMIV, Linköping, Schweden

Fragestellung. Eine Fehlintubation kann zu ernsthaften Komplikationen führen, speziell wenn es sich um Notfallintubationen bei bereits instabilen Patienten handelt. Das Ziel unserer Studie war die Evalua- tion der Tubus-Fehlplatzierungen in den Fällen, bei denen die Patienten kurz nach der medizinischen Intervention verstorben waren.

Methoden. In allen Fällen wurden die Post-mortem-CT (pmCT) Untersuchungen mit einem Multislice-CT (Somatom 6, Somatom 16 und Somatom Definition Flash, Siemens medical) in Schichtdicken zwischen 1 und $3 \mathrm{~mm}$ durchgeführt. Die Analyse der Tubuspositionen erfolgte an einer CT-Workstation (Multi Modality Workplace VE23A, Siemens medical).

Ergebnisse. Insgesamt wurden 2000 pmCT-Untersuchungen aus drei rechtsmedizinischen Instituten durchgesehen. In 163 Fällen wurde ein Trachealtubus identifiziert. In $28 \%$ dieser Fälle wurde eine Fehlintubation (oesophageal) oder Fehllage (glottisch/intraglottisch/supracarinal/ bronchial) im pmCT festgestellt. In 67 Fällen war der Trachealtubus bereits durch die Notfallmediziner nach Abbruch der Reanimationsmaßnahmen entfernt worden.

Schlussfolgerungen. Unsere Studie zeigt die Möglichkeit, mittels pmCT nichtinvasiv die Lage von Trachealtuben zu dokumentieren. Die Fehlintubationsrate lag mit $28 \%$ der Fälle gering über den Zahlen von vergleichbaren klinischen Studien. Eine mögliche Erklärung ist in einigen Fällen der Abbruch der Reanimationsmaßnahmen ohne die Möglichkeit einer klinisch-radiologischen Überprüfung der Tubuslage vor Ort. Von einer frühzeitigen Entfernung des Beatmungstubus ist speziell in diesen Fällen abzusehen, um im Falle einer fraglichen medizinischen Fehlbehandlung relevante Befunde zu erhalten.

\section{V71}

\section{Komplikationen nach Tracheotomie im Post-mortem-CT (PMCT)}

\section{A. Tzikas', H. Vogel', P. Jahnke', A. Heinemann'}

'Institut für Rechtsmedizin, Hamburg, Deutschland

Hintergrund und Fragestellung. Die Tracheotomie soll die Atmung/Beatmung sichern. Misslingt sie, kann sie Ursache des Todes sein. Gezeigt werden soll, ob und wenn ja welche Komplikationen der Tracheotomie im PMCT aufgezeigt werden können und inwieweit ein Mehrwert gegenüber der konventionellen Obduktion zu erzielen ist.

Material und Methoden. Herausgesucht wurden die Beobachtungen seit 2008 (Beginn des Einsatzes der Computertomographie zur Unterstützung der Leichenschau und der Autopsie), bei denen angenommen wurde, dass die Tracheotomie mit Komplikationen verbunden war, die im PMCT sich fassen ließen.

Ergebnisse. Sieben Fälle wurden ausgewertet. Einmal war bei einem Kind die Notfalltracheotomie misslungen - die Luftröhre wurde nicht getroffen; das Kind hatte ein Haselnussstück aspiriert. Einmal war die Luftröhrenkanüle in die Speiseröhre eingeführt worden. In einem weiteren Fall war die Hinterwand der Luftröhre durch die eingeführte Luftröhrenkanüle aufgeschlitzt worden; als Ursache wurde ein großer Osteophyt an einem Halswirbel angenommen. Einmal lag ein Emphysem des Mediastinums vor, weshalb aufgrund des PMCT zunächst eine Perforation der Luftröhre bei Einführung der Luftröhrenkanüle vermutet wurde; die Autopsie bestätigte diese Vermutung nicht. Zweimal wurde ein ungünstiger Ort für den Luftröhrenschnitt angenommen. In einem weiteren Fall schließlich war eine seltene Variation der A. jugularis anterior in der multiphasischen PMCT-Angiographie hervorragend darstellbar; sie hatte eine unstillbare Blutung bei Kanülenwechsel begünstigt. Bildwiedergaben in $3 \mathrm{D}$ und Autopsie ergänzten einander. Die Dokumentations-, aber auch die Begutachtungsqualität konnte mittels PMCT in mehreren Fällen deutlich erhöht werden.

Schlussfolgerung. Die Tracheotomie hat Risiken, die todesursächlich sein können. Speziell Blutungskomplikationen und besondere anatomische Bedingungen können durch Bildgebung in der Begutachtung wesentlich erleichtert werden. 


\section{V72}

Bildgesteuerte Gasanalyse: Entwicklung eines Untersuchungsprotokolls zur Evaluation der Gaszusammensetzung

\author{
C. Egger', V. Varlet ${ }^{2}$, F. Smith ${ }^{2}$, A. Rinaldi ${ }^{2,3}$, A. Dominguez ${ }^{2,3}$, J. Grimm ${ }^{2,4}$, S. Grab- \\ herr ${ }^{2}$
}

'Institut für Rechtsmedizin Lausanne-Genf, Universität Genf, Genf, Schweiz, ${ }^{2}$ Institut für Rechtsmedizin Lausanne-Genf, Universität Lausanne, Lausanne, Schweiz, ${ }^{3}$ Fachhochschule für Gesundheit, Medizinisch Technische Radiologie, Lausanne, Schweiz, ${ }^{4}$ Department für Diagnostische und Interventionelle Radiologie, Universitätsklinik Lausanne, Lausanne, Schweiz

Ziel. Verschiedene Gase sind in der postmortalen Computertomographie (PMCT) gut zu detektieren, aber nicht ohne weiteres $\mathrm{zu}$ unterscheiden. Dennoch ist es wichtig solche radiologisch sichtbare Gasansammlungen interpretieren zu können, zum Beispiel zur Unterscheidung einer vitalen Gasembolie von Fäulnisgas. Ziel des Projektes ist es, zunächst eine praktisch anwendbare und sinnvolle Methode zur Entnahme und Analyse von Gas im Leichnam zu definieren. Diese soll anschließend dazu verwendet werden, einen Schlüssel zur radiologischen Gasunterscheidung zu entwickeln.

Methoden. Bisher wurden insgesamt 11, davon 9 Fäulnisleichen und zwei Leichen mit einem postmortalen Intervall von weniger als 24 Stunden und Verdacht auf Gasembolie untersucht. Die Punktionsstellen für die Probenentnahmen wurden mittels PMCT gewählt. Ein spezielles System zum Punktieren von Gas wurde entwickelt. Dies gelang mittels Nadeln, Spritzen und wassergefüllten, hermetisch verschlossenen $\mathrm{He}$ adspace-Röhrchen unter CT-Kontrolle. Die Gasanalysen wurden mittels Gas-Chromatography-Mass Spectrometry/Thermal Conductivity Detection (HS-GC-MS/TCD) durchgeführt.

Ergebnisse. Intrakardiales Gas in Fällen von vitaler Gasembolie bestand in den beiden untersuchten Fällen hauptsächlich aus Stickstoff (N2), kleineren Mengen von Sauerstoff $\left(\mathrm{O}_{2}\right)$ und Kohlendioxid $\left(\mathrm{CO}_{2}\right)$, korrespondierend zu Luft. Die Gasproben der verschiedenen Punktionsstellen der neun Fäulnisleichen setzten sich sowohl aus Kohlendioxid $\left(\mathrm{CO}_{2}\right)$, Sauerstoff $\left(\mathrm{O}_{2}\right)$, Stickstoff $\left(\mathrm{N}_{2}\right)$ und Wasserstoff $\left(\mathrm{H}_{2}\right)$ zusammen, als auch aus Spuren von Methan $\left(\mathrm{CH}_{4}\right)$, Ammoniak $\left(\mathrm{NH}_{3}\right)$, Schwefelwasserstoff $\left(\mathrm{H}_{2} \mathrm{~S}\right)$ und Kohlenmonoxid $(\mathrm{CO})$, was dem sog. „Fäulnisgas" entspricht.

Schlussfolgerung. Wir haben ein Protokoll zur bildgesteuerten Probenentnahme von Gas an menschlichen Leichen und dessen chemischanalytischer Untersuchung entwickelt. Die Analyse der Gase erlaubt eine Unterscheidung von Fäulnisgas und Luft. Dies ermöglicht uns, Hypothesen zur radiologischen Unterscheidung von vitaler Gasembolie und Fäulnisgas zu überprüfen, was für die Interpretation der Daten von PMCT-Untersuchungen notwendig ist.

\section{V73}

\section{Rechtsmedizinische Bildgebung: virtuelle Projektion subkutaner} Gasakkumulationen auf die Haut

\section{W. Schweitzer', T. Ruder', M. Thali', L. Ebert ${ }^{1}$ \\ 'Institut für Rechtsmedizin der Universität Zürich, Zürich, Schweiz}

Hintergrund. Während eingeblutete Gewebequetschungen durch die Haut als Verfärbungen im Sinne von Unterblutungen erkennbar werden können, könnte der Darstellung von Gas auf der Haut eine wenigstens ergänzende Bedeutung zukommen, indem das Weichteilemphysem den Stellenwert einer relativ umfangreichen Weichteilschädigung hat. Während durchsichtige Darstellungsmodelle für Luft oder Gas eindrucksvoll aussehen, trägt diese Art der Darstellung aus rechtsmedizinischer Sicht der Relevanz einer konkreten Konturabgrenzung weniger gut Rechnung.

Material und Methode. Wir berechnen Farbkarten für aus postmortalen CT-Daten gewonnene hautentsprechende Oberflächendarstellungen, welche Ausdehnung und Form von subkutanem Weichteilemphysem visualisieren, indem diese auf die darüberliegende Hautfläche projiziert werden. Zur ersten Prüfung der Tauglichkeit solcher Darstellungen werden Verletzungen als Folge stumpfer Gewalt bei 10 Verstorbenen dokumentiert.

Ergebnisse und Diskussion. Die Farbdarstellung von auf die Haut projizierten Emphysemverteilungsmustern ist durch klare Abgrenzbarkeit gekennzeichnet. Im Vortrag werden Fallbeispiele gezeigt und die Bedeutung für rekonstruktive Aspekte im Fall diskutiert.

\section{V74}

Multiphase post-mortem computed tomography angiography in cases of damage of the heart and larger blood vessels of the thorax due to diseases and blunt trauma

K. Wozniak', A. Moskala', E. Rzepecka-Wozniak', M. Strona', P. Kluza', K. Latacz ${ }^{2}$ 'Jagiellonian University Medical College, Chair and Department of Forensic

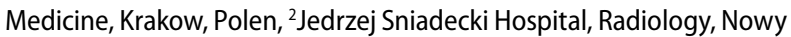
Sacz, Polen

Objectives. To present the objectified images of vascular lesions in cases with the possibility of damage due to diseases or as result of blunt chest trauma.

Material. Post-mortem CT (PMCT) as routine introduction to conventional forensic autopsy is performed at the Department of Forensic Medicine of Jagiellonian University Medical College in Kraków. In cases when introductory information suggested the possibility of damage to the vessels or preliminary evaluation of the "native" PMCT acquisition indicated such condition the multiphase PMCTA was performed.

Methods. Multiphase PMCTA was carried out under the international scientific project TWGPAM (Technical Working Group Postmortem Angiography Methods), by providing a hydrophobic contrast agent in three phases: 1. arterial, 2. venous and 3. dynamic. CT acquisition with 16 layered Siemens Emotion. Reconstructions with slice thickness $1.5 \mathrm{~mm}$ and $0.75 \mathrm{~mm}$. Evaluation of the results conducted with a computer program OsiriX.

Results. Among the cases examined the authors selected 1. case of ruptured dissecting aortic aneurysm, and 2. rupture of the heart as a result of alleged "kick by a horse". Images from conventional autopsies are confronted with results of evaluation of the M-PMCTA.

Conclusions. Presented cases prove that PMCTA is an excellent tool for post-mortem diagnostic of the heart and blood vessels lesions with wide documentary possibilities. Both $2 \mathrm{D}$ and $3 \mathrm{D}$ CT reconstructions complement standard autopsy and improve the general quality of post-mortem examination.

\section{V75}

Transplantation des Herzens und Einsatz von unterstützenden Devices im PMCT und in der PMCT-Angiographie

\section{B. Vogel', A. Heinemann', H. Gulbins', H. Reichenspurner', H. Vogel' \\ 'Institut für Rechtsmedizin, Hamburg, Deutschland}

Hintergrund und Fragestellung. Der Ersatz der Pumpfunktionen des Herzens ist Gegenstand der Forschung in der Krankenversorgung. Die Indikation zur Herztransplantation wird ausgeweitet. Zur Überbrückung von Wartezeiten und mit eigenen Indikationen werden unterstützenden Pumpen („assisting devices“) eingesetzt. Beide Bereiche betreffen Risikopatienten. Ein unerwünschter Verlauf lässt sich nicht immer erreichen. Die Untersuchung eines Verstorbenen mit Sektion und/oder PMCT bietet andererseits die Möglichkeit zur Analyse; sie hat das Potenzial der Qualitätskontrolle. Gezeigt werden soll, welche Befunde im PMCT sich erheben lassen.

Material und Methoden. Analysiert wurden die PMCT von Verstorbenen nach Herztransplantation und nach Implantation eines LVAD und/oder eines RVAD. Erfasst wurde die eingebrachten Devices, deren 
Position, des Weiteren die Nähte am Herz und an den großen Gefäßen und Veränderungen, die auf die Eingriffe am Herzen zurückzuführen waren.

Ergebnisse. Ausgewertet wurden insgesamt 8 Patienten. Sie stammten von verschiedenen Zentren aus Norddeutschland. Unspezifische Zeichen waren die der Herzinsuffizienz und post- und perioperativer Infektionen, Maßnahmen zur Reanimation und von Eingriffen am Abdomen. Spezifisch waren die Position der Devices, die Nähte am Herzen, die Nähte der Abdichtung von großen Gefäßen nach Entfernung von Sonden und Material (Sonden und anderes), dass zur Rhythmuskorrektur eingebracht worden war. Es ließen sich Veränderungen fassen, die für ein Gelingen des Eingriffs sprachen und solche, die mit dem unglücklichen Ausgang zu verbinden waren. Die Aussagen mit der PMCTAngiographie waren weiterführend als die mit der einfachen PMCT. Schlussfolgerung. PMCT und PMCT-Angiographie erlauben eine detaillierte Analyse des chirurgischen Vorgehens bei Herztransplantation und Device-Platzierung. Dies gilt auch für Reanimationsmaßnahmen. Sie können zu einer Qualitätskontrolle verwandt werden.

\section{V76 \\ Einfluss eines hohen Radiological Alteration Index auf die Durch- führbarkeit und Interpretation der "multi-phase post-mortem CT angiography" \\ C. Chevallier, ${ }^{1,2}$, J. Grimm ${ }^{1,2}$, P. Vaucher ${ }^{1,3}$, P. Mangin ${ }^{1,3}$, S. Grabherr \\ 'Institut für Rechtsmedizin, Forensische Medizin/Bildgebung, Lausanne, Schweiz, ${ }^{2}$ Universität Klinik, Radiologie, Lausanne, Schweiz, ${ }^{3}$ Institut für Rechtsmedizin, Forensische Medizin/Bildgebung, Genf, Schweiz}

Fragestellung. Um den Zustand eines Leichnams genauer zu charakterisieren, wurde der Radiological Alteration Index (RAI) eingeführt. Dieser quantifiziert mittels postmortaler Computertomographie (PMCT) das Vorhandensein von Gas im Leichnam. Die MultiphasenPMCT-Angiographie (MPMCTA) erlaubt eine detaillierte Darstellung des Gefäßsystems zur Detektion von Gefäßverletzungen. Bislang ist nicht bekannt, ob die Durchführung der Technik auch bei einem hohen RAI möglich ist und ob in diesen Fällen spezielle Artefakte auftreten. Das Ziel dieser Studie war daher: a) herauszufinden, bis zu welchem RAI eine Leiche noch sinnvoll mittels der MPMCTA untersucht werden kann und b) die Artefakte zu beschreiben, die bei einem erhöhten RAI beobachtet werden können.

Methoden. Aus einer Datenbank mit 270 MPMCTA-Fällen wurden insgesamt 28 Fälle ausgewählt, davon 14, die einen RAI über 50 aufwiesen. Als Kontrollgruppe dienten 14 Fälle aus derselben Datenbank, bei denen Alter, Geschlecht und Todesursache identisch waren, der RAI aber unter 10 lag. In allen Fällen wurden auftretende Artefakte bezüglich Art und Lokalisation charakterisiert. Die Auswertung der Daten erfolgte durch einen Radiologen mit mehrjähriger Erfahrung in forensischer Radiologie.

Ergebnisse. Der Vergleich der beschriebenen Artefakte zeigte, dass mit Anstieg des RAI die Art der beschriebenen Artefakte variierte. Im Vergleich zur Kontrollgruppe konnten wir neue, bisher noch nicht beschriebene Artefakte feststellen, die nicht technikverbunden, sondern fäulnisbedingt oder verletzungsbedingt zu sein scheinen. In Fällen, in denen der RAI durch ein Trauma erhöht war, fand sich häufig eine unvollständige Perfusion des Gefäßsystems, bedingt durch den traumatischen Abriss großer Arterien oder Venen. Bei Fäulnisleichen fanden sich dagegen vermehrt kleine Kontrastmittelaustritte in spezifischen Regionen (Nierenrinde, Milz, Schilddrüse, Prostata und Nebennieren). Gleichzeitig nahmen Artefakte, welche durch im Gefäßsystem verbliebenes Blut und postmortale Blutgerinnsel entstehen, mit ansteigendem RAI ab.

Schlussfolgerungen. Die Durchführung einer MPMCTA ist auch be Leichen mit hohem RAI uneingeschränkt möglich. Allerdings verändert sich die Art der auftretenden Artefakte. Es ist wichtig, diese Artefakte und ihr Auftreten im Verhältnis zum Leichenzustand zu kennen.

\section{V77}

Koronararterien in der multiphasischen Postmortem-CT-Angiographie (MPMCTA) im Vergleich mit Koronarangiographien ante mortem

\section{A. Heinemann', P. Jahnke', S. Grabherr', H. Vogel' \\ 'Institut für Rechtsmedizin, Hamburg, Deutschland}

Hintergrund und Fragestellung. Die postmortale CT-Angiographie (PMCT-Angiographie) hat ein Potenzial bei dem Nachweis eines Herztodes. Ihre Befunde zeigen Veränderungen mit Krankheitswert, die auch bei der Sektion dargestellt werden können. Die PMCT-Angiographie und die Sektion zeigen die Morphologie der Herzkranzarterien post mortem. In der vorliegenden Studie soll untersucht werden, wieweit von der Morphologie post mortem auf die Funktion ante mortem geschlossen werden darf.

Material und Methoden. Die Darstellung der Herzkranzarterien bei der MPMCTA wurde in 10 Fällen verglichen mit Darstellungen der Koronararterien (CT-Koronarangiographie und Koronarangiograhie) beim gleichen Patienten, die jeweils in den letzten 4 Wochen vor dem Tode durchgeführt worden waren. Die MPMCTA-Angiographien wurde mit Serien nach i.a.-, i.v.-Injektion und Zirkulationsphase von Kontrastmittel auf Paraffinbasis mit einer Virtangio ${ }^{\circledR}$-Perfusionsmaschine ausgeführt, die Herzkranzarterien wurden auf Sequenzen mit o,8 bzw. $1 \mathrm{~mm}$ Schichtdicke dargestellt und analysiert. Die Ante-mortem-Koronarangiographien bei Lebenden wurden von den zuletzt behandelnden Kliniken zur Verfügung gestellt.

Ergebnisse. Der Vergleich zeigte, dass viele Veränderungen ante mortem deutlich waren. Regelmäßig war post mortem zunächst in der arteriellen Phase der LCA-Stamm nicht gefüllt. Dies könnte seine Ursache in einen unterschiedlichen Tonus des Herzmuskels und/oder einer veränderten Lage des Herzens post mortem haben. In Betracht kommt auch ein anderer Druckgradient; beachtlich sind hier und bei Perfusionshindernissen die physikalischen Eigenschaften des öligen Kontrastmittels. Einzelne Veränderungen, die ante mortem mit Krankheitswert beschrieben waren, konnten nicht oder erst bei einer zweiten Durchsicht erfasst werden. Vereinzelt fanden sich falsch-positive Stenosen in der MPMCTA, u. a. durch postmortale Gerinnung. Veränderungen durch Angioplastien und Stentplatzierungen sowie Bypass-Anlagen waren gesondert zu betrachten.

Schlussfolgerung. Die Kenntnis der Ergebnisse einer ante mortem erfolgten Koronardarstellung erhöht die Sensitivität und Spezifität der Post-mortem-Darstellung. Bei der Auswertung der MPMCTA ist das besondere Perfusionsverhalten des öligen Kontrastmittels unter den gegebenen Druckverhältnissen zu beachten.

\section{V78}

Kontrastmittelübertritt ins venöse System bei intraarterieller Injektion in der multiphasischen PMCT-Angiographie (MPMCTA)

\section{A. Heinemann', H. Vogel', M. Kammal', C. Birkenbach', K. Püschel' 'Institut für Rechtsmedizin, Hamburg, Deutschland}

Hintergrund und Fragestellung. Die MPMCTA ist eine der etablierten Methoden zur postmortalen Angiographie und wird derzeit im Rahmen einer Multizenterstudie evaluiert. Ihr phasengebundener, dynamischer Charakter erlaubt eine Analyse der Perfusionsverhältnisse insbesondere im Verhältnis zwischen arteriellem und venösem System. Bei eigenen Untersuchungen ließ sich bei intraarterieller Injektion die Darstellung von Gefäßen und Hohlräumen des venösen Systems beobachten, ohne dass hierfür eine Veränderung mit Krankheitswert als Ursache fassbar war. Beabsichtigt ist, dies an Beispielen zu demonstrieren und eine erste Deutung zu versuchen.

Material und Methoden. Bei der PMCT-Angiographie wird transfemoral oder transaxillär Kontrastmittel arteriell injiziert. Anschließend wird nach Füllung des venösen Systems mit Kontrastmittel erneut ein Ganz- 
körperscan ausgeführt. Danach erfolgt eine Zirkulation des Kontrastmittels im Körper mit einer adaptierten Perfusionsmaschine. erreicht wird, mit einem Ganzkörperscan die Untersuchung abgeschlossen. Zur Klärung, wo ein vorzeitiger KM-Übertritt ins venöse System stattfindet, wurden bei PMCT-Angiographien zusätzliche Serien von Herz und Oberbauch zwischen die angegebenen Ganzkörperscans platziert.

Ergebnisse. Ein KM-Übertritt ließ sich bislang 8-mal erkennen. Verschiedene Orte ließen sich bestimmen, in denen ein Übertritt des Kontrastmittels ins venöse System zu erkennen war. Dies waren in absteigender Häufigkeit die Leber, das Herz, und die Nieren. AV-Fehlbildungen waren dabei nicht konkret zu objektivieren, ein Übertritt über ein offenes Foramen ovale ließ sich ausschließen. Diese Vorkommnisse könnten u. a. für eine Durchlässigkeit der kapillären Barriere für das ölige Kontrastmittel sprechen. Sie scheint in der Leber am größten. Schlussfolgerung. Die PMCT-Angiographie unterscheidet sich in ihren Befunden von der klinischen Angiographie. Die Kenntnis der Unterschiede schützt vor Irrtümern.

V79

Integrierte computerunterstützte Analyse und visuelle Aufbereitung forensischer Fälle basierend auf multimodaler 3D-Bildgebung

\section{A. Bornik ${ }^{1,2}$, M. Urschler ${ }^{1,2}$, E. Scheurer ${ }^{1}$ \\ 'LBI klinisch-forensische Bildgebung, Graz, Österreich, Institut für maschi- nelles Sehen und Darstellen - TU Graz, Graz, Österreich}

Einleitung. Methoden der dreidimensionalen Bildgebung wie CT oder MR liefern im rechtsmedizinischen Kontext auf nichtinvasive Weise Informationen über innere Verletzungen. Insbesondere bei Lebenden stellen solche Daten eine wertvolle Ergänzung, z. B. zur äußerlichen Untersuchung dar. Bei der forensische Analyse der Daten hinsichtlich der Ursache von Verletzungen und des Tat- oder Unfallhergangs ist eine isolierte Analyse der einzelnen Informationsquellen suboptimal um komplexe Zusammenhänge zu erkennen und richtig zu interpretieren. Gegenwärtig werden CT- und MR-Daten zumeist mit Hilfe von Radiologie-Software bearbeitet und analysiert, welche forensische Fragestellungen nicht explizit unterstützt. Bilder und 3 D-Modelle, z. B. aus photogrammetrischer Rekonstruktion, werden mit Software aus dem Unterhaltungsbereich erstellt, welche einerseits keine Integration medizinischer 3D-Daten erlaubt und Bedienung durch Experten erfordert. Mangels Integration müssen forensische Fragestellungen rein mental bearbeitet bzw. verifiziert werden - eine anschauliche integrierte Präsentation aller Daten ist nicht möglich.

Methoden. Die von uns entwickelte Software versucht, genau diese Probleme zu lösen, indem sie auf Basis aktueller Algorithmen zur Analyse und gemeinsamen Visualisierung von $3 \mathrm{D}$-Oberflächenmodellen und volumetrischer Daten ein integriertes Werkzeug zur computerunterstützten Fallanalyse und zur anschaulichen Fallaufbereitung für das Verfahren vor Gericht realisiert. Alle notwendigen Arbeitsschritte wie Befunden aus rechtsmedizinischer Sicht, die Extraktion wichtiger Details und die folgende interaktive räumliche Fusion aller verfügbaren Daten werden unterstützt. Auf dieser Basis können fallrelevante, intermodale räumliche Zusammenhänge analysiert und Hypothesen hinsichtlich der Verletzungskausalität interaktiv erörtert werden. Abschließend können die Ergebnisse für Laien in Form von Grafiken oder Videos exportiert werden. Die Benutzerschnittstelle der Software ist dabei so gestaltet, dass eine Bedienung durch forensische Experten möglich ist.

Ergebnisse. Erste Testfälle haben gezeigt, dass durch die integrierte Verarbeitung Zusammenhänge in den verschiedenen Daten leichter erkannt und mit geringem zeitlichem Aufwand visuell aufbereitet werden können. Im Rahmen der Präsentation soll die Technologie der Software anhand von Fallbeispielen vorgestellt werden.

\section{V80}

\section{Case report: Hypothermia}

I. Hasegawa', H. Vogel', K. Püschel'

'Institut für Rechtsmedizin, Hamburg, Deutschland

Case report. In this case, a 70-year-old male was found in a rice field in winter. Before he left his house in the evening, he drank a large quantity of alcohol. The exact amount of alcohol consumed was unknown. An estimated 12 hours after death, a police inspection was performed, and 14 hours after death, a post-mortem CT scan was performed in the sforensic institute. Furthermore, an autopsy was performed 15 hours after death. In the thoracic CT, the pulmonary area was unusually clear for a cadaver 14 hours after death. The sedimentation from gravity was extraordinarily thin, and GGO (ground glass opacity) was not observed. Usually, in post-mortem CTs, thoracic CTs show variable images, but always have sedimentation from gravity.

Methods. After CT scanning, legal dissection was performed. The weights of the lungs were $349 \mathrm{~g}$ for the left and $342 \mathrm{~g}$ for the right. Pleural effusion in the pleural cavity was not observed. The blood-alcohol concentration was $1.96 \mathrm{mg} / \mathrm{mL}$, and the urine-alcohol concentration was $2.60 \mathrm{mg} / \mathrm{mL}$. Finally, the cause of death was determined to have resulted from hypothermia.

Conclusions. In previous studies, it has been said that the average total weight of the left and right lung is approximately $1 \mathrm{~kg}$. However, in our retrospective survey on lung weight in hypothermia cases, the average weight of the total lung is approximately $500-600 \mathrm{~g}$. At the moment, the post-mortem physiology of hypothermia is not well known. "Why are lungs from hypothermia cases light in weight?" The answer to this question is not known, but this is not contradictory to the post-mortem CT findings. Low Hounsfield units (CT values) in the pleural area are one of the remarkable features of hypothermia.

V81

Die virtuelle Tatortbegehung - der erste Schritt zum forensischen Holodeck

S. Ross', M. Thali', L. Ebert ${ }^{1}$

'Institut für Rechtsmedizin, Forensische Bildgebung, Zürich, Schweiz

Fragestellung. Die virtuelle Rekonstruktion von Tathergängen unter Verwendung verschiedenster bildgebender Verfahren spielt eine zunehmend größere Rolle in der Forensik. 3D-Rekonstruktionen aus CT-Bildern, Oberflächenscans von Verstorbenen sowie potenziellen Tatwerkzeugen sowie dreidimensionale Laserscans von Tatorten dienen dabei als Grundlage für digitale Visualisierungen von Tatorten und Tathergängen. Problematisch dabei ist, dass dreidimensionale Umgebungen zweidimensional dargestellt werden und zudem keine Möglichkeit bieten, sich frei in den erzeugten Szenarien bewegen zu können. Um diesen Problemen zu begegnen, haben wir einen ersten Schritt unternommen, unter Verwendung von Techniken aus der virtuellen Realität Szenen aus Daten von Oberflächenscans und 3 D-CT-Rekonstruktionen im Sinne des Wortes frei begehbar zu machen.

Methoden. Das von uns entwickelte System besteht aus handelsüblichen Bestandteilen (3D Brillendisplay Oculus Rift, Hydra Game Controller, Tracking Kamera, Windows PC). Es können Daten in gängigen 3 D-Formaten dargestellt werden. Das System erkennt sowohl Kopfbewegungen als auch Standortveränderungen des Nutzers im Raum und passt die Szenerie entsprechend an.

Ergebnisse. Erste Versuche mit unserem System zeigen eine erstaunlich gute Immersion des Benutzers in die virtuelle Szenerie/den digitalen Tatort. Limitationen des Systems sind die Kabelgebundenheit des Brillendisplays und die begrenzte Auflösung des Brillendisplays.

Schlussfolgerungen. Der entwickelte Prototyp zur virtuellen Tatortbegehung zeigt großes Potential für zukünftige Anwendungen in diesem Bereich. Wir demonstrieren in unserem Vortrag die technischen Prin- 
zipien unserer Entwicklung inklusive einem Ausblick auf zukünftige Möglichkeiten dieser Technik.

\section{V82}

Ersticken eines Kleinkindes im Rucksack: Morphologie, Befunde am Rucksack und Ergebnisse der weiterführenden Ermittlungen

\section{K. Jachau', R. Lessig', K. Brandstädter', A. Märtens ${ }^{2}$ \\ ${ }^{1}$ Institut für Rechtsmedizin, Magdeburg, Deutschland, ${ }^{2}$ Polizeidirektion Sachsen-Anhalt Nord, ZKB, ${ }^{2}$. FK, Magdeburg, Deutschland}

Fallbericht. Ein 1 Jahr und 6 Monate altes Kleinkind wurde durch den Notarzt in der Häuslichkeit wiederbelebt und in die Universitätsklinik verbracht. Hier wurde der Hirntod festgestellt. Die Kindsmutter gab beim Abschiednehmen vom Kind gegenüber dem Klinikpersonal an, diesem „etwas angetan zu haben“.

Ergebnisse. Die umgehende rechtsmedizinische Untersuchung erbrachte lediglich vereinzelte kleinfleckige Blutungen in der Gesichts- und Halshaut. Auf die Notwendigkeit einer umgehenden Sektion wurde hingewiesen und diese am selben Tag verfügt. Die vorab erfolgte Computertomographie erbrachte keine todesursächlich zu diskutierenden Befunde. Im Rahmen der Obduktion fanden sich zudem kleinfleckige Blutungen in den Überzügen der Organe und der Innenseite der Schädelschwarte. Feingeweblich waren Zeichen des Sauerstoffmangels nachweisbar. In der Beschuldigtenvernehmung gab die Mutter an, dass Kind 6o Minuten im verschlossenen Rucksack belassen zu haben. Nach der entsprechenden Spurenasservierung wurde der Rucksack hinsichtlich der Luftdurchlässigkeit untersucht.

Schlussfolgerung. In der Zusammenschau der makroskopischen und histologischen Befunde der Obduktion, den spurentechnischen und physikalischen Gegebenheiten am Rucksack und der Berücksichtigung der in der Beschuldigtenvernehmung getätigten Angaben der Kindsmutter wurde als Todesursache Ersticken benannt. Im Rahmen weiterer Ermittlungen stellte sich heraus, dass die Kindsmutter vor mehreren Jahren in einem anderen Bundesland ein weiteres Kind erstickt hatte. Diesbezüglich war zunächst im Rahmen der Sektion die Diagnose eines plötzlichen Säuglinstodes geäußert worden und erst nach dem Geständnis der Mutter revidiert worden.

\section{V83}

\section{Knoten im Herz - Hämangiom als Ursache des plötzlichen Todes} eines zwölfjährigen Kindes

\section{Stiller', H. Voß², H.- J. Holzhausen ${ }^{3}$, F. Lupatsch ${ }^{3}$}

'Martin-Luther-Universität Halle-Wittenberg, Institut für Rechtsmedizin, Halle/Saale, Deutschland, ${ }^{2}$ Brandenburgisches Landesinstitut für Rechtsmedizin, Frankfurt (Oder), Deutschland, ${ }^{3}$ Martin-Luther-Universität HalleWittenberg, Institut für Pathologie, Halle/Saale, Deutschland

Hintergrund. Bei Todesfällen von Kindern und Heranwachsenden, insbesondere wenn diese unbeobachtet und plötzlich eintreten, stellt sich bei aller Tragik immer die Frage eines Fremdverschuldens, möglicherweise auch die Frage nach einer Verletzung der Aufsichtspflicht. Nichtsdestotrotz müssen gerade im Kindesalter seltene Tumorentitäten und Fehlbildungen als Ursachen eines plötzlichen natürlichen Todes aus scheinbar völliger Gesundheit heraus einkalkuliert werden.

Fallbericht. Vorgestellt wird der Fall eines zwölfjährigen Jungen. Anamnestisch soll lediglich ein Autismus bestanden haben. Die Umstände des Todeseintritts waren unklar. Ermittelt wurde nur, dass das Kind am frühen Abend das elterliche Haus verlassen hatte, um eine Fahrradtour zu machen. Da es nach etwa einer Stunde nicht wieder daheim eingetroffen war, wurde vom besorgten Vater eine Suche gestartet, in deren Folge der Junge auf dem Fahrrad auf dem Gehweg liegend aufgefunden wurde. Laien- und anschließende notärztliche Reanimationsversuche blieben erfolglos. Die seitens der Staatsanwaltschaft angeord- nete Obduktion wurde zur Klärung der Todesursache und Ausschluss eines möglichen fremdverschuldeten (Verkehrs-)Unfallgeschehens vorgenommen. Zeichen einer stumpfen Gewalteinwirkung fanden sich nicht, das Kind zeigte einen weitestgehend altersentsprechenden Entwicklungszustand. Lediglich das Herz hatte mit $370 \mathrm{~g}$ ein deutlich $\mathrm{zu}$ hohes Gewicht. Zudem fiel im linksventrikulären Myokard eine relativ scharf begrenzte, derbe Herdbildung von ca. $8 \mathrm{~cm}$ im Durchmesser auf. Histologisch wiesen zahlreiche schmale, mäanderförmige Lumina auf das Muster eines Gefäßtumors hin. Der endotheliale Ursprung der auskleidenden Zellen wurde mittels $\mathrm{CD}_{31}$ bestätigt und die Diagnose eines intramuskulären Hämangioms gestellt. Auffällig war die massive Hypertrophie des umgebenden Myokards, die als unmittelbaren Todesmechanismus eine akute koronare Insuffizienz nahelegt.

\section{V84}

"Verschwinden" des Epiduralhämatoms - eine Kasuistik

\section{S. Miyaishi', M. Miura', K. Taniguchi', K. Püschel}

'Universität Okayama, Institut für Rechtsmedizin, Okayama, Japan, ${ }^{2}$ Universitätsklinikum Hamburg-Eppendorf, Institut für Rechtsmedizin, Hamburg, Deutschland

Falldarstellung. Ein 85-jähriger Mann wurde bewusstlos auf der Straße aufgefunden. Er war offensichtlich gestürzt. Ein Epiduralhämatom (EDH) wurde in der linken Temporookzipitalregion mittels CT festgestellt. Im Kontroll-CT 8 Stunden später war das Hämatom „verschwunden“. Nunmehr zeigten sich drei massive Hirnparenchymblutungen. Der Patient verstarb nach zwei Tagen.

Sektionsbefunde. $163 \mathrm{~cm}$ Körperlänge bei $47 \mathrm{~kg}$ Körpergewicht. Dickschichtige, $6,5 \times 9 \mathrm{~cm}$ Kopfhautblutung okzipital. Von hier ausgehende lineare Schädelfraktur bis hin zur linken Temporalregion. Kein (!) epidurales Hämatom sowie keine Verletzung der harten Hirnhaut; diese war allerdings entlang der Frakturlinie von der Tabula interna des Schädeldachs abgeschält. Leicht koagulierte dünnschichtige subdurale Blutungen über allen Hirnanteilen. Drei massive kontusionelle Blutungsareale im Hirnparenchym. - In der Leber Herde eines primären Leberzellkarzinoms (Histologie: Mittel- bis hochgradig differenziertes hepatozelluläres Karzinom) mit Metastasen in Lunge und Wirbelsäule. - Ansonsten keine Verletzung oder Krankheit der übrigen Organe. Als Todesursache wurden die massiven Hirnblutungen diagnostiziert.

Diskussion. Das „Verschwinden“ eines EDH ist als ein seltenes Phänomen bekannt. Als pathogenetischer Mechanismus wurde die Ein-/ Ausschwemmung des Hämatoms ins lockere subkutane Bindegewebe der Kopfhaut durch den Spalt der Fraktur bei Steigerung des intrakraniellen Drucks rekonstruiert. Im vorliegenden Fall kam es durch die Größenzunahme der Hirnblutungen zur massiven Hirnschwellung, wodurch wiederum das EDH sozusagen aus dem Schädelinneren herausgedrückt wurde.

Schlussfolgerung. Wenn ein zuvor festgestelltes EDH im CT als Befund „verschwindet“, kann seine Existenz nur durch die Abschälung der harten Hirnhaut von der Tabula interna des Schädels nachgewiesen werden. Auch wenn die postmortale Bildgebung gerade beim Schädelhirntrauma besonders sinnvoll ist, liefert die Obduktion wesentliche Zusatzergebnisse.

\section{V85}

\section{Ungewöhnliche Befunde bei einer Bahnleiche}

\section{Preuss', F.-W. Ast', M. Klintschar ${ }^{2}$, B. Vennemann'}

'Institut für Rechtsmedizin der MHH, Außenstelle Oldenburg, Oldenburg, Deutschland, ${ }^{2}$ Institut für Rechtsmedizin der MHH, Hannover, Deutschland

Hintergrund. Bahnleichen stellen einen nicht unerheblichen Anteil des rechtsmedizinischen Obduktionsguts dar, wobei in den meisten Fällen die Klärung der Identität sowie der Vitalität der erlittenen Verletzungen 
im Vordergrund steht. Zudem ist regelmäßig zu diskutieren, ob es sich um einen Unfall oder ein suizidales Geschehen handelt.

Fallbericht. Wir berichten über einen 56 Jahre alt gewordenen Mann, dessen Leiche auf einem Gleisbett liegend aufgefunden wurde und offensichtlich von einem Schienenfahrzeug in Bauchhöhe überfahren und vollständig durchteilt worden war. Sichere Vitalitätszeichen für diese Verletzungen lagen nicht vor. Während der Obduktion fanden sich Strommarken an den Extremitäten, die zunächst nicht ohne weiteres erklärbar waren.

Schlussfolgerung. Es wird anhand der Obduktionsbefunde und der polizeilichen Ermittlungen vor Ort über die rechtsmedizinische Rekonstruktion dieses ungewöhnlichen Stromtodesfalles berichtet.

\section{V86}

\section{Der Helikopterabsturz und das fragwürdige Kontraktionsband}

J. Tschui', C. Jackowski', C. Schyma'

'Institut für Rechtsmedizin der Universität Bern, Forensische Medizin, Bern, Schweiz

Einleitung. Üblicherweise wird der histologische Nachweis von Kontraktionsbändern im Herzmuskel auf einen vorhergehenden ischämischen Herzmuskelschaden zurückgeführt und je nach Fallkonstellation als todesursächlich relevanter Befund gewertet.

Fallbericht. Wir präsentieren den Fall eines tödlich verlaufenen Helikopterabsturzes, bei welchem alle drei vor Ort verstorbenen Insassen ausgedehnte Knochenbrüche und Verkohlungen durch die sofortige Brandentwicklung erlitten hatten. Die histologische Untersuchung des Herzmuskels aller Beteiligten ergab das Bild von unter anderen Umständen als ischämischen Schaden zu beurteilenden Befunden, insbesondere von zahlreichen Kontraktionsbändern.

Schlussfolgerung. Hätte es sich um den alleinigen Absturz des Piloten gehandelt, hätte ein kardiales Ereignis als Absturzursache diskutiert werden können. Die vorliegende Kasuistik lädt jedoch dazu ein, die histolopathologischen Herzmuskelbefunde nach schwerem Thoraxtrauma zu diskutieren.

V87

\section{Tödlicher Zahnarztbesuch}

V. Sterzik', T. Tatschner', N. Roewer' ${ }^{2}$ D. Barrera ${ }^{3}$, M. Bohnert ${ }^{7}$

${ }^{1}$ Institut für Rechtsmedizin, Würzburg, Deutschland, ${ }^{2}$ Universitätsklinikum Würzburg, Klinik und Poliklinik für Anästhesiologie, Würzburg, Deutschland, ${ }^{3}$ Kriminalpolizeiinspektion, Schweinfurt, Deutschland

Fallbericht. Aus „panischer“ Angst vor zahnärztlichen Eingriffen entschied sich eine 23-jährige Frau für die Extraktion ihrer Weisheitszähne unter Intubationsnarkose. Es habe sich laut Unterlagen um einen elektiven Routine-Eingriff bei der als ASA I und Mall II eingestuften Patientin gehandelt. Kurz nach Einleitung der Narkose sei es zu einem Abfall der $\mathrm{O}_{2}$-Sättigung und des Blutdrucks gekommen, kurze Zeit später verstarb die junge Frau trotz eingeleiteter Reanimationsmaßnahmen. Zunächst bestand der Verdacht auf eine allergische Reaktion auf das als Muskelrelaxans eingesetzte Succinylcholin. Bei der Obduktion und histologischen Begutachtung waren jedoch trotz regelrecht in der Trachea sitzendem Beatmungstubus ein blutiges Lungenödem sowie eine umschriebene Läsion der Ösophagusschleimhaut im mittleren Anteil auffällig. Als Ursache konnte letztlich eine zunächst unbemerkt gebliebene Fehlintubation in den Ösophagus ermittelt werden.

\section{V88}

\section{Ösophagusruptur durch extremen Sadomasochismus - eine Kasuistik}

S.C. Kölzer', C.G. Birngruber', R. Gliemann², R. Dettmeyer', M.A. Verhoff'

'Universität Gießen, Institut für Rechtsmedizin, Gießen, Deutschland, ${ }^{2}$ Niedergelassner Psychiater, Gießen, Deutschland

Fallbericht. Im vorliegenden Fall kam es bei einer 32-jährigen Frau zu einer Ösophagusruptur im Rahmen von außergewöhnlichen sadomasochistischen Praktiken. Die Frau stellte sich selbst im Krankenhaus vor, da sie seit drei Tagen unter Luftnot litt, nachdem sie laut eigenen Angaben in der Dusche ausgerutscht sei. Zunächst wurden ein Pneumothorax sowie mehrere Rippenfrakturen diagnostiziert. Im Verlauf der weiteren Diagnostik wurde schließlich eine Ösophagusruptur als Ursache des Pneumothorax festgestellt. Mit diesem Befund konfrontiert, gab die Patientin an, im Rahmen von sexuellen Praktiken einen etwa $10 \mathrm{~cm}$ langen Knebel verschluckt zu haben, der von ihrem Lebensgefährten nach dem Schlucken aufgepumpt worden sei. Neben der Ösophagusruptur wies die Patientin zahlreiche unterschiedlich alte äußerlich sichtbare Verletzungsspuren auf, die im Zusammenhang mit sadomasochistischen Praktiken entstanden waren. Das Einverständnis der Frau in diese extremen Sexualpraktiken blieb trotz eingehender Ermittlungen und einem aufgefundenen „Sklavenvertrag“ bis zuletzt nicht hinreichend erwiesen. Selbst bei einer Einwilligung dürfte allerdings die Körperverletzung als Verstoß gegen die guten Sitten eine rechtswidrige Handlung dargestellt haben ( $\$ 228$ StGB). Der Lebensgefährte wurde wegen schwerer Körperverletzung zu einer langjährigen Freiheitsstrafe verurteilt und suizidierte sich später in der Haft.

Schlussfolgerung. Neben einer Darstellung der Morphologie der Verletzungen sollen auf Grundlage einer Literaturrecherche das Vorkommen und die Entstehung derartiger Verletzungen sowie die Beziehung der beiden Sexualpartner im sadomasochistischen Kontext diskutiert werden.

\section{V89}

Fallstudie zu einer letalen Paracetamol-Intoxikation in Kombination mit Temazepam und Alkohol

\section{M.A. Neukamm', M. Hermanns-Clausen², V. Auwärter', S. Vogt', D. Geisenber-} ger $^{1}$

'Universitätsklinikum, Institut für Rechtsmedizin, Freiburg, Deutschland, ${ }^{2}$ Universitätsklinikum, Vergiftungsinformationszentrale, Freiburg, Deutschland

Fallbericht. Ein 50 Jahre alt gewordener Mann wurde in seiner Wohnung auf dem Boden liegend leblos aufgefunden. Die Obduktion ergab unspezifische Vergiftungsbefunde, eine Leberzellnekrose konnte nicht festgestellt werden. Chemisch-toxikologische Untersuchungen des Oberschenkelvenenserums ergaben eine Paracetamol-Konzentration von $300.000 \mathrm{ng} / \mathrm{ml}$, eine Temazepam-Konzentration von ca. $530 \mathrm{ng} /$ $\mathrm{ml}$ und 1,33 g-\%o Ethanol. Die Konzentrationen passen zu einer Einnahme einer hohen Dosis von Paracetamol wenige Stunden zuvor. Als todesursächlich kann ein Atemstillstand angenommen werden, welcher durch eine Überdosis von Paracetamol im Zusammenspiel mit der atemdepressiven Wirkung von Temazepam und Alkohol hervorgerufen wurde, ohne dass es zu den typischen Leberzellschädigungen durch die Paracetamol-Metabolite gekommen ist.

Schlussfolgerung. Der Verlauf der Paracetamol-Intoxikation wird im Zusammenhang mit Laborwerten sowie morphologischen und histologischen Befunden diskutiert. 
V90

\section{Der Fluch des Diplomaten - eine kunsthistorische Personenidenti- fizierung}

\section{R. Krischel', M. Rothschild ${ }^{2}$ \\ 'Wallraf-Richartz-Museum, Köln, Deutschland, ${ }^{2}$ Institut für Rechtsmedizin, Köln, Deutschland}

Einleitung. Im Jahr 2011 bekam das Wallraf-Richartz-Museum in Köln anlässlich seines 150-jährigen Bestehens von der Bundesrepublik Deutschland eine Dauerleihgabe zugesprochen: ein Gemälde der venezianischen Renaissance, ganz offensichtlich von Jacopo Tintoretto geschaffen und einen würdevollen Herrn in Dreiviertelansicht darstellend. Aber wer war der Abgebildete?

Methoden. Für die Identifizierung wurden neben Überlegungen zur dargestellten Kleidung, zum Hintergrund, zur Pose und Art des Portraits auch Überlegungen zur Bilddatierung herangezogen, die schließlich den Abgebildeten als Paolo Tiepolo identifizieren ließen. Tiepolo war einer der wichtigsten venezianischen Diplomaten und Staatsmänner der 2. Hälfte des 16. Jahrhunderts.

Ergebnisse. Aber das Portrait zeigte noch ein überraschendes Detail: Im linken oberen Stirnbereich fand sich eine flächige Rötung. In einem 2009 in Mailand erschienen Buch über die Familie Tiepolo wurde ein Attentat erwähnt, so dass möglich schien, dass Paolo Tiepolo sich seinen Widersachern stolz mit der erlittenen Verletzung dargestellt zeigen ließ. Allerdings stellte sich bei Nachforschungen heraus, dass diese Angabe im Buch auf einem Transkriptionsfehler beruhte. Die zweite mögliche Erklärung für eine Verletzung schien zunächst die Schlacht von Lepanto zu sein, die Tiepolo in einem eigenen Werk beschrieb, allerdings finden sich nirgends Hinweise darauf, dass er tatsächlich an der Schlacht teilgenommen hatte, geschweige denn hierbei verwundet worden war. So blieb die Frage nach einer anderen Natur der Rötung. Am ehesten entsprach der Fleck einem Naevus flammeus. Und tatsächlich gab es einen vom Volksmund besungenen Fluch („macchia“ der Tiepolo). Ob mit „macchia“ ein sichtbarer Fleck gemeint war, ist in keiner Quelle eindeutig beschrieben. Es würde aber zu seiner Biographie durchaus passen, dass er sich trotzig mit diesem Makel in einem derart herrschaftlichen Portrait abbilden ließ. Da bekannt ist, dass derartige „Feuermale“ durchaus gehäuft in Familien vorkommen, ließe sich auch hierdurch die „macchia“ der Tiepolo quasi materialisiert belegen.

Schlussfolgerung. Insgesamt stellt der Fall ein spannendes Beispiel für eine kunsthistorische Identifizierung einer historischen Person unter rechtsmedizinischer Beteiligung dar.

\section{V91 \\ Struktur der Gewaltambulanzen an den Instituten für Rechtsmedi- zin in Deutschland}

\section{E. Mützel', D. Seifert'², H. Grass' ${ }^{3}$, A.S. Debertin ${ }^{4}$, S. Banaschak ${ }^{5}$ \\ ${ }^{1}$ Rechtsmedizin, München, Deutschland, ${ }^{2}$ Rechtsmedizin, Hamburg, Deutschland, ${ }^{3}$ Akademie für öffentliches Gesundheitswesen, Düsseldorf, Deutschland, ${ }^{4}$ Rechtsmedizin, Hannover, Deutschland, ${ }^{5}$ Rechtsmedizin, Köln, Deutschland}

Einleitung. In einem Gutachten über eine „Bestandsaufnahme zur Situation der Frauenhäuser, Fachberatungsstellen und anderer Unterstützungsangebote für gewaltbetroffene Frauen und deren Kinder" stellt die Bundesregierung fest, dass die Bekämpfung der Gewalt zu den aktuellen und langfristigen Schwerpunkten der Gleichstellungspolitik der Bundesregierung gehört. Die Bekämpfung von Gewalt ist eine Aufgabe, die sich nicht nur die Bundesregierung auf die politische Agenda geschrieben hat. Rechtsmedizinische Angebote sind in diesem Kontext kaum bekannt.

Methoden. Die AG „Klinische Rechtsmedizin“ hat sich deshalb bemüht, eine Zusammenstellung aller in Deutschland an rechtsmedizinischen Instituten existierenden Gewaltambulanzen vorzustellen. Nach schrift- licher Anfrage aller Institutsleiter ließen sich bei der Durchsicht der Antworten folgende Kategorien darstellen:

- Institute mit einer Ambulanz zur Untersuchung von erwachsenen und kindlichen/jugendlichen Gewaltopfern, die eine überwiegend zeitlich begrenzte Förderung aus öffentlicher Hand erhalten,

- Institute, die in das Projekt ASS (anonyme Spurensicherung) eingebunden sind, jedoch keine (weitere) Finanzierung oder finanziell geförderte Strukturen erhalten. Untersuchungen von Opfern von Gewalt werden ansonsten nur im Rahmen der Aufträge von Kriminalpolizei bzw. Staatsanwaltschaft durchgeführt,

- Institute, die keine Förderung erhalten, aber Erwachsene und/oder Kinder/Jugendliche kostenlos, mit Spendengelder oder Finanzierung durch die Universität untersuchen, teils auch im Rahmen einer interdisziplinären Vernetzung oder durch Beteiligung an Kinderschutzgruppen in Kliniken tätig sind,

- Institute, die Untersuchungen im Auftrag der Staatsanwaltschaft und Polizei durchführen, ggf. im Auftrag des Weißen Ringes unter Vorlage eines Untersuchungsschecks.

Ergebnisse. Diese Zusammenstellung zeigt, dass nur sehr wenige Institute eine Förderung durch die Öffentliche Hand (z. B. Ministerien) erhalten, aber viele eine Untersuchung für Opfer von Gewalt anbieten, obwohl keine Förderung vorhanden ist. Es soll eine Diskussion angeregt werden, inwieweit die Erkenntnisse dieser Auswertung außerhalb der rechtsmedizinischen Gesellschaft verbreitet werden können oder sollen, und wie das Angebot nachhaltig in die politische Debatte eingebracht werden kann.

\section{V92}

Netzwerk ProBeweis - Erfahrungen aus dem Aufbau eines Ambulanznetzwerkes

\section{T. Germerott ${ }^{1}$, A.S. Debertin ${ }^{7}$}

'Medizinische Hochschule Hannover, Institut für Rechtsmedizin, Hannover, Deutschland

Einleitung. Die Einrichtung von Gewaltambulanzen stellt ein wichtiges strategisches Ziel zur Existenzsicherung des Fachgebietes der Rechtsmedizin an universitären Standorten dar.

Methoden. Am 01.06.2012 startete unter Leitung des Institutes für Rechtsmedizin der Medizinischen Hochschule Hannover (MHH) in Niedersachsen das niederschwellige Projekt „Netzwerk ProBeweis“ für Betroffene von häuslicher oder sexueller Gewalt. Das Projektziel ist der Aufbau eines dezentralen Ambulanznetzwerkes zur gerichtsverwertbaren Verletzungsdokumentation und Spurensicherung bereits vor der Erstattung einer Strafanzeige. Das vorgestellte Projekt wird vom Niedersächsischen Ministerium für Soziales, Frauen, Familie, Gesundheit und Integration zunächst für drei Jahre finanziell gefördert.

Ergebnisse. Zusätzlich zur einleitenden Vorstellung der Projektstruktur sollen erste Erfahrungen zur Akzeptanz von „Netzwerk ProBeweis“ bei (Partner-)Kliniken, regionalen Opferunterstützungseinrichtungen und Betroffenen berichtet werden. Ferner wird eine erste Analyse des Fallkollektivs präsentiert.

Diskussion. Durch die ministerielle Förderung ist es gelungen, neben zentralen Anlaufstellen an den Instituten für Rechtsmedizin der MHH auch periphere Kliniken als Anlaufstellen im Flächenland Niedersachsen einzubinden. Die Gewaltopferversorgung im rechtsmedizinischen Alltag stellt einen doppelten Zugewinn dar. Einerseits wird in der Opferversorgung eine bisher bestehende inakzeptable diagnostische Lücke geschlossen, andererseits ergibt sich eine positive Rückkopplung hierdurch gewonnener Erfahrungen für die Lehre und Forschung. 
V93

Gründung regionaler rechtsmedizinischer Untersuchungsstellen nordwestlich von Hamburg - eine Verbesserung der regionalen niedrigschwelligen Versorgungssituation von Gewaltopfern?

\author{
N. Wilke', C. Reimann', D. Seifert', K. Püschel' \\ 'Institut für Rechtsmedizin, Universitätsklinikum Hamburg-Eppendorf, \\ Hamburg, Deutschland
}

Einleitung. Das Bundesministerium forderte in seinen Aktionsplänen zur Versorgungssituation von Gewaltopfern in Deutschland u. a. den Ausbau des niedrigschwelligen Versorgungsangebotes.

Methoden. Eine Auswertung niedrigschwelliger Anfragen rechtsmedizinischer Dienstleistungen aus der Region nordwestlich von Hamburg über 10 Jahre (2000-2009) konnte zeigen, dass trotz der infrastrukturellen Nähe zur Ambulanz für Opfer von Gewalt des Instituts für Rechtsmedizin in Hamburg lediglich 17 Anfragen gestellt wurden. Als Reaktion darauf wurden 2010 im Rahmen eines Pilotprojektes nordwestlich von Hamburg zwei regionale rechtsmedizinische Untersuchungsstellen gegründet. Es werden Auszüge aus den Ergebnissen der ersten 3,5 Projektjahre (Anfang 2010 bis Mitte 2013) vorgestellt.

\section{V94}

Gewalt im sozialen Umfeld - eine prospektive und retrospektiv angelegte Analyse körperlicher Gewalttaten im Hamburger Stadtteil St. Pauli

\section{S. Koetz', K. Püschel', A. Heinemann', D. Seifert ${ }^{1}$ \\ 'Institut für Rechtsmedizin, Hamburg, Deutschland}

Einleitung. Rechtsmedizinisch relevante Informationen über Gewalt unter Jugendlichen und jungen Erwachsenen im sozialen Umfeld (ausgenommen häusliche und sexualisierte Gewalt) im Stadtteil St. Pauli wurden analysiert.

Methoden. Für die Betrachtung der Jahre 2003 bis 2010 wurde eine retrospektive Analyse von Untersuchungsbefunden aus der Datenbank des Institutes für Rechtsmedizin durchgeführt. Hierbei wurden 18- bis 30-jährige Gewaltopfer aus dem Bereich des Polizeikommissariates 15 betrachtet, die im Institut für Rechtsmedizin untersucht worden sind. Zusätzlich erfolgte eine prospektive Datenerhebung mittels persönlich geführter Befragung von Gewaltopfern am PK 15 von Mai bis Juli 2011 in den Nächten von Freitag auf Samstag und Samstag auf Sonntag, jeweils von $0.00-8.00 \mathrm{Uhr}$.

Ergebnisse. Insgesamt wurden retrospektiv 103 und prospektiv $34 \mathrm{Ge}$ waltopfer betrachtet. Die Mehrzahl unter ihnen war in beiden Studienabschnitten männlichen Geschlechts (retrospektiv 69,9\%, prospektiv $74,7 \%$ ). Die Taten wurden größtenteils auch von Männern ausgeübt (retrospektiv 92,6\%, prospektiv 91,2\%). Der vorwiegende Teil der Opfer war zum Tatzeitpunkt zwischen 21 und 25 Jahre alt (retrospektiv 46,6\%, prospektiv 44,1\%) und stand unter dem Einfluss von Alkohol (retrospektiv 89,3\%, prospektiv 94,1\%). Bei den untersuchten Fällen wurde vorwiegend körperliche Gewalt ausgeübt (retrospektiv 60,4\%, prospektiv 91,2\%). Tatwerkzeuge wurden weniger häufig genutzt (retrospektiv 40,2\%, prospektiv 8,8\%). Die Verletzungen waren größtenteils im KopfHals-Bereich (retrospektiv 86,4\%, prospektiv 63,6\%) und der oberen Extremitäten (retrospektiv 35,9\%, prospektiv 21,1\%) lokalisiert.

Schlussfolgerung. Opfer einer gewalttätigen Handlung im sozialen Umfeld werden vorwiegend 21- bis 25-jährige alkoholisierte Männer, die sich nachts an Wochenendtagen im öffentlichen Raum oder öffentlich zugänglichen Gebäuden aufhalten. Die angreifenden Personen sind häufig männlichen Geschlechts und dem Opfer meist nicht bekannt. Es wird hiermit die Notwendigkeit einer Gewaltprävention besonders im sozialen Raum deutlich. Im Hinblick auf die hohen Alkoholkonzentrationen der Gewaltopfer könnte eine Einschränkung des Alkoholausschanks im Untersuchungsgebiet das Gewaltaufkommen minimieren bzw. dessen Intensität mildern.

\section{V95}

Häusliche Gewalt - eine retrospektive Fallanalyse aus dem Institut für Rechtsmedizin Hannover

\section{Todt', M. Awe', A.S. Debertin', A. Fieguth}

'Medizinische Hochschule Hannover, Institut für Rechtsmedizin, Hannover, Deutschland

Einleitung. Jede dritte bis fünfte Frau in Deutschland wird ausweislich einer repräsentativen Studie des Bundesministeriums für Familie, Senioren, Frauen und Jugend mindestens einmal im Leben Opfer von häuslicher oder sexueller Gewalt durch einen früheren oder den aktuellen Lebenspartner. In Niedersachsen wurden im Jahr 2011 etwa 17.000 Gesamtfallzahlen häuslicher Gewalt registriert und ca. 27.00o Frauen suchten Hilfe in Frauenhäusern oder bei Opferschutzeinrichtungen. Die Expertise aus der klinischen Rechtsmedizin ist hierbei für die körperliche Untersuchung dieser Gewaltopfer mit gerichtsverwertbarer Dokumentation der Verletzungen und Spurensicherung von großer Bedeutung.

Ergebnisse. In der vorliegenden Studie wurden retrospektiv für den Zeitraum 2001 bis 2010 die körperlichen Untersuchungen $(n=3098)$ des Instituts für Rechtsmedizin der Medizinischen Hochschule Hannover ausgewertet. Es ergaben sich insgesamt 216 rechtsmedizinische Untersuchungen nach körperlicher Gewalt und/ oder sexuellem Missbrauch in einer Partnerschaft (7\%). Hierbei wurden 199 weibliche und 17 männliche Geschädigte im Alter von 15 bis 82 Jahren untersucht. Die im Rahmen dieser Untersuchungen festgestellten Verletzungen wurden nach Art, Lokalisation und Lebensbedrohlichkeit analysiert. Ferner erfolgte eine Auswertung der Vorerkrankungen, des Alkohol-/Drogenkonsums zum Tatzeitpunkt und der anamnestischen Angaben der Geschädigten. Des Weiteren wurde in einem Teil der Fälle $(n=59)$ eine rechtsmedizinische Untersuchung der Beschuldigten durchgeführt, welche ebenfalls in der Auswertung der vorliegenden Studie berücksichtigt wurden.

Schlussfolgerung. Die Ergebnisse der Studie verdeutlichen, dass im vorliegenden Untersuchungskollektiv Frauen überproportional häufig (92\%) und wiederholt (41\%) durch den Lebenspartner körperlich misshandelt und/ oder sexuell missbraucht wurden. Insbesondere bei körperlicher Gewalt und sexuellem Missbrauch in einer Partnerschaft befinden sich die Geschädigten in einer emotionalen Ausnahmesituation. Die damit verbundene Zurückhaltung bei der Erstattung einer Strafanzeige lässt eine hohe Dunkelziffer vermuten.

\section{V96}

Sittlichkeitsdelikte im Einzugsgebiet des Instituts für Rechtsmedizin der Universität Zürich (Schweiz) im Zeitraum 2006 bis 2010

R.M. Martinez', M. Thali', C. Bartsch ${ }^{1}$

'Institut für Rechtsmedizin der Universität Zürich, Forensische Medizin und Bildgebung, Zürich, Schweiz

Fragestellung. In der Schweiz sind Handlungen gegen die sexuelle Integrität im Strafgesetzbuch geregelt. Die meisten Sexualstraftaten sind sogenannte Offizialdelikte (z. B. Vergewaltigung) und werden somit auch ohne Strafanzeige der geschädigten Person offiziell strafrechtlich verfolgt. In vielen Ländern wurden bereits Studien zu demographischen Geschädigten- und Tätermerkmalen durchgeführt, in der Schweiz fehlen bisher systematische Untersuchungen zu möglichen Eigenschaften bzw. einem Risikoprofil von Vergewaltigungsopfern (speziell gefährdete Klientel).

Methode. Im Rahmen eines Pilotprojekts wurden retrospektiv alle im Institut für Rechtsmedizin der Universität Zürich (IRM-UZH) untersuchten Geschädigten nach polizeilich angezeigten Sexualdelikten für den oben genannten 5-Jahres-Zeitraum mit Hilfe eines hierfür erarbeiteten Erhebungsbogens dokumentiert und statistisch nach unterschiedlichen Kriterien ausgewertet. 
Ergebnisse. Von insgesamt knapp 1686 körperlichen Untersuchungen am IRM-UZH fanden sich 187 nach erfolgten Vergewaltigungen (11\%). Im Gesamtuntersuchungsgut waren fast ausschließlich Frauen (95,7\%) als Geschädigte abgrenzbar. Die Altersverteilung der geschädigten Personen lag zwischen 15 und 69 Jahren bei einem Median von knapp 25 Jahren. Bei fast der Hälfte der Untersuchten (45\%) lagen vorbestehend medizinische Erkrankungen vor, hiervon stammten $57 \%$ aus dem psychiatrischen Formenkreis. Im Unterschied zu den verschiedenen Länderstudien waren in $40 \%$ der Fälle die Täter den Geschädigten fremd und die Vergewaltigungen ereigneten sich in $43 \%$ an öffentlichen Orten nach Mitternacht. In 54\% der Fälle fand eine rechtsmedizinische Untersuchung innerhalb der ersten 12 Stunden nach dem Ereignis, in 22\% zwischen 12 und 24 Stunden und in lediglich $2 \%$ nach einem Zeitraum von mehr als 72 Stunden statt.

Schlussfolgerungen. Die Ergebnisse der vorliegenden Zürcher Pilot-Studie ermöglichen einen detaillierten Überblick über die polizeilich angezeigten und somit rechtsmedizinisch untersuchten Sittlichkeitsdelikte und lassen besondere charakteristische Eigenschaften von "Opfer" und Ereignis erkennen. Es zeigt sich, dass die Mehrheit der rechtsmedizinisch beurteilten Fälle die sogenannten „klassischen“ Vergewaltigungen umfasst, während der größte Anteil aller Sexualdelikte im Dunkelfeld womöglich völlig anders abläuft und eine andere Klientel betrifft.

\section{V97}

Interpersonelle und instrumentelle Gewalt bei Konflikten im StraBenverkehr

\section{J.- L. Pfeiffer', K. Püschel', D. Seifert ${ }^{1}$ \\ 'Universitätsklinikum Hamburg-Eppendorf, Institut für Rechtsmedizin, Hamburg, Deutschland}

Einleitung. Aggression und Gewalt im Straßenverkehr sind ein häufiges Phänomen. In milder Form sind bis zu einem Drittel der Bevölkerung - als Täter oder Opfer - beteiligt. Schwerere Formen mit Schäden an Fahrzeugen oder Personen finden sich hingegen seltener, können aber verheerende Folgen - bis zum Tod - nach sich ziehen.

Material und Methoden. In einer 10 Jahre umfassenden, retrospektiven Studie wurden Verletzungen nach Konflikten im Straßenverkehr bei körperlich untersuchten Personen am Institut für Rechtsmedizin (IfR) des Universitätsklinikums Hamburg-Eppendorf (UKE) identifiziert. Mittels deskriptiver Statistik wurden charakteristische Merkmale (wie Geschlecht, Alter und Art des Verkehrsmittels) der beschädigten und der beschuldigten Person, ihre Beziehung zueinander, Art und Qualität der Gewaltanwendung, Verletzungsmuster und weiterführende medizinische Behandlung analysiert.

Ergebnisse. Es wurden 116 Fälle von verletzten Personen nach Konflikten im Straßenverkehr identifiziert. Eine signifikant größere Anzahl der geschädigten $(75,9 \%, n=88)$ und beschuldigten $(82,7 \%, n=96)$ Personen sind männlich. Die meisten Beschuldigten sind Einzeltäter (75,9\%, $\mathrm{n}=88)$. In 95 Fällen $(81,9 \%)$ wurde physische Gewalt $(81,8 \%)$ angewandt. 36 Fälle umfassten den Einsatz instrumenteller Gewalt, welche in mehr als der Hälfte der Fälle $(n=20)$ den Einsatz des Fahrzeuges als Waffe beinhaltet. Das verursachte Trauma ist größtenteils stumpf und betrifft den Gesichts- und Hirnschädel sowie die oberen und unteren Extremitäten. Die medizinische Versorgung konnte überwiegend ambulant erfolgen, während in 12 Fällen (10,3\%) eine stationäre Behandlung notwendig war. Es gab 8 Fälle (7,8\%) mit potenziell lebensgefährlichen Verletzungen. Kraftfahrzeugfahrer sind überrepräsentiert: Die beschuldigten Personen waren in 71 Fällen (61,2\%) motorisiert. In 6 Fällen $(5,2 \%)$ waren die beschuldigten Personen Radfahrer, in 20 Fällen $(17,2 \%)$ Fußgänger und in 8 Fällen $(7,8 \%)$ Fahrgäste.

Schlussfolgerung. Es stellt sich annähernd eine in einem Konflikt im Straßenverkehr verletzte Person pro Monat am IfR vor. Es gibt signifikante Unterschiede zwischen den beiden Geschlechtern und der Art des Verkehrsmittels mit Überrepräsentierung von Männern und Kraftfahrzeugfahrern.

\section{V98}

Vitamin-D-Mangel-Rachitis - eine seltene, aber wichtige Differenzialdiagnose der Kindesmisshandlung

B. Navarro-Crummenauer', K. Uebbing', D. Breitmeier', F. Koerber', M. Krause', K.-H. Ludwig', R. Urban'

'Institut für Rechtsmedizin, Forensische Ambulanz, Mainz, Deutschland, ${ }^{2}$ Uniklinik Köln, Abteilung für Kinderradiologie, Köln, Deutschland, ${ }^{3}$ Klinikum Mutterhaus der Borromäerinnen, Abteilung für Kinder- und Jugendchirurgie, Trier, Deutschland, ${ }^{4}$ Klinikum Mutterhaus der Borromäerinnen, Abteilung für Kinder- und Jugendmedizin, Trier, Deutschland

Fallbericht. Ein 9 Monate alter Säugling, erstes Kind einer 45-jährigen Mutter und eines 55-jährigen Vaters, wurde nach einem anamnestisch berichteten Wickeltischsturz mit anschließendem Erbrechen stationär in der Kinderklinik aufgenommen. Es wies keine äußerlich erkennbaren Verletzungen auf. In einer Schädelsonographie ergab sich der Verdacht auf subdurale Flüssigkeitsansammlungen. Eine MRT des Schädels bestätigte das Vorliegen derselben mit unterschiedlicher Signalintensität, ferner fand sich eine deutliche Erweiterung der inneren Liquorräume. Eine Funduskopie erbrachte keine retinalen oder Glaskörperblutungen. In einem Röntgenskelettscreening zeigten sich eine disseminierte ausgeprägte Mineralisierungsminderung aller Knochen, mit u. a. becherförmiger Ausziehung der Metaphysen, langstreckigen periostalen Auflagerungen der langen Röhrenknochen sowie einem Rosenkranz der ventralen Rippenanteile. Der Säugling war deutlich dystroph bei gleichzeitig erheblich reduziertem Längenwachstum. In Laboruntersuchungen zeigten sich ein exzessiver Mangel an Vitamin D, Vitamin B12 und Eisen, so dass als Ursache für die Knochenveränderungen eine Vitamin-D-Mangel-Rachitis ausgeprägtester Form diagnostiziert wurde. Die Kindeseltern teilten mit, dass das Kind ausschließlich vegan ernährt werde und sie ihm zudem keine Vitamin-DTabletten hätten geben wollen. Die Entstehung der Subduralergüsse bleibt diskussionswürdig.

Schlussfolgerung. Der Fall wird unter Berücksichtigung der bisher bekannten Literatur referiert und zur Diskussion gestellt. Die Fallpräsentation soll daran erinnern, dass auch seltene Differenzialdiagnosen bei der Beurteilung einer möglichen Kindesmisshandlung in Erwägung gezogen und abgeklärt werden müssen.

\section{V99}

Kongenitale Pseudarthrose - eine seltene, aber wichtige Differenzialdiagnose der Kindesmisshandlung

B. Navarro-Crummenauer', K. Uebbing', D. Breitmeier', F. Koerber', P.-M. Herding $^{3}$, B. Rosenkrant ${ }^{4}$, R. Urban ${ }^{7}$

'Institut für Rechtsmedizin, Forensische Ambulanz, Mainz, Deutschland, ${ }^{2}$ Uniklinik Köln, Abteilung für Kinderradiologie, Köln, Deutschland, ${ }^{3}$ Marienhaus Klinikum St. Elisabeth, Abteilung für Kinder- und Jugendmedizin, Neuwied, Deutschland, ${ }^{4}$ Gemeinschaftsklinikum Kemperhof, Abteilung für Orthopädie und Unfallchirurgie, Koblenz, Deutschland

Fallbericht. Ein 17 Monate altes, bisher scheinbar völlig gesundes Mädchen wird von den Eltern in der Unfallchirurgie mit einer Schonhaltung des rechten Beines vorgestellt, nachdem sie unbeobachtet auf einer Treppe „herumgeturnt“ habe. Das Kind wies keine äußeren Verletzungen auf. In Röntgenaufnahmen zeigten sich eine frische Tibiaquerfraktur rechts, eine deutliche s-förmige Verbiegung der Tibia, eine Valgusfehlstellung der Fibula sowie ein fibröser Kortikalisdefekt an der rechten distalen Fibula. Nach ambulanter Gipsversorgung wurde das Kind entlassen und 2 Wochen später zur Abklärung des Röntgenbefundes stationär aufgenommen. Seit dem Aufnahmetag bestand eine starke Schwellung des rechten Unterschenkels ohne Unfallanamnese; in Röntgenaufnahmen zeigte sich eine dislozierte Tibia-Refraktur, die wiederum konservativ behandelt wurde. Im Rahmen der weiteren Diagnostik ergaben sich keine Anhaltspunkte für eine systemische Kno- 
chenerkrankung oder einen Knochentumor. Sieben Tage nach Entlassung wurde das Kind, erneut ohne Traumaangabe, mit einer zweiten Tibia-Refraktur in der Kinderklinik vorgestellt. Von orthopädischer und kinderradiologischer Seite wurde im Verlauf die Diagnose einer kongenitalen Pseudarthrose gestellt. Es ist von einem Mischtyp des sklerotischen Crawford-Typ I und des dysplastischen Crawford-Typ IV mit zystischen Veränderungen im Bereich der Fibula und pathologischer Fraktur sowie anschließender Pseudarthrose der Tibia auszugehen. Aufgrund der Korrelation einer kongenitalen Pseudarthrose mit einer Neurofibromatose wurden entsprechende Untersuchungen initiiert, die jedoch negativ verliefen.

Schlussfolgerung. Der Fall wird unter Berücksichtigung bisheriger wissenschaftlicher Erkenntnisse zu diesem Krankheitsbild vorgestellt und soll aufzeigen, dass selbst bei knöchernen Verletzungen von Kleinkindern ohne Schilderung eines adäquaten Unfallhergangs eine sorgfältige Abklärung möglicher Differenzialdiagnosen erfolgen muss.

\section{V100 \\ Applikation von Medikamenten in die Augenmuskulatur von Leichen im Rahmen der Todeszeitschätzung mittels eines Insulin- Pen-Systems}

\section{S. Potente', S. Plenzig', P. Trageser', S. Tönnes}

'Goethe-Universität Frankfurt, Inst. für Rechtsmedizin, Frankfurt am Main, Deutschland

Einleitung. Als Ergänzung zur temperaturgestützten Todeszeitschätzung nach Henßge (Nomogramm-Methode) ist die Komplexmethode (engl.: „compound method“) etabliert. Hierbei werden Leichenerscheinungen und supravitale Reaktionen in Abhängigkeit vom zuvor berechneten Todeszeitintervall geprüft. Neben der elektrischen Reizung von Gesichtsmuskulatur und mechanischer Reizung peripherer Muskulatur steht als weitere supravitale Reaktion die chemische Reizung der Augenmuskulatur durch Injektion verschiedener Medikamente zur Verfügung. Obwohl diese gegenüber weiteren Befundkomplexen einige Vorteile bietet („binäres“ Befundmuster, Abdeckung großer Zeitbereiche, prinzipielle Wiederholbarkeit), wird sie in der Praxis recht selten angewendet.

Methoden. In einer Pilotstudie wurde die Möglichkeit des Einsatzes von Insulin-Pen-Systemen (Sanofi-Aventis) für die Applikation von Medikamenten in die Augenmuskulatur erprobt. Vorteile werden gesehen in der Verwendung hochfeiner und leicht auswechselbarer Kanülen, einer einfachen und verlässlichen Dosiermöglichkeit, eines geringeren Traumas sowie der Bereitstellung praktischer und transportabler Kits. Schlussfolgerung. Erste Ergebnisse werden vorgestellt und diskutiert.

\section{V101 \\ Retrospektive Analyse der Kindesobduktionen der Kölner Rechts- medizin}

\section{B. Tantius', M.A. Rothschild', S. Banaschak ${ }^{1}$ 'Institut für Rechtsmedizin Köln, Köln, Deutschland}

Methoden. In den Jahren 1998 bis 4/2013 wurden im Institut für Rechtsmedizin Köln (ab 05/2003 inklusive Aachen) 310 Kinder im Alter zwischen o und 13 Jahren obduziert. Hierunter befanden sich 102 Säuglinge, bei denen nach den rechtsmedizinischen Untersuchungen ein plötzlicher Kindstod angenommen wurde; diese Fälle wurden nachfolgend nicht weiter berücksichtigt. 45 der übrigen 208 Kinder starben eines natürlichen Todes, 87 eines nichtnatürlichen Todes. Bei weiteren 76 blieb die Todesart auch nach Obduktion ungeklärt. Insgesamt 48 Kinder starben infolge eines Unfallgeschehens, z. B. durch Ertrinken, Verkehrsunfälle oder Wohnungsbrände. 39 Kinder wurden Opfer eines Tötungsdeliktes, davon starben 17 an den Folgen einer Misshandlung, weitere $7 \mathrm{im} \mathrm{Rahmen} \mathrm{eines} \mathrm{erweiterten} \mathrm{Suizids} \mathrm{(davon} \mathrm{starben} 5 \mathrm{im} \mathrm{Jahr}$ 2013).

Ergebnisse. Bei den misshandlungsbedingten Todesursachen dominierten Schütteltrauma und stumpfe Gewalt gegen das Abdomen, während bei den Tötungen in anderem Zusammenhang Ersticken und stumpfe Gewalt gegen den Kopf vorherrschten. Weiterhin fanden sich hier mehrfach Erstechen, Vergiften und Liegenlassen eines Säuglings. Die erweiterten Suizide wurden durch Erschlagen mit einem Hammer, Ersticken, Erdrosseln, Erschießen oder Ertränken begangen. Bei den 76 ungeklärten Fällen verstarben 27 Kinder während oder im Anschluss an eine ärztliche Maßnahme bzw. aufgrund einer Fehlbehandlung.

\section{V102}

Lungenembolie - eine unterschätzte Diagnose? Retrospektive Analyse des Sektionsgutes 2002-2011

\section{R. Wolff-Maras', F. Opitz', A. Fieguth', M. Klintschar', T. Germerott}

'Institut für Rechtsmedizin, Medizinische Hochschule Hannover, Hannover, Deutschland

Einleitung. Eine Lungenembolie als autoptische Diagnose findet sich bei ca. 10\% aller Verstorbenen, jedoch werden nur ca. $25 \%$ der letztlich letal verlaufenden Lungenembolien vor dem Versterben diagnostiziert. Da vor dem Auftreten einer (letalen) Lungenembolie nur selten relevante Beschwerden, zum Beispiel klinisch wegweisende Zeichen einer Thrombose, auftreten, ist in Fällen mit entsprechenden Risikofaktoren (Alter, Immobilität, Multimorbidität, große operative Eingriffe, maligne Erkrankungen), aber auch bei plötzlichen Todesfällen vermeintlich gesunder Menschen, eine todesursächliche Lungenembolie in Betracht zu ziehen.

Methoden. Zur Klärung des Vorkommens und möglicher Entstehungsmechanismen von Lungenembolien, auch in Abhängigkeit von ärztlichen Konsultationen, wurden retrospektiv aus dem Sektionsgut des Institutes für Rechtsmedizin in Hannover die Fälle mit einer makroskopisch nachgewiesenen todesursächlichen Lungenembolie über einen Zeitraum von zehn Jahren analysiert. Einbezogen wurden neben den Obduktionsprotokollen auch die Ergebnisse gegebenenfalls erfolgter weiterführender Untersuchungen.

Ergebnisse. Die detaillierten Ergebnisse der Studie werden anlässlich des Vortrags unter Berücksichtigung der aktuellen Literatur präsentiert.

\section{V103}

Trauma-Verletzungen nach Herz-Lungen-Wiederbelebung: manuelle gegen mechanische Reanimation (LUCAS ${ }^{\text {TM } 2) . ~}$

\section{Lardi', C. Egger', R. Larribau'², P. Mangin', T. Fracasso'}

'Universitätszentrum für Rechtsmedizin Genf, Genf, Schweiz, ${ }^{2}$ Notaufnahme, Universitätsspital Genf, Genf, Schweiz

Einleitung. Seit den 196oer-Jahren des vergangenen Jahrhunderts ist die manuelle Herz-Lungen-Wiederbelegung für ihre Wirksamkeit bei Kreislaufstillstand weithin bekannt. Neuerdings gibt es auch moderne technische Vorrichtungen, die die Überlebenschancen verbessern sollen. Ende November 2011 wurde ein entsprechendes Gerät bei den Genfer Notfallärzten eingeführt. LUCAS $^{\text {ntw }} 2$ ist eine mechanische Reanimationshilfe mit automatischer Kompression-Dekompression. Dieses Gerät ist mit einem Saugnapf ausgestattet, die in der Brustregion platziert werden muss. Diese Automatisierung ermöglicht erweiterte Reanimationsphasen und verbessert die Mobilität der Patienten. Im Rahmen der Obduktion fanden sich nach erfolglosem Einsatz dieses Geräts typische Verletzungen, vor allem rundliche Vertrocknungen. Solche Läsionen sind oft mit Brustbein- und Rippen-Bruch verbunden. In der Literatur liegen einige Studien über reanimationstypische Verletzungen vor, bei denen es sich jedoch zumeist um Einzellfallberichte 
mit schlechter Vergleichbarkeit handelt. Aus diesem Grund haben wir im eigenen Obduktionsgut die Verletzungen nach traditioneller Reanimation und nach LUCAS $^{\text {mix }} 2$-Behandlung zusammengetragen und verglichen.

Material und Methoden. In einer retrospektiven Studie wurden 27 Fälle, die mit LUCAS $^{\text {тm }} 2$ reanimiert wurden, mit einer Kontrollgruppe nach Standard-Reanimation verglichen. Jedes Trauma kurz vor dem Todeseintritt oder als Todesursache wurde aus dem Kollektiv ausgeschlossen. Die traumatischen Reanimationsfolgen wurden im Hinblick auf Art, Anzahl, Lokalisation der Verletzungen, sowie auf Alter, Geschlecht und Reanimationsdauer analysiert.

Ergebnisse. In beiden Gruppen wurden keine unmittelbar tödlichen Verletzungen festgestellt. Es fanden sich jedoch mehrere Rippen- und Brustbeinbrüche sowie behandlungsbedürftige Lungen- und Leberprellungen. Unsere Ergebnisse werden hier präsentiert und zur Diskussion gestellt.

\section{V104}

\section{Histopathology of the thyroid gland in mechanical asphyxia}

T. Ishikawa ${ }^{1,2,3}$, T. Michiue ${ }^{2,3}$, O. Kawamoto ${ }^{2,3}$, T. Seo ${ }^{2}$, S. Matsushita ${ }^{2}$, H. Maeda ${ }^{2,3}$ 'Tottori University, Division of Legal Medicine, Faculty of Medicine, Tottori, Japan, ${ }^{2}$ Osaka City University Medical School, Legal Medicine, Osaka, Japan, ${ }^{3}$ Medico-legal Consultation and Postmortem Investigation Support Center, Forensic Autopsy Section, Osaka, Japan

Introduction. We investigated histological changes of the thyroid gland in acute mechanical asphyxia due to neck compression in relation to biochemical findings, compared with other types of asphyxia as well as acute deaths due to brain injury and ischemic heart disease.

Materials and methods. Forensic autopsy cases at our institute were examined: total $n=45 ; 32$ males and 13 females; 9 -(median, 63) years of age; postmortem interval 6-72 h (median, $21.5 \mathrm{~h}$ ). These cases involved deaths due to asphyxiation by neck compression ( $n=20$ : atypical hanging, $\mathrm{n}=6$; ligature/manual strangulation, $\mathrm{n}=14$ ), other asphyxiation $(\mathrm{n}=14$ : aspiration of vomitus/food, $n=4$; chest compression, $n=5$; smothering, $n=5)$, acute brain injury $(n=5)$, and acute myocardial infarction/ ischemia (AMI, $n=6$ ), without medical intervention. Serial horizontal sections of formalin-fixed, paraffin-embedded thyroid tissue specimens were prepared for hematoxylin-eosin (HE) and Azan staining to examine: parenchymatous hemorrhage, lymphocytic infiltration, follicular size, hyperplasia, follicular destruction, vacuolation in the follicle and epithelial cells, follicular metachromasy, and crystallization in the follicle.

Results and discussion. Follicular destruction was more frequently detected in asphyxia and acute brain head injury death than in other cause-of-death groups as well as in hanging and smothering than in aspiration among subgroups of asphyxial death. Blood thyroid hormone levels showed similar findings, as reported previously; however, there was no relationship with follicular destruction. Other histological changes were independent of the cause of death.

Conclusions. These findings suggest that collapsed thyroid follicles indicate a systemic hypoxia rather than mechanical injury to the neck; however, aspiration cases showed a different finding that was similar to that of acute cardiac death.

\section{V105}

Procalcitonin (PCT) als postmortaler Sepsismarker - Vergleich verschiedener Asservate hinsichtlich ihrer Anwendbarkeit

\section{Windgassen', S. Schmidt', J.-R. Nofer ${ }^{2,3}$, H. Pfeiffer ${ }^{2}$, A. Schmeling ${ }^{2}$}

'Universität des Saarlandes, Institut für Rechtsmedizin, Homburg, Deutschland, ${ }^{2}$ Universitätsklinikum Münster, Institut für Rechtsmedizin, Münster, Deutschland, ${ }^{3}$ Universitätsklinikum Münster, Centrum für Laboratoriumsmedizin, Münster, Deutschland

Einleitung. Die postmortale Diagnostik einer Sepsis stellt immer noch ein diagnostisches Problem in der Rechtsmedizin dar, da sie mit einer Reihe unspezifischer Befunde verbunden ist. Der in der Klinik weitgehend etablierte diagnostische Marker Procalcitonin (PCT) hat auch in der postmortalen Diagnostik Relevanz erlangt und seine Anwendbarkeit wurde in mehreren Studien demonstriert. Hierbei kann sich allerdings das Problem stellen, dass das gängige Untersuchungsmedium Serum hämolytisch wird, was die Anwendbarkeit von PCT-Testungen einschränkt.

Methoden. Wir untersuchten als alternative Untersuchungsmedien Augenkammerwasser (AKW) und Liquor, mithin Substanzen, die im Rahmen einer Sektion häufig zu gewinnen sind und verhältnismäßig stabil gegenüber Hämolyse sind. Untersucht wurde ein Kollektiv aus 25 Sektionsfällen in denen in der Zusammenschau der Befunde eine Sepsis als Todesursache diagnostiziert wurde. Als Kontrollgruppe diente ein Kollektiv von ebenfalls 25 Fällen, in denen eine Sepsis als Todesursache ausgeschlossen werden kann. Es wurde die grundsätzliche Nutzbarkeit von PCT als Sepsismarker in den 3 untersuchten Medien getestet.

Ergebnisse. Für alle 3 untersuchten Medien zeigten sich statistisch signifikante Unterschiede zwischen der Sepsis- und der Kontrollgruppe. Erwartungsgemäß stellte Hämolyse v. a. im Serum ein Problem dar, wohingegen AKW und Liquor hiervon wenig betroffen waren.

Schlussfolgerung. Wir kamen zu dem Schluss, dass PCT als postmortaler Sepsismarker seine Berechtigung hat und dass AKW und Liquor für die Bestimmung geeignete Medien sind, die sich durch ihre Stabilität gegenüber Hämolyse auszeichnen.

\section{V106}

Zur Differenzierung von Todesfällen durch Schusswaffengebrauch anhand der Ergebnisse der Legalinspektion

\section{K. Gerlach', B. Jöster', V. Dittmann}

'Institut für Rechtsmedizin der Universität Basel, Forensische Medizin, Basel, Schweiz

Methoden. Das Institut für Rechtsmedizin (IRM) Basel führt bei Schusstodesfällen im Auftrag der Staatsanwaltschaften Basel-Stadt (BS) und Basel-Landschaft (BL) Untersuchungen durch. Seit Inkrafttreten einer einheitlichen Strafprozessordnung 2011 ist das Vorgehen zur Abklärung eines außergewöhnlichen Todesfalls in Art. 253 StPO geregelt. Die räumlichen Gegebenheiten ermöglichen es in den Kantonen BS und BL, dass in nahezu jedem Schusswaffentodesfall eine Legalinspektion am Leichenfundort durch Rechtsmediziner durchgeführt wird. Die Legalinspektion dient in erster Linie der rechtsgenügenden Klärung, ob eine Fremdeinwirkung vorlag. Insofern sind die Anforderungen an Qualität und Aussagekraft der Legalinspektion hoch. Mit der in den Kantonen BS und BL üblichen Zusammenarbeit von Kriminaltechnik, Polizei und Rechtsmedizin wird diesen Anforderungen Rechnung getragen.

Ergebnisse. Studien zeigen, dass für Suizide in der Schweiz eine geringe Obduktionsrate besteht und auch Schusswaffentodesfälle selten obduziert werden, wenn sie bei der Legalinspektion als Suizid oder Unfall bewertet wurden. Von 2002 bis 2011 begutachtete das IRM Basel 200 Todesfälle durch Schusswaffen, in $92 \%$ wurde eine Legalinspektion und in $86 \%$ eine Sektion durchgeführt. Damit lag die Sektionsrate bis 2011 deutlich höher als in der Literatur beschrieben. Nach Inkrafttreten der StPO 2011 zeigte sich schweizweit ein Rückgang der Sektionsrate für alle 
Todesfälle. Ursächlich könnten Abs. 2 und Abs. 3 Art. 253 der StPO sein, wonach weiterführende rechtsmedizinische Untersuchungen nur dann zu beauftragen sind, wenn ein ausreichender Verdacht auf eine Straftat besteht. Es ist davon auszugehen, dass die strafrechtliche Beurteilung eines Todesfalls zunehmend allein auf die Befunde der Legalinspektionen abgestützt wird.

Schlussfolgerung. Mit dieser retrospektiven Auswertung sollte daher geprüft werden, inwieweit die Ergebnisse der Legalinspektion geeignet sind, bei Todesfällen durch Schusswaffengebrauch mit der notwendigen Sicherheit zwischen Unfall, Suizid oder Delikt zu differenzieren.

\section{V107}

\section{Ehrenmorde: zur Situation in Hamburg und Berlin}

\section{S. Elakkary', B. Franke', D. Shokri', S. Hartwig', M. Tsokos', K. Püschel' 'Institut für Rechtsmedizin Hamburg, Hamburg, Deutschland}

Fragestellung. Gewalt, die auf der Ehre der Familie basiert, ist eine Form der häuslichen Gewalt. Diese Gewalt wird insbesondere gegen die Frauen auf der ganzen Welt praktiziert. Sie umfasst eine breite Palette von Straftaten, die Schwerste davon ist der sogenannte Ehrenmord. Für derartige Verbrechen wurden unterschiedliche Definitionen angenommen. Eine eigene Arbeitsdefinition wird vorgestellt. Wir präsentieren Art und Umfang dieses Problems und diskutieren wie universal es ist. Ehrenmorde sind unabhängig von Ethnizitäten, sozialen Klassen und Religionen. Diskutiert werden einige der alten sowie neuen Strafgesetze betreffend die Ehrenmorde aus verschiedenen Regionen der Welt. Die verschiedenen Bemühungen der internationalen staatlichen und nichtstaatlichen Organisationen, die dieses Problem bekämpfen, werden dargestellt.

Methoden. Die wissenschaftliche Literatur wurde im Hinblick auf verschiedene Definitionen für Ehrenmord ausgewertet, um daraus unsere eigene Arbeitsdefinition entwickeln zu können. Danach untersuchten wir die Veröffentlichungen über jene Fälle, die als Ehrenmorde in Hamburg und Berlin in der Zeit zwischen 2000 und 2012 in den Medien kategorisiert wurden. Die Sektionsprotokolle, forensisch-medizinischen Gutachten sowie die staatsanwaltlichen Akten von diesen Fällen wurden analysiert.

Ergebnisse. Von den 5 Fällen in Hamburg und 15 Fällen in Berlin, die durch die Medien als Ehrenmord identifiziert wurden, konnten nach unserer Definition lediglich ein Fall in Hamburg und drei Fälle in Berlin als Ehrenmord benannt werden. In Hamburg war als Opfer eine Frau und in Berlin waren zwei weibliche und ein männliches Opfer als Opfer von Ehrenmorden betroffen. Diese Fälle werden kasuistisch präsentiert.

Schlussfolgerung. Durch eine zutreffende Definition und Analyse der forensischen Aktenunterlagen für die sog. Ehrenmorde, ist nachweisbar, dass solche Straftaten in Deutschland zahlenmäßig weit überschätzt wurden.

\section{V108}

\section{Die "forensische Andrologie“ in der klinischen Rechtsmedizin - eine Zweijahresbilanz}

\section{K. Albrecht ${ }^{1,2}$, S. Ückert ${ }^{2}$, M. Kuczyk ${ }^{2}$, M. Klintschar ${ }^{1}$}

'Med. Hochschule Hannover, Institut für Rechtsmedizin, Hannover, Deutschland, ${ }^{2}$ Med. Hochschule Hannover, Klinik für Urologie und Urologische Onkologie, Hannover, Deutschland

Einleitung. Die gutachterliche Untersuchung von angeschuldigten Sexualstraftätern gehört zum alltäglichen Spektrum der rechtsmedizinischen Tätigkeit. Neben der routinemäßigen Untersuchung einer geschädigten Person und des dazugehörigen Angeschuldigten, können in einigen Fällen ergänzende Fragen auftreten, welche potenziell vorliegende genitale bzw. sexuelle Störungen beim Beschuldigten thema- tisieren. Nach entsprechender Einlassung könnten diese vermeintlich vorliegenden andrologischen Störungen die Unmöglichkeit zur Durchführung einer sexuellen Straftat begründen. Aufgrund einer dann unter Umständen vorliegenden spezifischen klinischen Fragestellung unter Einschluss einer erforderlich werdenden urologischen Untersuchung, ist mitunter eine interdisziplinäre Zusammenarbeit zwischen Klinischer Rechtsmedizin und Urologie/Andrologie notwendig.

Methode. Es werden 13 Fälle bzw. forensisch-andrologische Fragestellungen, welche innerhalb eines Zweijahresintervalls an die seit dem Jahr 2011 bestehende klinisch-forensische Kooperation zwischen dem Institut für Rechtsmedizin und der Urologischen Klinik der Med. Hochschule Hannover gerichtet wurden, vorgestellt.

Ergebnisse. Die Fallbearbeitungen erforderten neben der reinen Aktenauswertung in 7 Fällen eine zusätzliche klinisch-urologische Untersuchung, die neben der Verifizierung einer angegebenen Potenzstörung, zudem genitale Erkrankungen beim jeweiligen Beschuldigten bestätigen oder ausschließen sollte, welche möglicherweise einer Penetrationsfähigkeit entgegenstehen könnten (z. B. Morbus Peyronie, Mikropenis, Zustand nach urologischer Operation oder genitales Trauma).

Schlussfolgerung. Die erkennbar zunehmende spezifischere Fragenausrichtung bezüglich der physiologischen Möglichkeit oder des Ausschlusses zur Durchführung eines angeschuldigten Sexualdeliktes, erfordert neben der rechtsmedizinischen Expertise fallabhängig eine zusätzliche urologische Expertenmeinung, welche i. S. einer Kooperation das gutachterliche Aufgabenspektrum der Klinischen Rechtsmedizin - auch zukünftig - sinnvoll erweitern wird.

\section{V109}

Immunohistochemical detection of interleukin (IL)-8 in cases of blunt head injury and its application for wound age determination

\section{T. Hayashi', K. Ago', M. Ago', E. Higo', M. Ogata'}

'Department of Legal Medicine, Graduate School of Medical and Dental Sciences, Kagoshima University, Kagoshima, Japan

Introduction. Immunostaining for intra-axonally transported proteins, particularly beta-amyloid precursor protein (APP), is now recognized as an effective tool for detecting traumatic axonal injury. Interleukin (IL)-8, one of the CXC chemokines (chemotactic cytokines), has recently been postulated to have important functions in the central nervous system as a positive regulator of myelination in addition to its principal role in directing migration of neutrophils into the acutely inflamed site. Methods. In this study, immunohistochemical examinations were performed for IL-8 and APP in sections of the corpus callosum obtained from 22 cases of blunt head injury and 23 control cases.

Results. IL-8 immunostaining was detected in a part of APP-positive axonal bulbs and varicose axons (sinusoidally swollen axons), in 8 out of 10 cases of head injuries that survived for more than 3 days after the injury, but failed to label axons in shorter survival and in control cases. In addition, IL-8 was also expressed on the oligodendrocytes surrounding the IL-8-positive injured axons.

Conclusions. These results suggest that IL-8 expression is increased in the oligodendrocytes that have formed the myelin sheath of the injured axons in order to promote the regeneration of the sheath from 3 days after the head. Immunohistochemical detection of IL- 8 on the corpus callosum may be useful for estimating the wound age as well as a diagnostic marker of traumatic axonal injury. 


\section{V110}

Immunohistochemical detection of intrathrombotic macrophagederived cytokines and its application to thrombus age estimation in murine deep vein thrombosis model

T. Kondo', M. Nosaka', Y. Ishida', A. Kimura', Y. Kuninaka', M. Kawaguchi'
'Wakayama Medical University, Forensic Medicine, Wakayama, Japan

Methods. We immunohistochemically examined the expression of IFN $\gamma$, TNF $\alpha$ and TNF receptor $\mathrm{p}_{55}$ (TNF-Rp55) in a stasis-induced venous thrombus murine model. IFN $\gamma+$, TNFa+ and TNF-Rp55+ cells could be first detected 7 days, 3 days and 3 days after IVC ligation. Thereafter, the numbers of these positive cells increased with time after IVC ligation.

Results. Double-color immunofluorescence analyses demonstrated that each molecule was expressed by intrathrombotic macrophages. In all samples with postligation intervals of 7 days or less, IFN $\gamma /$ macrophage ratio (IFN $\gamma / \mathrm{Mf}$ ), TNF $\alpha /$ macrophage ratio (TNFa/Mf) and TNF-Rp55/ macrophage ratio (TNF-Rp55/Mf) were $<0.2,<0.2$ and $<0.4$, respectively. In contrast, IFN $\gamma / \mathrm{Mf}$ and $\mathrm{TNF} \alpha / \mathrm{Mf}$ were greater than 0.2 and 0.3 at $\geq 10$ days after the IVC ligation, respectively. These observations suggested that IFN $\gamma / \mathrm{Mf}$ ratios of $>0.2$ and $\mathrm{TNF} \alpha / \mathrm{Mf}$ ratios of $>0.3$ indicated thrombus age of 310 days. Moreover, TNF-Rp55/Mf ratios of $>0.7$ strongly suggested thrombus age of $>14$ days.

Conclusions. The present study demonstrated that the immunohistochemical detection of IFN $\gamma$, TNF $\alpha$ and TNF-Rp55 was suitable to estimate the age of venous thrombi. However, the variation in TNF-Rp55/ Mf ratios is wider than those of the other 2 markers. Thus, IFN $\gamma$ and TNFa could be more practical markers.

\section{V111}

\section{Alkohol- und Drogenkonsummarker-Bestimmung im Urin von} Inhaftierten in zwei Justizvollzugsanstalten

\section{A. Thierauf', A. Franz', L. Huppertz', V. Auwärter' \\ 'Institut für Rechtsmedizin, Freiburg, Deutschland}

Fragestellung. Es gibt zahlreiche Situationen, die einen Verzicht auf Alkohol und Drogen erfordern. Dazu gehört aus Gründen des Selbstund Fremdschutzes auch der Aufenthalt in einer Justizvollzugsanstalt (JVA). Trotz dieses Verbots muss davon ausgegangen werden, dass sowohl Drogen als auch Alkohol von Inhaftierten beschafft und konsumiert werden. Während Drogen in die JVA eingeführt werden müssen, werden alkoholische Getränke unter Ausnutzung des Gärprozesses auch innerhalb der Haftanstalt hergestellt. Um Alkohol- und Drogenkonsum entgegenzuwirken, finden Kontrollen statt. Zwei unterschiedliche Konzepte (Drogenspürhund, Kontrolle durch Angestellte) wurden im Hinblick auf ihre Wirksamkeit untersucht. Dazu wurden Urinproben von freiwillig teilnehmenden Inhaftierten zweier Haftanstalten anonym gesammelt und auf das Vorhandensein von Alkoholkonsummarkern (EtG und EtS) sowie Drogen und Medikamente bzw. deren Stoffwechselprodukte (Opiate, Opioide, Amphetaminderivate, Kokain, Cannabinoide) untersucht. Unabhängig von dieser Fragestellung bieten die gewonnenen Ergebnisse einen auf beweissicheren Daten beruhenden Einblick in die tatsächliche Prävalenz des Gebrauchs berauschender Mittel in Justizvollzugsanstalten.

Methoden. Die Urinproben wurden mit akkreditierten Routinemethoden aufgearbeitet. Die Untersuchung auf EtG, EtS, Opiate, Opioide, Amphetamine und Kokain erfolgte mittels LC-MS/MS; die Analyse des Urins auf Abbauprodukte des Cannabiswirkstoffs THC erfolgte mit GC-MS.

Ergebnisse. In $28 \%$ der Urinproben wurden Drogen oder potenziell missbräuchlich eingenommene Medikamentenwirkstoffe bzw. deren Abbauprodukte nachgewiesen. Alkoholkonsummarker fanden sich in 2-3\% der Proben.
Schlussfolgerung. Die Durchführung von Kontrollmaßnahmen kann die Verfügbarkeit von Drogen in Haftanstalten offenbar nicht umfassend verhindern.

\section{V112}

Analysenbefunde in Urin und Haaren bei Untersuchungen im Rahmen der Fahreignungsdiagnostik

\section{F. Musshoff', , A. Lunow-Linzbach', H. Sachs', B. Madea'}

IInstitut für Rechtsmedizin, Bonn, Deutschland, ${ }^{2}$ Forensisch Toxikologisches Centrum GmbH, München, Deutschland

Einleitung. Gemäß den Beurteilungskriterien für die Fahreignungsdiagnostik in der 2. Auflage kann ein Drogenabstinenzprogramm durch Urinkontrollen oder Haaranalysen begleitet werden. In einer retrospektiven Studie wurden die Befunde von Urinkontrollen und Haaranalysen gegenübergestellt.

Methoden. Zur Auswertung gelangten 766 Haaranalysen im Rahmen der Fahreignungsdiagnostik sowie 3703 Urintests (Ethylglucuronid wurde hier nicht berücksichtigt).

Ergebnisse. Während bei den Urinkontrollen eine allgemeine Positivrate von 6,8\% auszumachen war, lag sie bei Haaranalysen bei Verwendung der in den Beurteilungskriterien propagierten Entscheidungsgrenzen bei $19,5 \%$. Bei den Haaranalysen verteilten sich die positiven Fälle wie folgt: 46\% THC, 31\% Kokain, $13 \%$ Amphetamin, 4\% Benzodiazepine, $3 \%$ Opiate, $1 \%$ Methadon und ebenfalls $1 \%$ weitere Opioide. Urin: $54 \%$ THC-COOH, $16 \%$ Amphetamine, $12 \%$ Benzoylecgonin (Kokainmetabolit), $8 \%$ Opiate, $2 \%$ Benzodiazepine, $1 \%$ Methadon. Berücksichtigt man nicht die Entscheidungsgrenzen und legt die laborinternen Bestimmungsgrenzen zugrunde, so erhöht sich bei Haaranalysen die Positivrate sogar auf $22,9 \%$, beim Urin auf 10,1\%. In 219 zuvor unauffälligen Urinfällen erfolgte aus verschiedenen Gründen zusätzlich eine Haaranalyse, die in $21 \%$ zu einem positiven Befund führte. In 279 positiven Fällen war bekannt, mit welcher Substanzklasse der Klient zuvor auffällig geworden war. In 63\% dieser Fälle war bei den Analysen im Rahmen der Fahreignungsdiagnostik dann dieselbe Substanzklasse auffällig, in weiteren $5 \%$ der Fälle tauchte zusätzlich eine weitere Gruppe auf und in $32 \%$ eine völlig andere.

Schlussfolgerung. Der Anteil positiver Fälle bei Analysen im Rahmen der Fahreignungsdiagnostik hat sich deutlich erhöht. Waren vor der 2. Auflage der Beurteilungskriterien vornehmlich Urinkontrollen mit einer Positivrate von $2-3 \%$ zu verzeichnen, werden nun insbesondere durch die Haaranalyse viel mehr Fälle aufgedeckt, bei denen keine Abstinenz zu bescheinigen ist. Ein polytoxikologisches Screening ist gerechtfertigt, was die Häufigkeit mehrfach positiver Befunde bei Abstinenzprogrammen und zudem ein zu beobachtender Substanzshift belegen.

\section{V113}

Atem- und Blutalkoholmessung in der Praxis - eine einjährige Studie aus dem Einzugsbereich des Polizeipräsidiums Mittelhessen

\section{Roiu', C.G. Birngruber', V. Spencer', H. Wollersen', R. Dettmeyer', M.A. Verhoff}

'Universität Gießen, Institut für Rechtsmedizin, Gießen, Deutschland

Einleitung. Bisherige Studien zur Vergleichbarkeit von Atemalkoholkonzentration (AAK) und Blutalkoholkonzentration (BAK) waren auf die Frage der Messgenauigkeit von AAK-Messgeräten und auf die Konvertierbarkeit der Messergebnisse beider Methoden fokussiert. Die vorliegende Studie aus dem Gebiet des Polizeipräsidiums Mittelhessen sollte vor dem Hintergrund der Diskussion eines möglichen Einsatzes der AAK-Messung im Strafverfahren erstmals beide Methoden im Praxiseinsatz unter realen Bedingungen vergleichen und die jeweiligen Fälle bis zu ihrem juristischen Abschluss verfolgen. 
Methoden. Für den Zeitraum eines Jahres wurde Beschuldigten, bei denen im Rahmen eines Strafverfahrens eine Blutentnahme (BE) zur BAK-Messung angeordnet war, eine zusätzliche freiwillige AAK-Messung auf dem „Dräger Evidential 7110“ angeboten. Die AAK-Messung sollte zum frühestmöglichen Zeitpunkt erfolgen, jedoch nicht zu einer Verzögerung der BE führen. Im Nachgang wurden von allen Strafverfahren die Ermittlungs- bzw. Gerichtsakten angefordert, um den Ausgang des Verfahrens zu analysieren.

Ergebnisse. In die Studie konnten 92 Fälle einbezogen werden. In 61 Fällen wurde ein Strafverfahren eröffnet. Davon konnten in 43 Fällen die Akten ausgewertet werden. 24 Fälle erfüllten a priori die Kriterien eines „einfachen und völlig eindeutigen Falls“ und wären im Nachhinein mit einer alleinigen AAK-Messung ausgekommen. In 55 Fällen konnten die Zeitdifferenzen zwischen AAK-Messung und BE berechnet werden. In 18 Fällen wurde die BE vor der AAK-Messung durchgeführt. Die verbliebenen 37 erbrachten eine Zeitersparnis zwischen 3 Minuten und 70 Minuten mit einem Mittelwert von 28 Minuten zu Gunsten der AAKMessung.

Schlussfolgerung. In keinem der Fälle, die vorher unter Zugrundelegung gängiger Kriterien für eine alleinige AAK-Messung im Strafverfahren geeignet erschienen, ergaben sich im Nachhinein Folgebehauptungen oder Fragestellungen, die eine Blutprobe hätte notwendig werden lassen. Allerdings ist die diesbezüglich bewertbare Fallzahl von 24 viel zu gering, um verlässliche Aussagen treffen zu können. Der erhoffte und häufig als Argument für eine AAK-Messung anstelle der BE vorgebrachte erhebliche Zeitgewinn ließ sich in der Studie nicht verifizieren.

\section{V114}

ADHS: Effekte einer nichtstimulanten medikamentösen Therapie auf verkehrsrelevante Leistungsfunktionen und das konkrete Fahrverhalten

\section{P. Strohbeck-Kuehner', D. Sabljic', B. Alm², G. Skopp', E. Sobanski \\ 'Institut für Rechts- und Verkehrsmedizin, Verkehrsmedizin, Heidel- berg, Deutschland, ${ }^{2}$ Zentralinstitut für Seelische Gesundheit, Mannheim, Deutschland}

Einleitung. Kraftfahrer mit einer Aufmerksamkeitsdefizit-/Hyperaktivitätsstörung (ADHS) weisen ein deutlich erhöhtes Unfallrisiko auf. Zudem werden sie auch gehäuft durch Verkehrsverstöße und durch die Teilnahme am Straßenverkehr unter Einfluss von Alkohol und Drogen auffällig. Ursache hierfür sind Aufmerksamkeitsstörungen, motorische Überaktivität und Impulsivität sowie die hohe Komorbidität mit Alkohol- und Drogenmissbrauch, die kennzeichnend für diese Störung sind. Studien aus dem amerikanischen Raum sowie eine eigene Studie konnten zeigen, dass sich eine medikamentöse Behandlung mit Stimulanzien positiv auf verkehrsrelevante psychophysische Leistungsfunktionen (visuelle Orientierung, Reaktionsfähigkeit und Daueraufmerksamkeit) und auf die Fahrleistung bei Fahrsimulatoren auswirkt. Über die Auswirkungen nichtstimulanter Medikamente auf die Leistungsfunktionen und insbesondere auf das konkrete Fahrverhalten ist dagegen nur wenig bekannt. Dargestellt werden die Effekte einer nichtstimulanten medikamentösen Behandlung auf verkehrsrelevante Leistungsfunktionen und das konkrete Fahrverhalten bei Erwachsenen mit einer ADHS im Vergleich zu einer unbehandelten Wartelisten-Kontrollgruppe.

Methoden. In einem Parallelgruppendesign mit Messwiederholung wurden mit 43, bis dahin unbehandelten Probanden eine verkehrspsychologische Testbatterie (ART 2020) sowie eine standardisierte Fahrverhaltensbeobachtung durchgeführt. Zudem mussten alle Probanden ein standardisiertes Fahrtentagebuch über einen Zeitraum von einer Woche führen. 22 Probanden erhielten Atomoxetin (ATX) und 21 Probanden blieben in der Warteliste. Drei Monate später wurde die Testung wiederholt.

Ergebnisse und Schlussfolgerung. Die Ergebnisse der Studien zeigen eine deutliche Verbesserung des konkreten Fahrverhaltens in der ATXGruppe im Vergleich zur Kontrollgruppe hinsichtlich Orientierung, risikobezogener Selbstkontrolle und Handlungszuverlässigkeit. Auch kam es zu einer Abnahme selbstberichteter kritischer Verkehrssituationen bei der ATX-Gruppe im Vergleich zur Kontrollgruppe. Auswirkungen auf die Ergebnisse der Leistungstests waren hingegen minimal. Im Unterschied zu Stimulanzien bewirkt ATX offensichtlich weniger eine Verbesserung der psychophysischen Leistungsfähigkeit als vielmehr eine Veränderung des Fahrstils.

\section{V115}

Eliminationskinetik und Erstellung von Formeln zur Berechnung von Erwartungswerten getränkecharakteristischer Aromastoffe zur Überprüfung von Nachtrunkbehauptungen

\section{K. Schulz', C. Erfurt' ${ }^{1}$ D. Thieme ${ }^{2}$}

'Institut für Rechtsmedizin der TU Dresden, Toxikologie, Dresden, Deutschland, ${ }^{2}$ Institut für Dopinganalytik und Sportbiochemie, Kreischa, Deutschland

Fragestellung. Über den Nachweis getränkecharakteristischer Aromastoffe Anethol, Eugenol, Carvon und Menthol (mit Neomenthol, Menthon und Isomenthon) in Serumproben zur Überprüfung von Nachtrunkbehauptungen wurde bereits berichtet. Es sollten die Eliminationskinetik der Aromastoffe abgeleitet und Formeln zur Berechnung der Erwartungswerte aufgestellt werden. Weiterhin sollten die 95\% Konfidenzintervalle (95\% Vertrauensbereiche) zur Berechnung der Erwartungswerte abgeleitet werden.

Methoden. Der Nachweis dieser Aromastoffe im Serum erfolgt mittels Gaschromatographie und massenspektrometrischer Detektion nach vorangegangener Headspace-Festphasenmikroextraktion (HS-SPMEGC-MS). Die Methode ermöglicht exzellente Nachweis- und Bestimmungsgrenzen von weniger als $5 \mathrm{ng} / \mathrm{ml}$ Serum. Zur Berechnung der 95\% Konfidenzintervalle wurde die Statistik-Software SPSS Statistics verwendet.

Ergebnisse. Am Beispiel des Menthols wurde die Eliminationskinetik der Aromastoffe abgeleitet und Formeln zur Berechnung von Erwartungswerten dieser Aromastoffe im Serum aufgestellt. Anhand dieser Formeln sind - bei Kenntnis der Eliminationskonstante kb und des Reduktionsfaktors rA - Erwartungswerte für die jeweiligen Aromastoffe im Serum zu jedem beliebigen Zeitpunkt innerhalb der Eliminationsphase berechenbar. Aus der Korrelation der Mess- und Erwartungswerte aus Trinkversuchsergebnissen wurden 95\% Konfidenzintervalle zur Berechnung der Erwartungswerte abgeleitet. Bei 100 Verkehrsteilnehmern mit behauptetem Konsum von Pfefferminzlikör wurden die Angaben zum Trinkverlauf überprüft und die Ergebnisse zusammenfassend dargestellt.

Schlussfolgerung. Die Berechnung der Erwartungswerte mit Vertrauensbereich ermöglicht eine Plausibilitätsprüfung der Angaben zum Trinkverlauf von Beschuldigten in Straßenverkehrsdelikten.

\section{V116}

Retrospektive Analyse von Blutproben auf synthetische Cannabinoide - Epidemiologie, Konsummuster und Ausfallerscheinungen

\section{N. Jänicke', W. Pogoda', C. Wunder', A. Paulke', S. Tönnes'}

'Institut für Rechtsmedizin, Abteilung Forensische Toxikologie, Frankfurt/ Main, Deutschland

Fragestellung. Synthetische Cannabinoide in Räuchermischungen werden durch routinetoxikologische Untersuchungen nicht erfasst, daher existieren nur vage Abschätzungen zur Epidemiologie und forensischen Relevanz z. B. für Verkehrsdelikte. Daher wurden Blutproben retrospektiv mit einer, im Gegensatz zu kontemporären epidemiologischen Studien, umfassenden analytischen Methode nachuntersucht und im Fallkontext ausgewertet. 
Methoden. Aus allen Blutproben des Jahres 2010 wurde eine repräsentative Stichprobe gezogen, die mit einer vollumfänglich validierten LCMS/MS Methode auf 30 synthetische Cannabinoide nachuntersucht wurde. Bei positiven Befunden wurden die Fallunterlagen zur weiteren Auswertung herangezogen.

Ergebnisse. Von bisher ausgewerteten 130 Proben wurde in 9 Fällen ein damals nicht nachgewiesener Konsum von synthetischen Cannabinoiden festgestellt (7\%). Es handelte sich um JWH-122 ( $\mathrm{n}=5,<0,1-3,4 \mathrm{ng} /$ $\mathrm{ml})$, JWH-250 ( $\mathrm{n}=3,2,7-86 \mathrm{ng} / \mathrm{ml}), A M-251 \quad(1,6 \mathrm{ng} / \mathrm{ml})$, JWH-o15 (<o,1 ng/ml), JWH-o18 (o,3 ng/ml), JWH-o81 (<0,1 ng/ml) und JWH-o73 $(<0,1 \mathrm{ng} / \mathrm{ml})$. In allen Fällen lag auch Konsum weiterer psychoaktiver Substanzen vor. Neben der erwarteten Kombination mit ausschließlich Cannabis $(\mathrm{n}=5)$ fand sich in jeweils einem Fall Amphetamin + Alkohol, Kokain + Alkohol, nur Alkohol und Bromazepam + Tramadol + Alkohol. Ausgeprägte von Polizei oder Arzt festgestellte Ausfallerscheinungen lagen nur in zwei Fällen vor.

Schlussfolgerungen. Die Auffälligkeiten hätten sich in Unkenntnis der Befunde zu synthetischen Cannabinoiden auch den in jedem Fall konsumierten weiteren Rauschmitteln zuordnen lassen, Schlussfolgerungen zu eigenständigen „Spice“-Wirkungen konnten nicht abgeleitet werden. Der geschätzten Prävalenz von $7 \%$ in 2010 steht in 2013 noch kein einziger positiver Fall entgegen (es wurden aber nur 3\% aller Blutproben diesbezüglich untersucht, Fälle mit ansonsten ungeklärter Symptomatik), was dafür spricht, dass synthetische Cannabinoide in forensischen Fällen heutzutage höchstens in Ausnahmefällen vorkommen.

\section{V117 \\ Screeningverfahren zum simultanen Nachweis von Opioiden und ihrer Metaboliten als therapiebegleitendes Konzept}

\section{K. Eckart', D. Breitmeier', J. Röhrich', K. Uebbing' ', R. Urban ${ }^{7}$ \\ 'Institut für Rechtsmedizin, Toxikologie, Mainz, Deutschland}

Einleitung. Opioide bzw. Opiate werden in erheblichem Umfang therapeutisch und missbräuchlich verwendet. Neben der großen Vielzahl an medizinisch eingesetzten Präparaten treten auch zunehmend chemisch modifizierte Varianten auf dem illegalen Markt auf. Daher sollte ein analytisches Verfahren entwickelt werden, dass den Nachweis möglichst vieler therapierelevanter Opioide ermöglicht, wobei auch neu und gegebenenfalls illegal auf den Markt kommende Substanzen und als wesentlicher Aspekt auch Phase-II-Metaboliten (meist Glucuronide) mit berücksichtigt werden.

Methode. Eine validierte Methode zur simultanen Bestimmung von Opioide in Serum und postmortalen Proben wird vorgestellt. Sie beinhaltet eine Aufreinigung des Probenmaterials zur Analytik mit einer C18-Festphasenextraktion. Der erhaltene Extrakt wird mittels Flüssigchromatographie-Tandem-Massenspektrometrie (UPLC 1290 Infinity und 6490 Triple Quad der Firma Agilent) im positiven Multiple Reaction-Monitoring-Modus auf 35 verschiedene Opioide bzw. deren Metabolite untersucht.

Ergebnisse und Diskussion. Es wurden in erster Linie Proben aus einer klinischen Studie auf Sufentanil, Fentanyl, Piritramid und Hydromorphon untersucht. Die festgestellten Spiegel lagen für Sufentanil und Fentanyl bei $>1 \mathrm{ng} / \mathrm{ml}$, für Piritramid zwischen $8-250 \mathrm{ng} / \mathrm{ml}$ und schließlich für Hydromorphon bei ca. $50 \mathrm{ng} / \mathrm{ml}$ Serum. Mit der Methode gelang es weiterhin Sufentanil in Post-mortem-Probenmaterial (Femoralblut, Herzblut, Urin, Liquor, Mageninhalt, Leber, Gehirn, Niere, Lunge und Muskel) empfindlich nachzuweisen. Mit dem dargestellten Verfahren konnte in einem Todesermittlungsverfahren eine hochdosierte Aufnahme von Sufentanil todeszeitnah nachgewiesen werden.

Schlussfolgerung. Das vorgestellte Screeningverfahren ermöglicht den sensitiven Nachweis der Analgetika im Serum und insbesondere in Post-mortem-Proben. Mit dieser Methodik konnten sowohl Serumproben von Schmerzpatienten therapiebegleitend untersucht werden als auch diverse postmortal gewonnene Proben im Zusammenhang mit Todesermittlungsverfahren. Die neue Methode erleichtert ferner die
Verifizierung positiver Immunoassay-Ergebnisse für Opiate durch eine hohe Empfindlichkeit und das breite Screening einschließlich seltener Substanzen.

\section{V118}

\section{Plötzlicher Tod unter Einfluss von Cannabis}

\section{B. Hartung' ', S. Kauferstein'², S. Ritz-Timme' ', T. Daldrup ${ }^{1}$}

'Heinrich-Heine-Universität, Institut für Rechtsmedizin, Düsseldorf, Deutschland, ${ }^{2}$ Johann Wolfgang Goethe-Universität, Institut für Rechtsmedizin, Frankfurt a. M., Deutschland

Einleitung. Pflanzliches Cannabis enthält über 60 verschiedene Cannabinoide, wobei $\Delta 9$-Tetrahydrocannabinol (THC) als das potenteste Cannabinoid angesehen wird. Während die schmerzlindernden Eigenschaften von Cannabis immer wieder hervorgehoben werden, werden die potenziell verheerenden Wirkungen von Cannabis auf das HerzKreislauf-System kaum wahrgenommen oder abgestritten. Es besteht jedoch wenig Zweifel daran, dass Cannabis bei vorbelasteten Konsumenten zu Herzrhythmusstörungen, Myokardinfarkten oder auch Apoplexen führen kann. Die Vorerkrankung des Herzens ist dabei in den meisten Fällen nicht bekannt.

Fallberichte. Wir stellen die Aufarbeitung der Todesfälle von zwei jungen Männern vor, die an den Folgen eines akuten Cannabiskonsums verstorben sind, wobei jeweils neben einer Obduktion auch toxikologische, feingewebliche, immunhistochemische und DNA-analytische Untersuchungen veranlasst worden sind.

Schlussfolgerung. In der Zusammenschau aller Befunde gehen wir davon aus, dass akuter Cannabiseinfluss auch ohne das Vorliegen relevanter Grunderkrankungen tödliche Folgen haben kann.

\section{V119}

\section{H1-Antihistaminika als „K.-o.-Mittel“?}

\section{Huppertz', V. Auwärter', S. Vogt ${ }^{1}$}

'Institut für Rechtsmedizin, Forensische Toxikologie, Freiburg, Deutschland

Einleitung. Immer wieder kommt es zu Beibringungen von Medikamenten oder Drogen, wobei sich zum Teil weitere kriminelle Handlungen anschließen. In den meisten nachgewiesenen Fällen handelt es sich bei den verabreichten Substanzen um Benzodiazepine oder andere Hypnotika. Eine Verabreichung von Gamma-Hydroxy-Buttersäure (GHB) kann nur relativ selten nachgewiesen werden, was sowohl auf die kurze Nachweisdauer als auch auf das endogene Vorhandensein zurückzuführen ist. Die Beibringung von $\mathrm{H}_{1}$-Antihistaminika der ersten Generation, wie Diphenhydramin (DPH) oder Doxylamin wurde zwar in der wissenschaftlichen Literatur beschrieben, spielt aber eher eine untergeordnete Rolle.

Methoden. Zur Untersuchung gelangten Blut- und Urinproben zweier Frauen (17 J. und $31 \mathrm{~J}$., einander nicht bekannt und in unterschiedlichen Gruppen unterwegs), welche bei einer Karnevalsveranstaltung kollabiert waren und die Vermutung äußerten, „etwas ins Glas“ bekommen zu haben. Die Untersuchungen erfolgten nach Routineverfahren mit Immunoassay, GC-MS, LC-MSn und HPLC-DAD.

Ergebnisse. Bei beiden Personen lag eine deutliche Alkoholisierung vor. Weitere toxikologische Untersuchungen ergaben in allen Proben einen positiven Nachweis für DPH. Eine gewollte Einnahme wurde verneint. Die Untersuchung auf Metabolite des DPH, insbesondere auf Diphenylmethoxyessigsäure (DPMA) und dessen Konzentrationsverhältnis zu DPH führte zu der Annahme, dass die Aufnahme des DPH in engem zeitlichem Zusammenhang mit der Probennahme stattgefunden haben muss.

Schlussfolgerung. Wenn auch bislang selten beschrieben, scheinen $\mathrm{H}_{1-}$ Antihistaminika der ersten Generation als K.-o.-Mittel geeignet, insbesondere wenn gleichzeitig Alkohol aufgenommen wird. Hierbei ist die 
relativ einfache Verfügbarkeit entsprechender Präparate zu bedenken. Es erscheint daher sinnvoll und notwendig, in Verdachtsfällen auch auf diese Stoffe zu untersuchen.

\section{V120 \\ Positionale Asphyxie aufgrund einer Intoxikation mit MDPV, Methoxetamin und Doxepin? \\ A.H. Ewald', M. Kettner', P.H. Schmidt \\ IInstitut für Rechtsmedizin der Universität des Saarlandes, Homburg, Deutschland}

Fragestellung. Ein 27 Jahre alter Mann wurde leblos mit dem Kopf in Tieflage in hyperextendierter Position aufgefunden. Sein Gesicht habe auf einem Stuhl aufgelegen, der sich auf einer Treppe des von ihm bewohnten Hauses befand. Neben körperlichen Defekten könnte eine solch hilflose Situation auch durch eine Intoxikation verursacht werden. In der Wohnung des Verstorbenen fanden sich als Hinweis auf eine Substanzeinnahme $300 \mathrm{~mL}$ GBL und geringe Mengen Amphetamin. Methoden. Es wurde eine vollständige Autopsie durchgeführt, zu der auch eine toxikologische Untersuchung gehört. Diese beinhaltet $\mathrm{zu}$ nächst eine immunologische Voruntersuchung. Anschließend wurden Extrakte der Körperflüssigkeiten, -gewebe mittels GC-MS und LC-MS/ MS untersucht. Urin und Blut wurden spezifisch auf GHB, GBL, und 1,4-Butandiol mittels LC-MS/MS untersucht. Relevante nachgewiesene Substanzen wurden mittels GC-MS bzw. LC-MS/MS quantifiziert.

Ergebnisse. Bei der Obduktion fand sich ein ausgeprägtes Totenflecksystem, eine prall gefüllte Harnblase sowie flüssiges Leichenblut. Be der toxikologischen Untersuchung konnten weder GHB, GBL, 1,4-butanediol noch Amphetamin nachgewiesen werden. Stattdessen fanden sich die Designerdrogen Methylendioxypyrovalenon (MDPV), Methoxethamin, Doxepin und Nordoxepin.

Schlussfolgerungen. Die Konzentrationen der nachgewiesenen Substanzen Methoxetamin, Doxepin und insbesondere MDPV sind potenziell geeignet, eine letale Intoxikation erklären zu können. Zumindest sind sie jedoch unserer Meinung nach geeignet, die Inkapazitation mit anschließender positionaler Asphyxie zu erklären.

\section{V121}

Zeiten ändern sich: Rechtsmedizin und Radiologie bilden eine neue Spezialisierung $=$ Forensische Bildgebung!

T. Germerott', M.J. Thali', P. Flach ${ }^{2}$

'Medizinische Hochschule Hannover, Institut für Rechtsmedizin, Hannover, Deutschland, ${ }^{2}$ Universität Zürich, Institut für Rechtsmedizin, Zürich, Schweiz

Einleitung. Durch die zunehmende Implementierung bildgebender Verfahren, vorrangig der Computertomographie, in die rechtsmedizinische Routine zahlreicher Institute weltweit ist die postmortale Bildgebung heute ein wichtiger Bestandteil der modernen Rechtsmedizin. Methoden. Basierend auf zahlreichen wissenschaftlichen Arbeiten hat sich die postmortale Computertomographie, insbesondere im Hinblick auf den Nachweis von Gasansammlungen im Leichnam, Frakturen und Lokalisation von Fremdkörpern als der herkömmlichen Obduktion überlegen herauskristallisiert. In Abhängigkeit von der jeweiligen Fragestellung sind die postmortale Angiographie und die postmortale Magnetresonanztomographie wertvolle ergänzende Methoden für die Befunderhebung.

Ergebnisse. Aufgrund der bisherigen Erkenntnisse bezüglich der postmortalen Bildgebung ist eine Subspezialisierung im Fachgebiet der Rechtsmedizin absehbar. Essenziell für eine qualitativ hochwertige Fallanalyse ist die Zusammenführung der Bildgebungsbefunde und der autoptisch erhobenen Befunde. Dieses wird durch eine enge $\mathrm{Zu}-$ sammenarbeit und intensive Kommunikation zwischen Rechtsmedizi- nern und (in der Rechtsmedizin tätigen) Radiologen erreicht. Wesentliche Voraussetzungen hierfür sind seitens des Radiologen grundlegende rechtsmedizinische Kenntnisse bezüglich Definitionen von Todesart und Todesursache, postmortaler Veränderungen und der Befunderhebung in Bezug auf forensische Fragestellungen. Andererseits sind jedoch auch seitens der rechtsmedizinischen Ärzte grundlegende Kenntnisse der radiologischen Verfahren und deren Möglichkeiten anzustreben. Schlussfolgerung. Anhand von verschiedenen Aspekten der postmortalen Bildgebung sollen die Notwendigkeit und mögliche Wege der Verknüpfung von radiologischem und rechtsmedizinischem Wissen mit dem Ziel einer qualitativ hochwertigen und umfassenden Fallbearbeitung aufgezeigt werden.

\section{V122}

Unterscheidung von Heroin und Kokain mittels spektraler Bildgebung im Dual-Energy-CT

\section{J. Grimm 1,2, R. Wudy', E. Ziegeler', S. Wirth', S. Grabherr' , F. Fischer', M. Scherr ${ }^{3}$}

'Universitätsklinik Lausanne, Institut für Diagnostische und Interventionelle Radiologie, Lausanne, Schweiz, ${ }^{2}$ Universität Lausanne, Institut für Rechtsmedizin Lausanne-Genf, Lausanne, Schweiz, ${ }^{3}$ Klinikum der Ludwig-Maximilans-Universität München, Institut für Klinische Radiologie, München, Deutschland, ${ }^{4}$ Ludwig-Maximilians-Universität, Institut für Rechtsmedizin, München, Deutschland

Fragestellung. Die Unterscheidung von Heroin und Kokain bei Bodypackern kann klinisch und forensisch von großer Bedeutung sein. Ziel dieser Studie war zu prüfen, ob sich Heroin und Kokain mittels spektraler Bildgebung im Dual-Energy-CT in vitro unterscheiden lassen.

Methoden. 20 Proben von Heroin und Kokain verschiedener Konzentrationen wurden standardisiert mit $1000 \mathrm{~N}$ komprimiert und mittels 64 Zeilen Dual-Energy-CT untersucht. Die Dichte der Proben in Hounsfield-Einheiten (HU) und die spektralen Kurven wurden evaluiert. Die Ergebnisse hieraus wurden prospektiv an 6 originalen Packs aus einem Bodypacker getestet. Für die statistische Auswertung wurde Wilcoxon's Test verwendet.

Ergebnisse. Werte sind angegeben als Median und Range. Unter standardisierter Kompression war die Dichte der Kokainproben [-29,87 HU $(-125,85 ; 16,16 \mathrm{HU})]$ größer als die der Heroinproben [-184,37 HU $(-199,81 ;-159,25 \mathrm{HU}) ; \mathrm{p}<0,01]$. Der durchschnittliche Steigungsfaktor der spektralen Kurve war negativ für Kokain mit -2,36 HU/keV (-7,15; $-0,67 \mathrm{HU} / \mathrm{keV})$ und positiv für Heroin mit 1,75 HU/keV $(1,28 ; 2,5 \mathrm{HU} /$ $\mathrm{keV}) ; \mathrm{p}<\mathrm{o}, \mathrm{ol}$. Während eine korrekte Einordnung der sechs originalen Bodypacks anhand der Dichte in HU nicht gelang, wurden alle 6 Proben anhand des durchschnittlichen Steigungsfaktors der spektralen Kurve korrekt als Kokain klassifiziert. Im Gegensatz zur Dichte war der durchschnittliche Steigungsfaktor der spektralen Kurve unabhängig von Konzentration und Kompression der hier untersuchten Proben.

Schlussfolgerungen. Während ihre Dichte in HU in hohem Maß von Konzentration und Kompression der untersuchten Kokain- und Heroinproben abhängt, scheint eine Unterscheidung anhand des durchschnittlichen Steigungsfaktors ihrer spektralen Kurve vielversprechend. Dieser ist im hier untersuchten Rahmen unabhängig von Kompression und Konzentration der Proben. 


\section{V123}

\section{Einfluss der Kompression von Drogen und Streckmitteln auf das} Materialverhalten im Dual-Energy-CT

\section{P. Laberke', J. Fornaro', S. Blum', R. Hausmann', S. Wildermuth', S. Leschka' ${ }^{1}$ Institut für Rechtsmedizin, KSSG, St. Gallen, Schweiz, ${ }^{2}$ Institut für Radio- logie, KSSG, St. Gallen, Schweiz}

Einleitung. In bisherigen Studien konnte gezeigt werden, dass mittels eines Low-dose-Dual-Energy-CT eine Detektion und Unterscheidung von Heroin und Kokain außerhalb des Körpers, in Leichen und beim Lebenden grundsätzlich möglich ist. Der Dual-Energy-Index (DEI) zeigt dabei abhängig von Heroin und Kokain in Bodypacks eine gegenläufige Entwicklung, die bisher zuverlässig für die Zuordnung herangezogen werden konnte.

Methoden. Bei den chemischen Analysen der ausgeschiedenen Bodypacks fanden sich in allen bisher untersuchten Fällen Übereinstimmungen des aufgrund des DEI anzunehmenden Inhalts. Zur Abklärung des unterschiedlichen Dual-Energy-Verhaltens von Kokain- und Heroinmischungen wurden neben den reinen Drogen auch die einzelnen Streckmittel bezüglich ihres individuellen DEI untersucht. Da bei der toxikologischen Aufarbeitung von asservierten Drogenpäckchen zudem eine sehr hohe Kompression des Inhalts festgestellt werden konnte, stellte sich nun die Frage, inwieweit die aufgefallenen Veränderungen im DEI auch durch den Kompressionsgrad der Substanzen erklärt bzw. beeinflusst werden. Hierzu wurde der DEI von Heroin, Kokain und den gängigsten Streckmitteln in Reinform unter verschiedener Kompression und bei verschiedenen Röhrenspannungen $(80-140 \mathrm{kV})$ verglichen. Schlussfolgerung. Die Ergebnisse werden vorgestellt und diskutiert.

\section{V124}

Ein System für die virtuelle Autopsie unter Verwendung von chirurgischen Navigationstechniken

\section{Ebert', T. Ruder', S. Ross', W. Schweitzer', R. M. Martinez', M. Thali', G. Ampanozi}

'Institut für Rechtsmedizin Zürich, Virtopsy, Zürich, Deutschland

Einleitung. Medizinische Bildmodalitäten, insbesondere die Computertomographie (CT), werden immer häufiger bei rechtsmedizinischen Untersuchungen eingesetzt. Unserer Erfahrung nach empfinden viele Rechtsmediziner mit wenig oder keiner Erfahrung in der diagnostischen Radiologie es als schwierig, sich in medizinischen Schnittbildern zu orientieren und die anatomischen Zusammenhänge zu erkennen. Dies ist insbesondere deshalb wichtig, da die Bilder unter anderem verwendet werden, um Obduktionen zu planen und durchzuführen. Um diesem Problem zu begegnen, haben wir ein computergestütztes System entwickelt, welches es erlaubt, die Schnittebene eines CT-Datensatzes mit Hilfe eines chirurgischen Lokators zu definieren und Bildschirmfotos für Dokumentationszwecke zu erstellen.

Methoden. Das System verwendet Techniken aus der computerassistierten Chirurgie und besteht aus den folgenden Komponenten: einem Computersystem, einem Tracker, einem chirurgischen Lokator, einem Wandbildschirm und reflektiven optischen Markern. Der Arbeitsablauf ist folgender: Mindestens vier Marker werden auf den Verstorbenen geklebt, ein CT-Scan wird erstellt und an den Navigationscomputer geschickt. Dieser berechnet die Registrierung automatisch. Nun kann mit Hilfe eines getrackten Lokators die Schnittebene bestimmt werden. Ein Laser projiziert die Position dieser Ebene auf den Körper.

Diskussion. Das präsentierte System hilft, Rechtsmedizin und forensische Radiologie näher zusammenzubringen. Für das Planen von Obduktionen, das Demonstrieren radiologischer Befunde für medizinische Laien und das Unterrichten könnten derartige Systeme in Zukunft hilfreich sein.

\section{V125}

Erhebung der Akzeptanz von anonymisierten und patientenspezifischen 3D-Modellen zur Dokumentation klinisch-forensischer Befunde für rechtsmedizinische Gutachten

J. Höller', M. Urschler, ${ }^{1,2}$, E. Scheurer,3

'Ludwig Boltzmann Institut für Klinisch-Forensische Bildgebung, Graz, Österreich, ${ }^{2}$ Technische Universität, Institut für Maschinelles Sehen und Darstellen, Graz, Österreich, ${ }^{3}$ Medizinische Universität, Graz, Österreich

Einleitung. Forensische Auswertungen sowohl von äußerlich ersichtlichen als auch von inneren, lediglich durch MR- oder CT-Aufnahmen sichtbar zu machenden, Verletzungsbefunden, erfordern eine Dokumentation und Darstellung dieser Daten zur Speicherung, Aufbereitung und Präsentation vor Gericht im Rahmen von Gutachten. Insbesondere die übersichtliche und auch für medizinische Laien verständliche $3 \mathrm{D}$ Visualisierung von Befunden beim Lebenden ist ein Thema, welches in den letzten Jahren auf steigendes Interesse stößt.

Methoden. Mögliche Ansätze zur Erstellung von 3D-Modellen umfassen den Einsatz von Laserscannern oder photogrammetrischen Aufbauten, zwei Techniken die sowohl teuer als auch aufwändig sind. Wir haben in den vergangenen Jahren kostengünstigere Alternativen zur Erzeugung von anonymisierten generischen und patientenspezifischen $3 \mathrm{D}$-Modellen vorgestellt, welche einerseits aus vorgefertigten, eingeschränkt parametrisierbaren Basismodellen und andererseits mittels Structured-Light 3 D-Rekonstruktionen des Patienten unter Nutzung des Microsoft Kinect Sensors erstellt wurden. In der vorliegenden Arbeit untersuchen wir die Akzeptanz der Verwendung von generischen bzw. patientenspezifischen $3 \mathrm{D}$-Modellen im Umfeld des Gerichts. Dazu haben wir einen anonymisierten Online-Fragebogen mit 17 Fragen ausgearbeitet und an Juristen verteilt. Die Fragen umfassen den Vergleich der vorgeschlagenen 3D-Modelle mit einer herkömmlich verwendeten zweidimensionalen schematischen Körperskizze im Sinne der Übersicht und Lokalisierung von Verletzungen, die Beurteilung der Sicherung der Persönlichkeitsrechte, die Möglichkeiten zur Darstellung vor Gericht, die Bewertung der Fälschungssicherheit, sowie die Einschätzung der Beeinflussbarkeit durch die Darstellungsform.

Ergebnisse. Unsere ersten Ergebnisse zeigen, dass 3D-Modelle gut zur Darstellung von forensisch relevanten Informationen geeignet sind, vor allem in Bezug auf die Lokalisation von Befunden. Die nicht ausreichende Wahrung der Persönlichkeitsrechte und die mögliche Beeinflussung durch die Darstellung werden bei personenspezifischen $3 \mathrm{D}$ Modellen jedoch als kritisch gesehen, selbst nach Anonymisierung z. B. durch einen Balken.

Schlussfolgerung. Anonyme generische $3 \mathrm{D}$-Modelle zeigen die beste Eignung für Dokumentation und Darstellung, wobei vor Gericht auch interaktive Präsentationen der Daten für die Befragten vorstellbar sind.

\section{V126}

Die Magnetresonanztomographie des Beckenkamms als mögliches Merkmal für die Altersdiagnostik bei U20-Fußballspielern

\section{Wittschieber', V. Vieth², M. Timme', J. Dvorak ${ }^{3}$, A. Junge ${ }^{4}$, A. Schmeling ${ }^{7}$}

'Universitätsklinikum Münster, Institut für Rechtsmedizin, Münster, Deutschland, ${ }^{2}$ Universitätsklinikum Münster, Institut für Klinische Radiologie, Münster, Deutschland, ${ }^{3}$ Schulthess Klinik, Abteilung für Neurologie, Zürich, Schweiz, ${ }^{4}$ Schulthess Klinik, FIFA Medical Assessment and Research Centre, Zürich, Schweiz

Einleitung. Die Altersschätzung lebender Personen spielt sowohl in den forensischen Wissenschaften als auch in der Sportmedizin eine immer bedeutsamere Rolle. Speziell im Fußball sind seit langer Zeit bereits altersspezifische Turniere etabliert, um gleiche Chancen für alle Teilnehmer zu garantieren. Allerdings sollten Altersschätzungen hierbei nicht auf Methoden beruhen, die eine Strahlungsexposition der untersuchten Personen voraussetzt. Die vorliegende Studie beschäftigt sich daher mit 
der Frage, ob die strahlenfreie Magnetresonanztomographie (MRT) der bislang noch relativ wenig für die Altersdiagnostik untersuchten Beckenkamm-Apophyse bei der Bewertung der Skelettreife von U2OFußballspielern von Nutzen sein könnte.

Methoden. In einem prospektiven Ansatz wurden deshalb von 152 gesunden männlichen Fußballspielern zwischen 18 und 22 Jahren Gradienten-Echo-GE-3D-Sequenzen des gesamten Beckens erstellt und die knöcherne Entwicklung der Beckenkamm-Apophysen mithilfe eines etablierten Klassifikationssystems mit 4 Reifungsstadien bewertet.

Ergebnisse. In allen Fällen war eine eindeutige Stadienbestimmung möglich. Die Analyse der erhaltenen statistischen Parameter zeigte von Stadium zu Stadium einen steten Anstieg der Altersmediane um ca. 1 Jahr. Allerdings konnten die Parameter in der untersuchten Altersgruppe zu keiner weiteren Differenzierung zur Bewertung der Skelettreife beitragen.

Schlussfolgerung. Es ist somit festzuhalten, dass die MRT des Beckenkamms zwar grundsätzlich für die Altersdiagnostik geeignet ist, aber weitere Untersuchungen, insbesondere in den Altersgruppen zwischen 10 und 20 Jahren, notwendig sind, um die Möglichkeiten dieser Methodik voll auszuschöpfen und für die Altersschätzung am Lebenden zu etablieren.

\section{V127 \\ Mobile erweiterte Realität („,augmented reality“, AR): erste Erfah- rungen im Obduktionssaal}

\section{A. Sassenberg', D. Simons' ${ }^{2}$ I. Reicht ${ }^{2,3}$, H.-P. Schlemmer ${ }^{2}$, H.-P. Meinzer ${ }^{3}$, M.} Müller ${ }^{3}$, M. Fangerau ${ }^{3}$, K. Yen ${ }^{1}$

IInstitut für Rechtsmedizin und Verkehrsmedizin Heidelberg, Heidelberg, Deutschland, ${ }^{2}$ Deutsches Krebsforschungszentrum, Abt. f. Radiologie $\left(\mathrm{E}^{010}\right)$, Heidelberg, Deutschland, ${ }^{3}$ Deutsches Krebsforschungszentrum, Abt. f. Medizinische und Biologische Informatik $\left(\mathrm{E}^{130}\right)$, Heidelberg, Deutschland

Einleitung. Der Begriff „Erweiterte Realität (AR)“ beschreibt im Allgemeinen die computergestützte Erweiterung der Wahrnehmung und wird im medizinischen Kontext bereits vielfach eingesetzt. Im Vordergrund stehen computergestützte Operationstechniken, Biopsien oder auch Simulatoren, die das Trainieren von invasiven Techniken erleichtern sollen. Prinzipiell ist die Anwendung von AR im Obduktionssaal denkbar. Besonders interessant kann hierfür unter anderem die dreidimensionale Darstellung von Knochenbrüchen an Stellen sein, die während der Obduktion schwer zugänglich sind. Ein weiterer Vorteil ist die dreidimensionale Echtzeit-Darstellung von Organen, welche eine kontaminationsfreie und relativ unkomplizierte Entnahme von histologischen und chemisch-toxikologischen Proben vor Obduktion unterstützt. Außerdem kann die Lage von Fremdmaterial im selben Schritt geprüft werden. Im klinisch-forensischen Kontext ist hier insbesondere die Lage von nach medizinischer Indikation eingebrachten Mitteln ( Tuben, Zugänge, Implantate etc.) überprüfbar.

Methoden. Um diese Aufgabenstellung in den Obduktionssaal überführen zu können, kommt die mobile AR-Softwareanwendung „SurgeryPad“, entwickelt in der Abteilung MBI, zum Einsatz. Dazu müssen im Vorfeld der Obduktion zwei Vorraussetzungen geschaffen werden. Zunächst, wird eine Ganzkörper-Computertomographie (CT) durchgeführt. Vor der CT werden um die interessierenden Stellen auf die Haut röntgendichte Marker (Rebeck Patientenmarker, Fobeck GbR) aufgeklebt. Im zweiten Schritt werden die CT-Schnittbilder mit der Open-source-Software „Medical Imaging Interaction Toolkit (MITK) Workbench“ auf einem PC nachbearbeitet, um die einzelnen Organe dreidimensional zu segmentieren. Unter diesen Voraussetzungen kann während der Obduktion ein Tablet-Computer (iPad 3, Apple Inc.) über die Oberfläche des Leichnams geführt werden, wobei die Tablet-Kamera zum Leichnam gewandt ist. Mit der „SurgeryPad“-App werden die Kamerabilder mit den im Vorfeld aufgenommenen CT-Bildern in Echtzeit registriert und die zuvor segmentierten Organe und Strukturen des Körpers in relativer Position zur Kamera am Display dargestellt.
Schlussfolgerung. Im Rahmen des Vortrags sollen erste Erfahrungen und Ergebnisse unserer Untersuchungen mit mobiler erweiterter Realität vorgestellt werden.

\section{V128 \\ Virtobot 2.0 - ein System für robotergestützte Photogrammetrie, Oberflächendokumentation und Biopsie}

L. Ebert', W. Ptacek' ${ }^{2}$, R. M. Martinez', R. Breitbeck', M. Fürst' ${ }^{2}$, M. Thali'

IInstitut für Rechtsmedizin Zürich, Virtopsy, Zürich, Schweiz, ${ }^{2}$ ACMIT Austrian Center for Medical Innovation and Technology, Medical Robots, Wiener Neustadt, Österreich

Einleitung. In der Routine der rechtsmedizinischen Bildgebung gibt es Arbeitsabläufe, welche repetitiv sind, oder welche hohe Genauigkeit benötigen. Zu diesem Zweck wurde am Institut für Rechtsmedizin in Bern der Virtobot entwickelt, welcher automatisierte Oberflächenscans erstellen kann, sowie bildgestützt Koaxialnadeln setzen kann, um semiautomatisch Gewebeproben zu entnehmen. Die Erfahrungen aus dem ersten Virtobot flossen in die Entwicklung des zweiten Virtobot, welcher hier vorgestellt wird und am Institut für Rechtsmedizin in Zürich im Einsatz ist.

Technik. Der zweite Prototyp des Virtobot kann mit Hilfe eines vollautomatischen Werkzeugwechsels eine automatische Photogrammetrie, einen Oberflächenscan sowie eine CT gestützte Biopsie durchführen. Dazu ist der Roboter mit einer passiven Trackingkamera gekoppelt, welche die Position des Roboters relativ zum Verstorbenen vermisst. Um den Arbeitsablauf zu vereinfachen haben wir die Software neu entwickelt und eine automatische Registrierung hinzugefügt.

Diskussion. Die aktuelle Version des Virtobot lässt sich durch die einfachere Bedienung besser in den Arbeitsablauf integrieren. Durch die weitergehende Automatisierung können Arbeitsabläufe beschleunigt werden.

\section{V129}

Digitale Bilderfassung des nahen Infrarotspektrums (NIR) für Anwendungen in den Bereichen Rechtsmedizin/Biologische Spurenkunde/Kriminaltechnik

M.M. Schulz', T. Gilg', M. Graw', M. Hein', P. Kühnel', V. Sterzik ${ }^{3}$

${ }^{1}$ Institut für Rechtsmedizin, München, Deutschland, ${ }^{2}$ Kriminalpolizeiinspektion, Augsburg, Deutschland, ${ }^{3}$ Institut für Rechtsmedizin, Würzburg, Deutschland

Einleitung. Die visuelle Wahrnehmung des menschlichen Auges ist auf Reflektions- bzw. Absorptionseigenschaften im Wellenlängenbereich zwischen ca. 400 und $700 \mathrm{~nm}$ beschränkt. Im unsichtbaren, nahen Infrarotbereich NIR (ca. 800-1400 nm) weisen viele Stoffe ein unterschiedliches Verhalten auf und es ergeben sich neue Bildeindrücke, die sich in vielerlei Hinsicht als sehr nützlich erweisen, beispielsweise bei der Differenzierung von Blutspuren auf dunklen Textilien. Nach ersten Untersuchungen mittels filmbasierter Infrarotfotographie bereits in den dreißiger Jahren des vergangenen Jahrhunderts wurden sporadisch durch Rechtsmediziner weitere Aspekte dieses Phänomens ermittelt, teils auch mit IR-Bildwandlern.

Methoden. Nunmehr zur Verfügung stehende technische Lösungen ermöglichen eine einfache, direkte, bildmäßige Erfassung und Betrachtung, auch im Hinblick auf etwas in Vergessenheit geratene, bisher beschriebene, kriminalistische Anwendungen.

Schlussfolgerung. Im Rahmen des Vortrags werden zeitgemäße Techniken zur bildmäßigen Erfassung und digitalen Dokumentation des NIRSpektrums vorgestellt und an Hand von Beispielen die Anwendungsmöglichkeiten demonstriert. 


\section{Poster der 92. Jahrestagung der Deutschen Gesellschaft für Rechtsmedizin}

P1

\section{Humane Schädel-Hirn-Traumen - Beteiligung purinerger Rezepto- ren an der Astrogliose}

\author{
K. Bremicker', M. Grohmann', K. Becker', B. Ondruschka' ${ }^{2}$, J. Dreßler', M. Weber \\ H. Franke \\ 'Universität Leipzig, RB-Institut für Pharmakologie und Toxikologie, Leip- \\ zig, Deutschland, ${ }^{2}$ Universität Leipzig, Institut für Rechtsmedizin, Leipzig, \\ Deutschland, ${ }^{3}$ Universität Halle, Institut für Rechtsmedizin, Halle (Saale), \\ Deutschland
}

Einleitung. Schädel-Hirn-Traumen (SHT) stellen insbesondere bei jungen Erwachsenen eine der häufigsten Ursachen für lebenslange schwere Behinderungen oder Tod dar. Die traumatischen Verletzungen führen zu einer Vielzahl zellulärer Veränderungen im menschlichen Gehirn, wobei die Kenntnis der auslösenden Faktoren sowie die Beteiligung spezifischer Rezeptoren und Transduktionsmechanismen für die Optimierung einer zielgerichteten therapeutischen Intervention von eminenter Bedeutung sind. In vorangegangenen In-vitro-Studien sowie In-vivo-Untersuchungen an Ratten konnten wir die Beteiligung purinerger Rezeptoren, insbesondere des $\mathrm{P}_{2} \mathrm{Y}_{1}$ Rezeptor(R)-Subtypes, an der Entstehung und Aufrechterhaltung der reaktiven Astrogliose sowie in antiapoptotischen Prozessen nach mechanischer Schädigung nachweisen. Ziel der aktuellen Studie ist es, (i) die Übertragbarkeit dieser Ergebnisse auf das menschliche Gehirn zu prüfen, sowie (ii) postmortale Veränderungen ausgewählter Markerproteine in Bezug zum Unfallzeitpunkt und Todeszeitpunkt zu setzen.

Methodik. Für die Untersuchungen wurde postmortales Hirngewebe von SHT-Patienten im Vergleich zu einer Kontrollgruppe genutzt. Die Charakterisierung der astroglialen Reaktion im Bereich der traumatischen Schädigung im präfrontalen Cortex erfolgte mittels immunhistochemischer und histologischer Färbungen, Western Blot sowie PCRTechniken. Die statistische Auswertung der ermittelten Daten wurde in Abhängigkeit von den Überlebenszeiten jeweils im Vergleich zur Kontrollgruppe durchgeführt.

Ergebnis. Die Analyse der Ergebnisse vorliegender Studie ergab, dass SHT beim Menschen in Abhängigkeit von der Überlebenszeit zu einer signifikanten Erhöhung (i) der GFAP-positiven Zellen [GFAP-Immunoreaktivität (-IR)] sowie (ii) des GFAP-Gehalts (Protein) führt. In Abhängigkeit vom posttraumatischen Intervall kommt es weiterhin (iii) zu einer verstärkten $\mathrm{P}_{2} \mathrm{Y}_{1} \mathrm{R}-$ Expression (IR, Protein). Dieser Rezeptorsubtyp wird auf (iv) GFAP-positiven Astrozyten und MAP2-positiven Neuronen exprimiert. Darüber hinaus konnte (v) das Vorhandensein weiterer $\mathrm{P}_{2} \mathrm{X} / \mathrm{Y}$ Subtypen auf glialen Zellen sowie (vi) das Vorhandensein verschiedener Apoptosemarker (aktive Caspase 3, TUNEL) nachgewiesen werden. (vii) In Abhängigkeit vom Todeszeitpunkt kommt es zur Veränderung ausgewählter Markerproteine, z. B. GFAP, interessant für die forensische Wundaltersdiagnostik.

Schlussfolgerung. Die Studie zeigt erstmalig die direkte Beteiligung des $\mathrm{P}_{2} \mathrm{Y}_{1} \mathrm{R}-\mathrm{Subtypes}$ an der durch ein SHT verursachten Astrogliose beim Menschen, was auf eine spezifische Rolle der purinergen Rezeptoren in Gliazellen bei physiologischen und pathophysiologischen Prozessen hinweist und sie zu einem interessanten Ziel therapeutischer Interventionen machen kann.

\section{P2}

Fibrinogen staining as a marker for blood-brain barrier breakdown indicating death from epilepsy in children

\author{
S. Ahlström?', P. Saukko', H. Kalimo' \\ 'Universität von Turku, Rechtsmedizin, Turku, Finland
}

Introduction. The diagnosis of death from epilepsy poses a classic problem in forensic pathology. The morphological findings are mostly scarce and without an eyewitness to report a seizure, there may be nothing indicating epilepsy [1]. During epileptic seizures, there is a significant rise in blood pressure, which causes a breakdown of the bloodbrain barrier (BBB) with a consequent extravasation of plasma proteins, which are drained into the cerebrospinal fluid (CSF). From the CSF flowing in the subarachnoidal space around cerebellum, plasma proteins are taken up by cerebellar Purkinje cells (PC). Previous research has shown that fibrinogen uptake by $\mathrm{PC}$ is a good marker of a BBB breakdown [2]. We describe two cases of small children found dead, where the autopsy showed no apparent cause of death.

Child 1. A 4-year-old girl was found dead in bed one morning. During the last few days, she had been unusually tired. She had also wet her pants. The forensic autopsy showed nothing particular. The neuropathological examination disclosed signs of acute global cerebral ischemia and numerous strongly fibrinogen positive PC indicating a breach of the BBB.

Child 2. A 2,5-month-old girl, who had been taken into the care of a municipal children's home because of her parent's drug abuse, was found dead at 4.50 a.m. The forensic autopsy revealed nothing particular. The neuropathological examination showed identical alterations as in child 1.

Discussion. The symptoms described for child 1 may well have been minor epileptic fits. Thus, with no other plausible cause of death, based on the neuropathological findings together with the history, death was attributed to epilepsy. The age and history of child 2 considered, the most likely cause for the breakdown of the BBB would be an epileptic seizure. The mother's drug abuse during pregnancy may have caused cerebral changes that could make the child more susceptible to epileptic fits. These two cases show that the fibrinogen staining of cerebellum may be of considerable significance when investigating cases of sudden unexpected death among small children.

1. Saukko P, Knight B (2004) Knight's Forensic Pathology 3rd edition. London

2. Ikegaya $\mathrm{H}$ et al (2004) Accumulation of plasma proteins in Purkinje cells as an indicator of blood-brain barrier breakdown. Forensic Sci Int 16:146(2-3):121-4

\section{P3}

Metastasiertes Karzinom der Adenohypophyse - Kasuistik

\section{U. Flössel', M. Sergon², U. Schmidt', C. Erfurt'}

${ }^{1} \mathrm{TU}$ Dresden, Institut für Rechtsmedizin, Dresden, Deutschland, ${ }^{2}$ Universitätsklinikum Dresden, Institut für Pathologie, Dresden, Deutschland

Einleitung. Maligne Tumoren der Adenohypophyse sind extrem selten und häufig nur aufgrund der Metastasierung von Adenomen zu unterscheiden.

Fallbericht. Eine 59 Jahre alte Frau wurde nach einem Sturz mit einer Rippenserienfraktur und schmalem Pneumothorax zur stationären Behandlung eingewiesen. Klinisch waren eine infantile Cerebralparese sowie ein Hypophysenadenom bekannt, welches in der Vergangenheit operativ behandelt worden sei. Sieben Tage nach dem Sturzereignis verstarb sie unerwartet während des stationären Aufenthalts.

Ergebnisse. Im Rahmen der Obduktion zeigten sich ausgehend von der Sella turcica ein $3 \times 2 \times 2 \mathrm{~cm}$ messender Tumor sowie pulmonale Metastasen. 
Schlussfolgerung. Es werden die makroskopischen, histologischen und immunhistochemischen Befunde präsentiert und diskutiert.

\section{P4}

\section{Nicht diagnostizierte schwere Herzverletzung eines Pkw-Fahrers}

\section{Valent', J. Sidlo', S. Galbavy², J. Sikuta²}

${ }^{1}$ Gesundheitsamt, Institut für Rechtsmedizin, Bratislava, Slovakai, ${ }^{2}$ Comenius Universität Bratislava und Gesundheitsamt, Institut für Rechtsmedizin, Bratislava, Slovakai

Einleitung. Die Verletzungen von intrathorakalen Organen bei Verkehrsunfällen mit Autofahrern hängen eng mit der Geschwindigkeit des Fahrzeugs sowie mit der Art der Kollision zusammen. Die Schwere der Verletzungsfolgen ist von der Verwendung von Rückhaltesystemen wie Anschnallgurte und insbesondere Airbags abhängig.

Kasuistik. Ein 53-jähriger männlicher Fahrer eines Geländewagens (Ford Maverick) prallte frontal gegen einen Baum und verstarb nach 28-tägigem Krankenhausaufenthalt. Trotz ausgiebiger Diagnostik und Operationen wurde keine Verletzung des Herzens festgestellt. Die Todesursache war aber eine persistierende Perforation nach traumatischer Myokardruptur des linken Herzventrikels.

Schlussfolgerung. Der Fall ist besonders aus diagnostischer und gerichtsmedizinischer Sicht interessant, da beim Vorliegen von ThoraxTraumata auch Spätfolgen einer möglichen Herzverletzung Auswirkungen auf das Überleben des Patienten haben können.

\section{P5}

\section{Mensch vs. Maschine - Rolle von Morphologie und Molekular- pathologie in der Todesursachenfeststellung}

\section{Stiller', H.-J. Holzhausen'2, F. Bartel', O. Niederstrasser ${ }^{3}$, F. Lupatsch² \\ ${ }^{1}$ Martin-Luther-Universität, Institut für Rechtsmedizin, Halle/Saale, Deutschland, ${ }^{2}$ Martin-Luther-Universität Halle-Wittenberg, Institut für Pathologie, Halle/Saale, Deutschland, ${ }^{3}$ BG-Kliniken Bergmannstrost, Neurologische Klinik, Halle/Saale, Deutschland}

Fallbericht. Ein 31 Jahre alter Lehramtsstudent wurde in einer Lebenskrise nach mehrfachem Aufsuchen der Notaufnahme stationär in der Neurologischen Klinik aufgenommen. Die stark wechselnde Symptomatik (Brustschmerzen, Lähmungserscheinungen) führte nicht zu einer klinischen Diagnose. Es bestanden sogar erhebliche Zweifel, da fassbare Befunde nicht erhoben werden konnten. Wegen des plötzlichen Todeseintritts und der von den Eltern erhobenen massiven Behandlungsfehlervorwürfe erfolgte eine gerichtliche Obduktion.

Ergebnisse. Makroskopisch dominierte das unspezifische Bild eines akuten Linksherzversagens. Die neuropathologische Untersuchung des Gehirns ließ relevante Erkrankungen ausgeschlossen erscheinen. Im Ergebnis der histologischen und immunhistochemischen Untersuchungen der peripheren Nerven und der Organe zeigte sich hingegen das Muster einer ausgeprägten Polyneuritis. Zusätzlich bestand eine lymphozytäre Hepatitis. Im Herzmuskel waren eine vermehrte bindegewebige Durchsetzung sowie zahlreiche lymphozytäre Infiltrate auffällig. Die molekularpathologischen Untersuchungen von Nervengewebe, Herzmuskel und Leber erbrachten lediglich für Letztere in der Epstein-Barr-Virus(EBV)-PCR ein positives Ergebnis.

Diskussion. Vor dem Hintergrund der EBV-Durchseuchungsrate war die diagnostische Bedeutung des molekularpathologischen Untersuchungsergebnisses kritisch zu sehen. Zudem bestand keine Übereinstimmung des selektiven Erreger-DNA-Nachweises mit der histomorphologisch nachgewiesenen Organbeteiligung der Entzündung. Um Hinweise zur Verwertbarkeit der Molekularpathologie in der Erregerdiagnostik bei unklaren Todesfällen mit möglicher infektiöser Komponente zu erhalten, wurden molekularpathologische Vergleichsuntersuchungen im rechtsmedizinischen Sektionsgut ausgeführt.
Schlussfolgerung. Der vorliegende Fall, die Ergebnisse der Stichprobenanalyse sowie ihre Bedeutung werden kritisch diskutiert.

\section{P6}

\section{Anatomical features of complete myocardial bridges and their role} in sudden death apparition

\section{A. Bondarev', M. Tasnic ${ }^{2}$, I. Catereniuc ${ }^{2}$, E. Costru-Tasnic ${ }^{2}$}

"Universität "Nicolae Testemitanu" Chisinau, Zentrum für Rechtsmedizin, Chisinau, Moldovien, Republik, ${ }^{2}$ Universität „Nicolae Testemitanu“ Chisinau, Anatomie, Chisinau, Moldovien, Republik

Background and aim. Complete myocardial bridges (CMB) are myocardial strips covering a portion of the underepicardial coronary artery on one or more of its parts. The incidence of CMB reaches $85-86 \%$. Researchers underline the role of myocardial bridges (MB) in cardio-vascular diseases, especially of the heart emergencies, including sudden death in young people and children with clean coronary vessels. The aim was to distinguish anatomical features of $\mathrm{CMB}$ and their possible involvement in ischemic heart suffering.

Material and methods. 200 formalized human hearts were studied by fine anatomical dissection methods at macroscopic, macro-microscopic and microscopic levels.

Results. CMB were found in $62.5 \%$ cases. Most frequently CMB cover the anterior interventricular branch, followed by the diagonal branches of both ventricles, first marginal branch and posterior interventricular branch. The width of about $1 / 3$ of CMB (34\%) was about $10-19 \mathrm{~mm}$, in $25 \%$ of cases its width was $20-29 \mathrm{~mm}$, and in $18 \%$ of the dissected hearts 1-9 $\mathrm{mm}$ and only in $4 \%$ of cases wide bridges, up to $70 \mathrm{~mm}$, were found on anterior interventricular branch. The study revealed deformation and narrowing of the vessel under the bridge what could have an important role in heart ischemic sufferings and sudden death. Investigations indicate that the direction of the myocardial fibres varies. While in thin MB the direction of the myocardial fibres is similar to the first myocardial layer, in thick bridges, especially those located above the anterior interventricular branch, myocardial fibres surround the vessel, forming a myocardial tunnel around the vessel.

Conclusions. The degree of systolic compression of the coronary vessel by $\mathrm{MB}$ depends on many factors: the topography of the bridge, its thickness, width and muscle-conjunctive composition, muscle fibres' orientation and the association of some myocardial bridges on the same vessel. Systolic compression of coronary vessels by MB may cause sudden death of young, healthy persons.

\section{P7}

Letale Amyloidose-assoziierte Kardiomegalie - ein rechtsmedizinischer Fallbericht

\section{C.G. Birngruber', M.A. Verhoff', V. Spencer', O.M. Türk', R. Dettmeyer' 'Rechtsmedizin Gießen, Gießen, Deutschland}

Fallbericht. Ein an einer ATTR-Amyloidose erkrankter, dialysepflichtiger, eingeschränkt mobiler und unter anderem mit Opiaten medizierter Mann war nach einem längeren Krankenhausaufenthalt kurz vor der geplanten Entlassung unbeobachtet in seinem Patientenzimmer gestürzt. Mit leichten thorakalen Schmerzen wurde er ohne weitere Diagnostik zunächst nach Hause entlassen. Dort habe sich eine zunehmende Schmerzsymptomatik mit Atembeschwerden entwickelt, die zu einer erneuten Klinikeinweisung sechs Tage nach dem angegebenen Sturzereignis geführt habe. Hierbei wurden Rippenserienfrakturen diagnostiziert, der Patient verstarb am Folgetag.

Ergebnisse. Die gerichtliche Obduktion ergab als Hauptbefund ein erheblich wandverdicktes und vergrößertes Herz (1096 g) mit hartgummiartiger Konsistenz, speckig glänzender Myokard-Schnittfläche und stenosierender Koronarsklerose. Die Lungenschlagadern waren ausge- 
weitet und sklerosiert, die Leber zeigte eine Muskatnusszeichnung bei feinknotig zirrhotischem Umbau. Akut hatten sich ein Lungenödem, ein Hirnödem sowie eine Blutfülle der inneren Organe ausgebildet. Die im Rahmen des zweiten Klinikaufenthaltes diagnostizierten Rippenserienfrakturen infolge eines stumpfen Thoraxtraumas konnten nachvollzogen werden. Es fanden sich jedoch keine Verletzungen, denen eine todesursächliche Bedeutung zugerechnet werden konnte. Die forensisch-toxikologischen Analysen mit Blutalkoholbestimmung verliefen nur für die verordneten Medikamente positiv. Als Todesursache wurde eine protrahierte globale Herzdekompensation infolge der Herzveränderungen durch die Amyloidose angenommen.

Schlussfolgerung. Vorgestellt wird das Krankheitsbild der Amyloidose unter pathophysiologischen und histopathologischen Gesichtspunkten.

\section{P8}

\section{Staining characteristics of the myocardium may indicate the agonal} duration of carbon monoxide related death

\section{K. Nishi', S. Furukawa', S. Morita', L. Wingenfeld' ${ }^{2}$ H. Okunaga'}

'Shiga University of Medical Science, Department of Legal Medicine, Shiga, Japan, ${ }^{2}$ Ludwig-Maximilians Universität München, Institut für Rechtsmedizin, München, Deutschland

Introduction. It has been described that the myocardium did not show any ischemic types of changes or other lesions in human hearts obtained from fatal carbon monoxide poisoning cases, although some reports indicated the existence of pathological changes in the myocardium from carbon monoxide poisoning cases.

Methods. We investigated the changes in myocardium obtained from several individuals who died due to suicidal carbon monoxide poisoning, in house fire cases and suicidal burning with kerosene using conventional staining and immunohistochemical staining. All died without resuscitation attempts of any type.

Results. The conventional staining revealed that hypoxic/ischemic changes, such as myocardial cells with color-changing, colliquative myocytolysis and/or contraction bands could be detected mainly in the right ventricle and longitudinal sections of the interventricular septum. Immunohistochemical staining revealed that in hypoxic/ischemic situation the cardiac cells might be progressing the cascade of the signaling pathways related to ischemic, hypoxic and/or apoptotic antigens to protect the hypoxic damage according to the periods of agony in each case. The results together with our previous study indicate that the expression of cold inducible RNA binding protein and RNA binding motif protein 3 may be related with the anoxia or hypoxia and is not related with cold stress in the human tissues and that these antigens may become useful tools to detect early hypoxic reaction in the myocardium.

\section{P9}

Immunohistochemistry of connexin 43 and zonula occludens-1 for investigating myocardial injury in forensic autopsy

O. Kawamoto ${ }^{1,2}$, T. Michiue $^{1,2}$, T. Ishikawa $a^{1,2,3}$, H. Maeda $^{1,2}$

'Osaka City University Medical School, Legal Medicine, Osaka, Japan, ${ }^{2}$ Medico-legal Consultation and Postmortem Investigation Support Center, Forensic Autopsy Section, Osaka, Japan, ${ }^{3}$ Tottori University, Division of Legal Medicine, Faculty of Medicine, Tottori, Japan

Introduction. Connexin 43 (Cx43) and zonula occludens-1 (ZO-1) are major gap junction proteins in human ventricular cardiomyocytes, which play crucial roles in myocardial contractility. The present study investigated these proteins as immunohistochemical markers of myocardial injury in forensic autopsy.

Materials and methods. Forensic autopsy cases of acute death due to ischemic heart disease ( $n=23$ : with/without apparent infarction, $n=15 / 8$ ), mechanical asphyxiation $(n=24)$, drowning $(n=10)$, hypothermia (cold exposure), hyperthermia (heatstroke) and methamphetamine (MA) abuse $(n=5)$ were used to examine immunohistochemical positivity and distribution of $\mathrm{Cx} 43$, non-phosphorylated (np) $\mathrm{Cx} 43$ and ZO-1 in the myocardium.

Results and discussion. $\mathrm{Cx} 43$ and npCx43 showed various localizations at the intercalated disc, in the cytoplasm and along the lateral cell border, and the distribution of npCx43 depended on the cause of death: $n p C x 43$ positivity in the cytoplasm was increased in most cases of acute ischemic heart disease with/without apparent infarction $(n=20 / 23$; $87.0 \%$ ), suggesting redistribution due to ischemic myocardial injury; however, such a finding was infrequent in asphyxiation, drowning and hyperthermia. ZO-1 was usually detected diffusely in the myocardial cytoplasm, showing a tendency to be more intense in acute ischemic heart disease, hyperthermia and MA abuse than in other groups, but was localized at the intercalated disc in some cases of fatal MA abuse $(n=2 / 5 ; 40 \%)$. These findings suggest that immunohistochemistry of npCx43 and ZO-1 is useful to detect specific myocardial injury due to ischemia and MA toxicity.

\section{P10}

Post-mortem CT morphometry of great vessels with regard to the cause of death for investigating terminal circulatory function in forensic autopsy

N. Sogawa ${ }^{1,2}$, T. Michiue ${ }^{1,2}$, T. Ishikawa $a^{1,2,3}$, O. Kawamoto ${ }^{1,2}$, S. Oritani', H. Mae$d a^{1,2}$

'Osaka City University Medical School, Legal Medicine, Osaka, Japan, ${ }^{2}$ Medico-legal Consultation and Postmortem Investigation Support Center, Forensic Autopsy Section, Osaka, Japan, ${ }^{3}$ Tottori University, Division of Legal Medicine, Faculty of Medicine, Tottori, Japan

Introduction. Postmortem CT (PM-CT) is useful to investigate the viscera in situ before opening the body cavity at autopsy. The present study was a morphometric analysis of the great vessels with regard to the cause of death as a possible index of terminal circulatory function in forensic autopsy cases.

Materials and methods. PM-CT data of forensic autopsy cases within 3 days post-mortem $(n=87)$ were analyzed using a CT data analysis system Volume Analyzer SYNAPSE VINCENT (FUJIFILM Medical Co., Ltd., Tokyo, Japan). Horizontal section images of the great vessels were reconstructed for the ascending and descending thoracic aorta as well as the superior vena cava at the level of the bifurcation of the trachea, and the abdominal aorta and inferior vena cava at the level of the 12th thoracic vertebra; the perimeter $(\mathrm{mm})$ and area $(\mathrm{mm} 2)$ of cross sections of individual great vessels were measured, and the vessel flattening index (vFI) was calculated as the ratio of the cross section area (a) to estimated circle area having the same perimeter $(\mathrm{l}): \mathrm{vFI}=4 \pi \mathrm{a} / \mathrm{l} 2$.

Results and discussion. Perimeters and cross section areas of the aorta and vena cava depended on the age and/or gender of subjects; however, vFI showed distinct difference among the causes of death, although a slight gender-related difference or postmortem dependence was partly detected: the index was low for each vessel in fatal bleeding, and low for the abdominal aorta and inferior vena cava in hyperthermia (heatstroke), but was higher for each vessel, including the abdominal aorta and inferior vena cava, in hypothermia (cold exposure) and sudden cardiac death. These findings provide quantitative data to reinforce autopsy findings for interpreting terminal circulatory function. 


\section{P11}

\section{Komplikationen bei perfemoralem Aortenklappenersatz (TAVI)}

\section{B. Madea', R. Amberg', G. Kernbach-Wighton ${ }^{2}$ \\ 'Facharztpraxis für Rechtsmedizin, Freiburg, Deutschland, ${ }^{2}$ Institut für Rechtsmedizin, Bonn, Deutschland}

Einleitung. Die Anzahl der perfemoralen Aortenklappenersatzeingriffe hat in Deutschland - im Unterschied zu seinen Nachbarn - in den letzten Jahren erheblich zugenommen (2010: 25\% der Aortenklappeneingriffe, gegenwärtig 30\%). Die Indikationsstellung scheint hierbei schrittweise immer weiter gefasst zu werden.

Fallbericht. Es wird über eine 83 Jahre alt gewordene Patientin $(114 \mathrm{~kg}$ Körpergewicht, $159 \mathrm{~cm}$ Körperlänge) berichtet, bei der die Diagnose einer relevanten Aortenklappenstenose und eines hohen Risikos bei offener Operation gestellt wurde. Beim transfemoralen Klappenersatz misslang die Positionierung und führte zur Embolisation der entfalteten Klappe (Sapien XT) ventrikelwärts. Es wurde eine zweite, gleichartige Klappe positioniert, die in der Aorta hielt. Da der Klappenoberrand die Koronarostien einengte, wurden langstreckige Stents eingesetzt, die mit einem Ende weit in das Aortenlumen ragten. Da die Patientin kardiosrespiratorisch instabil geworden war, konnte keine Folgeoperation durchgeführt werden. Bei der Umlagerung glitt die Patientin vom Operationstisch. Sie verstarb in der folgenden Nacht an einem Pumpversagen des Herzens.

Diskussion. Die häufigsten Komplikationen beim transfemoralen Klappenersatz bestehen in vaskulären Komplikationen durch die Einbringung großlumiger Schleusen (30\%) und in cerebralen Insulten (bis $10 \%$ ), die aber häufig klinisch inapparent bleiben. Auffällig waren auch AV-Blöcke, die dann noch die zusätzliche Implantation eines Schrittmachers erforderlich machten. Selten kommt es zu Koronarokklusionen, Ventrikelrupturen, Aortenanulusrupturen, Aortendissektionen, einem kardiogenen Schock oder der ventrikelwärtigen Empolisation der Klappe. Die Indikation zur TAVI muss daher so gestellt werden dass im Komplikationsfall noch chirurgisch interveniert werden kann.

\section{P12}

\section{Plötzlicher Tod eines vier Tage alt gewordenen Säuglings in Folge persistierenden Ductus arteriosus Botalli}

\section{B. Madea', C. Schyma', Y. Albalooshi', E. Doberentz' \\ 'Institut für Rechtsmedizin, Bonn, Deutschland}

Einleitung. Ein persistierender Ductus arteriosus Botalli ist als Ursache eines plötzlichen und unerwarteten Neugeborenentodes sowie pulmonaler Hämorrhagien seit Jahren identifiziert. Insbesondere Frühgeborene weisen ein erhöhtes Risiko zur Entwicklung eines hämodynamisch signifikanten persistierenden Ductus arteriosus Botalli auf.

Fallbericht. Vorgestellt wird der plötzliche und unerwartete Todesfall eines vier Tage alt gewordenen Säuglings, der 2 Wochen vor dem errechneten Termin geboren worden war. Bei der Obduktion zeigte sich ein sehr muskelkräftiger arterieller Gefäßkurzschluss zwischen der Arteria pulmonalis und dem Aortenbogen mit einem Durchmesser knapp unter dem der Arteria pulmonalis. Als Folge der pulmonalen Hyperperfusion massive akute Blutstauung der Lungen. Todesursache war ein kongestives Herzversagen in Folge Shuntings von der systemischen in die pulmonale Zirkulation.

1. Agarwal R, Decorari AK, Paul VK (2007) Patent ductus arteriosus in preterm neonates. AIIMS Protocols

2. Lewis NJ, McKeever PK, Rutty G (2004) Patent ductus arteriosus as a natural cause of pulmonary haemorrhage in infants. American Journal of Forensic Medicine and Pathology 25:200-204

\section{P13}

\section{Palacos-Embolisation nach Vertebroplastie}

B. Madea', R. Amberg', G. Kernbach-Wighton'

${ }^{1}$ Institut für Rechtsmedizin, Bonn, Deutschland, ${ }^{2}$ Facharztpraxis für Rechtsmedizin, Freiburg, Deutschland

Einleitung. Im Zuge des Aufschwungs der sogenannten mikroinvasiven Verfahren hat die Stabilisierung osteoporotischer Wirbelkörper durch die Einspritzung von Knochenzement eine gewisse Bedeutung erlangt. Dazu wird dieser via Pedikel punktiert und dünnflüssiges Palacos unter hohem Druck injiziert.

Fallbericht. Wir berichten über einen 6o Jahre alt gewordenen Mann, der leblos in seinem Fahrzeug mit laufendem Motor aufgefunden wurde. Es bestand keine Einleitung der Abgase in das Wageninnere. Bei der Obduktion fand sich ein nicht mehr frischer Infarkt der Herzhinterwand bei einem Herzgewicht von 840 g (Körpergewicht: $128,5 \mathrm{~kg}$ ) als Todesursache. Zusätzlich fanden sich venöse Gefäßverschlüsse von Lumbalvenen, die bis in die Vena cava inferior reichten. Es handelte sich um eine weiße, derbe, nicht schneidbare Masse. Bei weiterer Präparation fand sich im Hilusbereich der rechten Pulmonalarterie eine geflechtartige Ansammlung von streifenartigen, bis zu 2,5 $\mathrm{cm}$ langen und $2 \mathrm{~mm}$ durchmessenden Fragmenten desselben Materials. Die Präparation der Wirbelsäule ergab eine Durchsetzung des zweiten und dritten Wirbelkörpers mit einem festen weißlichen Material. Über der oberen Lendenwirbelsäule war eine narbige Einziehung sichtbar. Aus der Vorgeschichte war eine Vertebroplastie wegen Osteoporose vor mehr als einem Jahr bekannt.

Schlussfolgerung. Im gegenständlichen Fall war es offensichtlich bei der Injektion in den Wirbelkörper zu einer venösen Embolisation des injizierten Materials via V. cava inferior bis in den rechten Lungenhilus gekommen, die klinisch unbemerkt geblieben ist. Ein Beitrag zum Todeseintritt wäre nur als zusätzliche kardiale Dauerbelastung bei erheblichen Vorschäden zu diskutieren. Die Injektion von dünnflüssigem Palacos unter hohem Druck in reich vaskularisierte Räume beinhaltet ein erkennbares Risiko für eine embolische Verschleppung des Materials.

\section{P14}

\section{Komplikationen extrakorporaler Membranoxygenierung (ECMO)}

B. Madea', R. Amberg', G. Kernbach-Wighton'

${ }^{1}$ Institut für Rechtsmedizin, Bonn, Deutschland, ${ }^{2}$ Facharztpraxis für Rechtsmedizin, Freiburg, Deutschland

Einleitung. Die extrakorporale Membranoxygenierung bildet eine Ultima-ratio-Therapie bei Ausfall der Lungenfunktion infolge von Unreife oder Krankheit. Sie stellt ihrer Art nach ein extrakorporales Organersatzverfahren dar und kann über längere Zeit (Wochen) eine ausreichende Sauerstoffsättigung aufrechterhalten. Beim Erwachsenen ist sie bei schweren Formen des ARDS mit und ohne Herzinsuffizienz indiziert. Je nach Positionierung des Membransystems im Kreislauf wird zwischen venovenöser und venoarterieller ECMO, die beide mit einem Pumpensystem arbeiten, sowie einer pumpenlosen arteriovenösen Form unterschieden. Kriterien für den Einsatz des jeweiligen Systems bilden die noch erhaltene Lungenfunktion und die Herzleistung. Fallbericht. Berichtet wird über den Einsatz einer venoarteriellen ECMO bei einem 65 Jahre alte gewordenen Patienten nach einer Viruspneumonie und einem Herzinfarkt mit zunehmender Herzinsuffizienz. Kanüliert wurde hier von der Vena femoralis her via V. cava bis in den rechten Vorhof. Aufgrund der scharfen, großlumigen ( $5 \mathrm{~mm} \mathrm{Dm}$ ) Katheterspitze wurde die Region des Sinusknotens perforiert. Der Patient verstarb mit den Zeichen einer elektromechanischen Entkoppelung. Bei der Obduktion fanden sich eine blutige Herzbeuteltamponade von $220 \mathrm{ml}$ sowie eine akuter Myokardinfarkt von $3 \times 1,5 \mathrm{~cm}$ Größe in der Vorderwand und eine Narbe von $6 \times 5 \mathrm{~cm}$ in der Hinterwand. Es bestand eine koronare 2-Gefäß-Erkrankung mit 2 Stents in der A. coronaria si- 
nistra sowie eine allgemeine Arteriosklerose mit einer infrarenalen YProthese. Der plötzliche Todeseintritt während des Eingriffs war für die behandelnden Ärzte zunächst unerklärlich.

Diskussion. Die Indikation für das Verfahren war zweifellos gegeben. Dem mit dem Einsatz der ECMO verbundenen hohen technischen und personellen Einsatz steht eine ebenfalls hohe Komplikationsrate gegenüber. Eine Verletzung der Sorgfaltspflicht war aber nicht erkennbar.

\section{P15}

\section{Fusobakterien-Sepsis bei jungen Erwachsenen}

\section{B. Madea', R. Amberg' ${ }^{2}$ M. Parchina ${ }^{3}$, C. Heß', G. Kernbach-Wighton'} ${ }^{1}$ Institut für Rechtsmedizin, Bonn, Deutschland, ${ }^{2}$ Facharztpraxis für Rechtsmedizin, Freiburg, Deutschland, ${ }^{3}$ Institut für Medizinische Mikrobiologie, Immunologie und Parasitologie, Bonn, Deutschland

Einleitung. Fusobakterien gehören zur normalen Population der Schleimhaut des Mundes, der oberen Atmungswege und des Gastrointestinaltraktes. Infektionen setzen eine Invasion in das Gewebe voraus und sind selten. Am bekanntesten ist das Lemierre-Syndrom, bei dem es zu einer septischen Thrombophlebitis der V. jugularis interna kommen kann.

Fallbericht. Im gegenständlichen Fall wurde ein 19 Jahre alt gewordener Mann (123 kg Körpergewicht; $186 \mathrm{~cm}$ Körperlänge) am Morgen seines Geburtstages tot in seinem Bett gefunden, nachdem er am Vorabend darüber geklagt hatte, sich verhoben zu haben, und sich übergeben musste. Bei der zwei Tage später durchgeführten Obduktion fiel eine weit fortgeschrittene Fäulnis mit Dunsung und teilweise grünlicher Verfärbung des gesamten Körpers und durchschlagenden Venennetzen auf. Die in diesem Zustand erheblich erschwerte Befunderhebung ergab keine makroskopisch fassbare Diagnose. Bei der mikrobiologischen Untersuchung eines Abstrichs aus dem linken Lungenunterlappen war in der kulturellen Untersuchung sehr spärlich Staph. aureus bei ansonsten standortüblicher Flora nachweisbar. In anaerober Kultur konnte dann hauptsächlich Fusobacterium necrophorum nachgewiesen werden. Die chemisch-toxikologische Untersuchung ergab keinen Hinweis auf eine Intoxikation.

Diskussion. 2009 wies eine dänische Studie eine hohe Inzidenz von $\mathrm{Fu}$ sobacterium necrophorum bei Peritonsillarabszessen nach. Die Mortalität liegt zwischen 10-20\%. Nach der Einführung der Antibiose sind zwischen 1950 bis 1980 nur wenige Fälle publiziert worden. Betroffen sind gesunde Erwachsene, der Verlauf ist häufig foudroyant, beginnt mit mildem Unwohlsein und führt über Erbrechen zu einer raschen Dekompensation. Aus der Vorgeschichte ergaben sich keine Anhaltspunkte für eine vermehrte Infektanfälligkeit.

\section{P16}

\section{Unerkannte todeskausale Pleuraempyeme}

\section{B. Madea', R. Amberg', G. Kernbach-Wighton}

'Institut für Rechtsmedizin, Bonn, Deutschland, ${ }^{2}$ Facharztpraxis für Rechtsmedizin, Freiburg, Deutschland

Einleitung. Pleuraempyeme entwickeln sich typischerweise mit Lobärpneumonien (2-5\% der Fälle). Symptome sind Husten, Auswurf, Fieber, Nachtschweiß, Gewichtsabnahme, Atemnot. Im Rahmen einer Antibiose kann die Symptomatik zurückgehen. Häufiger bleiben Pleuraempyeme undiagnostiziert. Es wird über zwei Fälle berichtet, bei denen ein undiagnostiziertes Pleuraempyem zum Tode führte.

Fall 1. Im ersten Fall wurde ein 50-jähriger Mann mit einer bekannten Alkoholabhängigkeit 15 Tage vor seinem Tod bei seinem Hausarzt vorstellig, um eine Entziehungskur zu beantragen. Seine Familie teilte mit, dass er in den letzten Wochen mehrere Kilogramm Gewicht verloren und gehustet habe. Er wurde in den frühen Morgenstunden tot auf dem Sofa in seinem Domizil aufgefunden. Bei der Obduktion stellten sich ein grün-gelbliches, rahmiges Pleuraempyem (2000 ml) der rechten Brusthöhle mit massiver Verdickung der Pleura visceralis sowie eine Bronchopneumonie dar. Außer einer Steatosis hepatis und einer Funktionshypertrophie der Nieren ( $540 \mathrm{~g}$ ) waren nur mäßige Veränderungen im Sinne einer Herzerweiterung und einer allgemeinen Arteriosklerose vorhanden. Die Blutalkoholkonzentration betrug $1,47 \nabla$. Die mikrobiologische Probe war steril.

Fall 2. Im zweiten Fall begab sich eine 68-jährige Frau in ärztliche Behandlung, da sie sich krank gefühlt und seit 30 Jahren keinen Hausarzt mehr gesehen habe. Nach einem 4-wöchigen Krankenhausaufenthalt und 20 Stunden nach der Implantation eines Schrittmachers verstarb sie unter dem Bild einer Rhythmusstörung, nachdem sie einige Stunden zuvor schon einmal reanimationspflichtig geworden war. Bei der Obduktion enthielt die linke Lungenhöhle $2800 \mathrm{ml}$ eines gelblich-eitrig durchsetzten Ergusses. Das Herz war mit $500 \mathrm{~g}$ an der kritischen Grenze (Körpergewicht: 69 kg, Körperlänge: $163 \mathrm{~cm}$ ), die Leber rechtskardial gestaut. Es bestand eine Arteriolosklerose der Nieren und eine allgemeine, mäßige Arteriosklerose.

\section{P17}

\section{Expression von Hitzeschockproteinen (HSP) 27 und 70 beim Tod} durch Brandeinwirkung

\section{B. Madea' , L. Genneper', E. Doberentz'}

'Institut für Rechtsmedizin, Bonn, Deutschland

Einleitung. Hitzeschockproteine sind eine Gruppe von Proteinen, die zu den molekularen Chaperonen gezählt werden. Sie wurden 1962 zum ersten Mal beschrieben und werden aufgrund ihrer zytoprotektiven Funktion nach einer Reihe von Stressstimuli exprimiert. Immunhistochemisch kann die Expression von Hitzeschockproteinen einfach visualisiert werden.

Methoden. In der vorliegenden Untersuchung wurde die Hitzeschockproteinexpression (HSP 27 und HSP 70) bei 53 Brandleichen und 100 Kontrollfällen ohne thermischen Stress untersucht. Neben Lungengewebe wurden Myokard und Nierengewebe in die Untersuchung einbezogen. Sowohl HSP 27 als auch HSP 70 werden rasch nach Hitzeeinwirkung exprimiert.

Ergebnisse. Im Ergebnis zeigt sich eine direkte Korrelation zwischen HSP-Expression, Überlebenszeit und Todesursache. Bei Brandtodesfällen war die Hitzeschockexpression immer deutlich höher ausgeprägt als in der Kontrollgruppe.

Schlussfolgerung. Die immunhistochemische Darstellung der HSP-Expression eignet sich als Vitalitätsmarker bei Brandtodesfällen.

\section{P18}

Postmortal-biochemische „Near-table-Analysen“ zum Kohlenhydrat-Stoffwechsel

\section{G. Kernbach-Wighton', S. Sudan', C. Hess', B. Madea'}

'Institut für Rechtsmedizin, Universitätsklinikum Bonn, Bonn, Deutschland

Einleitung. Diabetes mellitus stellt die häufigste endokrine Erkrankung dar. Das Coma diabeticum repräsentiert dabei eine der zehn häufigsten Todesursachen. Eine schnelle Screening-Methode zur Testung direkt bei der Obduktion wäre somit sehr vorteilhaft.

Methoden. Vorliegend wurden Glukose und Laktat in Glaskörper und Liquor mit dem Accutrend ${ }^{\star}$ (Roche) bestimmt, und zwar in 42 zufällig ausgewählten Todesfällen (entspr. 106 Proben; nicht immer konnten Liquor und Glaskörper bds. entnommen werden). Die TodesursachenDiagnostik umfasste Todesumstände, Makro- und Mikromorphologie sowie Toxikologie und beinhaltete ein breites Spektrum natürlicher und nichtnatürlicher Todesursachen. Nach Vornahme der „Near-table-Methode“ (Traub'scher Summenwert) wurden die Proben nach gängigen Labormethoden untersucht (photometrische Bestimmung v. 
Glucose und Lactat; Labor u. Technik; Olympus 400o) und die Labormesswerte den „Near-table-Resultaten“ gegenüber gestellt. Die statistische Auswertung zielte v. a. auf die Frage, ob das Accutrend ${ }^{\oplus}$ hinsichtlich seiner Präzision gängige (Labor-)Methoden evtl. ersetzen könnte. Vorteil wäre, dass bereits bei der Sektion richtungweisende Aussagen zur Todesursache möglich wären, die über bisherige qualitative bzw. Resultate deutlich hinausgingen.

Ergebnisse und Schlussfolgerung. Zusammengefasst existieren - vergleichbar zur Pilotstudie - durchaus nennenswerte Differenzen zu herkömmlichen Laborverfahren. So wichen in $88,7 \%$ der Fälle (94 von 106) die mit Accutrend ${ }^{\oplus}$ gemessenen Summenwerte nach oben ab. Dadurch würden entsprechend „falsch-positive“ Fälle generiert. Im Mittel betrug die Abweichung 106,5 mg/dl (Summenwert). Verglichen mit den nach Labormethoden ermittelten Werten lagen die „Accutrend ${ }^{\circledR}$-Resultate im Mittel um 29,8\% höher. In der Konsequenz wären entsprechend weitergehende Analysen im klinisch-chemischen Labor vorzunehmen. Es ließen sich zudem keine Häufungen bestimmter Todesursachen identifizieren. Die Studie konzentriert sich derzeit noch auf eine Identifikation und Analyse der Ursachen der festgestellten Messwertdifferenzen.

\section{P19}

Histologische Untersuchungen bei kieferorthopädischer Therapie an einer forensisch asservierten Unterkieferhälfte

\section{G. Kernbach-Wighton', C. Reichert', B. Madea', A. Jäger', W. Götz' \\ 'Institut für Rechtsmedizin, Universitätsklinikum Bonn, Bonn, Deutschland}

Einleitung. Die Untersuchung von Humanpräparaten unter forensischen Aspekten erlaubt Studien zu strukturellen Veränderungen durch therapeutische Verfahren, wie sie sonst nur im Tierversuch oder in vitro möglich wären. Besonders in der Kieferorthopädie, vor allem bei Kindern und Jugendlichen, sind feingewebliche Veränderungen nur selten histologisch nachzuweisen. Im vorgestellten Fall konnten histologische Alterationen im Zahnhalteapparat durch eine oftmals durchgeführte orthodontische Behandlung beobachtet werden.

Methoden. Untersucht wurde der rechte Unterkiefer eines 15-Jährigen (Dekapitation nach auf Gleiskörper) mit festsitzender kieferorthopädischer sog. Straight-wire-Therapie, Brackets auf den Zähnen 43 bis 45 (superelastisches Drahtmaterial zur Nivellierung des Zahnbogens). Behandlungsunterlagen, Orthopantomogramm und Kiefermodelle wurden vom Kieferorthopäden zur Verfügung gestellt. Nach Präparation und Fixierung wurde das Corpus mandibulae unentkalkt in Methylmetacrylat (Technovit ${ }^{\circledR}$ ) eingebettet, Knochendünnschliffe in sagittaler Richtung mittels Trennschleif-Methode nach Donath gefertigt und mit Toluidinblau gefärbt.

Ergebnisse. Histologische Schliff-Untersuchungen zeigten typische Veränderungen an Zahnwurzeln bzw. Halteapparat, wie sie als häufige Nebenwirkungen bei solcher kieferorthopädischer Behandlung auftreten können. So war eine Intrusion des $Z_{4} 6$ durch apikale Wurzelresorptionen und ein allseitig gedehntes Parodontalligament gekennzeichnet. Vestibuläre Schliffe zeigten eine Mesialrotation mit vestibulärer Bewegung des $Z_{44}$ anhand von Knochen- und Wurzelresorptionen und eine Mesialkippung von $Z 43$ durch stark gedehnte suprakrestale Fasern. Durch distale Verlagerung von $Z 47$ kam es zur Verdrängung am Keim des noch nicht durchgebrochenen dritten Molaren.

Schlussfolgerung. Die Ergebnisse zeigen, dass histologische Untersuchungen forensisch asservierter Humanpräparate wertvolle Beiträge zum funktionellen Verständnis struktureller Veränderungen bei orthodontischen Behandlungen leisten können.

\section{P20}

Unerwartete Todesursache einer fortgeschrittenen Leberzirrhose Fallbericht und Diskussion der Begleitumstände

\section{Schwerer', M. Graw', L. Wingenfeld', O. Peschel'}

${ }^{1}$ Institut für Rechtsmedizin, Ludwig-Maximilians-Universität, München, Deutschland

Fallbericht und Fragestellung. Ein 55-jähriger Alkoholiker entließ sich gegen ärztlichen Rat aus stationärer Krankenhausbehandlung. Eine Leberzirrhose III. Grades mit Ikterus generalisatus und Aszites waren ebenso bekannt wie rezidivierend Bluterbrechen und Teerstühle. Am ersten Abend zu Hause sei der Patient kollabiert. Ein zunächst von der ebenfalls alkoholkranken Ehefrau ausgelöster „Notruf zur Leichenschau“ wurde nach kurzer Zeit von ihr storniert, weil „der Mann wieder leben“ würde. Die Todesfeststellung erfolgte nach neuerlichem Notruf am Folgemorgen. Die Obduktion diente zur Klärung der Fragestellung, ob ein Sturz als todesursächlich anzunehmen war bzw. ob der Patient bei früherer medizinischer Behandlung überlebt hätte.

Methoden und Ergebnisse. Die äußere Besichtigung zeigte hämatinisiertes Blut von der Mundumgebung bis zum Schultergürtel. Im Rahmen der Leichenöffnung waren in der Bauchhöhle 3300 ml blutig durchsetzte Flüssigkeit festzustellen. Die Organpräparation ergab im Magen ca. $150 \mathrm{ml}$ hämatinisiertes Blut ohne Nachweisbarkeit eines umschriebenen Schleimhautdefektes. Zudem zeigte sich auf dem Boden einer Leberzirrhose ein pilzförmig wachsender Tumor an der Oberseite des rechten Leberlappens mit zentraler nekrotischer Einschmelzung als Blutungsquelle in die freie Bauchhöhle. Die weiteren Obduktionsbefunde entsprachen denen eines ausgeprägten Blutverlustes.

Schlussfolgerung. Der gegenständliche Fall unterstreicht die Notwendigkeit einer gerichtlichen Leichenöffnung im Gegensatz zur äußerlichen Leichenschau: Der letztlich todesursächlich relevante Lebertumor wäre ohne die innere Besichtigung nicht feststellbar gewesen. Ausgehend vom Ausmaß des Blutverlustes kann die Sachverhaltsschilderung einer Bewusstseinstrübung mit Sturz zwanglos erklärt werden. Dass der geschilderte Sturz als Blutungsursache in den Bauchraum anzusehen ist, kann nicht belegt werden. Ob eine frühere Notarztalarmierung zu einer suffizienten Blutstillung und somit zum Überleben hätte führen können, ist nicht mit der notwendigen Sicherheit nachweisbar.

\section{P21}

Tödlich verlaufendes Leberversagen einer 31-jährigen afrikanischen Frau - Fallbericht mit differenzialdiagnostischer Diskussion und histologischer Sicherung des Grundleidens

\section{Schwerer', E. Mützel', M. Graw', A. Nerlich², O. Peschel}

'Institut für Rechtsmedizin, Ludwig-Maximilians-Universität, München, Deutschland, ${ }^{2}$ Institut für Pathologie des Klinikums Bogenhausen, München, Deutschland

Fallbericht und Fragestellung. Eine 31-jährige Afrikanerin mit progredienten abdominellen Beschwerden reiste zur weiterführenden Behandlung aus ihrem Heimatland Nigeria nach Deutschland. Bereits bei der stationären Aufnahme in einer Münchener Klinik wurde ein Leberversagen mit hepatischer Encephalopathie gesichert. Trotz zeitnaher Indikationsstellung verstarb die Patientin vor einer angestrebten Lebertransplantation. Die Obduktion diente der Klärung der Todesursache sowie der Fragestellung, ob eine Lebertransplantation das Leben der Patientin gerettet hätte.

Methoden und Ergebnisse. Im Rahmen der gerichtlichen Obduktion fand sich eine $6150 \mathrm{~g}$ schwere, von Nekrosen durchsetzte Leber mit Kapselschwellung und Kapselrissen sowie $3000 \mathrm{ml}$ blutig durchsetztem Aszites. Als weitere Zeichen des Leberversagens bestanden ein Ikterus generalisatus, ein Lungenödem, hämorrhagische Pleuraergüsse sowie Schleimhautunterblutungen der ableitenden Harnwege. Zudem fanden sich Schocknieren und ein ausgeprägtes Hirnödem. Ein Schnelltest auf 
HIV 1/2 verlief negativ. Die Histologie der Leber zeigte eine Infiltration aller Organabschnitte durch teils kohäsiv, teils dissoziativ wachsende Tumorverbände. Multifokal fanden sich intravasale Tumorzellnester, teils mit angelagerten Blutgerinnseln. Die Gefäßendothelien waren atypiefrei. Die Aufarbeitung der übrigen Organe zeigte eine Verdickung der Magenwandung durch ein diffus wachsendes Magenkarzinom. Schlussfolgerung. Die Patientin verstarb an einem Leberversagen auf dem Boden eines Budd-Chiari-Syndroms bei hepatisch metastasierendem Magenkarzinom. Ein makroskopisch zunächst vermutetes hepatisches Angiosarkom bzw. eine hepatische Manifestation eines HIV-unabhängigen afrikanischen Kaposi-Sarkoms wurde durch die Histologie ausgeschlossen. Eine Indikation zur Lebertransplantation erschien nicht gegeben.

\section{P22}

\section{Todesfälle durch Pflanzen- und Pilzvergiftungen in Bratislava und} im Landkreis Trnava im Zeitraum von 2008 bis 2012

\section{J. Sikuta', , J. Sidlo', R. Kuruc', L. Mikulas', A. Zummerova'}

${ }^{1}$ Comenius Universität Bratislava und Gesundheitsamt, Institut für Rechtsmedizin, Bratislava, Slovakai, ${ }^{2}$ Slovakai

Einleitung. Die relativ selten vorkommenden Pflanzen- und Pilzintoxikationen ereignen sich meistens akzidentiell wegen der Verwechslung mit essbaren Pflanzen und Pilzen oder auf Grund der falschen Einnahme von Heilpflanzen. Die Giftigkeit der Pflanzen ist durch die spezifischen Inhaltsstoffe bedingt, die in der gesamten Pflanze oder nur in einem Teil vorkommen. Diese Gifte werden in der Medizin als Heilmittel verwendet (Atropin, Kolchizin u. a.). Viele Menschen verwenden die Heilkraft der Pflanzen in ihrer natürlichen Form, indem die Pflanzen zu Hause gezüchtet oder in der Natur gesammelt und dann konsumiert werden.

Methoden. Die Obduktionsprotokolle des Instituts für Rechtsmedizin der Comenius Universität und des Amts für die Aufsicht über die Gesundheitsfürsorge in Bratislava (Einzugsgebiet: 1,18 Mio. Einwohner) aus den Jahren 2008 bis 2012 wurden retrospektiv analysiert. Das Ziel der Studie bestand darin, die Häufigkeit und die Art der tödlichen Vergiftungen durch Pflanzen und Pilze festzustellen. In allen Fällen wurden eine Obduktion, histologische, toxikologische Untersuchungen durchgeführt und die Krankenakten ausgewertet.

Ergebnisse. Im Zeitraum 2008 bis 2012 wurden insgesamt 304 Intoxikationen diagnostiziert, unter denen 6 Pflanzen- und Pilzvergiftungen (2\%) waren. Dabei handelte es sich um vier Pflanzenvergiftungen mit Colchicum autumnale (Herbstzeitlose) - 66-jähriger Mann; Atropa belladona (Tollkirsche) - 30-jähriger Mann; Aconitum anthora (Gifteisenhut) - 49-jähriger Mann; Datura stramonium (Engelstrompete) - 81-jährige Frau. Zwei tödliche Pilzvergiftungen durch den grünen Knollenblätterpilz betrafen einen 44-jährigen Mann und eine 66-jährige Frau. Fünf Fälle wurden im Jahr 2010 und ein Fall im Jahr 2012 festgestellt. Die meisten Intoxikationen ereigneten sich im Monat Dezember, wohingegen die Pflanzen- und Pilzvergiftungen sich ausschließlich auf die Sommermonate beschränkten.

Schlussfolgerung. Bei den seltenen tödlichen Pflanzen- und Pilzintoxikationen ( $2 \%$ aller Intoxikationen) handelte es sich um drei akzidentielle Intoxikationen, in einem Fall um eine vorsätzliche Vergiftung und in zwei Fällen konnte man den Vorsatz nicht mit Sicherheit feststellen.
P23

\section{Rhabdomyolyse und myoglobinurisches Nierenversagen nach} BTM-Konsum

\section{R. Dettmeyer', S. von Gerlach'², V. Spencer', G. Lasczkowski'}

${ }^{1}$ Institut für Rechtsmedizin, Gießen, Deutschland, ${ }^{2}$ Institut für Pathologie und Zytologie, Wetzlar, Deutschland

Einleitung. Eine Heroin-Intoxikation kann in seltenen Fällen zu einer Rhabdomyolyse und einem myoglobinurischen Nierenversagen führen, wie dies kasuistisch auch nach dem Konsum von Amphetaminen beschrieben ist (Scandting u. Spital 1988). Das klinische Erscheinungsbild kann offenbar variieren, wie der nachfolgende Fall zeigt.

Fallbericht. Ein seit mehr als 12 Jahren als BTM-Konsument bekannter 30-jähriger Mann wird nach berichtetem BTM-Konsum mit akutem Nierenversagen, beginnendem Leberversagen und sog. „KompartmentSyndrom" bei nekrotisierender Fasziitis am rechten Unterschenkel stationär aufgenommen. Er stirbt trotz Dialyse nach 10 Tagen unter der klinischen Verdachtsdiagnose einer Sepsis bei Endokarditis. In der Todesbescheinigung wird ein natürlicher Tod angegeben.

Obduktionsbefunde. Es zeigte sich ein Zustand nach Faszienspaltung am rechten Unterschenkel mit ausgedehnten streifigen Marmorierungen der Unterschenkelmuskulatur und Thrombosen der Unterschenkelvenen. Eine Endokarditis wurde autoptisch ausgeschlossen. Trotz akuter Stauungshyperämie und Ödem der inneren Organe sprachen die Obduktionsbefunde bei fehlendem abstreifbaren Milzbrei für sich allein nicht für eine Sepsis.

Histologie und Immunhistochemie. Histologisch zeigten sich areaktive Nekrosen der Unterschenkelmuskulatur ohne granulozytäre Reaktion und ohne bakterielle Besiedlung. Es dominierten vakuolisierte und zum Teil leere Muskelfaserschläuche. Immunhistochemisch konnte in den Lichtungen der Tubuli renales reichlich Myoglobin nachgewiesen werden.

Schlussfolgerung. Bei auch klinisch nie nachgewiesener Bakteriämie, fehlender septischer Milzreaktion und fehlender lokaler granulozytärer bzw. phlegmonös-eitriger Entzündung muss als Ursache des Kompartment-Syndroms des rechten Unterschenkels mit Rhabdomyolyse am ehesten an eine vorangegangene Drogenintoxikation gedacht werden. Derartige Fälle sind in der Literatur kasuistisch mitgeteilt. Anders als in der Todesbescheinigung angegeben, liegt ein nicht-natürlicher Tod vor.

\section{P24}

Possible sex discrimination of the mandible by means of postmortem CT morphometry with a proposal of novel parameters

T. Kanou', S. Oritani', T. Michiue ${ }^{1,2}$, T. Ishikawa ${ }^{1,2,3}$, A. Hishmat ${ }^{1}$, N. Sogawa ${ }^{1,2}$, O. Kawamoto ${ }^{1,2}$, H. Maeda, ${ }^{1,2}$

'Osaka City University Medical School, Legal Medicine, Osaka, Japan, ${ }^{2}$ Medico-legal Consultation and Postmortem Investigation Support Center, Forensic autopsy section, Osaka, Japan, ${ }^{3}$ Tottori University, Division of Legal Medicine, Faculty of Medicine, Tottori, Japan

Introduction. Major human sex differences in the mandible after adolescence include the overall size and the shape of the chin and mandibular angle depending on attached muscle development; however, objective interpretation of the accuracy of discrimination is difficult for these morphological indicators. The present study investigated the measurements of the mandible by means of morphometry using postmortem CT (PM-CT) data for sex discrimination in forensic autopsy cases of Japanese adult subjects with the proposal of novel parameters representing the overall size and shape.

Materials and methods. PM-CT data of forensic autopsy cases of Japanese subjects after adolescence (age $>16$ years; $n=200$ : 100 subjects for male and female each) were used for $3 \mathrm{D}$ reconstruction of the mandible, and the dimensions and angles were measured on virtual images. 
Results and discussion. The distance between the gnathion and condylus (gn-cdl) and bigonial width (go-go) as well as the angle formed by bilateral gn-cdl lines (Agn-cdl) correlated with bicondylar breadth (cdlcdl), independent of body height, but showed no sex difference. The distance from the gn to cdl-cdl line (oblique length), the ratio of Agncdl to cdl-cdl, and the oblique triangle area formed by bilateral gn-cdl and $c d l-c d l$ lines $(\Delta \mathrm{obl})$, which were proposed as parameters representing the protrusion of the chin, slightly depended on the body height $(p<0.001)$ and showed significant difference between sexes $(p<0.001)$ : sensitivity and specificity at respective discriminating points were 0.72 and 0.78 at $105.2 \mathrm{~mm}$ for oblique length, 0.77 and 0.82 at 0.49 for the Agn-cdl to cdl-cdl ratio, and 0.77 and 0.80 at $654 \mathrm{~mm} 2$ for $\Delta$ obl. These findings suggest the efficacy of CT morphometry of the mandible for sex discrimination with quantitative assessment.

\section{P25 \\ Possibility of identification of the person by structural features of the relief of the hard palate}

P. Romodanovsky', E. Barinov'

${ }^{1}$ Moscow State University of Medicine and Dentistry, Department of Forensic Medicine and Medical Law, Moscow, Russland

Introduction. The choice of a hard palate as the object of research for identification is caused by its resistance to the influence various endogenous and exogenous factors.

Patients and methods. The study of anatomical features of lateral folds of the mucous membrane of the hard palate was performed using visual methods (via dental mirror) and the use of alginate casts and gypsum model in 500 persons of both sexes, aged 18 to 70 years.

Results. The peculiarities of picture of the hard palate mucous membrane can be divided into five forms of lateral folds: 1 -form - linear, it can be straight or winding, 2nd - two diverging lines in the form of a tick, which rests on the tip of the middle seam, 3 rd - a line running from the middle of the seam and splits into two branches from the middle, 4 th - a line running from the middle of the seam and forming a ring pattern at its free end, 5 th - the line running from the middle of the seam and divided into 3 branches from the middle. For identification of the person it is advisable to distinguish five levels of conditional arrangement folds. Levels are limited to the right and left upper edge of the alveolar process: Level 1 - is the projection of the line between conventional interdental canine and 1st premolar, 2nd - is the projection of the line between the centers of conventional crowns one's premolars, $3 \mathrm{rd} \mathrm{-} \mathrm{is}$ the projection of conditional straight interdental space between the 1st and 2nd premolars, 4 th - is projection conditional line between the centers of second premolars crowns, 5 th - is the projection conditional line between the teeth of the second premolar and the first molar. Based on the above we suggested a classification of the main elements of the hard palate, based on the allocation of five anatomical forms of the lateral folds of the hard palate mucous membrane and a certain level of their location in each case.

Conclusions. The study of the structural features of the hard palate relief gives new possibilities for identification.
P26

Experimentelle Ermittlung der maximalen Reichweiten kleinster Blutspritzspuren

M.M. Schulz', F. Wehner', J.M. Lutterbach', C. Kaiser', O. Peschel', M. Graw', J. Adamec $^{1}$

'Institut für Rechtsmedizin, München, Deutschland, ${ }^{2}$ Institut für Gerichtliche Medizin, Tübingen, Deutschland

Einleitung. Die Eingrenzung der Lage der Blutquelle relativ zur Zieloberfläche anhand von Form und Verteilungsmuster dort befindlicher Blutspritzspuren ist eine der wichtigen Aufgaben innerhalb der Blutspurenmuster-Verteilungsanalyse. Nachdem die Flugbahn eines Blutspritzers und insbesondere die Distanz, die er vom Ursprungsort zur Zieloberfläche zurücklegt, auch von der Größe abhängig ist, kann theoretisch die minimale vorgefundene Blutspritzspurengröße zur Eingrenzung der Entfernung der Blutquelle zur Zieloberfläche herangezogen werden. Wissenschaftlich fundierte Daten diesbezüglich fehlen bisher, die im Fachschrifttum vorhandenen Angaben erlauben keine sicheren Rückschlüsse.

Methoden. Aus diesem Grund (und anlässlich eines konkreten Falles, in dem die Entfernung des Geschädigten zu einer Mikroblutspritzspuren aufweisenden Wand zum Zeitpunkt der Schussabgabe sehr wichtig war) wurde mit Hilfe einer speziellen Spritzapparatur der Zusammenhang zwischen der minimal festzustellenden Größe der Spritzspuren und der Entfernung vom Ursprungsort untersucht. Die Stoßenergie, die zur Entstehung der Spritzspuren geführt hat, wurde von einem willkürlich gewählten Niveau schrittweise gesteigert, bis keine weitere Veränderung des Spurenbildes (minimale Spurengröße in Abhängigkeit von der Distanz zur Blutquelle) festzustellen war. Als Zieloberfläche wurde Papier gewählt, die Spurengrößen wurden mit Hilfe eines geeichten USB-Mikroskops gemessen.

Ergebnisse. Die Auswertung zeigte ein konsistentes Spurenbild für jedes Stoßenergieniveau (jeweils 5 -fache Wiederholung), erwartungsgemäß waren die minimal festgestellten Spritzspurendurchmesser in gleichen Distanzen von der Blutquelle bei höheren Stoßintensitäten größer. Ab einem gewissen Intensitätsniveau brachte eine weitere Steigerung keine Veränderung der Ergebnisse mit sich, so dass das Experiment eine Eingrenzung des erreichbaren Maximums für jede Spurengröße ermöglicht hat. Blutspritzspuren mit einem Durchmesser beispielsweise von 0,5 mm erreichen demnach (unter für geschlossene Räume gewöhnlichen Bedingungen) maximal eine Distanz von ca. 2 m. Die Abhängigkeit der Spurengröße von der maximalen zurückgelegten Strecke zeigt einen annähernd exponentiellen Verlauf.

\section{P27}

Kombinierter Einsatz von 3D-Laserscan und Hemospat ${ }^{\oplus} /$ Elcovision $^{\circledR}$ - die perfekte Tatortdokumentation?

\section{A. Klein', E. Schönfeldt', S. Johnke', A. Gehl'}

'Institut für Rechtsmedizin, Hamburg, Deutschland, ${ }^{2}$ Polizeiakademie

Niedersachsen, Nienburg/W., Deutschland, ${ }^{3}$ Landeskriminalamt, Polizei Hamburg, Deutschland

Methoden. Dargestellt wird eine Methode der computergestützten Blutspurenanalyse, die eine Rekonstruktion und räumliche Visualisierung der Blutspurenentstehung erlaubt. Mittels $3 \mathrm{D}$-Laserscan $(\mathrm{Z}+\mathrm{F}$ imager $5006 \mathrm{H}$ ) werden einzelne, $z$. T. experimentell erzeugte, teils an Leichenauffindeorten vorgefundene Blutspuren dokumentiert. Digitale Fotos der Blutspur werden maßstabsgerecht entzerrt und mittels kommerzieller Blutspurenanalysesoftware (Hemospat ${ }^{\circledast} /$ Elcovision $^{\circledR}$ ) ausgewertet und in den $3 \mathrm{D}$-Laser-Raum geladen. Die berechnete Flugrichtung der Blutspuren und der entsprechende Auftreffwinkel werden im virtuellen dreidimensionalen Raumbild in Form von Flugachsen visualisiert und zu einer Blutungsquelle („region of origin“) zusammengeführt. 
Das Verfahren zeigt die interdisziplinäre Kooperation zwischen Rechtsmedizin und Polizei in Hamburg.

Schlussfolgerung. Erfordernisse sowie Vor- und Nachteile der Methodik werden aufgezeigt.

\section{P28}

Analyse von Videoaufnahmen konsensueller Choke-outs mit Täter- $/$ Opfer-Konstellation

\section{W. Schweitzer', M. Thali', L. Ebert ${ }^{1}$ \\ 'Institut für Rechtsmedizin der Universität Zürich, Zürich, Schweiz}

Hintergrund. Es ist eine rechtsmedizinische Herausforderung, zu überlebten (oder auch tödlichen) Strangulationen Aussagen zu treffen. Es kommt bei Gutachtensaufträgen oder Gerichtsverhandlungen gerne zu Fragen auch über konkrete Zeitverhältnisse, bei denen man sich heutzutage auf ältere Arbeiten - etwa Drosselstudien mithilfe von aufblasbaren Manschetten - stützen muss. Dazu kommt glücklicherweise (aber in diesen Fragen eben erschwerend) dazu, dass wissenschaftliche Strangulationsversuche bei Freiwilligen heute nicht mehr bewilligt werden.

Methode und Material. Da nun aber seit einiger Zeit konsensuelle Strangulationsangriffe einer strangulierenden Person („Täter") auf den Hals einer anderen Person („Opfer") bis zum Bewusstseinsverlust (sog. Choke-out) auch im Internet frei und öffentlich videopubliziert werden, vornehmlich mit Beteiligung von Jugendlichen und jungen Erwachsenen, haben wir uns diesen Umstand zunutze gemacht und bislang 19 Sequenzen auf zeitliche Verlaufsaspekte und andere erkennbare Merkmale analysiert. Beginn und Ende der Strangulation, Beginn und Ende des Bewusstseinsverlusts wurden visuell erhoben.

Ergebnisse und Diskussion. In zwei Sequenzen sind die sog. Opfer weiblich, in zwei sind die sog. Täter weiblich. In allen 19 Videos wird ein schräger Unterarmwürgegriff angewendet. Die in der Kampfsportszene bekannte Effizienz dieses sog. Blutwürgers veranschaulicht die mediane Zeitdauer zwischen Würgegriffanlage und sichtbaren Folgen des Bewusstseinsverlusts von 5,85 Sekunden. Die Zeitdauer des sichtbaren Bewusstseinsverlusts bis zum augenscheinlichen Wiederaufwachen beträgt im Medianwert 8,1 Sekunden. Allerdings sind zwei KampfsportTrainingsszenen unter den Videos, wo die Zeitdauer zwischen Beginn des Unterarmgriffs und Bewusstseinsverlust 28,9 Sekunden beträgt; die beiden Strangulierenden sind weiblich. Auf dem Poster werden Schlüsselbilder und -sequenzen dargestellt und Implikationen für die gutachterliche Praxis diskutiert.

\section{P29}

\section{Zum Stellenwert radiologischer Methoden in der forensischen Altersdiagnostik im Rahmen des Sozialrechts}

\section{K. Zindler', F.-J. Kramer', J. Lotz ${ }^{3}$, W. Grellner}

'Universitätsmedizin Göttingen, Abteilung Rechtsmedizin, Göttingen, Deutschland, ${ }^{2}$ Universitätsmedizin Göttingen, Klinik für Mund-, Kiefer- und Gesichtschirurgie, Göttingen, Deutschland, ${ }^{3}$ Universitätsmedizin Göttingen, Institut für Diagnostische und Interventionelle Radiologie, Göttingen, Deutschland

Einleitung. Bei der forensischen Altersdiagnostik im Sozialrecht gilt die Legitimation von bildgebenden Methoden als umstritten. Aufgrund gerichtlicher Vorgaben war es möglich, radiologische Verfahren bei dieser Klientel einzusetzen und deren Wertigkeit an einem größeren Fallmaterial zu prüfen.

Material und Methoden. Die vorliegende Arbeit basiert auf einer Auswertung von $33(\mathrm{~m}=32 ; \mathrm{w}=1)$ vorwiegend durch das Jugendamt beauftragten forensischen Altersgutachten aus einem 1-Jahres-Zeitraum (Zielgröße: Lebensalter 18). Die Begutachtung erfolgte nach den Empfehlungen der AGFAD und unter Beachtung der Vorgaben des VG
Göttingen, das bildgebende Verfahren (CT) zuließ. Neben epidemiologischen Daten wurden die Ergebnisse der unterschiedlichen Teilmethoden ausgewertet.

Ergebnisse. 91,0\% der Untersuchten stammten aus Afghanistan. Das angegebene Durchschnittsalter lag bei 16 Jahren und 8 Monaten. In $60,5 \%$ erfolgte eine genaue, in 39,5\% eine ungefähre Altersangabe. Das ermittelte Mindestalter betrug in 87,9\% über 18 Jahre. In allen Fällen zeigte die körperliche Untersuchung eine vollständige Ausbildung der sexuellen Reifezeichen. In 27 Fällen erfolgte ein Röntgen der linken Hand, wobei sich in 92,6\% eine vollständige und in 7,4\% eine weitgehende Ausreifung zeigte. Ein Orthopantomogramm (Weisheitszahnentwicklung) konnte in 84,8\% verwertet werden: Die Stadien E+F nach Demirjian lagen in je 7,1\%, Stadium $G$ in $28,6 \%$ und Stadium $H$ in $42,9 \%$ vor. $14,3 \%$ zeigten Mischstadien. Bezüglich der Ossifikation der Brustbein-Schlüsselbein-Gelenke lag in $66,7 \%$ bds. ein korrespondierendes Stadium vor (9,1\% Stadium 2; 27,3\% Stadium 3; 54,5\% Stadium 4; 9,1\% Stadium 5). 27,3\% zeigten seitenbezogene Stadienunterschiede und in $6,0 \%$ lag ein Stadienübergang vor.

Schlussfolgerung. Es lag eine deutliche Diskrepanz zwischen dem angegebenen und dem ermittelten Alter vor. Die im Sozialrecht wichtige Altersgrenze von 18 Jahren konnte nur unter Zuhilfenahme radiologischer Methoden als sicher überschritten beurteilt werden. Dabei zeigte die CT-Untersuchung der Brustbein-Schlüsselbein-Gelenke die höchste Effizienz.

Fazit. Radiologische Methoden sind auch im Sozialrecht unerlässlich, um ein Mindestalter von 18 Jahren mit hinreichender Sicherheit nachweisen zu können.

\section{P30}

Alleged medical malpractice in forensic autopsy cases: a retrospective study in the Southern part of Osaka City and surrounding areas

T. Ishikawa ${ }^{1,2,3}$, T. Michiue ${ }^{2,3}$, O. Kawamoto ${ }^{2,3}$, M. Nakano², A. Kawahito' ${ }^{2}$, H. Mae$d a^{2,3}$

'Tottori University, Division of Legal Medicine, Faculty of Medicine, Tottori, Japan, ${ }^{2}$ Osaka City University Medical School, Legal Medicine, Osaka, Japan, ${ }^{3}$ Medico-legal Consultation and Postmortem Investigation Support Center, Forensic Autopsy Section, Osaka, Japan

Introduction. We reviewed our forensic autopsy cases over the past 11 years to investigate the characteristics of alleged medical malpractice in relation to the responsibilities of physicians and other health care staff. Materials and methods. Forensic autopsy data from 2002 to 2012 at our institute, which covers the Southern part of Osaka City and surrounding areas, were reviewed, and hospital death cases $(n=487)$ were collected, including sudden unexpected deaths in hospital and unnatural deaths after medical intervention.

Results and discussion. Among 487 hospital deaths involving forensic autopsy, there were 71 cases of alleged medical malpractice, showing an annual incidence from 3 to 11 cases. The most common sites of alleged malpractice were inpatients' wards $(n=28)$, followed by outpatients' wards for internal medicine $(n=15)$, the emergency unit $(n=8)$, psychiatry $(n=8)$, surgery $(n=7)$, and others $(n=33)$, including unspecified sites. Health care staff involved were physicians $(n=53)$, nurses $(n=10)$, and others including care workers $(n=8)$. About half of the cases $(n=32)$ were related to misdiagnosis, which was more frequent than malpractice involving therapeutic procedures by physicians $(n=9)$. Misdiagnosis was more frequent in internal medicine $(n=4)$ than in surgery $(n=3)$. The causes of death varied, including traumas (head, lung, and bowel injuries, drowning, poisoning, and asphyxia) and diseases (cerebral infarction, pneumonia, ischemic heart disease, and cardiomyopathy). Both patients' families and medical staff usually accepted these results; cases progressing to civil law courts were infrequent. The critical assessment of clinically unexpected deaths is essential for medical professionals from a practical and ethical viewpoint to promote the efficacy of health care rather than a legal obligation. 
P31

\section{The study of malpractice in obstetrics}

\section{E. Barinov', P. Romodanovsky', E. Cherkalina', I. Balashova'}

${ }^{1}$ Moscow State University of Medicine and Dentistry, Department of Forensic Medicine and Medical Law, Moscow, Russland

Introduction. The investigation was conducted to prove the criteria of forensic medical estimation of malpractice.

Methods. It was studied in the commission of 1058 forensic medical examinations carried out in civil cases involving malpractice.

Results. Among all cases of malpractice in $13 \%$ the cases were related to obstetricians and gynecologists. At the pre-hospital stage adverse outcomes in obstetric practice arise as a result of the low level of womens' health, extragenital pathology, insufficient qualification of primary health care doctors, the low percentage of hospitalization of pregnant women in specialized departments of hospitals at the early stages. At a hospital stage failures arise at untimely hospitalization of pregnant women, the absence of in-patient treatment in high-risk groups, the lack of hospital beds in specialized maternity hospitals. No less negative was also the inconsistent of numerous individuals, as well as a high level of obstetric injury, the lack of an adequate supply of modern blood substitutes. The causes of failures at the hospital stage include the following factors: lack of medical provision of modern hospitals with antibiotics, analgesics, uterotonics drugs, lack of disposable underwear sets for each mother and newborn, special clothing for the entire staff, as well as enhanced nutrition for pregnant women. The main mistakes in obstetric practice were the techniques of childbirth or pregnancy in the form of late childbirth's $(80 \%)$, when the intrauterine suffering of the fetus took place. In $7 \%$ of cases there were birth injuries. Later, a specialist unit (intensive care, surgery, neurology) was observed in $6 \%$ of cases. Incorrect replacement of blood transfusion was observed in $3 \%$ of cases. The wrong treatment was observed in $4 \%$ of cases.

Conclusions. The study of malpractice in obstetrics improves the quality of care.

\section{P32}

\section{The study of malpractice in cardiology}

\section{O. Kosuhina', E. Barinov', I. Balashova', P. Romodanovsky'}

${ }^{1}$ Moscow State University of Medicine and Dentistry, Department of Forensic Medicine and Medical Law, Moscow, Russland

Introduction. The investigation was conducted to prove the criteria of forensic medical estimation of malpractice.

Patients and methods. Out of 1058 forensic medical examinations carried out in civil cases involving malpractice there were 39 cases of malpractice in cardiology.

Results. The objective reasons of malpractice in cardiology include the severity of the disease complications (47\%), presence of concomitant diseases, worsening of the disease (13\%), the age of the patient $(10 \%)$, the duration of the period from the beginning of the disease before application to a specialist (15\%), self-treatment (6\%), motor activity disturbance and the rules during transportation of patient ( $9 \%)$. Subjective reasons included superficial examination of the patients ( $77 \%)$, admission of patients to hospital at the weekend or on state holidays (13\%), lack of consistent, balanced views of diagnosis schemes, treatment and rehabilitation period (10\%). In the total number of the cases of malpractice there were the following types of insufficient medical aid: diagnostics failure, failure in the medical assistance organization, failure in the delivery of treatment, failure on the maintenance of medical records. Diagnostic failures prevailed and included lack of complete medical history (57\%), incomplete examination of all organs and systems (13\%), incomplete laboratory diagnostic tests ( $15 \%$ ), incomplete differential diagnosis of the disease, including dynamics (5\%), the underestimation of the severity of the disease (3\%), the wrong choice of the basic method of examination
(3\%), the underestimation of the severity of concomitant pathology $(1 \%)$ a survey conducted late (1\%), late diagnosis of the underlying disease (1\%), misinterpretation or ignorance of the data (0.5\%), ignored earlier studies (pre-hospital or carried out in other hospitals; $0.3 \%$ ), the nonengagement with the necessary consultants (of $0.2 \%$ ).

Conclusions. The study of malpractice cases in cardiology improves the quality of care.

\section{P33}

Ein seltener Fall - Selbstbeschädigung der Zunge zum Vortäuschen einer Straftat

\section{E. Doberentz', Y. Albalooshi', B. Madea'}

'Institut für Rechtsmedizin, Universität Bonn, Bonn, Deutschland

Einleitung. Selbstbeschädigungen können unterschiedlichste Motivationen zu Grunde liegen. Die häufigsten Ursachen sind psychischneurologische Erkrankungen oder Störungen. Selbst beigebrachte Verletzungen können aber auch zur Vortäuschung einer Straftat und zur Erlangung von Aufmerksamkeit dienen. Von einem solchen Fall soll hier berichtet werden.

Fallbericht. Ein junger Student asiatischer Herkunft gab vor, überfallen worden zu sein, mit dem Zwang zum Islam zu konvertieren. Dabei habe man ihn geschlagen und mit einem Messer in die Zunge geschnitten. Bei der klinischen und anschließenden rechtsmedizinischen Untersuchung fanden sich nur Zeichen scharfer Gewalteinwirkungen in Form von oberflächlichen Ritz- und Schnittverletzungen an der Stirn und auf der Zunge.

Schlussfolgerung. Selbstbeigebrachte Verletzungen der Zunge sind sehr selten und kommen vor allem in Form von Abbeißen im Rahmen neurologischer Erkrankungen und bei Unfällen vor.

\section{P34}

Differenzierung von Hirnödem oder normalen postmortalen Veränderungen mittels Computertomographie

\section{N. Berger', G. Ampanozi', W. Schweitzer', T.D. Ruder', D. Gascho', L. Ebert', M.J. Thali', P.M. Flach ${ }^{7}$ \\ 'Institut für Rechtsmedizin Zürich, Zürich, Schweiz}

Zielsetzung. Bis zum heutigen Zeitpunkt gibt es keine reliable Methode, um ein bereits vor dem Tod bestehendes oder agonales Hirnödem postmortal mittels Computertomographie (PMCT) sicher zu bestimmen. Normale postmortale Veränderungen des Gehirns in der CT-Untersuchung ähneln Veränderungen, die in Hirnödemen bei lebenden Patienten zu finden sind, da es unmittelbar bei Eintreten des Todes zu einem generalisierten, zytotoxischen Hirnödem kommt. Die Differenzierung zwischen einem bereits vorbestehenden oder vor allem agonalen Hirnödem und normalen postmortalen Veränderungen des Gehirns ist hiermit erschwert. Ziel dieser Studie war, Befunde in der PMCT, mit Ergebnissen in der unmittelbar folgenden forensischen Autopsie zu vergleichen und Kriterien zu Evaluation zu ermitteln.

Material und Methoden. Zwei Radiologen mit Erfahrung in postmortaler Bildgebung evaluierten retrospektiv ${ }^{89} 9$ PMCT. Hierbei wurden Tonsillenherniation, Weite der inneren und äußeren Liquorräume und Houndsfield-Messungen (HU) der grauen und weißen Substanz abhängig von der entsprechenden Altersgruppe notiert. 134 Männer und 55 Frauen mit einem Altersspektrum von 20 bis 88 Jahren (im Mittel 52,6 Jahre) wurden miteinbezogen. Von diesen wiesen 103 keine neuropathologischen Veränderungen auf. 18 wiesen ein Trauma des Kopfes auf. Die Resultate wurden mit den Ergebnissen der forensischen Autopsie verglichen, in der als Zeichen für erhöhten Hirndruck ein erhöhtes Hirngewicht (>1400 g), abgeflachte Gyri und verwaschene Sulci sowie hernierte Tonsillen gewertet wurden. 
Ergebnisse. Vorläufige Resultate weisen darauf hin, dass in der PMCT basierend auf radiologischen Zeichen wie hernierten Tonsillen, HUWerten, und engen Liquorräumen, ein vorbestehendes Hirnödem bestimmt werden kann.

Schlussfolgerung. PMCT eignet sich für die Beurteilung eines vorbestehenden Hirnödems trotz postmortaler Veränderungen des Gehirns.

\section{P35 \\ Das „Basler Grau“ - Optimierung der fotographischen Befunddoku- mentation im Obduktionssaal}

\section{H. Wittig ${ }^{1}$, T. Rost', V. Dittmann ${ }^{7}$ \\ 'Institut für Rechtsmedizin, Basel, Schweiz}

Einleitung. Die fotographische Dokumentation relevanter Befunde im Obduktionssaal bleibt auch im Zeitalter moderner radiologischer Bildgebung ein wichtiger Teilaspekt der rechtsmedizinischen Tätigkeit. Das Bild als Beweismittel sollte in erster Linie authentisch sein. Dies schließt sauberes Arbeiten und eine ästhetische Bildgestaltung aber nicht aus. Methoden. Unter dem Gesichtspunkt einer ästhetischen Bildgestaltung wurden verschiedene, in den meisten Obduktionssälen verfügbare, bzw. einfach zu besorgende Materialien auf ihre Tauglichkeit als Fotohintergrund getestet. Neben einfacher Reinigung und Reflexarmut wurde dabei auch auf Farbtreue, Kontrastbildung und Farbhomogenität sowie zuverlässige Belichtungsmessung geachtet. Verglichen wurden neben Edelstahl (Obduktionstisch) und einer üblichen Organtischplatte insbesondere kommerzielle Kunststoffplatten in grau, weiß und schwarz, trockene und feuchte OP-Tücher sowie spezielle Fotountergründe in blau und grau.

Ergebnisse. Die Vor- und Nachteile der jeweiligen Materialien werden einander gegenübergestellt. Danach erwies sich nach unserer Ansicht die Fotofolie "9o10 Dovegrey" des Herstellers COLORAMA für die Anforderungen des Obduktionssaales als optimal und hat seither als „Basler Grau“ Eingang in die tägliche Routine gefunden. Zur besseren Handhabung wurde die Folie, die relativ kratzfest, nahezu reflexfre und leicht zu reinigen ist, auf einer $100 \times 60 \mathrm{~cm}$ messenden Kunststoffplatte fixiert. Für spezielle Anforderungen können diese Platten mit einfachen Mitteln modifiziert werden.

Schlussfolgerung. Auch bei optimalem Hintergrund bleibt jedoch Sauberkeit die wichtigste Voraussetzung für optisch ansprechende $\mathrm{Ob}$ duktionsfotos, mit denen man sowohl im Gerichtssaal als auch in Publikationen ein gutes Bild abgeben kann.

\section{P36}

\section{Postmortale multiphasische CT-Angiographie zur Klärung von Behandlungsfehlervorwürfen}

\section{A. Heinemann', C. Schröder', S. Grabherr² \\ ${ }^{1}$ Institut für Rechtsmedizin, Hamburg, Deutschland, ${ }^{2}$ Centre Universitaire Romand de Médicine Légale (CUMRL), Lausanne, Schweiz, Schweiz}

Einleitung. Die Klärung von Todesfällen bei der Begutachtung von Behandlungsfehlervorwürfen oder bei der klinischen Qualitätssicherung nach potenziell iatrogen verursachten Komplikationen kann durch die multiphasische postmortale CT-Angiographie (MPMCTA) sinnvoll unterstützt werden. Dabei wird auf Basis eines Standardprotokolls mit einem speziellen Perfusor ein lipophiles Kontrastmittel in das arterielle sowie das venöse Gefäßsystem eingebracht und anschließend eine Teilzirkulation erzeugt.

Methode. Gezeigt werden drei exemplarische Fälle aus der Multizenterstudie der europäischen TWGPAM-Arbeitsgruppe, bei denen die MPMCTA gegenüber der Obduktion einen entscheidenden Mehrwert beim Nachweis von Blutungsquellen darstellte.

Ergebnis. Die MPMCTA kann dazu beitragen, bei postoperativen diffusen Blutungen, z. B. im Abdomen oder im Thorax bei der statischen
Befunderhebung im Rahmen der Obduktion mitunter nicht darstellbare Leckagen zu demonstrieren, eine Abgrenzung zwischen Blutungen venösen und arteriellen Ursprungs sowie grundsätzlich die Dokumentation von Perfusionsverhältnissen nach vaskulären Eingriffen zu ermöglichen. Auch kann bei alternativ möglichen Blutungsquellen eine Priorisierung vorgenommen werden.

Schlussfolgerung. Im forensischen Bereich könnte zukünftig der zunächst bestehende Mehraufwand einer Kombination einer MPMCTA mit der Autopsie für die Ermittlungs- und Kosteneffizienz des Strafverfahrens eine beschleunigte Weichenstellung darstellen, ggf. mit der Vermeidung von aufwendigen Nachbegutachtungen.

P37

Kriterien der direkten und indirekten Zuordnung einer Blutung in der postmortalen CT-Angiographie (MPMCTA)

\section{A. Heinemann', P. Jahnke', H. Vogel', C. Birkenbach', S. Grabherr'}

K. Püschel'

${ }^{1}$ Institut für Rechtsmedizin, Hamburg, Deutschland, ${ }^{2}$ Centre Universitaire Romand de Médicine Légale (CUMRL), Lausanne, Schweiz, Schweiz

Hintergrund und Fragestellung. Die multiphasische postmortale CT-Angiographie (MPMCTA) wird eingesetzt zur Klärung der Ursache einer Blutung. Dabei kann nicht immer von einem unmittelbaren Nachweis einer Gefäßleckage mittels Kontrastmittelbrücke ausgegangen werden. Hat die Blutung zum Tod geführt, wird im Idealfall das blutende Gefäß gezeigt. Ist seit der akuten Blutung Zeit vergangen, ist ein Kontrastmittelaustritt ggf. nicht sicher zu fassen. In diesem Fall macht eine Gefäßpathologie wahrscheinlich, wo und warum es zur Blutung kam. In Einzelfällen wird ein Kontrastmittelaustritt beobachtet, ohne dass die Verbindung zu einem Gefäß erkennbar ist. Geklärt werden soll, wie in den verschiedenen Fällen Aussagen möglich sind.

Material und Methoden. 110 MPMCTAs (multiphasisch, Kontrastmittel auf Paraffinbasis, Virtangio-Methode) wurden im Hinblick auf Beobachtungen evaluiert, die entweder eine Blutung einem Gefäß eindeutig zuordneten (direkter Nachweis) oder die erlaubten, auf ein Gefäß als Blutungsquelle zu schließen (indirekter Nachweis).

Ergebnisse. Es fanden sich verschiedene Gruppen. Sie unterschieden sich durch Unterschiede der Art und Weise, mit denen eine Blutung einem Gefäß zugeordnet werden konnte. Dies waren a) Kontrastmittelaustritt aus Gefäßen, b) Kontrastmittelaustritt ohne sichtbare Gefäßzuordnung, c) Gefäßveränderungen mit Krankheitswert ohne Kontrastmittelaustritt bei vorangegangener Blutung (indirekter Nachweis) oder d) Pathologien an Weichteilen und Knochen mit Blutung ohne Kontrastmittelaustritt bei vorangegangener Blutung (indirekter Nachweis). Schlussfolgerung. Gelingt es bei der Angiographie mit einem Kontrastmittel auf Ölbasis nicht, das blutende Gefäß durch Kontrastmittelfüllung und Kontrastmittelaustritt direkt sichtbar zu machen, hilft ggf. der indirekte Nachweis. Die Spezifität dieser indirekten Hinweise sollte weiter evaluiert werden.

\section{P38}

„Pseudo-Zisternographie“ - Detektion eines Pitfalls in der postmortalen Computertomographie bei der Unterscheidung von fataler Luftembolie und Fäulnisveränderungen

N. Berger', T.D. Ruder', R. Majcen', D. Gascho', W. Schweitzer', S. Ross', G. Ampanozi', M.J. Thali', P.M. Flach

'Institut für Rechtsmedizin Zürich, Zürich, Schweiz

Fallbericht. Ein Bauarbeiter wurde bei der Arbeit durch ein tonnenschweres Bauelement eingeklemmt und konnte nur noch tot geborgen werden. Gleichentags wurde eine postmortale Ganzkörper-Computertomographie (PMCT) vor der forensischen Autopsie durchgeführt. 
Ergebnisse. Neben ausgeprägten Verletzungen des Thorax, der Wirbelsäule und des Beckens wurde zusätzlich positionsabhängig intrakraniell Gas nachgewiesen, obwohl keine Strukturen des Schädels verletzt wurden und keine Gasembolie vorlag. Zusätzlich wäre für Fäulnisveränderungen, welche ebenfalls zu intrakraniell gefundenem Gas führen könnten, zu wenig Zeit vergangen und es waren keine weiteren Fäulniszeichen detektierbar. Bei Beurteilung der vorliegenden Verletzungen des Thorax lag nahe, dass im Rahmen einer zusätzlich vorliegenden Chancefraktur Gas intrathekal entlang der Wirbelsäule ins Gehirn aufgestiegen ist und so eine „Pseudo-Zisternographie“ mit Gas um den Circulus arteriosus Willisi verursacht hat. Dies könnte bei ungenauer Betrachtung der Bilder zu falsch-positiven Befunden wie postmortalen Veränderungen bei Fäulnis, Luftembolien oder Vermutungen über ein Schädeltrauma führen.

Schlussfolgerung. Dieser Fall weist einen Befund auf, welcher in einer Autopsie in dieser Präzision nicht dargestellt werden kann und zeigt auf, dass vor der Autopsie durchgeführte CT-Untersuchungen Vorteile mit sich bringen und als Mahnung dienen sollen, alle evaluierten Befunde in einen logischen Kontext zu setzen, um postmortale Fehlbefunde zu vermeiden.

\section{P39}

Ein Roboter für automatisierte Reihenmessungen an Leichenhaut

V. Sterzik', M. Bohnert', L. Belenki², A. Liehr², C. Ratajczak³, M. Wülker ${ }^{3}$ ${ }^{1}$ Institut für Rechtsmedizin, Würzburg, Deutschland, ${ }^{2}$ Freiburger Materialforschungszentrum, Freiburg, Deutschland, ${ }^{3}$ Offenburg University of Applied Sciences, Offenburg, Deutschland

Um Reihenmessungen von Reflexionsspektren an Leichenhaut im postmortalen Verlauf durchzuführen, wurde in Zusammenarbeit mit der Hochschule Offenburg ein robotergestütztes mobiles Messsystem entwickelt. Die Basis bildet ein kommerzieller Industrieroboter, der mit Kamera, Reflexionsspektrometer und Temperaturerfassung ausgestattet wurde, um Reflexionsspektrum, Fotographie der Oberflächen und Temperatur zu jedem Messzeitpunkt aufzeichnen zu können. Die Steuerung und Aufzeichnungen der Messungen erfolgen über Lab$V{ }^{\star}{ }^{\star}$. Durch die Automatisierung der Messungen ist die Voraussetzung für eine systematische Erfassung der Messreihen ohne äußere Störeinflüsse gegeben.

\section{P40}

\section{$3 \mathrm{D}$ site of event reconstruction based on material registered with officer's forehead camera}

\section{W. Tunikowski', K. Maksymowicz', J. Kosciuk' ' T. Jurek', M. Kudla'}

'Meidizinische Universität Wroclaw, Institut für Rechtsmedizin, Wroclaw, Polen, ${ }^{2}$ Technologie Universität Wroclaw, ${ }^{3} \mathrm{D}$ Scanning and Modelling Laboratory, Wroclaw, Polen

Introduction. Based on their previously conducted studies the authors demonstrate possible application of material registered using a digital forehead camera for $3 \mathrm{D}$ crime event reconstruction. The study determines the expediency and functionality of equipping intervention officers present at the site of the event with the above device.

Methods. The original site of the event may become distorted by various factors occurring in the time between the actual event and its registration, e.g. through necessary, yet invasive to the site, rescue actions by the intervention forces. Information which is valuable to the investigating authorities and which may become altered, e.g. due to undertaken rescue actions, may include the spatial position of the subjects at the time of their discovery, micro traces of blood on floor tiles, the extent to which the subjects' clothing is damaged, etc.

Results and conclusions. The authors demonstrate test results from a simulated site of event registered using a camera recording from the van- tage point of the intervention officer first to have contact with the site. The test is conducted in such a way that data is registered with zero or least impact by the camera "operator"; the authors believe that site recording must not be done at any expense of an officer's physical fitness. The authors additionally indicate potential applications of data obtained from the camera for three-dimensional reconstruction of space and participants of the event. The authors believe that three-dimensional surveying of the site has a significant meaning for its further archiving, demonstration and analysis purposes. Finally, the authors evaluate the technical potential and obstacles related to obtaining and processing the above described data, as well as its significance for further work of the investigating authorities.

\section{P41}

\section{Beispiel einer mehrstufigen Betrachtung des Verlaufs eines Tötungsdeliktes unter Verwendung der 3D-Wiedergabe}

\section{K. Maksymowicz', W. Tunikowski', J. Kosciuk2, T. Jurek}

'Medizinische Universität Wroclaw, Lehrstuhl für Gerichtsmedizin, Wroclaw, Polen, ${ }^{2}$ Technische Universität Wroclaw, ${ }^{3} \mathrm{D}$-Scanning und Modelling-Labor, Wroclaw, Polen

Einleitung. Auf der Basis eines analysierten und begutachteten Mordfalls präsentieren die Autoren einen breiten Anwendungsbereich von Scanning, Modelling und Animation unter Verwendung der $3 \mathrm{D}-\mathrm{Wie}-$ dergabe, um den Tatablauf mehrstufig zu betrachten. Das Beweismaterial zur Analyse der gegenständlichen Sache bildeten die gesicherten mutmaßlichen Straftatwerkzeuge, die Obduktionsbefunde und die Fotodokumentation des Tatorts. Die Sachverständigen wurden beauftragt mit der Identifizierung des Tatwerkzeugs, mit der Analyse der Verletzungen sowie mit der Rekonstruktion des Tatablaufs mit besonderer Berücksichtigung der Rolle des Verdächtigen.

Methoden und Ergebnisse. Um die von der Staatsanwaltschaft gestellten Aufgaben zu erfüllen, haben die Autoren das Beweismaterial auf drei unterschiedliche Aspekte überprüft, um sie in einen kohärenten und logischen Zusammenhang zu bringen, der es erlaubt, den wahrscheinlichsten Tatverlauf wiederzugeben. Die erste Stufe der Analyse - die Identifizierung des Tatwerkzeugs - beruhte auf der Suche nach gemeinsamen Elementen zwischen den charakteristischen Merkmalen des Beweiswerkzeugs und den Verletzungsmerkmalen. In der zweiten Analysestufe wurde aufgrund des Blutspurenmusters die räumliche Ortung ihrer Quellen (Schlagwunden des Kopfes), also des Kontakts eines Werkzeugs mit dem Körper der Verletzten, festgestellt. Auf diese Art und Weise wurde die wahrscheinlichste maximale Höhe der Kopfposition der Verletzten während der Beibringung der Verletzungen bestimmt. In der dritten Stufe wurden die dreidimensionalen Gestaltmodelle der Tatbeteiligten festgelegt und die Beschränkungen ihrer gegenseitigen Bewegungsrelationen durch die Raumhindernisse überprüft.

Schlussfolgerung. Der in der Arbeit analysierte Fall zeigt die Möglichkeiten der mehrstufigen Rekonstruktion von Tatabläufen unter Verwendung der $3 \mathrm{D}$-Wiedergabe. 


\section{P42}

Doping und Dopingbekämpfung in der Bundesrepublik Deutschland - Analyse des Berichts der Bundesregierung zur Evaluation des Gesetzes zur Verbesserung der Bekämpfung des Dopings im Sport (DBVG)

\author{
M. Parzeller', S. Prittwitz', C. Prittwitz ${ }^{2}$ \\ 'Institut für Rechtsmedizin, Goethe-Universität, Frankfurt am Main, \\ Deutschland, ${ }^{2}$ Institut Kriminalwiss./Rechtsphilosophie, Goethe- \\ Universität, Frankfurt am Main, Deutschland
}

Fragestellung. Der Beitrag befasst sich mit dem Bericht der Bundesregierung vom September 2012 zur Evaluation des Gesetzes zur Verbesserung der Bekämpfung des Dopings im Sport (DBVG).

Methoden. Dem Bericht der Bundesregierung liegen eine empirische Rechtstatsachenforschung und eine retrospektive Gesetzesfolgenabschätzung u. a. auf der Grundlage von Statistiken zu einschlägigen Ermittlungs- und Strafverfahren im AMG zugrunde. Zudem werden in dem Bericht der Bundesregierung gesetzgeberische Konsequenzen aufgezeigt und sonstige zu ergreifende Maßnahmen im Kampf gegen Doping im Sport angeführt. Der Bericht wird analysiert und Schwachstellen in der Begründung werden aufgezeigt.

Ergebnisse. Kritisch ist zu bewerten, dass der Beobachtungszeitraum zu kurz gewählt wurde, um zielführende Änderungen der Effektivität bei der Strafverfolgung im Kampf gegen Doping nachweisen zu können. Sowohl eine Vielzahl von Einstellungen als zahlreiche offene Strafverfahren sprechen derzeit gegen die positive Bewertung durch die Bundesregierung. Weitere Probleme ergeben sich aus der uneinheitlichen Behandlung des einfachen Besitzes als Anfangsverdacht einer Strafbarkeit nach $\$ \$ 95$ Abs. 1 Nr. 2b, 6a Abs. 2a S. 1, AMG, möglichen Strafbarkeitslücken bei Wirkstoffen, der Durchführung von Verfahren im Bereich der internationalen Rechtshilfe, der ungeklärten Frage einer additiven Mengenberechnung nach der Dopingmittelmengenverordnung (DmMV) etc.

Schlussfolgerungen. Entgegen der ursprünglichen Intention des Gesetzgebers und entgegen der Einschätzung durch die Bundesregierung belegt der Bericht einen Erfolg des DBVG im Kampf gegen Doping im Spitzensport nicht. Allerdings wurde durch die Gesetzesnovellierung eine Aufhellung des Dunkelfelds des Dopings und Arzneimittelmissbrauchs im Bodybuilding erreicht. Der Einsatz von Arzneimitteln zur Leistungssteigerung stellt aber in unserer Gesellschaft kein isoliertes Problem des Sports dar, sondern Formen des Arzneimittelmissbrauchs betreffen die unterschiedlichsten Bereiche der Gesellschaft (z. B. Doping am Arbeitsplatz).

\section{P43}

Der Tod beim Sport aus natürlicher Ursache - Ergebnisse einer Follow-up-Mortalitätsstudie von 1972-2012

\section{B. Zedler', H. Bratzke', M. Parzeller ${ }^{1}$ \\ 'Institut für Rechtsmedizin, Goethe-Universität, Frankfurt am Main, Deutschland}

Fragestellung. Plötzliche und unerwartete Todesfälle beim Sport werfen regelmäßig die Frage nach der Todesursache auf, da die körperliche Aktivität üblicherweise als gesundheitsfördernd angesehen wird.

Methoden. Die retrospektive Follow-up-Mortalitätsstudie basiert auf dem Datenmaterial des Instituts für Rechtsmedizin des Klinikums der Johann Wolfgang Goethe-Universität in Frankfurt.

Ergebnisse. Über einen Zeitraum von 41 Jahren (1972-2012) wurden in über 35.500 forensischen Obduktionen 138 Fälle mit einer natürlichen Todesursache im Zusammenhang mit sportlicher Betätigung dokumentiert. Die 130 betroffenen männlichen Sportler waren durchschnittlich 52,4 Jahre, die 9 weiblichen Sportlerinnen im Durchschnitt 44 Jahre alt. Am häufigsten waren die Sportarten Fußball $(n=25)$, Laufsport $(n=20)$, Schwimmen $(n=20)$, Radfahren $(n=18)$, Tennis $(n=7)$, Kegeln $(\mathrm{n}=5)$ und Tauchen $(\mathrm{n}=5)$ vertreten. Die häufigsten Todesursachen waren ein frischer Myokardinfarkt ( $n=34$; Altersdurchschnitt 52,0 Jahre), ein Reinfarkt ( $\mathrm{n}=29$; Altersdurchschnitt: 59,5 Jahre) oder eine koronare Herzerkrankung ( $\mathrm{n}=45$; Altersdurchschnitt: 55,4 Jahre). Weitere Ergebnisse werden zum Body-Mass-Index (BMI), zum Herzgewicht und zur jahreszeitlichen Verteilung vorgestellt.

Schlussfolgerungen. Sportliche Betätigungen können insbesondere bei Patienten mit vorgeschädigtem Herzen (KHK, Z. n. Myokardinfarkt) zum plötzlichen Herztod führen, wenn die Belastung nicht im adäquaten Verhältnis zum Gesundheitszustand des Sportlers steht.

\section{P44}

Tod aus natürlicher Ursache bei sexuellen Aktivitäten - Ergebnisse einer Follow-up-Mortalitätsstudie von 1972-2012

\section{B. Zedler', H. Bratzke', M. Parzeller}

IInstitut für Rechtsmedizin, Goethe-Universität, Frankfurt am Main, Deutschland

Fragestellung. Beim Orgasmus kommt es zu einem Anstieg verschiedener kardiopulmonaler Parameter. Die dadurch hervorgerufene Belastung entspricht etwa 75 Watt und kann vor allem bei körperlichen Vorschäden zu einer Dekompensation der physischen Reserven bis hin zum Auftreten von natürlichen Todesfällen führen.

Methoden. Die retrospektive Follow-up-Mortalitätsstudie basiert auf dem Datenmaterial des Instituts für Rechtsmedizin des Klinikums der Goethe-Universität in Frankfurt.

Ergebnisse. Über einen Zeitraum von 41 Jahren (1972-2012) wurden bei über 35.500 forensischen Obduktionen 94 Fälle mit einer natürlichen Todesursache im Zusammenhang mit sexuellen Handlungen dokumentiert. Bis auf 6 Frauen waren ausschließlich Männer betroffen. Der Altersdurchschnitt der Frauen betrug 41,3 Jahre und der der Männer 57,4 Jahre. Todesursächlich waren Myokardinfarkte $(n=18)$, Reinfarkte $(n=16)$ oder eine ausgeprägte koronare Herzerkrankung $(n=27)$. In 8 Fällen wurden rupturierte Aortenaneurysmen, in 8 Fällen kardiomyopathische Veränderungen, in je einem Fall eine Myokarditis und eine thrombotische Verlegung einer Koronararterie als todesursächlich gewertet. Hirnblutungen führten in 12 Fällen zum Tod. In 3 Fällen wurde ohne weitere Differenzierung, z. B. ein akutes Herzversagen oder ein plötzlicher Herztod, als Todesursache angeführt. Am häufigsten wurde der plötzliche Tod von Männern bei außerehelichen sexuellen Kontakten mit Frauen $(n=42)$, mit Prostituierten $(n=35)$ oder einer Geliebten $(n=7)$ dokumentiert. Mit der eigenen Ehefrau ereigneten sich 9 und mit der Lebensgefährtin 4 tödliche Fälle. Bei sexueller Betätigung ohne Sexualpartner, z. B. Selbstbefriedigung, kamen 23 Todesfälle vor. Homosexuelle Kontakte waren bei 10 Todesfällen angeführt. Bei 6 Fällen lagen keine näheren Angaben vor. Bei den Frauen trat der Tod in 3 Fälle nach einem Sexualkontakt mit einem Lebensgefährten und in 2 Fällen mit einem Bekannten bzw. Geliebten ein. Bei einem weiteren Fall lagen keine Angaben vor. Weitere Ergebnisse werden zum Body-Mass-Index (BMI), zum Herzgewicht, zur Auffindesituation und zur jahreszeitlichen Verteilung erörtert.

Schlussfolgerungen. Sexuelle Betätigungen können insbesondere bei Patienten mit vorgeschädigtem Herzen (KHK, Z. n. Myokardinfarkt) zum plötzlichen Herztod führen. 
P45

The role of anomalies of dental series of children in the republic of armenia in forensic identification cases

\section{Bisharyan \\ ${ }^{1}$ Ministry of Health, Republican Scientific-Practical Center of Forensic Medicine, Jerewan, Armenien}

Introduction. Indicators of age dynamics of dental anomalies in the school period can be an important aspect in the identification activities using data from the dental status of the child.

Methods. The features of age dynamics of dental anomalies in 4158 children of Armenia in the age from 3 to 17 years had been studied.

Results. Parallel increases in the prevalence of crowding of the teeth with age in children 3-17 years old in the study of these anomalies of dental series were revealed: narrowing, diastema and overcrowding. In 3-year-old persons the number of mentioned anomalies 20.83 \pm 2.91 per 1000 children, in 17-year-old persons the number $653.0 \pm 9.63(\mathrm{p}<0.05)$ were found. In our opinion this natural growth due to an increase of place deficit in the areas of the jaws, and some other reasons took place. It was found a strong correlation between crowding of dental rows of the upper and lower jaws: Pearson's coefficient has reached $r=0.84$. An increase in the prevalence of narrowing of dental series due to age, from $10.42 \pm 0.7$ in 3 -year-olds to $204.08 \pm 8.21$ in 17 -year-olds was observed $(\mathrm{p}<0.05)$. It was found that the greatest age fluctuations exposed prevalence of diastema. The number of children with permanent dentition at the age of 17 years $(137.76 \pm 7.02)$ took place in 2 times more than the 3-year-olds (62.5 4.93$)$, and 2 times less than that of 8 -yearolds (295.17 \pm 9.29$)$. It was found the high prevalence rates of the gap between teeth for children 8-10 years old compared to 11- to 17-year-olds $(\mathrm{p}<0.05)$. The strong correlation $(\mathrm{r}=\mathrm{0} .77)$ concerning the registration of teeth gaps between the upper and lower jaws was revealed.

Conclusions. Analysis of the prevalence rates of anomalies of dental series at the children of different ages showed that in 8-year-olds they differ from each other, and for children between 11 and 17 years they are practically identical, except for the crowding of the teeth. In addition, there is a correlation of bunched location teeth between the upper and lower jaws.

\section{P46}

\section{Pulslos am Leben? - Kunstherz trotzt Herztod!}

\section{J. Manhart', U. Hammer', A. Büttner}

'Institut für Rechtsmedizin, forensische Medizin, Rostock, Deutschland

Fragestellung. Herzunterstützungssysteme (LVAD, „left ventricular assist device") werden seit über 40 Jahren am Menschen angewendet. Es werden externe von internen Systemen unterschieden. Das interne HeartMate-System der Firma Thermo Cardio System Inc. (Woburn, USA) wurde in den 1980er Jahren entwickelt und erhielt 1994 erstmals die Zulassung der FDA für die Anwendung am Menschen. Die erste Pumpengeneration war pneumatisch betrieben, deren Nachfolger elektrisch. Alle Systeme werden extern mit Strom versorgt und gesteuert. Das aktuelle HeartMate-II-Assist-System weist nochmalige Verbesserungen in der Bauform und den Abmessungen auf. Die Axialpumpe ist mechanisch robust und technisch simpel aufgebaut. Es wird ein kontinuierlicher Flow bei bis zu $10.000 \mathrm{U} / \mathrm{min}$ gewährleistet. Da das System auf eine aktive Füllung des linken Ventrikels angewiesen und somit besonders anfällig für Rhythmusstörungen ist, werden den Patienten immer interne Cardioverter-Defibrillatoren (ICD) implantiert.

Methoden und Ergebnisse. Anhand des Sektionsfalles eines seit etwa 5 Jahren wegen einer dilatativen Kardiomyopathie mit dem HeartMateII-Assist-System versorgten 59 Jahre alt gewordenen Patienten soll auf die Probleme und Schwierigkeiten bei der Sektionstechnik und Präparation hingewiesen werden unter Berücksichtigung besonderer kriminologischer und klinischer Aspekte.
Schlussfolgerungen. Die Möglichkeit eines zumindest telefonischen "Standby“-Supports durch den Hersteller bzw. Vertreiber ist unter der Sektion zu nutzen. Die Anwesenheit eines Kardiotechnikers oder Herzchirurgen mit Erfahrungen in der Implantation derartiger Systeme wäre wünschenswert, ist in der Praxis jedoch nicht immer umsetzbar. Der Hersteller wird regelhaft an einer Untersuchung des Gerätes interessiert sein. Die Entscheidung, inwieweit diese durch den Hersteller zulässig sein kann (obwohl zumeist nur der Hersteller die Untersuchung technisch durchführen kann!), obliegt im Fall einer gerichtlichen Obduktion der Staatsanwaltschaft. Der ICD ist regelmäßig in die Untersuchung einzubeziehen.

P47

Untersuchungen zu Häufigkeit und Inhalt von Behandlungsfehlervorwürfen aus dem Institut für Rechtsmedizin der Universitätsmedizin Greifswald

\section{B. Heinig', K. P. Philipp 2 , B. Bockholdt ${ }^{2}$}

${ }^{1}$ Evangelisches Geriatriezentrum, Berlin, Deutschland, ${ }^{2}$ Universitätsmedizin Greifswald, Institut für Rechtsmedizin, Greifswald, Deutschland

Einleitung. Eine umfangreiche systematische Untersuchung zur Inzidenz und zum Wesen medizinischer Behandlungsfehler bzw. Behandlungsfehlervorwürfen in Deutschland wurde im Rahmen einer bundesweiten Multizenterstudie von Preuß et al. vorgelegt. Im Jahr 2010 wurden bei den Gutachterkommissionen der Landesärztekammern 11.016 Anträge zu mutmaßlichen letalen oder nichtletalen Behandlungsfehler eingereicht. In einem Großteil der Fälle bestätigt sich der Vorwurf nicht. Eine Untersuchung der Begutachtungen zu letalen und nicht letalen Behandlungsvorwürfen aus dem Einzugsgebiet des Instituts für Rechtsmedizin der Universitätsmedizin Greifswald über mehrere Jahre existiert bisher nicht.

Material und Methoden. Zur Auswertung standen die Obduktionsprotokolle und die sog. Zusammenhangsgutachten nach Aktenlage des Instituts für Rechtsmedizin der Universitätsmedizin Greifswald aus den Jahren 1996-2008 zur Verfügung.

Ergebnisse. Im Untersuchungszeitraum wurden 295 Gutachten zur Frage eines Behandlungsfehlers erstellt. Dabei handelte es sich um 256 letale und 39 nichtletale Fälle. In 78 der letalen Fälle konnte sowohl das Obduktionsgutachten als auch das sich daran anschließende $\mathrm{Zu}$ sammenhangsgutachten auswertet werden. Der Anteil der Behandlungsfehlervorwürfe bei den Obduktionen liegt bei 7,2\% mit steigender Tendenz in den letzten Jahren. Die Chirurgie war das am häufigsten betroffene Fachgebiet (23\%). In 9,4\% der Fälle waren Pflegefehler der Inhalt des Vorwurfs.

Schlussfolgerungen. Das Spektrum des Obduktionsgutes des Institutes hat sich in den letzten Jahren des Untersuchungszeitraumes dahingehend verändert, dass die Vorwürfe von Behandlungsfehlern bei den Todesermittlungsverfahren zunahmen und häufiger der Grund zur Obduktionsanordnung waren. Die häufigsten Vorwürfe betreffen, wie auch in der vorhandenen Literatur, am häufigsten die chirurgischen Fächer. Dass sich erhobene Vorwürfe bestätigten und es zu einer Hauptverhandlung gekommen war, war praktisch eine absolute Ausnahme. 
P48

Defining the criteria for releasing of organs and tissues from the deceased for transplantation: what role should the forensic pathologist play in this process (the Belarus' case)

\section{A. Famenka?}

'State Service of Forensic Medicine, Minsk, Weißrussland

Aim. The objective of the study is to provide arguments supporting the position that organ procurement for transplantation from the deceased donors can occur without compromising the forensic pathologists' specific medico-legal responsibilities.

Methods. Legal and regulatory framework, as well as peculiarities of practice related to the role of forensic pathologists in the procurement of transplant organs from the deceased donors in Belarus, are analyzed by reviewing the relevant legal acts, regulations and guidelines. Concerns which often are raised with regard to the process of authorization or denial of the procurement of organs from the deceased donors are then analyzed in terms of their objectivity and reasonableness.

Results. In Belarus, current legal and regulatory framework governing the forensic pathologists' specific medico-legal responsibilities does not specify the criteria of the decision-making process with regard to authorization or denial of the procurement of organs from the deceased donors. Under these circumstances, forensic pathologists quite often deny organ procurement for transplantation from the deceased donors on the basis of the belief that their ability to carry out their medico-legal responsibilities can be compromised. However, most arguments for such a denial have no reliable evidence to support them, and apparently stem from lack of cooperation between forensic pathologists and transplant teams.

Conclusions. The results of the study suggest that in most cases, organ procurement for transplantation from the deceased donors does not interfere with fulfilling the statutory mandate of forensic pathologists to decide on cause and manner of death, and provide a solid factual foundation for expert opinions. Suggestions are made for encouraging cooperation between forensic pathologists and transplant teams in $\mathrm{Be}$ larus to maximize the potential for forensic pathologists' approval of the procurement of organs from the deceased donors.

\section{P49}

Häufigkeit und Bedeutung unspezifischer morphologischer Obduktionsbefunde auf eine Intoxikation

\section{K. Trübner', A. Klöppel', S. Nasse', T. Bajanowski'}

'Universitätsklinikum Essen, Institut für Rechtsmedizin, Essen, Deutschland

Zielsetzung. Ziel dieser Arbeit war eine retrospektive Datenerhebung und Analyse jener Todesfälle, für die eine Alkohol- und/oder chemischtoxikologische Untersuchung im Rahmen der Obduktionen am rechtsmedizinischen Institut Essen in den Jahren 2004 bis 2007 durchgeführt wurde. Dabei wurden insbesondere die dokumentierten unspezifischen morphologischen Befunde, die auf eine Intoxikation hinweisen (Hirnödem, hämorrhagisches Lungenöden, prall gefüllte Harnblase u. a.), ausgewertet.

Methoden. Von 2039 Obduktionen konnten 757 Todesfälle nähergehend hinsichtlich der Vorgeschichte, Auffindesituation, Sektionsbefunde, Ergebnisse der Toxikologie und Todesursache untersucht werden. In 243 Fällen $(11,9 \%)$ wurde eine Intoxikation als Todesursache ermittelt. Ergebnisse. Unter den Monointoxikationen (73,3\%) dominierten vorwiegend die Vergiftungen durch illegale Betäubungsmittel (30,9\%). Unter den Polyintoxikationen waren besonders die durch eine Kombination aus Alkohol und illegalen Betäubungsmitteln dominierend. $73,3 \%$ der Intoxierten waren männlichen und $26,7 \%$ weiblichen $\mathrm{Ge}$ schlechts. Mit 80 Fällen (30,4\%) war die Altersklasse der 30- bis 39-Jährigen am häufigsten vertreten. Von den dokumentierten morphologischen unspezifischen Befunden, die für eine Intoxikation sprachen, wurde am häufigsten ein Hirnödem (90,5\%) diagnostiziert. Ein hämorrhagisches Lungenödem wurde in $71,9 \%$ der Fälle, eine Blutstauung der inneren Organe in 53,3\% und der Befund einer prall gefüllten Harnblase wurde in $45 \%$ aller Intoxikationen beschrieben. Diese Befunde dienen vor allem als Grundlage für die Empfehlung toxikologischer Untersuchungen. So konnten 24 Todesfälle aufgeklärt werden, bei denen der Obduzent der Staatsanwaltschaft eine toxikologische Untersuchung zur Klärung der Todesursache aufgrund des Vorhandenseins solcher morphologischer Hinweise empfohlen hatte. In 16 Fällen wurde trotz dieser Hinweise keine toxikologische Untersuchung in Auftrag gegeben, so dass die Todesursache weiterhin ungeklärt blieb.

Schlussfolgerung. Das Vorhandensein von unspezifischen morphologischen Hinweisen auf eine Intoxikation sollte Anlass für die Anordnung einer toxikologischen Untersuchung bei allen ungeklärten Todesfällen sein.

\section{P50}

\section{Maternofetale Methanolvergiftung mit letalem Ausgang}

\section{H. Jung', A. Idor ${ }^{2}$, K. Trübner}

'Universität Tirgu Mures, Institut für Rechtsmedizin, Tirgu Mures, Rumänien, ${ }^{2}$ Universität Tirgu Mures, Institut für Rechtsmedizin, Tirgu Mures, Rumänien, ${ }^{3}$ Universitätsklinikum Essen, Institut für Rechtsmedizin, Essen, Deutschland

Einleitung. Die letale Dosis für Methanol beim Menschen soll zwischen 30 und 240 g liegen, aber schon Mengen von 5-10 g können schwere und auch tödliche Vergiftungen verursachen. Die häufigsten Intoxikationen kommen akzidentell vor. Da die toxische Wirkung hauptsächlich von den Oxydationsprodukten Formaldehyd und Ameisensäure ausgeht, treten die ersten Vergiftungssymptome verzögert ein. Tödliche Intoxikationen der Mutter und des Fötus während der Schwangerschaft wurden sehr selten in der Literatur beschrieben.

Fallbericht. Eine 39-jährige Frau wurde in der 35. Schwangerschaftswoche ihrer 4. Schwangerschaft mit der Diagnose „Methanolvergiftung, in utero toter Fötus" in ein Krankenhaus eingeliefert. Diagnostiziert wurde eine metabolische Azidose mit Hypernatriämie. Die toxikologische Untersuchung ergab eine Blutalkoholkonzentration von $275 \mathrm{mg} / \mathrm{dl}$, davon $170 \mathrm{mg} / \mathrm{dl}$ Methanol (Methode nach Widmark). Der Fötus wurde am nächsten Tag extrahiert und die Mutter starb 2 Tage später.

Obduktionsergebnisse. Die Obduktion ergab ein Hirnödem mit diffusen Blutungen im Putamen, Globus pallidus sowie im Hirnstamm; wenige hypoxische Petechien subpleural und subepikardial, diffuse Blutungen in der Nierenrinde.

Toxikologie. Mittels Gaschromatographie wurden das Blut der Frau bei der Aufnahme im Spital bzw. das Blut vom Fötus bei der Obduktion untersucht. Neben hohen Blutkonzentrationen von Methanol (170/199 mg/dl) und Ethanol (105/198 mg/dl) wurden auch Begleitalkohole identifiziert: Azeton, Isobutanol, 1-Butanol, Amylalkohol bei beiden und bei der Mutter zusätzlich noch 2-Butanol und n-Propanol.

Diskussion. Die Begleitstoffkonfiguration in unserem Fall zeigt den Konsum von Obstdestillaten und wahrscheinlich auch Methanol. Hohe Konzentrationen von Methanol sind für längere Zeit nach dem Konsum zu beobachten, es gibt eine Kompetition mit Ethanol für die Alkoholdehydrogenase. Die hämorrhagischen Nekrosen in den Hirnbasalganglien sind ein typischer Befund bei der Methanolintoxikation, wobei die Ätiologie ungeklärt ist.

Schlussfolgerung. Maternofetale tödliche Intoxikationen mit Methanol kommen sehr selten vor. Durch die gaschromatographische Begleitstoffanalyse können Informationen über die Art des konsumierten Getränks erhalten werden. 


\section{P5}

Localization of micro-objects in injuries as a trace evidence of blunt force trauma

\section{A. Maltsev ${ }^{1}$ \\ 'Kirov State Medical Academy, Department of Forensic Medicine, Kirov, Russland}

Introduction. Blunt force trauma is in importance for the investigation due to the fact that damages caused to the body or head with a blunt instrument in $42 \%$ and due to traffic accidents - in $30 \%$ of mechanical trauma cases which caused death according to analysis of cases of Kirov region of Russia.

Methods. 37 corpses with injuries which were caused by blunt force trauma were investigated. In all cases the large fragments of skin, scalp and bones with injuries from corpses were extracted and studied in laboratory. The following methods were carried out: macroscopic, microscopy by stereo microscope, X-ray fluorescence spectrometry, soft X-ray examination.

Results. It was found that the micro-objects which can be most frequently registered were the following: microfibres, micro particles of metals and paint coverings of cars and blunt instruments. In most cases micro-objects in the deep part of wounds, on the surface of the bone and on the periosteum have been found. In addition the foreign microobjects in the micro canals of bone tissue (Haversian canals) were discovered. In our opinion the foreign micro-objects can be formed mostly as a result of direct blow of trauma instrument to the hard surface of bone. Then the foreign micro-objects into the bone tissue had been knocked. As a result a lot of micro-objects to the bone tissue and periosteum were transferred. Comparative investigation and identification of micro-objects in the last part of study have been performed.

Conclusions. It is important to cut out the soft tissues and bone in a single block in the aim to avoid a micro-objects loss. The micro-objects detection and identification may be used as an evidence of trauma of certain blunt instrument.

\section{P52}

\section{Zur Morphologie und Phänomenologie von Armbrust-Schussver- letzungen}

\section{G. Kernbach-Wighton', B. Madea'}

'Institut für Rechtsmedizin, Universitätsklinikum Bonn, Bonn, Deutschland

Einleitung. Waffenrechtlich entspricht die Armbrust einer Schusswaffe. Diese „bogenähnliche Fernwaffe“ verschießt Pfeile oder Bolzen aus Metall, Kunststoff oder Holz. Moderne Armbrustbögen bestehen aus Glas-Kohlefasern bzw. Leichtmetall, bei Pfeilgeschwindigkeiten von über $400 \mathrm{~km} / \mathrm{h}$. Erwerb, Besitz und Führen bedürfen in Deutschland keiner Erlaubnis. In den USA, Frankreich und Südafrika ist es legal, mit Armbrüsten zu jagen. In den meisten deutschen Bundesländern ist jedoch die Jagd per Armbrust verboten. In Deutschland werden Armbrüste oftmals zum Schießsport verwendet. Jugendliche unter 18 Jahren dürfen eine Armbrust nur unter Aufsicht benutzen. Es wird über zwei Fälle von Armbrust-Schussverletzungen berichtet.

Fall 1. Ein 33-jähriger Mann wurde mit einer Armbrust beschossen und erlitt eine Fast-Durchschussverletzung des linken Oberschenkels oberhalb der Kniekehle. Der Pfeil wurde durch den Verletzten selbst entfernt. Nachfolgend erfolgte eine chirurgische Revision. Projektil war ein sog. Jagdpfeil (Broad-Head) mit vierschneidiger Spitze, Länge etwa $35 \mathrm{~cm}$. Die Hautverletzungen seien dreizackig bzw. sternförmig gewesen. Anamnestisch sei bereits vor 2 Monaten eine Verletzung durch einen Armbrustpfeil-Steckschuss erfolgt. Bei der Verletzungslokalisation habe es sich ebenso um den linken rückseitigen proximalen Oberschenkel gehandelt.
Fall 2. Ein 47-jähriger Mann wurde auf seinem Grundstück kniend tot aufgefunden, direkt vor ihm eine entspannte Armbrust ohne Pfeil. Es bestand eine Kopf-Steckschussverletzung durch einen vierschneidigen Jagd-Armbrustpfeil (Broad-Head) mit Eintritt in der oberen Mundpartie, bei aufsteigendem Wundkanal, Durchsetzung von Schädelbasis und rechter Hemisphäre sowie Steckenbleiben der Spitze in der Schädelkalotte hoch-okzipital.

Schlussfolgerung. Fallkonstellationen, ballistische Überlegungen, Wundmorphologie, technische Gegebenheiten bei den verwendeten Armbrüsten und herauszuhebende forensische sowie spurenkundliche Aspekte werden dargestellt und diskutiert.

\section{P53}

Kraniales CT als Grundlage von Tatrekonstruktion und Identifizierung eines Tatwerkzeugs

\section{B. Madea', H. Urbach ${ }^{2}$}

'Institut für Rechtsmedizin, Bonn, Deutschland, ${ }^{2}$ Radiologische Klinik, Neuroradiologie, Bonn, Deutschland

Einleitung. Befunde bildgebender Diagnostik stellen eine ideale Grundlage für eine Tatrekonstruktion und eventuell die Identifizierung eines Tatwerkzeugs dar. Dies soll am Fall eines einige Tage überlebten schweren Schädel-Hirn-Traumas in Folge eines Raubüberfalls, bei dem die Entstehung radiologisch und autoptisch dokumentierter Schädelverletzungen kontrovers diskutiert wurde, dargestellt werden.

Fallbericht. Ein 51 Jahre alter Mann erlitt bei einem Raubüberfall schwere Schädel-Hirn-Verletzungen, an denen er einige Tage später starb. Die Entstehung eines Bruchliniensystems parietookzipital links, der auch als Globusbruch bezeichnet wurde, wurde kontrovers beurteilt (einerseits Sturz, andererseits Schlag). Weiterhin war offen geblieben, welches Asservat (leere Weinflasche, Ringrichteisen, Holzhammer mit Blutantragungen) als Tatwerkzeug in Betracht kommt. Als Begutachtungsgrundlage standen auf Datenträger gespeicherte CT-Aufnahmen zur Verfügung.

Ergebnisse. Im Ergebnis der CT-Auswertung liegen umschriebene Gewalteinwirkungen auf den knöchernen Schädel an mindestens 2 Stellen vor (Schlag). Neben den mehrfachen Kopfschwartenverletzungen durch Schläge gegen den Kopf lässt die typische Befundkombination von Kopfschwartenverletzungen mit Platzwunden im Hinterhauptsbereich und Contre-Coup-Verletzung des Gehirns und an der Schädelbasis auf eine Kollision des frei beweglichen Kopfes gegen eine fixierte Unterlage (Sturz) schließen. Zur Erklärung der Weichteilverletzungen kommen Schläge mit allen drei gesicherten Werkzeugen in Betracht. Zur Entstehung der knöchernen Verletzungen kommt am ehesten eine Verursachung durch das Ringrichteisen in Betracht, während eine Entstehung durch Zuschlagen mit dem Holzhammer bzw. der Weinflasche eher auszuschließen sind.

\section{P54}

\section{Akzidentelle Strangulation im Erwachsenenalter}

\section{B. Madea', C. Rittner ${ }^{1}$}

'Institut für Rechtsmedizin, Bonn, Deutschland

Einleitung. Opfer akzidenteller Strangulation sind einerseits Säuglinge und Kleinkinder, andererseits Männer, die bei autoerotischen Handlungen verunglücken. Zufälliges Erhängen im Erwachsenenalter ohne autoerotische Betätigung kommt außerordentlich selten vor. Im Anschluss an eine jüngst von Bielefeld et al. publizierte Falldarstellung und Literaturübersicht soll ein Fall vorgestellt werden, der sich bereits vor mehr als vier Jahrzehnten in Bonn ereignete. Ein 49 Jahre alt gewordener Mann - von Beruf Arzt - wurde, nachdem er kurz zuvor noch in der Klinik lebend gesehen wurde, in einem Waldgelände unterhalb der Klinik in hilfloser Lage mit dem Hals in einer Astgabel eingeklemmt 
aufgefunden. Nach Einlieferung in die Klinik konnte nur noch der Tod festgestellt werden. Der Kopf war - aufgrund der Enge - nicht bis auf den Boden der Astgabel herabgesunken.

Sektionsbefunde. Einzelne Hautabschürfungen im Bereich von Hals und Gesicht. Geringe Einblutungen in das Platysma und den linken Musculus sternocleidomastoideus. Flohstichartige Blutungen in die Augenbindehäute, die Augeoberlider, die Kehldeckelschleimhaut, subepikardial und subpleural. Akutes Emphysem der Lungenoberlappen. Chemisch-toxikologische Untersuchungen verliefen negativ. Todesursache: Strangulation.

Schlussfolgerung. Für einen Suizid ergaben sich keine Anhaltspunkte. Es wurde rekonstruiert, dass der Verstorbene von der Klinik auf dem Weg nach Hause war. Um den Weg abzukürzen, ist er in dem abschüssigen Waldgelände nicht den in Serpentinen talwärts führenden Hangweg gegangen, sondern direkt durch das steil abfallende Waldgelände. Hierbei muss er akzidentell in die Astgabel gestürzt sein, aus der er sich nicht mehr befreien konnte.

P55

Ungewöhnliche Schwierigkeiten bei der Identifizierung einer weiblichen Frauenleiche

N. Stanislawski', A. Jarisch', E. Below', A.E. Klann', B. Bockholdt'
'Institut für Rechtsmedizin Greifswald, Greifswald, Deutschland

Einleitung. Bei aufgefundenen Leichenteilen hat der Rechtsmediziner den Ermittlungsbehörden eine Vielzahl von Fragen zu beantworten, um beispielsweise die Identität der betroffenen Person schnell zu klären. In der Literatur finden sich zahlreichen Publikationen zur rechtsmedizinischen Untersuchung von Leichenteilen im Rahmen von sog. defensiven Leichenzerstückelungen (Ziemke 1918, Haberda 1927, Koops et al. 1985).

Fallbericht. Im hier vorgestellten Fall wurden über mehrere Monate an umschriebenen Orten Leichenteile jeweils immer im Gewässerbereich aufgefunden. Obwohl zeitig sowohl das Geschlecht geklärt werden konnte als auch Angaben zur Körperhöhe vorlagen, gelang es relativ lange nicht, die Frau zu identifizieren. Problematisch war im vorliegenden Fall die Altersschätzung. Nach monatelanger umfangreicher polizeilicher Öffentlichkeitsarbeit verhalfen letztlich begünstigende Umstände, den Fall zumindest teilweise aufzuklären.

Diskussion. Wesentliche Fragen zur Klärung der Identität wie Geschlecht, Größe, Vorerkrankungen aber auch zu Zeitpunkt und Art der Zerlegung konnten durch die Rechtsmediziner schnell beantwortet werden. Die Altersschätzung war äußerst schwierig, im Wesentlichen deshalb, weil bis zum Schluss der Kopf nicht gefunden wurde. Auch nach Klärung der Identität sind aufgrund der Umstände des Falles zahlreiche Fragen offen geblieben.

\section{P56}

\section{Morphologische und molekularbiologische Befunde nach über} 60-jähriger Liegezeit im Erdgrab

\section{Geisenberger', S. Lutz-Bonengel', S. Pollak'}

'Institut für Rechtsmedizin, Freiburg i. Br., Deutschland

Im April 2013 erfolgte die Exhumierung eines Mannes, der vor über 60 Jahren verurteilt und hingerichtet worden war. Bei der privat in Auftrag gegebenen Exhumierung sollte das Skelett geborgen werden, um Material für eine DNA-Untersuchung zu gewinnen. Das gut erhaltene und fast vollständige Skelett des im Erdgrab bestatteten Leichnams wies eine symmetrische Fraktur des zweiten Halswirbels im Bereich der Gelenkflächen auf. Diese Verletzung war auf den Vollzug der Todesstrafe durch den Strang zurückzuführen. Die aus zwei Zähnen extrahierte und typisierte DNA ergab ein vollständiges STR-Profil, das mit jenem des Putativsohnes verglichen werden konnte und die Vaterschaft mit an Sicherheit grenzender Wahrscheinlichkeit bestätigte.

\section{P57}

Bericht zum Flugunfall eines Motorseglers ASH25M mit zwei Luftfahrzeugführern bei Pfronten am 23. Juli 2012. Falldiskussion unter Berücksichtigung flugmedizinischer und toxikologischer Befunde sowie der Ergebnisse der technischen Unfallaufarbeitung

M. Schwerer', T. Gilg', M. Graw ${ }^{1}$

'Institut für Rechtsmedizin, Ludwig-Maximilians-Universität, München, Deutschland

Fallbericht. Am 23. Juli 2012 gegen 14.30 Uhr beobachteten Zeugen den Absturz eines Segelflugzeugs am Kienberg bei Pfronten aus „sehr steilem Bahnneigungswinkel“. Das Flugzeugwrack wurde in einem Nadelwald mit $60 \mathrm{~cm}$ im Erdboden steckender Rumpfspitze und bis zum hinteren Sitz zertrümmertem Cockpit gefunden. Beide Piloten wurden tot geborgen.

Methoden und Ergebnisse. Das flugmedizinische Tauglichkeitszeugnis der Klasse 2 des verantwortlichen Luftfahrzeugführers (vorderer Cockpitsitz dieses Fluggerätemusters) war bis zum 16.04.2013, das „Medical“ des zweiten Unfallopfers bis zum 11.06.2012 gültig. Neben den Befunden eines jeweils schwersten Polytraumas ergab die Obduktion bei dem 77-jährigen, $124 \mathrm{~kg}$ schweren Opfer im vorderen Cockpitsitz Zeichen einer koronaren Herzkrankheit sowie eine abgeheilte Lungenthrombembolie. Gemäß hausärztlicher Unterlagen habe eine Dauermedikation mit Marcumar bestanden, die dem beurteilenden Fliegerarzt mutmaßlich nicht bekannt war. Eindeutige Vitalitätszeichen der Verletzungen waren bei dem Unfallopfer auf dem hinteren Cockpitsitz, nicht jedoch beim Unfallopfer im Vordersitz zu erheben. Beim verantwortlichen Luftfahrzeugführer war eine Alkoholkonzentration von 0,54\%o in der Muskulatur sowie von 0,19\% im Urin feststellbar, bei seinem Mitflieger 0,19\%o bzw. 0,o6\%.

Schlussfolgerung. Der gegenständliche Fall unterstreicht die Notwendigkeit, bei der Aufarbeitung von Flugunfällen neben den Ergebnissen der gerichtlichen Leichenöffnung die Befunde aus der haus- und der fliegerärztlichen Vorgeschichte, die Ergebnisse der Toxikologie und die technischen Sachverhalte zum Ereignis zu berücksichtigen. Am konkreten Beispiel sollen derartige Faktoren im Sinne einer möglichen Dunkelziffer bei bislang ungeklärten Flugunfällen diskutiert werden, insbesondere hinsichtlich der Bedeutung von Vorerkrankungen als mögliche Unfallursachen.

\section{P58}

Offene penetrierende Brust- und Lungenverletzung durch einen Pinsel

\section{J. Sidlo', J. Sikuta', H. Sidlova', R. Kuruc', D. Valent ${ }^{1}$}

${ }^{1}$ Comenius Universität Bratislava und Gesundheitsamt, Institut für Rechtsmedizin, Bratislava, Slowakei, ${ }^{2}$ Slowakische Gesundheits-Universität und Cytopathos $\mathrm{GmbH}$, Institut für Pathologie, Bratislava, Slowakei

Einleitung. Heutzutage sind offene penetrierende Brustverletzungen seltener als die verdeckten, wobei je nach Ausdehnung und Lokalisation leichte bis lebensgefährliche Verletzungen vorkommen können. Es wird die Kasuistik eines 13-jährigen Jungen vorgestellt, der durch einen in den Thorax eingedrungenen Pinsel verletzt wurde und nach 11-tägigem Krankenhausaufenthalt wegen einer unerwarteten Komplikation gestorben war.

Methoden. Die Autoren haben eine vollständige Fallanalyse unter Einbeziehung der Krankenakte und der Obduktionsergebnisse durchgeführt.

Ergebnisse. Bei der Obduktion des Patienten wurde eine Verletzung der Brustwand und der Lunge im Heilungsstadium festgestellt. Die unmit- 
telbare Todesursache war eine Hypoxie bei rezidivierenden Blutungen in die Lunge.

Schlussfolgerung. Die Brust- und Lungenverletzung erschien aus klinischer Sicht zunächst nicht ernsthaft und der Patient war nach kurzer Zeit wieder mobil und wurde in einer Abteilung mit normalem Krankenhausregime behandelt. Die unerwarteten Blutungsrezidive in die Atemwege verursachter den klinischen Tod und darauffolgend den Hirntod. Die Blutungsquelle konnte trotz intensiver makro- und mikroskopischer Untersuchungen in dem massiv eingebluteten Lungengewebe nicht präzise lokalisiert werden.

\section{P59}

\section{Zur Handlungsfähigkeit nach Schussverletzungen}

\section{F.-W. Ast', M. Klintschar', B. Vennemann}

'Medizinische Hochschule Hannover, Rechtsmedizin, Oldenburg, Deutschland, ${ }^{2}$ Medizinische Hochschule Hannover, Rechtsmedizin, Hannover, Deutschland

Einleitung. Im Rahmen von gerichtlichen Obduktionen ist bei Verstorbenen mit todesursächlichen Schussverletzungen auch die Frage der Dauer der Handlungsfähigkeit nach Schussabgabe regelmäßig zu diskutieren.

Methoden. Die autoptischen Befunde, hier insbesondere der nachgewiesene Schusskanal, die verletzten Körperregionen und Organsysteme, die Schussentfernung sowie die verwendete Munition und die Art der Waffe tragen neben den vorliegenden polizeilichen Anknüpfungstatsachen zur Klärung dieser Fragestellung bei.

Schlussfolgerung. In den folgenden beiden Kasuistiken werden Selbsttötungen nach Schussabgaben mit einer großkalibrigen Langwaffe bzw. mit einer Flinte vorgestellt, bei denen trotz des Erleidens von erheblichen Verletzungen nach erster Schussabgabe noch komplexe Handlungsweisen bzw. eine zweite Schussabgabe erfolgten.

\section{P60}

\section{Tötungsdelikt mit 11 Schussverletzungen - ein Fall von Notwehr?}

\section{Diers', S. Heide', R. Lessig'}

'Institut für Rechtsmedizin, Halle (Saale), Deutschland

Fallbericht. Ein 49-jähriger Mann wurde in einer Wohnung mit mehrfachen Schussverletzungen tot aufgefunden. Nach Angaben seines 52-jährigen Bekannten habe man zunächst gemeinsam in der Wohnung Tee und später auch alkoholische Getränke konsumiert. Das spätere Opfer habe im Verlauf des Gespräches Todessehnsüchte geäußert und gebeten, ihn zu erschießen. Er sei diesem Verlangen zunächst nicht nachgekommen und deshalb habe ihn der Mann mit einem Messer bedroht. $\mathrm{Da}$ er um sein eigenes Leben fürchtete, habe er schließlich auf den Mann schießen müssen. Danach stellte er sich der Polizei.

Ergebnisse. Bei der Obduktion konnten insgesamt 22 Schussdefekte der Haut festgestellt werden. Nach einer postmortalen CT-Untersuchung und aufwändigen Präparation ließen sich 11, sich teilweise überkreuzende Schusskanalverläufe durch den Körper darstellen, wobei es sich um 7 Durchschussverletzungen und 4 Steckschüsse handelte. Die vorläufige Einschätzung zur Schussrichtung musste nach der Untersuchung der Hautschussdefekte und der Bekleidung im Landeskriminalamt lediglich in einem Fall korrigiert werden. In der Hauptverhandlung versuchte der Angeklagte, eine Notwehrsituation geltend zu machen. Im rechtsmedizinischen Gutachten wurde jedoch deutlich gemacht, dass das Tatopfer an der Körpervorderseite, am Rücken und an der rechten Körperseite von Schüssen getroffen wurde. In Zusammenhang mit den kriminaltechnischen Untersuchungen konnte auch davon ausgegangen werden, dass ein Teil der Schussverletzungen in liegender Position beigebracht worden war. In Verbindung mit dem Nachtat- und Einlassungsverhalten des Angeklagten kam das Gericht deshalb zu der Über- zeugung, dass eine Notwehrlage nicht in Betracht kommt. Schließlich wurde der Angeklagte wegen Totschlags im minder schweren Fall zu einer Freiheitsstrafe von 5 Jahren und 9 Monaten verurteilt.

\section{P61}

\section{Kopfsteckschuss mit modifiziertem Schreckschussrevolver}

\author{
R. Pircher', L. Bielefeld', D. Geisenberger', T. Sänger', H.-J. Weisser', M. Große \\ Perdekamp \\ 'Institut für Rechtsmedizin, Freiburg, Deutschland
}

Fallbericht. Im Mai 2012 wurde von einer Wandergruppe in bewaldetem, unwegsamem Gelände ein skelettierter menschlicher Schädel (ohne Unterkiefer) mit runder Knochenlücke in der rechten Schläfenregion aufgefunden. Bei der Untersuchung des Schädels konnte in der Schädelhöhle ein kegelspitzförmiger Geschossmantel festgestellt werden, dessen maximaler Durchmesser dem kleinsten Durchmesser der Knochenlücke entsprach. Bereits im November 2010 waren im selben Waldgebiet weitere Teile eines menschlichen Skeletts, Kleidungsstücke sowie ein Schreckschussrevolver (9 mm Knall) mit abgesägtem Lauf gefunden worden.

Ergebnisse. Die kriminaltechnische Untersuchung des Schreckschussrevolvers hat ergeben, dass durch die Entfernung des Gaslaufes die Möglichkeit des Vorladens eines Geschosses besteht. Im konkreten Fall muss das aufgefundene Geschoss in das Reststück des Gaslaufes vorgeladen worden sein. Das DNA-Profil der aufgefundenen Skelettteile stimmt mit dem mitgeteilten DNA-Muster eines seit 2007 vermissten Mannes überein.

\section{P62}

\section{Herzbeuteltamponade? Hämaskos! Tödliche Verletzung der Leber bei Perikardpunktion}

K. Blässer ${ }^{7}$

'Institut für Rechtsmedizin, medizinische Abteilung, Würzburg, Deutschland

Einleitung. Die perkutane Perikardpunktion aus diagnostischer oder therapeutischer Indikation kennt im Komplikationsspektrum hauptsächlich Verletzungen intrathorakaler Strukturen. Vorliegend wird über eine unbemerkt gebliebene Fehlpunktion der Leber mit letalem Ausgang berichtet.

Fallbericht. Bei einer planmäßigen PTA mit Ballondilatation kam es zur Ruptur der A. coronaria sinistra. Der Versuch, die Defektstelle mittels Stentimplantation zu decken, gelang nur partiell. Um das röntgenologisch diagnostizierte Hämoperikard entlasten zu können, erfolgte von subxiphoidal eine Perikardpunktion, die nur wenig blutigen Erguss förderte. Nach zwischenzeitlicher erfolgreicher Reanimation der 36-jährigen adipösen Patientin konnte unter intensivmedizinischer Therapie eine stabile Kreislaufsituation hergestellt werden. Erneute Versuche einer Perikardpunktion in Loco-typico-Lokalisation verliefen frustran, erst nach Wechsel zu einem links-parasternalen Zugang konnte das Hämoperikard entlastet werden. Dennoch verstarb die Patientin eine Stunde später. Als Todesursache wurde eine Herzbeuteltamponade nach iatrogener Koronargefäßruptur angenommen.

Ergebnisse. Bei der Obduktion zeigten sich 25 Punktionsstellen im subxiphoidalen Hautareal. Weiterhin fand sich ein Hämaskos mit knapp 3 Litern Blut, als Blutungsquelle konnten 45 Punktionsverletzungen des linken Leberlappens identifiziert werden, 11 davon als Durchstichverletzungen. Der Tod war durch inneres Verbluten in Folge der Leber-Fehlpunktionen eingetreten. 
P63

\section{Tod im Jugendalter - „Schweinegrippe“ vs. Brugada-Syndrom}

K. Zindler', K. Klingel' , T. Kriebeß', C. Marschall', L.A. Ormandy', W. Grellner ${ }^{1}$ 'Universitätsmedizin Göttingen, Abteilung Rechtsmedizin, Göttingen, Deutschland, ${ }^{2}$ Universitätsklinikum Tübingen, Abteilung für Molekulare Pathologie, Tübingen, Deutschland, ${ }^{3}$ Universitätsmedizin Göttingen, Klinik für Pädiatrische Kardiologie und Intensivmedizin, Göttingen, Deutschland, ${ }^{4}$ Zentrum für Humangenetik und Laboratoriumsmedizin, Martinsried, Deutschland

Vorgeschichte. Ein 16-jähriger Junge wurde am Abend leblos von seiner Mutter im Bett aufgefunden. Anamnestisch litt er seit 2 bis 3 Tagen an einem grippalen Infekt mit Durchfall, Husten und Temperaturen bis $38,7^{\circ} \mathrm{C}$. Einen Arztbesuch lehnte er ab.

Wesentliche Obduktionsbefunde. Neben ausgeprägten hämorrhagischödematösen Lungenveränderungen (Lungengewicht rechts: 904 g; links: 716 g) fanden sich ein Hirnödem, blutgestaute innere Organe, eine Milzvergrößerung sowie Schocknieren. Der Herzmuskel war blass und ohne Herdbefund.

Zusätzliche Untersuchungen. Virologisch konnte in 2 Herzproben sowie in Abstrichen von Nase, Rachen und Lungen Influenza $\mathrm{A}\left(\mathrm{H}_{1} \mathrm{~N}_{1}\right)_{2}$ 2009RNA nachgewiesen werden. Histologisch zeigten die Lungen ausgedehnte intraalveoläre Hämorrhagien mit fokalen, vorwiegend peribronchial gelegenen, lymphozytären Entzündungsinfiltraten. Nebenbefundlich zeigte der rechte Herzventrikel eine ausgeprägte Trabekularisierung, eine diffuse interstitielle Fibrose und vermehrte Fetteinlagerungen. Der linke Ventrikel wies keine signifikante Fibrosierung auf, jedoch zeigte sich eine Anhäufung von atypischen dilatierten Kapillaren mit verstärkter Ausprägung im Bereich untergegangener Kardiomyozyten. Zeichen für eine Myokarditis lagen nicht vor. Molekulargenetisch konnten keine Veränderungen im Sinne einer ARVD verifiziert werden. Es zeigte sich jedoch eine Mutation c.5224T >C (p.Cys1742Arg, Exon 28, SCN5A-Gen) in einer für das Brugada-Syndrom typischen Region, die in der Literatur noch nicht beschrieben wurde.

Diskussion. Bei dem 16 Jahre alt gewordenen Jungen konnte virologisch eine akute $\mathrm{H}_{1} \mathrm{~N}_{1}$-Infektion mit makro- sowie mikroskopischen Korrelaten gesichert werden. Nebenbefundlich zeigten sich strukturelle Veränderungen am Herzen. Molekulargenetisch fand sich eine Mutation in einer für das Brugada-Syndrom typischen Region. Beide Befunde könnten ursächlich den Tod erklären, möglicherweise kam es jedoch im Rahmen eines potenziellen Brugada-Syndroms zu einer infektgetriggerten tödlichen ventrikulären Herzrhythmusstörung. Anschließende Untersuchungen des noch lebenden Bruders waren unauffällig.

Schlussfolgerung. Bei begründetem Verdacht auf eine genetische Herzerkrankung sollte im Sinne der Angehörigen eine weitere Abklärung erfolgen.

\section{P64}

Diagnose einer Tako-Tsubo-Kardiomyopathie nach einem Raubüberfall

\section{Wingenfeld', O. Peschel', M. Graw' \\ 'Institut für Rechtsmedizin der Ludwig-Maximillians-Universität, München, Deutschland}

Einleitung. Bei der Tako-Tsubo-Kardiomyopathie, auch Stress-Kardiomyopathie genannt, handelt es sich um eine seltene, akut einsetzende Funktionsstörung des Herzmuskels, die vorwiegend bei älteren Frauen auftritt. Die Symptome gleichen denen eines Herzinfarktes und treten meist unmittelbar nach einer außerordentlichen emotionalen oder körperlichen Belastung auf.

Fallbericht. Wir untersuchten eine 88-jährige Frau, die im Rahmen eines Raubüberfalls von zwei Männern angegriffen wurde. Nach dem Vorfall klagte das Opfer über links-thorakale Schmerzen. Klinisch wurde aufgrund von EKG-Veränderungen und des Herzkatheterbefundes die Diagnose einer Tako-Tsubo-Kardiomyopahtie gestellt.

Schlussfolgerung. In der Literatur sind nur einzelne Berichte dieser Krankheit in Zusammenhang mit einem Gewaltdelikt beschrieben worden. Das seltene Krankheitsbild soll anhand des Falles veranschaulicht werden.

\section{P65}

Plötzlicher und frühzeitiger Todesfall eines Säuglings mit einem Bland-White-Garland-Syndrom

\section{Böhm', S. Heide', R. Lessig', U. Mathony ${ }^{2}$}

${ }^{1}$ Rechtsmedizin Halle, Halle, Deutschland, ${ }^{2}$ Städtisches Klinikum Dessau, Klinik für Kinder- und Jugendmedizin, Dessau, Deutschland

Fallbericht. Ein 12 Wochen alter Säugling habe nach Angaben der Kindesmutter bislang keinerlei Auffälligkeiten geboten. In den frühen Abendstunden seien dann ein plötzliches Stöhnen, schwaches Schreien und eine unregelmäßige Atmung aufgetreten. Als schließlich nur noch eine Schnappatmung ersichtlich war, begann die Kindesmutter mit Reanimationsmaßnahmen, die durch die hinzugezogene Notärztin fortgesetzt wurden. Der Säugling wurde noch in das Städtische Klinikum gebracht, wo die Wiederbelebungsbemühungen nach etwa 2 Stunden erfolglos abgebrochen werden mussten.

Ergebnisse. Unter dem primären Verdacht auf ein mögliches Schütteltrauma erfolgte eine gerichtliche Sektion. Dabei fand sich neben den morphologischen Hinweiszeichen eines akuten Linksherzversagens ein Fehlabgang der A. coronaria sinistra aus dem Truncus pulmonalis (Bland-White-Garland-Syndrom). Darüber hinaus imponierten bereits eine ausgeprägte Linksherzhypertrophie und kugelige Dilatation des Herzens mit ausgedehnten Vernarbungen. Die Häufigkeit des Bland-White-Garland-Syndroms wird in der Literatur mit 1:30.000 bis 1:300.000 angegeben. Ohne chirurgische Intervention versterben $80-90 \%$ der betroffenen Kinder innerhalb des 1. Lebensjahres infolge von rezidivierenden Vorderwandinfarkten. In den ersten Lebenswochen besteht jedoch infolge des erhöhten pulmonal-arteriellen Drucks, des erhöhten Gesamthämoglobins und des fetalen Hämoglobingehalts eine noch ausreichende Blutversorgung des Myokards. Nach diesem symptomfreien Intervall kommt es gewöhnlich etwa ab dem 3. Lebensmonat zu ersten Symptomen, wie z. B. Trinkschwierigkeiten, Dyspnoe, Schwitzen, Erbrechen und pectanginösen Anfällen.

Schlussfolgerung. Der vorgestellte Fall zeigt, dass Koronaranomalien bereits bei jüngeren Säuglingen eine seltene Differenzialdiagnose des plötzlichen und unerwarteten Todes darstellen können.

\section{P66}

Spontane Harnblasenpolyp-Blutung als Ursache eines plötzlichen und unerwarteten Todeseintritts

M. Große Perdekamp ${ }^{1}$, A. Thierauf', S. Pollak

'Institut für Rechtsmedizin, Freiburg, Deutschland

Fallbericht. Geschildert werden die Obduktionsbefunde einer 62-jährigen Frau, die leblos in ihrer Wohnung aufgefunden wurde. Da keine Vorerkrankungen bekannt gewesen seien, habe der Leichenschauarzt eine ungeklärte Todesart bescheinigt. Bei der äußeren Leichenschau fiel eine spärliche Ausbildung der Totenflecken auf und als Hauptbefund der Leichenöffnung zeigte sich eine blutige Tamponade der Harnblase (8oo ml Blut). Blutungsquelle war ein Harnblasenpolyp mit spontaner Oberflächenarrosion. 


\section{P67}

Wie kann die Todesursache bei der Mittelohrentzündung zuverlässig erklärt werden?

\section{E. Kralj', J. Balažic ${ }^{1}$ \\ 'Institut für Rechtsmedizin, Medizinische Fakultät der Universität in Ljubl- jana, Ljubljana, Slowenien}

Einleitung. Mittelohrentzündung kommt besonders häufig bei Kleinkindern vor, meist in Zusammenhang mit einer Erkältung. Sie ist meistens eine akute bakterielle Entzündung, die durch das Aufsteigen der Keime über die Ohrtrompete oder seltener über hämatogene Infektion verursacht ist. Die typischen Symptome sind Ohrenschmerzen, Hörminderung, Rötung und Vorwölbung des Trommelfells und häufig Fieber, aber alle diese Symptome können fehlen oder unentdeckt bleiben. Gefürchtete Komplikationen sind Mastoiditis und Meningitis, welche im Extremfall zum Tod führen können. Über Sepsis infolge Mittelohrentzündung gibt es wenige Berichte. Dass diese Problematik nicht nur theoretisch ist, wollen wir mit 3 Fällen aus dem Obduktionsgut des Instituts für Rechtsmedizin in Ljubljana zwischen 1.1.2008 und 19.4.2013 (5566 Obduktionen) zeigen.

Fall 1. Ein 3 Jahre und 7 Monate altes, schwer behindertes Mädchen wurde zu Hause tot gefunden. Obduktionsbefunde waren eine linksseitige Pneumonie und eine rechtsseitige Mittelohrentzündung. Mikrobiologische Untersuchungen erbrachten Haemophilus influenzae in Mittelohr und Lungengewebe aber Staphylococcus aureus im Blut.

Fall 2. Ein 23 Monate altes Mädchen wurde wegen Bronchiolitis hospitalisiert und nach 2 Tagen entlassen. Am dritten Tag wurde es wieder hospitalisiert, aber starb nach 8 Stunden. Obduktion erwies massives linksseitiges Empyem, linksseitige Mittelohrentzündung und Bronchiolitis. Mikrobiologische Untersuchungen erbrachten Streptococcus pyogenes und Streptococcus pneumoniae in Mittelohr und Lungengewebe und Streptococcus pyogenes im Pleuraerguss, aber keine dieser Keime im Blut. Die CRP- und PCT-Werte waren 176 mg/L bzw. $0,67 \mu \mathrm{g} / \mathrm{L}$.

Fall 3. Ein 11 Monate alter Säugling wurde zu Hause leblos gefunden. Die Obduktion zeigte eine beidseitige Mittelohrentzündung und petechiale Blutungen. Histologische Untersuchungen bestätigten die Mittelohrentzündung, aber zeigten keine andere Inflammationsherde. Bei mikrobiologische Untersuchungen wurden Haemophilus influenzae und Klebsiella pneumoniae in Mittelohr und Klebsiella pneumoniae im Blut nachgewiesen. Die CRP- und PCT-Werte betrugen $<5 \mathrm{mg} / \mathrm{L}$ bzw. o, $06 \mu \mathrm{g} / \mathrm{L}$.

Schlussfolgerung. Die Erklärung der Todesursachen und Pathomechanismen des Todes in Fällen der Mittelohrentzündung bedarf mikrobiologischer, biochemischer und histologischer Untersuchungen.

\section{P68}

\section{Zwei Suizide mit Helium}

\section{Spiridonov}

'Universität Kazan, Rechtsmedizinisches Büro der Republik Tatarstan, Kazan, Russland

Einleitung. Helium ist ein weit verbreitetes technisches Gas, es ist leichter als Luft und an sich nicht toxisch. Wird Helium in einem geschlossenen Raum aus einem Behältnis freigelassen, so führt dies zur Verdrängung der Atemluft und zwangsläufig bei den im Raum befindlichen Personen zur Hypoxie und Asphyxie. Da Helium sehr oft zum Aufblasen von Luftballons verwendet wird, ist es für jedermann relativ einfach zu beschaffen.

Fall 1. Ein 24-jähriger Mann wurde in einer Wohnung in Rückenlage mit einer Plastiktüte über dem Kopf leblos aufgefunden. Unter die Plastiktüte führte ein Schlauch, dieser war an ein Behältnis mit Helium angeschlossen. In der Nähe der Leiche lagen mehrere Abschiedsbriefe, darunter ein Zettel, auf dem stand: „In dem Gasballon - Helium. Es ist nicht gefährlich. Einfach den Hahn im Uhrzeigersinn zudrehen!“. Die Obduktion der Leiche ergab lediglich Zeichen eines schnell eingetretenen Todes. Die toxikologische Untersuchung auf Alkohol, Drogen und Medikamente verlief negativ. Als Todesursache wurde Asphyxie unter Einatmung von Helium diagnostiziert.

Fall 2. Die Leiche eines 27-jährigen Mannes wurde von Familienangehörigen in einer Wohnung aufgefunden. Um den Kopf der Leiche befand sich eine Plastiktüte. Unter die Tüte führte ein Gummischlauch, der an einen Ballon mit Helium angeschlossen war. Die Obduktion ergab keine Besonderheiten bis auf Zeichen eines schnell eingetretenen Todes. Die toxikologische Untersuchung auf Alkohol und Drogen verlief negativ. In Herzblut, Mageninhalt, Leber, Galle und Niere wurden toxische Konzentrationen von Metoclopramid und Etaminal festgestellt. Todesursächlich war eine akute kombinierte Vergiftung mit Metoclopramid und Etaminal.

Schlussfolgerung. In beiden Fällen konnte Helium durch die toxikologische Untersuchung der Leichenproben nicht nachgewiesen werden. Durch die Leichenauffindesituation konnte jedoch die Rolle der Helium-Exposition in der Thanatogenese geklärt werden. Beide Fälle stellen ein Novum für unser Institut dar. Helium wird zurzeit bei Jugendpartys gern als Lachgas verwendet, ohne dass den Jugendlichen bewusst ist, dass Helium unter Umständen auch zum Tode führen kann.

\section{P69}

\section{Suizid mit einem Nylonseil in einem fahrenden Kastenwagen}

\section{K. Blässer}

'Institut für Rechtsmedizin, medizinische Abteilung, Würzburg, Deutschland

Fallbericht. Auf dem Fahrersitz eines am Rande eines Parkplatzes vorgefundenen Kastenwagens wurde die dekapitierte Leiche eines jungen Mannes gefunden; der Kopf lag auf dem Fahrzeugboden vor der Rücksitzbank. Die Zündung des Fahrzeuges war eingeschaltet, der Motor aus, der Schalthebel stand im 2. Gang, die Heckklappe war geöffnet. Etwa $60 \mathrm{~m}$ hinter dem Fahrzeug wurde ein $25 \mathrm{~m}$ langes Bergsteigerseil gefunden, dessen eines Ende um einen Baum geknotet war. Das andere Ende war zu einer Schlinge gebunden, die geringe Blutantragungen aufwies. Auf dem Parkplatzboden wurde nahe des Wagens ein „Betreten verboten"-Schild gefunden, das mit einigen Steinen beschwert war. Die Obduktion erbrachte eine zirkuläre Wundrandschürfung um die Abtrennungsstellen in der Haut des Kopfes und des Rumpfes sowie mehrere Dehnungsrisse in der Haut der Halsvorderseite. Die knöcherne Abtrennungsstelle lag zwischen dem 3. und 4. Halswirbelkörper. $\mathrm{Zu}$ sätzlich fand sich ein Bruch der Brustwirbelsäule zwischen dem 7. und 8. Brustwirbel; es bestand allgemeine Blutarmut. Histologisch konnte eine geringe Blutaspiration nachgewiesen werden.

Ergebnisse. Die Rekonstruktion zeigte, dass der Mann das Bergsteigerseil mit dem einen Ende an einem Baumstamm befestigt, das andere Ende durch die geöffnete Heckklappe in das Fahrzeuginnere geführt und sich die Schlinge um den Hals gelegt hatte. Danach hatte er das Fahrzeug auf ca. $35 \mathrm{~km} / \mathrm{h}$ beschleunigt. Den Punkt der Fahrtstrecke, bei dem sich das Seil zwischen Baumstamm und Hals erwartungsgemäß straffen würde, hatte der Mann mit dem Schild markiert. Nach der ruckartigen Dekapitation rollte das Fahrzeug bis zum Stillstand im Gebüsch des Parkplatzrandes aus. 
P70

Tod nach suizidialer Selbstanzündung - rechtsmedizinische Falldarstellung einer 30 -jährigen Frau

\section{N. Nigg Trawally', C. Bartsch', S. Gauthier' \\ 'Institut für Rechtsmedizin der Universität Zürich, Zürich, Schweiz}

Einleitung. Suizide durch Selbstverbrennungen sind v. a. im Nahen Osten, in Afrika oder in Südostasien häufig und werden dort nicht selten infolge religiöser, politischer oder kultureller Hintergründe verübt. In den Industrienationen hingegen ist diese Methode eher selten und mit zugrunde liegenden psychiatrischen Erkrankungen assoziiert. Eine schweizweite Suizidstudie für den Zeitraum zwischen 2000 und 2010 ergab eine Suizidrate durch Selbstverbrennung von etwa $1 \%$ aller Suizide in der Schweiz in diesem Zeitraum (vgl. Vortrag Gauthier et al.) Fallbericht. Im Folgenden wird der spezielle Fall einer 30 Jahre alt gewordenen Frau vorgestellt, die sich im Keller eines Mehrfamilienhauses mit Pinselreiniger übergoss und anzündete, wonach sie etwa 1o Stunden später im Spital an ihren Verletzungen verstarb. Die rechtsmedizinische Falldarstellung wird genutzt, um diese in Europa sehr selten angewendete Suizidmethode anhand bestehender Literatur aufzuzeigen und den hier gängigen Suizidmethoden gegenüberzustellen.

\section{P71}

\section{Autoerotischer Unfall oder Suizid durch Aufnahme von „Poppers“?}

\author{
L. Bielefeld', S. Pollak', S. Vogt ${ }^{?}$ \\ 'Institut für Rechtsmedizin Freiburg, Freiburg, Deutschland
}

Fallbericht. Ein 36 Jahre alt gewordener Mann wurde in Bauchlage leblos in seinem Zimmer in einer Wohngemeinschaft aufgefunden. In dem Zimmer wurden Sexspielzeuge und mehrere „Poppers“-Fläschchen festgestellt. Nach fremdanamnestischen Angaben habe der Mann an Depressionen gelitten. Als organische Vorerkrankung bestand ein Asthma bronchiale. Bei „Poppers“ handelt es sich um Nitrite, die zu einer starken Vasodilatation führen. Ihnen wird eine aphrodisierende und schmerzhemmende Wirkung zugesprochen, weshalb sie u. a. vor einem Analverkehr vom passiven Partner aufgenommen werden. Schlussfolgerung. Die Obduktionsbefunde und die Ergebnisse der chemisch-toxikologischen Untersuchungen werden vorgestellt.

\section{P72}

\section{Fatality after intake of para-methoxyamphetamine (PMA) and} amphetamine: a case report

\section{A. Bauer', J. Schöpfer', M. Schwerer², H. Sachs', B. Zinka², M. Graw2, G. Roider \\ 'Institut für Rechtsmedizin, Toxikologie, München, Deutschland, ${ }^{2}$ Institut für Rechtsmedizin, München, Deutschland, ${ }^{3}$ Forensisch Toxikologisches Centrum, München, Deutschland}

Introduction. The designer drug PMA (para-methoxyamphetamine) is the 4-methoxy derivative of amphetamine. It is one out of a group of methoxylated phenethylamine derivates with hallucinogenic properties. Already in 1984 it has been subjected to Regulations of the German Narcotics Law (BtMG); because of this it never became a very common drug. Therefore deaths related to PMA are rare. PMA shows less stimulant effects than amphetamine but carries a distinctive hallucinogenic potential. Described adverse effects as hyperthermia, tachycardia, hypertension and convulsions nevertheless are similar to adverse effects of common stimulants like amphetamine or methamphetamine.

Case report. We present a fatality of a 24 -year old man involving PMA and amphetamine. The man was found dead by his mother in his bathroom in the early afternoon hours. Last sign of life was at 7am on the same day when his brother had spoken to him through the closed bathroom door. During post mortem examination signs of massive global acute brain pressure as well as a lung rich of blood but poorly ventilated were found. The heart showed no macroscopic abnormalities.

Methods. A routine toxicological screening (femoral blood, urine, stomach content) was performed via GC-MS and LC-MS/MS. After extraction and further sample preparation concentrations of PMA and amphetamine were determined via GC-MS in femoral blood.

Results and discussion. In femoral blood $950 \mu \mathrm{g} / \mathrm{L}$ para-methoxyamphetamine and $230 \mu \mathrm{g} / \mathrm{L}$ amphetamine were found. PMA also was determined in urine and stomach contents. Beside the stimulant substances PMA and amphetamine, THC was detected in femoral blood in a concentration of $5.2 \mu \mathrm{g} / \mathrm{L}, \mathrm{THC}-\mathrm{OH}$ and THC-COOH were also detectable. The measured concentration of PMA is in the order of magnitude in which PMA concentrations attributed to acute oral overdosage are described in literature (average postmortem blood concentrations $1400 \mu \mathrm{g} / \mathrm{L}$; range $300-3400 \mu \mathrm{g} / \mathrm{L}$ ). Furthermore, an additional effect of the high amphetamine concentration $(230 \mu \mathrm{g} / \mathrm{L})$ has to be taken into consideration. Since no pathological-anatomical cause of death could be determined, death can be attributed to the uptake of PMA, maybe supported by amphetamine.

\section{P73}

\section{Todesfall nach Pfefferspray-Einsatz}

\section{E. Kralj', M. Čolnik', A. Kuštrin-Samba', J. Balažic'}

'Institut für Rechtsmedizin, Medizinische Fakultät der Universität in Ljubljana, Ljubljana, Slowenien

Einleitung. Über lagebedingten Erstickungstod nach Pfefferspray-Einsatz gibt es mehrere Berichte. Typischerweise wird in solchen Situationen Pfefferspray gegen Personen eingesetzt, die längere Zeit heftigen Widerstand gegen Vollstreckungsbeamte leisten. Während eines solchen Kampfes besteht aber die Gefahr, dass ein Teufelskreis einritt, bei dem erhöhte Adrenalinausschüttung, erhöhter Sauerstoffbedarf in Gehirn und Muskulatur, lagebedingte Behinderung der Atmung, bestehende Krankheiten, Drogen und andere Faktoren sich gegenseitig potenzieren und Situation weiter verschlechtern.

Fallbericht. Der 44-jährige Fahrer ist mit seinem Pkw bei einer Verkehrskontrolle absichtlich gegen den Wagen der Polizei gefahren und zur Autobahn geflohen. Danach ist er mit bis zu $200 \mathrm{~km} / \mathrm{h}$ bis zur Polizeisperre gefahren. Er hat die Sperre durchbrochen und ist mit ungefähr $90 \mathrm{~km} / \mathrm{h}$ bis zur zweiten Sperre weitergefahren, wo er wieder gegen einen Polizeiwagen gefahren und geflohen ist. Bei der dritten Polizeiblockade ist er gegen einen Lkw gefahren, wobei sein Motor ausging. $\mathrm{Da}$ er nicht aus dem Wagen aussteigen wollte, hat die Polizei die Seitenscheibe eingeschlagen und um 11:25 Uhr Pfeffer-KO JET-Spray ins Fahrzeuginnere gespritzt. Wegen seiner Aggressivität hat ihm die Polizei Hände und Beine gefesselt und ihn auf den Boden gelegt. Um 11:32 Uhr wurde der Rettungsdienst gerufen, der um 11:38 Uhr eingetroffen ist. Seine Pulsfrequenz war 156/min, die O2-Sättigung 78\%. Wegen seiner Aggressivität konnte ihm kein Sauerstoff appliziert werden. Danach wurde er ins Krankenhaus gebracht und vom Chirurgen untersucht. Da keine wesentlichen Verletzungen gefunden wurden, wurde er zur weiteren Diagnostik in die internistische Abteilung verlegt. Dort war er weiterhin aggressiv, so dass die Polizeibeamten und medizinisches Personal ihn nicht bändigen konnten. In den folgenden Minuten wurde er zunehmend zyanotisch und um 11:55 Uhr trat der Herzstillstand ein. Die 45-minütige Reanimation war erfolglos. Die Obduktion zeigte Petechien an den Augenlidern, eine generalisierte Blutstauung, eine Fraktur des linken oberen Fortsatzes des Schildknorpels, jedoch keine anderen wesentlichen Verletzungen. Der Tryptasespiegel von $60,3 \mu \mathrm{g} / \mathrm{L}$ hat auf eine Anaphylaxie hingewiesen.

Schlussfolgerung. Im o. g. Fall hat eine anaphylaktische Reaktion auf Oleoresin capsicum den Tod verursacht oder wesentlich zum Tod beigetragen. 
P74

Mehrfache Anwendungen von ethanolhaltigen Desinfektionsmitteln führen zu positiven Befunden auf Ethylglucuronid (EtG) in Urin

\section{S. Lott', M. Fleischmann', B. Madea' \\ 'Institut für Rechtsmedizin Bonn, Toxikologie, Bonn, Deutschland}

Fragestellung. Personal in medizinischen Kliniken und Instituten muss sich an die vorgegebenen Hygieneregeln halten und gerade bei Ausbrüchen von Grippe- oder Norovireninfektionen vorgeschriebene Desinfektionsmittel sehr häufig am Tag anwenden. Sind die vorgegebenen Desinfektionsmittel ethanolhaltig, stellt sich beispielsweise für eine Teilnahme an sog. Abstinenzprogrammen in Urin oder Haar die Frage, ob Ethanol aufgenommen und der Alkoholmarker EtG in relevanten Dosen gebildet wird.

Methoden. Getestet wurde das Händedesinfektionsmittel „Sterillium Viruguard", welches 99\% Ethanol enthält und typischerweise im klinischen Gebrauch angewendet wird. Insgesamt nahmen 10 freiwillige Personen am Versuch teil und wendeten alle 25 Minuten das genannte Desinfektionsmittel über einen Zeitraum von 6 Stunden an. Die insgesamt 17-malige Anwendung erfolgte anhand der Standard-Einreibemethode (EN 1500). Es wurden Urinproben in den Zeitabschnitten o, 1, 2, 4, 6, 8, 10, 12 und 24 Stunden nach der ersten Anwendung gesammelt und mittels LC-MS/MS auf Ethylglucuronid (EtG) getestet. Bei 7 von 10 Probanden konnte die Urinkontrolle vor der ersten Desinfektion als negativ bzw. unauffällig für EtG bestätigt werden. Bei 3 Probanden wurde bereits EtG in der Urinkontrolle vor der ersten Desinfektion über $100 \mathrm{ng} / \mathrm{ml}$ nachgewiesen. Daher wurden alle abgegebenen Urine dieser Probanden für die weitere Auswertung nicht berücksichtigt.

Ergebnisse. Tatsächlich wurde EtG durch die mehrfache Anwendung von „Sterillium Viruguard“ gebildet und konnte mittels LC-MS/MS in Urin nachgewiesen werden. Bei einem der Probanden wurde die Entscheidungsgrenze von $100 \mathrm{ng} / \mathrm{ml} \mathrm{EtG} \mathrm{in} \mathrm{Urin} \mathrm{zu} \mathrm{keinem} \mathrm{Zeitpunkt}$ überschritten. Bei den restlichen 6 Probanden erreichten die festgestellten Konzentrationen teilweise Werte deutlich oberhalb der Entscheidungsgrenze für die Fahreignungsdiagnostik (bis über $2000 \mathrm{ng} / \mathrm{ml}$ ). Dennoch sanken die Werte nach der letzten Anwendung innerhalb von 12 Stunden oder weniger soweit ab, dass die Entscheidungsgrenze nicht mehr überschritten ist.

Schlussfolgerungen. Eine Teilnahme an einem Urinkontrollprogramm wäre somit nach den hier erhaltenen Ergebnissen möglich, wenn sich die Anwendung der Desinfektion bis zur Urinabgabe für mindestens 12 Stunden vermeiden lässt. Bei noch häufigerer Anwendung als in dieser Studie oder für Haaranalysen bleibt die Frage weiterhin offen.

\section{P75}

\section{Ethyl glucuronide findings in hair samples from the mummies of the Capuchin Catacombs of Palermo}

F. Musshoff', , C. Brockmann', W. Rosendahß', D. Piombino-Mascali', B. Madea ${ }^{1}$ Institut für Rechtsmedizin, Bonn, Deutschland, ${ }^{2}$ Forensisch-Toxikologisches Centrum GmbH, München, Deutschland, ${ }^{3}$ Reiss-Engelhorn Museen, Mannheim, Deutschland, ${ }^{4}$ Medical Faculty, Dep. of Anatomy, Histology and Anthropology, Vilnius, Lithuania, Deutschland

Introduction. The Capuchin Catacombs of Palermo contain about 1800 preserved bodies: friars, priests, and also laymen, including men, women, and children. The bodies were accessible to family members so they could visit the deceased and commemorate them through prayer. Within the framework of the Sicily Mummy Project, we analyzed hair samples from 40 mummies for the presence of ethyl glucuronide (EtG) using a routine procedure in our accredited laboratory by means of liquid chromatography coupled to mass spectrometry. The limit of quantification was $2.3 \mathrm{pg} / \mathrm{mg}$.

Methods. The hair samples were from $1.5-12 \mathrm{~cm}$ in length. All samples were analyzed in 2 segments (seg. A $\mathrm{O}-3 \mathrm{~cm}$ and seg. B the rest). In ca- ses with hair samples $<4 \mathrm{~cm}$ of length, segmentation was performed to reveal samples representing each half. In 33 out of 80 segments positive results were obtained for EtG, with concentrations between 2.5 and $531.3 \mathrm{pg} / \mathrm{mg}$ (mean 72.4 , median $13.4 \mathrm{pg} / \mathrm{mg}$ ). In 15 cases positive results were revealed for both segments. In one samples a positive result was revealed only for segment $A$ and not for segment $B$, in further two samples only for segment $\mathrm{B}$. The results indicate that EtG analyses can be performed on mummy hair samples even several hundred years after death, suggesting an alcohol abuse during lifetime.

\section{P76}

Vergleich und Objektivierung von Symptomatik und Toxikologie von Blutalkoholwerten - präliminäre Daten aus dem Institut für Rechtsmedizin des Universitätsklinikums Bonn

\section{G. Kernbach-Wighton', K. Ehlert', B. Madea'}

'Institut für Rechtsmedizin, Universitätsklinikum Bonn, Bonn, Deutschland

Einleitung. 2012 ereigneten sich täglich im Mittel 108 Verkehrsunfälle, bei denen mindestens ein Beteiligter alkoholisiert war. Um einen realitätsnahen, am besten objektiven Eindruck von der Alkoholbeeinflussung eines Beschuldigten zu erhalten, werden neben Zeugenaussagen und Atemalkoholvortests vor Ort polizeiliche Feststellungen und Blutalkoholkonzentration (BAK) sowie Befunde einer ärztlichen Untersuchung neben einer Symptomfeststellung durch Polizeibeamte in Form eines sog. „Torkelbogens" dokumentiert. Zusammen dienen diese Kriterien zur Differenzierung zwischen relativer und absoluter Fahrunsicherheit und damit als Basis juristischer Sanktionen. Es stellt sich jedoch häufig die Frage, wie gut bzw. in welchem Grad die Dokumentation klinischer Untersuchungen mit der festgestellten BAK korreliert. Aus rechtsmedizinischer Sicht entsteht oftmals der Anschein einer nur unzureichenden Korrelation.

Methoden. An einer randomisierten Stichprobe von Fällen mit V. a. Trunkenheit im Straßenverkehr des Bonner Instituts für Rechtsmedizin der 2011/2012 erfolgte eine retrospektive Analyse. Es sollten mindestens 100 Fälle in die Studie eingeschlossen werden, von denen z. Z. 75 vollständig hinsichtlich Dokumentation und Alkoholanalysen erfasst wurden. Besonders fokussiert wurde hierbei auf eine detaillierte Analyse der sog. „Torkelbögen“ bezüglich der klinischen Symptomatik des Beschuldigten. Ziel der Studie ist die Entwicklung eines praktikablen Scores, welcher den „Ist-Zustand“ aus den Bögen und diesem gegenüber zu erwartende Symptombilder bezüglich der jeweiligen BAK beschreibt und vergleicht.

Ergebnisse und Schlussfolgerung. Als vorläufiges Resultat ist festzuhalten, dass oft erhebliche Divergenzen zwischen Analysenresultaten und im Vorweg sowohl der durch blutentnehmende Ärzte und auch aufnehmende Polizeibeamte festgestellten Symptombildern bestehen. Die Ergebnisse hinsichtlich möglicher Gründe für die festgestellten Diskrepanzen werden diskutiert und hieraus abzuleitende Modifikationen des Procedere zu einer besseren Standardisierung aufgezeigt.

\section{P77}

Suizid durch Selbstverbrennung - zur Aussagekraft von CO-Hb und Cyanid

\section{Blaas', A. Bittorf', D. Rentsch', A. Büttner}

'Institut für Rechtsmedizin, Rostock, Deutschland

Fragestellung. Die Untersuchung von Brandleichen soll durch den Nachweis von $\mathrm{CO}-\mathrm{Hb}$ und/oder Cyanid Aussagen zur Vitalität bei Brandausbruch stützen und die Abgrenzung zur „Leichenentsorgung“ ermöglichen. Wir berichten über einen ungewöhnlichen Suizid durch Selbstverbrennung, bei dem aufgrund der Auffindesituation und des negativen $\mathrm{CO}-\mathrm{Hb}-\mathrm{Befundes}$ extensive Untersuchungen folgten. Ein Tö- 
tungsdelikt konnte ausgeschlossen werden, die Ergebnisse der toxikologischen Analyse bieten jedoch Anlass für Diskussionen.

Methoden. Die Leichenasservate wurden einem „general unknown“Screening unterzogen. Die Bestimmung der CO-Sättigung erfolgte mittels der Multiwellenlängemethode; Cyanid wurde mit HS-GC-NPD gemessen. Zusätzlich wurde Mageninhalt mit 1-Chlorbutan extrahiert und die organische Phase direkt in das GC/MS injiziert.

Wesentliche Ergebnisse. Negativer $\mathrm{CO}-\mathrm{Hb}$ und Cyanid-Befund. Nachweis von Mirtazapin/Nordazepam, Perazin, Sertralin/Norsertralin im Oberschenkelvenenblut, darüber hinaus Promethazin im Urin sowie Undecan, Dodecan, Tridecan und Cyclotetradecan im Mageninhalt. Keine Alkoholisierung. Hitzeschädigungen der Körperoberfläche, diskrete Rußeinatmung, keine andersartigen Gewalteinwirkungen.

Schlussfolgerungen. Im vorliegenden Fall handelte es sich um einen 44 Jahre alt gewordenen Mann, der mit bekannten Suizidabsichten von einer psychiatrischen Station abgängig gewesen sei. Trotz des negativen $\mathrm{Co}-\mathrm{Hb}$ - und Cyanid-Befundes und ermittelten Sachverhaltes ließen sich die erhobenen Befunde einer suizidalen Selbstverbrennung mithilfe von Grillkohlenanzünder zuordnen: Das Brandsachverständigengutachten ermöglichte die zeitliche Eingrenzung und Rekonstruktion des Tatablaufs, seitens der Rechtsmedizin erfolgten die Identifizierung sowie die Beurteilung der Vitalität und der nachgewiesenen Medikamentenkonzentrationen. Als Todesursache kommt ein akuter Verbrennungstod, „flash fire“, in Betracht. Diskussionswürdig bleiben der nachgewiesene Psychopharmaka-"Cocktail" und die ärztliche Einschätzung der „Gesamtwirkung“ bzw. der Suizidalität des Patienten.

\section{P78}

\section{Tod durch Chloroquin-Cocktail - ein Fall von Sterbehilfe}

\section{Heß', B. Madea' \\ 'Institut für Rechtsmedizin Bonn, Forensische Toxikologie, Bonn, Deutsch- land}

Einleitung. Bei Chloroquin handelt es sich um ein Medikament, dass zur Prophylaxe und Therapie der Malaria eingesetzt wird. Seit den 1980er Jahren wurde Chloroquin immer wieder als Suizidmittel gewählt; in letzter Zeit werden wieder vermehrt Fälle berichtet, nachdem Sterbehilfeorganisationen Chloroquin in Kombination mit zentral dämpfenden Substanzen als humane und schmerzfreie Selbstmordvariante beschreiben.

Fall. Eine 43 Jahre alte Frau wurde leblos auf ihrem Sofa sitzend aufgefunden. Die Umstände des Falles wiesen auf einen Suizid hin: Sie habe keinen Lebenswillen mehr gehabt, nachdem ihr Brustkrebs metastasiert habe. Neben der Tatsache, dass die Frau Epileptikerin war, wurde auch mitgeteilt, dass sie Kontakt zu einer Sterbehilfeorganisation in der Schweiz aufgenommen hatte.

Methoden. Eine Obduktion wurde an unserem Institut durchgeführt. Standarduntersuchungsgänge mittels LC-MS/MS und GC-MS wurden durchgeführt. Chloroquin wurde mittels LC-MS/MS nach FlüssigFlüssig-Extraktion bestimmt.

Ergebnisse und Diskussion. Bei der Obduktion wurden nichtspezifische Befunde erhoben. Folgende Wirkstoffe konnten in Körperflüssigkeiten nachgewiesen werden: Chloroquin in toxischer Konzentration $(4,46 \mathrm{mg} / \mathrm{l})$ und weiterhin Diazepam $(632 \mathrm{ng} / \mathrm{ml}$ mitsamt den Metaboliten Nordiazepam, Temazepam und Oxazepam), das Antiepileptikum Lamotrigin $(1,05 \mathrm{mg} / \mathrm{l})$ und Phenobarbital $(6,86 \mathrm{mg} / \mathrm{l})$. Chloroquin zeigt bei Überdosierung starke Kardiotoxizität, die Steigerung der Herzkontraktilität nimmt durch die Hemmung der Reizweiterleitung stark ab, es kann zu Atem- und Kreislaufversagen kommen. Es konnte festgehalten werden, dass die Frau durch eine Mischintoxikation verstorben ist. Schlussfolgerung. In letzter Zeit kursieren im Internet Anleitungen zur Selbsttötung mit Hilfe einer Kombination von Benzodiazepinen oder Barbituraten, die den Suizidenten sedieren sollen, und des Antimalariamittels Chloroquin. Diese Methode soll ein schmerzfreies Versterben zulassen und wurde in diesem Fall, wie in anderen in letzter Zeit beschriebenen Fällen, nach Kontakt mit einer Sterbehilfeorganisation genutzt.

\section{P79}

\section{Nachweis einer durch Metformin induzierten Laktatazidose post} mortem

\section{Heß', B. Madea}

'Institut für Rechtsmedizin Bonn, Forensische Toxikologie, Bonn, Deutschland

Einleitung. Metformin ist ein orales Antidiabetikum für die Therapie des Typ-2-Diabetes. Die Inzidenz einer durch Metformin ausgelösten Laktatazidose liegt bei 3-9 Fällen pro 100.000 Patienten/Jahr. Es wurde nur eine geringe Korrelation zwischen Serumkonzentrationen und der Entwicklung einer Laktatazidose beschrieben. Es stellte sich die Frage, ob die Laktatkonzentration nach dem Tod im Liquor cerebrospinalis (CSF) oder der Glaskörperflüssigkeit (VH) die Post-mortem-Diagnose einer Laktatazidose ermöglicht.

Fall. Eine 58 Jahre alte Diabetikerin wurde ins Krankenhaus eingeliefert, nachdem bei ihr Symptome wie Übelkeit und Atembeschwerden festgestellt wurden und sie das Bewusstsein verloren hatte. Die Blutgasanalyse zeigte eine dramatische Veränderung im Säure-Base-Haushalt, der $\mathrm{pH}$ lag bei 6,59, die Bicarbonat-Konzentration bei 4,8 mmol/l. Trotz intensiver Therapie mit Bicarbonat entwickelte sie ein Nieren- und Leberversagen und die Frau verstarb einige Stunden später. Der geringe $\mathrm{pH}$ warf die Frage nach ihrer Medikation auf: Sie nahm regelmäßig das Antidiabetikum Metformin ein.

Methoden. Eine Obduktion wurde an unserem Institut durchgeführt. Standarduntersuchungsgänge mittels LC-MS/MS und GC-MS wurden durchgeführt. Das Biguanid Metformin wurde mittels LC-MS/MS nach Proteinfällung und Trennung über eine Amino-end capped analytische Säule bestimmt. Glukose und Laktat wurden mit immunchemischen Methoden bestimmt.

Ergebnisse und Diskussion. Bei der Obduktion wurden nichtspezifische Befunde erhoben. Neben den im Krankenhaus gegebenen Medikamenten konnte Metformin in einer toxischen Konzentration (FVB: $1190 \mu \mathrm{g} /$ $\mathrm{ml}, \mathrm{HB}: 1660 \mu \mathrm{g} / \mathrm{ml}$ und CSF: $888 \mu \mathrm{g} / \mathrm{ml}$ ) quantifiziert werden. Glukosekonzentrationen lagen bei $95 \mathrm{mg} / \mathrm{dl}$ in der CSF und $43 \mathrm{mg} / \mathrm{dl} \mathrm{im} \mathrm{VH}$ und schlossen eine diabetische Ketoazidose aus. Die Laktatkonzentration im CSF lag bei $627 \mathrm{mg} / \mathrm{dl} \mathrm{im}$ CSF und $321 \mathrm{mg} / \mathrm{dl} \mathrm{im} \mathrm{VH} \mathrm{und} \mathrm{damit}$ oberhalb der Referenzgruppe für CSF und innerhalb im VH (5-504 mg/ dl, Mittelwert: 293 mg/dl, n=69 im CSF und 0,2-592 mg/dl; Mittelwert: $305 \mathrm{mg} / \mathrm{dl} ; \mathrm{n}=127 \mathrm{im} \mathrm{VH}$ ). In einer ante mortem Serumprobe der Verstorbenen wurde eine Laktatkonzentration von $20 \mathrm{mmol} / \mathrm{l}$ (Referenzkonzentrationen bis $2,5 \mathrm{mmol} / \mathrm{l}$ ) bestimmt, so dass Nieren- und Leberversagen als Folge einer Metformin-assoziierten Laktatazidose als Todesursache festgehalten wurde.

Schlussfolgerung. Die LC-MS/MS-Analytik auf Metformin in Postmortem-Matrices und eine hohe Laktatkonzentration in der CSF können dazu beitragen, eine Laktatazidose auch nach dem Tod zu detektieren.

\section{P80}

Xylometazoline poisoning: a 40-fold nasal drop overdose caused by a compounding error in 3 children

F. Musshoff', B. Madea', J. Wölfle², D. Vlanic ${ }^{2}$

'Institut für Rechtsmedizin, Bonn, Deutschland, ${ }^{2}$ Universitätsklinikum, Allgemeine Pädiatrie, Bonn, Deutschland

Introduction. The imidazoline derivative xylometazoline, an alpha-2adrenergic agonist, is used as non-prescription nasal preparation due to its vasoconstrictive and decongestive properties. Especially in children, 
an overdose can quickly cause severe central nervous system depression and cardiovascular adverse effects.

Case report. In three 3-year-old boys (triplets) a xylomatazoline intoxication was diagnosed by toxicological analysis. On admission to an emergency unit all three children were still unresponsive. One triplet with a $3 \mathrm{l} / \mathrm{min}$ oxygen face mask ventilation, showed respiration of 15 to 20 breaths/min and an electrocardiogram demonstrated a sinus bradycardia of 64 beats/min with supraventricular extrasystoles. However, no interventions were necessary except fluid management via intravenous lines. Eleven hours after the event, two of the triplets were awake but still very confused. The third triplet woke up 20 hours after ingestion of nose drops.

Conclusions. Intoxication was caused by a compounding error in a pharmacy resulting in a concentration 40 times above the adequate dosage for children. In general, physicians, pharmacists and the public should be educated about the toxicity of over-the-counter preparations.

\section{P81}

Simultane Analytik von 62 synthetischen Cannabinoiden in humanem Plasma mittels Elektrosprayionisation HPLC/MS-MS

\section{Heß', M. Knuth', F. Musshoff', B. Madea'}

'Institut für Rechtsmedizin Bonn, Forensische Toxikologie, Bonn, Deutschland

Einleitung. Synthetische Cannabinoide überfluten seit einigen Jahren den Markt. Forensische Labore müssen in der Lage sein, die Muttersubstanzen im Serum nachzuweisen, doch der Nachweis gestaltet sich aufgrund der hohen Dynamik, der Substanzvielfalt und der niedrigen Serumkonzentrationen aufgrund der hohen Rezeptoraffinität der Substanzen problematisch.

Methoden. Nach einer Flüssig-Flüssig-Extraktion mit n-Hexan und Ethylacetat (99:1) wurden die Analyten über eine Luna-Phenyl-HexylSäule getrennt. Alle 62 Substanzen wurden mit einem Ionenübergang im „multiple reaction monitoring" in die Methode aufgenommen. Bei positivem Nachweis einer der Substanzen mit dieser ersten Qualifizierungsmethode erfolgte eine Bestätigung mittels zwei weniger umfangreichen (30 und 32 Substanzen) Methoden und zwei Ionenübergängen. Isomere Verbindungen konnten über die Retentionszeit, die Ionenverhältnisse oder unterschiedliche Fragmentmassen unterschieden werden. Die Methode beinhaltet die Analyte aus den folgenden chemischen Klassen: Cyclohexylphenole (z. B. CP-47,497), Aminoalkylindole (z. B. JWH-o81), Phenylacetylindole (z. B. JWH-250), Benzoylindole (z. B. RSC-4), Analoga von Endocannabinoiden (Methanandmaid), Naphthoylpyrrole (z. B. JWH-307) und Naphythylmethylindene (CRA-13). Die Methoden wurden nach den GTFCh-Richtlinien validiert.

Ergebnisse und Schlussfolgerung. Die LC-MS/MS-Methoden erlauben die simultane Detektion (Methode 1) und Quantifizierung (Methoden 2 und 3) von 62 synthetischen Cannabinoiden im Plasma. Linearität ist im Bereich von $0,1-5 \mathrm{ng} / \mathrm{ml}$ für alle Substanzen gegeben. Wiederfindungsraten, Matrixeffekte und Präzisionsdaten stimmen mit den Richtlinien der GTFCh überein.

P82

\section{Methämoglobinämie und Tod nach Inhalation von „Poppers“ - ein Fallbeispiel}

\section{Heß', B. Madea}

'Institut für Rechtsmedizin Bonn, Forensische Toxikologie, Bonn, Deutschland

Einleitung. Unter „Poppers“versteht man eine Reihe flüssiger und kurzzeitig wirksamer Drogen, die durch ihre gefäßerweiternde Wirkung hauptsächlich in der homosexuellen Szene aphrodisierend, schmerzhemmend und den Schließmuskel entspannend wirken sollen. Che- misch handelt es sich um Alkylnitrite (z. B. Amylnitrit). Organische Nitrite können allerdings auch als Oxidationsmittel dienen und das Eisenzentralatom des Hämoglobins zu dreiwertigem Eisen (Methämoglobin) oxidieren. Es existieren keine Daten, ob die Bestimmung des Analyts Methämoglobin nach dem Tod noch zu aussagekräftigen Befunden führt.

Fallbericht. Ein 35 Jahre alter Mann wurde in seiner Wohnung tot aufgefunden. Er habe bei seiner Auffindung eine Atemschutzmaske über Mund und Nase gehabt. Vor ihm habe eine geöffnete Dose mit transparentem Inhalt gestanden. Im Badezimmer wurde ein weiteres Fläschchen aufgefunden. Die Ehefrau habe angegeben, dass der Verstorbene das Material im Internet bestellt habe, um seine erotischen Reize zu verstärken.

Methoden. Eine Obduktion wurde an unserem Institut durchgeführt. Standarduntersuchungsgänge mittels LC-MS/MS und GC-(SPME)-MS wurden durchgeführt. Methämoglobin wurde mittels Flüssigchromatographie nachgewiesen. Um die Stabilität und Aussagekraft des Analyten Methämoglobin nach dem Tod beschreiben zu können, wurden 30 Femoralblutproben und Herzblutproben aus dem Obduktionsgut des Instituts für Rechtsmedizin Bonn sofort und 4 Wochen nach dem Tod auf Methämoglobin vermessen.

Ergebnisse und Diskussion. In der aufgefundenen Lösung konnte mittels SPME-GC/MS Isopropylnitrit detektiert werden. In Körperflüssigkeiten des Verstorbenen konnte kein Isopropylnitrit nachgewiesen werden, was an der leichten Flüchtigkeit und der kurzen Halbwertszeit der Substanz liegen könnte. Es fanden sich Amphetamin (51,1 ng/ml), MDMA $(241 \mathrm{ng} / \mathrm{ml})$ und THC $(17,2 \mathrm{ng} / \mathrm{ml})$ und Metaboliten im Femoralvenenblut. Aufgrund des Verdachts, dass das organische Nitrit in Kombination mit der Atemschutzmaske eine Methämoglobinämie und einen Atemstillstand ausgelöst hatte, wurde Methämoglobin bestimmt. Die Konzentration im Femoralvenenblut lag bei 20\% (Referenzwerte: $<1,5 \%)$. Zusätzlich wurde eine Carboxy-Hämoglobin-Konzentration von $14 \%$ detektiert. In den Formen Methämoglobin und Carboxy-Hämoglobin ist ein Sauerstofftransport nur noch schwer möglich und ein inneres Ersticken kann als todesursächlich angesehen werden.

Schlussfolgerung. Organische Nitrite können eine erhöhte Konzentration an Methämoglobin auslösen. Der Nachweis der leicht flüchtigen Substanzen nach dem Tod fällt schwer, die Folge Methämoglobinämie kann allerdings nachgewiesen werden. Der Analyt Methämoglobin zeigt sich nach dem Tod stabil und kann mit ante mortem Werten verglichen werden.

\section{P83}

Entwicklung und Validierung einer Methode zur Bestimmung von Begleitstoffen in Serum und Anwendung in einem Pilotversuch zur endogenen Bildung von 1-Propanol

\section{Angerer', V. Auwärter'}

'Rechtsmedizin Freiburg, Forensische Toxikologie, Freiburg, Deutschland

Einleitung. Die Begleitstoffanalyse ist ein wichtiges Instrument zur Beurteilung der Plausibilität einer Nachtrunkbehauptung. Dabei sind die wichtigsten Analyten, für die kinetische Berechnungen durchgeführt werden können, die beiden Begleitalkohole 1-Propanol und Isobutanol. Für eine korrekte Beurteilung ist es erforderlich zu wissen, ob und in welchem Umfang diese Alkohole endogen gebildet werden. Es wurde ein Pilotversuch zur Klärung dieser Frage durchgeführt, bei der ein Proband ausschließlich begleitstofffreie Getränke konsumierte.

Methoden. Es wurde eine Headspace-Methode unter Verwendung eines Perkin-Elmer-Gaschromatographen (Kapillarsäule von Restek RTX ${ }^{\oplus}$ 502.2, $60 \mathrm{~m}, 0,53 \mathrm{~mm}$ ID, $3 \mu \mathrm{m}$ Filmdicke) mit einem FID-Detektor entwickelt und nach den Richtlinien der GTFCh (Anhang E) validiert. Für die Probenvorbereitung wurden $1 \mathrm{~g}$ Natriumsulfat in ein HeadspaceVial vorgelegt und o,5 $\mathrm{ml}$ Serum zugesetzt. Als interner Standard wurde tert-Butanol verwendet. Für die Pilotstudie trank ein männlicher Proband (75 kg) innerhalb von $3,5 \mathrm{~h} 400 \mathrm{ml}$ Wodka (Grasovka, 40 Vol\%) 
gemischt mit $400 \mathrm{ml}$ Bitter Lemon. Ihm wurden im Abstand von ca. $1,5 \mathrm{~h}$ über einen Zeitraum von insgesamt $10 \mathrm{~h}$ Blutproben entnommen. Außerdem wurden sowohl der Wodka als auch das Bitter Lemon auf den Begleitstoffgehalt untersucht.

Ergebnisse. Die Nachweisgrenzen (LOD) betrugen zwischen o,o1 und $0,02 \mathrm{mg} / \mathrm{L}$ und die unteren Bestimmungsgrenzen (LLOQ) zwischen 0,03 und $0,05 \mathrm{mg} / \mathrm{L}$ für alle Analyten außer Methanol (LOD o,06 mg/L, LLOQ 0,25 mg/L) und Aceton (LOD 0,07 mg/L, LLOQ 0,24 mg/L). In der Pilotstudie wurde die maximale 1-Propanol-Konzentration im Serum etwa $7 \mathrm{~h}$ nach Trinkbeginn erreicht und betrug 0,58 mg/L, die BAK lag zu diesem Zeitpunkt bei 1,26\%. Die maximale Blutalkoholkonzentration wurde dagegen bereits 2 Stunden früher erreicht und betrug $1.63 \%$.

Schlussfolgerung. Eine Methode zur quantitativen Bestimmung von Begleitstoffen in Serum wurde erfolgreich entwickelt und validiert Durch das Pilotexperiment konnte gezeigt werden, dass vor allem bei höherer und länger andauernder Alkoholisierung mit einer relevanten Akkumulation von endogen gebildetem 1-Propanol gerechnet werden muss. Genauere Untersuchungen zur Aufbaukinetik sind erforderlich, um im Fall einer bereits vor dem Vorfall anzunehmenden Alkoholisierung einen korrekten Erwartungswertbereich für diesen Begleitalkohol abschätzen zu können.

\section{P84}

\section{Comparison of hydrogen and helium as carrier gas in a fast GC-MS}

\section{K. Hara', B. Waters', M. Kashiwagi', A. Matsusue', M. Takayama', S.-I. Kubo'} ${ }^{1}$ Faculty of Medicine, Fukuoka University, Department of Forensic Medicine, Fukuoka, Japan

Background and aim. Helium is the best carrier gas in GC-MS. Hydrogen is also good carrier gas, and its use for GC is increasing around world. Aim of this study was to investigate the utility of hydrogen as a carrier gas in fast GC-MS for actual drug screening examination in forensic toxicology.

Materials and method. Sample for setting measurement: a standard solution containing 13 drugs was prepared. Sample: whole blood was treated with urease. After the treatment, acetonitrile containing formic was also added into the blood. The mixture was vigorously shaken in a few minutes and centrifuged. After washing with n-heptane, calcium hydroxide was added into the extract and alkalized with sodium carbonate. Following centrifugation, the upper organic extract solution was dehydrated with sodium sulfate. The final extract solution was evaporated to dryness under a nitrogen stream. The sample residue was dissolved in mix solvent of n-propyl acetate and ethanol, and analyzed by fast GC-MS.

Conditions of GC-MS. Apparatus: QP-2010Ultra, Column: Combined two columns of Rtx-200/BPX-5. Carrier gas flow was adjusted in linear velocity. Temperature of GC oven: initially $80^{\circ}$ for $0.5 \mathrm{~min}$, temperature program: $70^{\circ} \mathrm{C} / \mathrm{min}$ to $200^{\circ} \mathrm{C}, 50^{\circ} \mathrm{C} / \mathrm{min}$ to $320^{\circ} \mathrm{C}$.

Results and discussion. The adjustment of linear velocity of carrier gas was performed in a range of vacuum capacity. The chromatographic profiles between both gases showed almost same retention time patterns. Although detection intensities of peaks with hydrogen at $180 \mathrm{~cm} / \mathrm{s}$ and $200 \mathrm{~cm} / \mathrm{s}$ were less than with helium, the hydrogen is feasible for Fast GC-MS screening examination in actual cases. Otherwise, detection intensities with hydrogen at $250 \mathrm{~cm} / \mathrm{s}$ were extremely low in comparison with helium. We recommend using helium if its supply is stable. Though, we could use hydrogen as carrier gas if sensitivity of the apparatus is enough for regular analysis.

\section{P85}

A method transferability study: adapting a QTOF-MS pesticide screening method to the application of forensic screening using enhanced confirmation strategies

J. Kempf', L. Huppertz', V. Auwärter', A. Pelander', M. Sundstroem², I. Ojanpe$\mathrm{ra}^{2}$, C. Baessmann ${ }^{3}$, K. Wendt ${ }^{3}$, S. Bodendiek ${ }^{3}$, P. Decker ${ }^{3}$

'Institut für Rechtsmedizin Freiburg, Forensische Toxikologie, Freiburg, Deutschland, ${ }^{2} \mathrm{Hj}$ jelt-Institute, Department of Forensic Medicine, University of Helsinki, Helsinki, Finland, ${ }^{3}$ Bruker Daltonik GmbH, Bremen, Deutschland

Introduction. A recently developed high-resolution accurate mass QTOF screening method for pesticides in food shall be extended into other application areas. As pesticides are a subset of compounds of forensic interest, the usability of this setup for forensic screening shall be tested. Various options for enhanced result confirmation like diagnostic ions or fragments generated in broad-band CID are tested to achieve maximum result affirmation.

Methods. 61 compounds of forensic interest were selected according to common findings in post-mortem and routine drug screening. Solvent based mixes were run on identical systems (Dionex RSLC, Bruker Daltonics impact ESI-QTOF) at all three sites using data acquisition in alternating full-scan/bbCID mode to set up a database containing name, sum formulae and RT, plus bbCID-fragments. Also, the $\mathrm{M}+1$ and $\mathrm{M}+2$ isotope of each compound were included. Urine and serum extracts were spiked at levels of $10-500 \mathrm{ng} / \mathrm{ml}$ and analyzed on the system in Bremen. The intensity threshold for compound detection was set to allow detection of all relevant traces in a $10 \mathrm{ppb}$ sample in solvent. A compound was finally rated as found, if the main adduct ion and its $\mathrm{M}+1$ or $\mathrm{M}+2$ isotope or an alternative adduct/fragment was detected. This approach was applied to authentic samples from routine cases (autopsy and roadside testing cases) which were run on the systems in Helsinki and Freiburg.

Results and discussion. Using the pesticide LC method, the chosen compounds are evenly spread across the chromatogram, with good peak shapes also for early eluting analytes and analytes known for chromatographic issues. RT values were independent from matrix and deviation between all three sites was $<0.2 \mathrm{~min}$. All spiked compounds can be identified, except pregabalin and THC-COOH at the $10 \mathrm{ng} / \mathrm{ml}$ level. Due to the low intensity thresholds, a significant number of false positives are observed in blank matrix samples. Applying the diagnostic ion criteria for detection, about two third of the random findings are removed by the criterion of detecting an isotope. After additionally taking into account the bbCID data, only caffeine and paracetamol are left as plausible true positive findings. The results for the authentic case samples were in perfect agreement with findings from routine analysis with no false positive findings.

\section{P86}

Screening for psychotropics using LC-MSn: adapting a comprehensive screening approach to specific needs

J. Kempf', J. Traber', L. Huppertz ${ }^{1}$

'Institut für Rechtsmedizin Freiburg, Forensische Toxikologie, Freiburg, Deutschland

Introduction. Various LC-MS approaches and types of instruments are used to develop an ultimate comprehensive screening method to detect and definitely identify as many compounds as possible in a single run. Nevertheless, in routine work the question for the detection of a dedicated set of substances e.g. hypnotics in cases of DFSA arises quite often. The aim of this project was to develop a screening method for psychotropics based on the ToxtyperTM open library concept.

Methods. Data of psychotropics from the Toxtyper library and spectral data of psychotropics available as reference standards in our lab were combined in a spectral library. These data were used to compile 
a scheduled precursor list (SPL) to trigger data dependent acquisition of spectra. A conventional ESI- and an ionBoosterTM source were used for ionization. All other parameters were adopted from the original Toxtyper approach. Samples were analysed on a Dionex RSLC coupled to a Bruker Daltonics amaZon speed ion trap. For evaluation, different drug-free serum samples fortified with different mixes of psychotropics at 2 low therapeutic concentrations and several authentic samples were analysed.

Results. The final SPL of the method contains the precursor mass and retention time of 105 psychotropic substances. Two sets (cLOW, $2 \times$ cLOW) of 12 mixes containing a total of 99 compounds were analysed using both ionisation techniques and the original screening approach. The customized method led to a higher rate of positive findings (92\%), especially at low concentration levels, than the comprehensive screening approach (87\%). Two analytes couldn't be detected, while 5 compounds could only be identified at cLOW when using the ionBooster. Results from routine analysis of several cases with known intake of psychotropic drugs were confirmed with positive findings, if the concentration range was above or around the assumed limit of detection from this evaluation study.

Conclusions. The open library concept enables fast and easy generation of new screening methods. The presented method is a fast and robust tool for the detection and identification of 105 psychotropics in human serum. Evaluation in spiked human samples showed detection of low therapeutic levels for the majority of compounds, making the screening applicable for clinical and forensic samples.

\section{P87}

\section{Analytik von $\gamma$-Hydroxybuttersäure im Serum mittels LC-MS/MS auf} der Basis der Adduktbildung

\section{Dziadosz', J.-P. Weller', M. Klintschar', J. Teske'}

${ }^{1}$ Medizinische Hochschule Hannover, Institut für Rechtsmedizin, Hannover, Deutschland

Einleitung. Die Kopplung von Flüssigchromatographie mit TandemMassenspektrometrie hat in den letzten Jahren in der Analytik von unterschiedlichen Wirkstoffen im biologischen Material an Bedeutung gewonnnen. Begrenzende Faktoren sind dabei z. B. die Ionisierbarkeit, die Molekülgröße, mögliche Adduktbildung oder Matrixeffekte. Die Bildung von Addukten ist bei der Elektrospray-Ionisation fundamental und führt im positiven und negativen Modus z. B. zu detektierbaren [M-H]+ bzw. [M-H]- Adduktionen. Andere Addukte werden während der Methodenentwicklung sehr oft ignoriert obwohl sie bei schwacher Bildungsreproduzierbarkeit die Präzision der Methode sehr beeinflussen können.

Zielsetzung. Ziel dieser Arbeit war die Erforschung der Anwendbarkeit der Adduktbildung von $\gamma$-Hydroxybuttersäure (GHB) mit den Komponenten der mobilen Phase der LC-MS/MS im negativen ElektrosprayModus. Infusionsexperimente ermöglichten die Identifizierung von zwei GHB-Addukten. Die Fragmentierung des GHB-Adduktes mit Natriumacetat (Target $=185 / 85$ ) wurde neben der GHB-Fragmentierung (Qualifier $=103 / 85$ ) als Massenübergang in der Methodenvalidierung verwendet.

Methoden. Die chromatographische Trennung erfolgte an einer C18Säule [Luna $5 \mu \mathrm{m} \mathrm{C18} \mathrm{(2)} 100 \mathrm{~A}, 150 \times 2 \mathrm{~mm}$ ). Die mobile Phase bestand aus $10 \% \mathrm{~A}\left(\mathrm{H}_{2} \mathrm{O} / \mathrm{Methanol}=95 / 5, \mathrm{v} / \mathrm{v}\right)$ and $90 \% \mathrm{~B}\left(\mathrm{H}_{2} \mathrm{O} / \mathrm{Metha}-\right.$ $\mathrm{nol}=3 / 97, \mathrm{v} / \mathrm{v})$, beide mit $10 \mathrm{mM}$ Ammoniumacetat und o, $1 \%$ Essigsäure $(\mathrm{pH}=3,2)$. Die Probenvorbereitung bestand lediglich aus einer Eiweißfällung mit $1 \mathrm{~mL}$ der mobilen Phase B.

Ergebnisse und Schlussfolgerung. Die entwickelte und validierte Methode erwies sich als interessante Alternative, um das Problem der Analyse von kleinen Wirkstoffen mit LC-MS/MS anhand einer Art der OnlineDerivatisierung zu lösen. Die berechnete Nachweis- und Bestimmungsgrenze lag bei $1 \mu \mathrm{g} / \mathrm{mL}$ und ermöglichte die Detektion von GHB bis in den endogenen Bereich.
P88

Systematic investigation of cocaine-positive samples with regard to the presence of adulterants in Mecklenburg from 2010 to 2012

R. Kegler', C. Lehmann², D. Rentsch', A. Büttner

${ }^{1}$ Rostock University Medical Center, Institute of Legal Medicine, Rostock, Deutschland, ${ }^{2}$ University Bonn-Rhein-Sieg, Department of Forensic Science, Rheinbach, Deutschland

Introduction. The determination of cocaine or its metabolites benzoylecgonine and ecgonine methylester is one of the routine works in toxicological laboratories. Since years, cocaine is one of the most consumed illicit drugs in Mecklenburg as well as in Germany. In the last years, several reports have demonstrated adulterants, which were added to cocaine samples. These encompassed caffeine, levamisole, phenacetin, lidocaine, and paracetamol. In Mecklenburg, levamisole have been detected in whole blood samples for the first time in 2009.

Methods. Determinations of whole blood samples for cocaine and its metabolites were performed by SPE, derivatization, and measurement using GC/MS operating in selected ion mode. Investigations of cocainepositive samples for adulterants were accomplished by LLE and LC with DAD. Cut-off values for cocaine-positive results were defined to concentrations of $C \geq 10.0 \mathrm{ng} / \mathrm{mL}$ for cocaine, benzoylecgonine or ecgonine methylester. Statistical analysis of cocaine-positive cases from 2010 to 2012 was performed with regard to age and gender of the persons as well as the types and concentrations of adulterants.

Results and discussion. In 2010 to 2012, nearly 2200 samples of whole blood were investigated for common drugs of abuse. One or more illicit drugs were found in 1648 cases (75\%), of which 232 samples $(14.1 \%)$ were positive for cocaine or its metabolites. From these 232 cases were 173 male ( $74.6 \%), 14$ female (6.0\%), and 45 (19.4\%) without declaration of gender. The main groups were aged between $21-25$ years (28.9\%), 26-30 years ( $38.4 \%)$, and $31-35$ years ( $25 \%)$. In $88(37.9 \%)$ cases adulterants could be detected. In these samples the identified substances include levamisole $(n=43)$, phenacetin $(n=41)$, both levamisole and phenacetin $(n=10)$, and lidocaine $(\mathrm{n}=4)$. The measured concentration level of levamisole ranged from $8.53^{-1203} \mathrm{ng} / \mathrm{mL}$ (median: $86.8 \mathrm{ng} / \mathrm{mL}$ ). The concentrations of phenacetin and lidocaine were $1.67-234 \mathrm{ng} / \mathrm{mL}$ (median: $30.8 \mathrm{ng} /$ $\mathrm{mL}$ ) and $20.0-162 \mathrm{ng} / \mathrm{mL}$ (median: $70.5 \mathrm{ng} / \mathrm{mL}$ ), respectively.

Conclusions. Our study presents a detailed overview of cocaine-positive cases and the incidence of adulterants in Mecklenburg from 2010 to 2012.

\section{P89}

Zur aktuellen Entwicklung des Metamfetaminkonsums in der Mitte Deutschlands - rechtsmedizinische Aspekte

S. Klingner', M. Grapp', H. Desel', W. Grellner'

'Universitätsmedizin Göttingen, Rechtsmedizin, Göttingen, Deutschland

Einleitung. Metamfetamin erlebt derzeit insbesondere in Sachsen und Bayern einen Aufschwung als Modedroge, soll sich aber zunehmend auch auf das übrige Deutschland verbreiten.

Material und Methoden. Ausgewertet wurden alle 2008 bis 2012 in unserem Institut zur Untersuchung auf Drogen eingegangenen Laborproben $(\mathrm{n}=15.179$, davon 2019 Metamfetaminanalysen). Die Metamfetamin-positiven Fälle $(\mathrm{n}=136, \mathrm{~m}=127, \mathrm{w}=9)$ wurden hinsichtlich Alter der Probanden, Blutkonzentration und möglichem Beikonsum anderer Drogen verglichen, die Proben aus $2012(n=39)$ zusätzlich auf das ermittelte Vergehen geprüft.

Ergebnisse. Die beauftragten Untersuchungen auf Metamfetamin stiegen im Beobachtungszeitraum deutlich an (Verdoppelung). Auch die Zahl der positiv getesteten Proben verdoppelte sich. Vor dem Hintergrund eines allgemein gestiegenen Probenaufkommens bei Drogenanalysen blieben die relativen Anteile annähernd konstant (12-15\% Metamfetaminanalysen, 6-9\% positive Fälle). 90\% der Probanden waren 
$<36$ Jahre alt (Altersspektrum 21-47 Jahre). Von den ermittelten Werten lagen $60 \%$ im wirksamen $(>10 \mathrm{ng} / \mathrm{mL}$ ) bis toxischen Bereich $(>200 \mathrm{ng} /$ $\mathrm{mL}$; Maximalwert $=898,5 \mathrm{ng} / \mathrm{mL}$ ). $41 \%$ der Konsumenten wiesen keinen Beikonsum auf, bei $59 \%$ lag dieser vor (64\% Cannabis, $40 \%$ Ecstasy, ferner Kokain, Opiate und Benzodiazepine). Untersuchungsanlass gaben 2012 zu 95\% Verkehrsdelikte (davon 43\% mit Fahrauffälligkeiten) ohne Zusammenhang zwischen Blutkonzentration und Schwere des Vorfalls. Diskussion. Auch in Süd- und Ostniedersachsen stieg der rechtsmedizinisch erfassbare Metamfetaminkonsum seit 2008 an. Die Konsumenten waren zum Großteil männlich und im Alter von 21-35 Jahren. Die Blutkonzentrationen lagen überwiegend im wirksamen bis toxischen Bereich. In über der Hälfte der Fälle wurde Metamfetamin nicht allein konsumiert, vorrangig zusammen mit Cannabisprodukten und Ecstasy. Die 2012 auffällig gewordenen Konsumenten zeigten fast ausschließlich Verkehrsvergehen ohne erkennbare Korrelation zwischen Blutkonzentration und Ereignis.

\section{P90}

\section{Solid phase microextraction (SPME) of antidepressant drugs}

\section{R. Kegler', A. Büttner ${ }^{1}$}

'Rostock University Medical Center, Institute of Legal Medicine, Rostock, Deutschland

Introduction. The role of antidepressant drugs in attempted or committed suicides is well known and the analyses of antidepressants in different biological samples belong to the routine works in toxicological laboratories. Direct chromatographic determination of these drugs in biological samples (whole blood, plasma) without precleaning is usually not possible due to interferences of the complex matrices. Simple and rapid bioanalytical methods for sample preparation are rare, since they generally involve complex and time-consuming steps (e.g. protein precipitation, filtration, centrifugation, solvent evaporation, solid phase extraction). In contrast, solid phase microextraction (SPME) provides a fast technique for the isolation of drugs from biological matrices. SPME integrates extraction and enrichment of the target compound into a single step by simply immersing and selectively adsorbing coatings of fibre probes into the biological sample. Subsequently, the target compound is unloaded by desorption directly into an LC-ready sample solvent.

Methods. Three in-house manufactured and two commercially available SPME probes were investigated with respect to their extraction performance for 16 antidepressant drugs from PBS, diluted, and pure plasma samples. All drug concentrations were at the comatose-fatal levels. Calibration curves down to therapeutic concentration levels were performed for selected analytes only. Quantitative determination was accomplished by LC/UV.

Results and discussion. Extraction yields of the 16 antidepressant drugs from PBS using PAN-C18 coatings were $61.7-106.4 \%$. By the use of $\mathrm{C} 18$, PEDOT, PPy, and PTh coatings, the extracted drug amounts ranged from $10.1-74.1 \%, 14.3-68.6 \%, 5.4-48.5 \%$, and $3.4-18.1 \%$, respectively. Reductions of the extraction yields were obtained using matrices with increased parts of plasma proteins. Good linear correlations $(\mathrm{r} 2=0.99)$ resulted for the calibration ranges down to therapeutic concentration levels. The precisions (CV) of extraction yields were $<20 \%$.

Conclusions. The SPME of antidepressants is a promising alternative to conventional methods. However, differences in extraction yields were found for the 16 investigated antidepressant drugs due to interactions between the molecular structures of drugs and polymer coatings.

\section{P91}

Know-how im Katastrophenfall: molekulargenetische Analysen an Knochenmaterial hochgradig postmortal veränderter Leichen

K. Thiele', A.-M. Pflugbeil', H. Bruchhaus', S. Becker', S. Jeraufke², E. Seidel', J. Edelmann', D. Labudde ${ }^{3}$, J. Dreßler ${ }^{1}$

'Institut für Rechtsmedizin der Universität Leipzig, Leipzig, Deutschland, ${ }^{2}$ Hochschule Mittweida - University of Applied Sciences, Mittweida, Deutschland, ${ }^{3} \mathrm{Hochschule} \mathrm{Mittweida} \mathrm{-} \mathrm{University} \mathrm{of} \mathrm{Applied} \mathrm{Sciences,}$ Bioinformatics Group Mittweida bigM, Mittweida, Deutschland

Einleitung. Eine schnelle molekulargenetische Individualisierung von Opfern einer Massenkatastrophe stellt noch immer eine Herausforderung dar, da bei hochgradig postmortalen Veränderungen der Opfer nur noch erhaltene kortikalisreiche Knochen, Zähne oder Fingernägel hierzu herangezogen werden kann. Ein hoher Durchsatz an molekulargenetischen Analysen wird durch eine effiziente mechanische Zerkleinerung der Knochen in Verbindung mit einer zeitlichen Minimierung des Analyseaufwands erreicht.

Material und Methodik. Im Rahmen der Studie wurden jeweils $600 \mathrm{mg}$ Knochenkortikalis der Femurdiaphyse von 17 hochgradig postmortal veränderten Leichen mit Liegezeiten bis 5,5 Monaten zur DNA-Analyse herangezogen. Hierzu wurden aus der gereinigten Knochenkortikalis 6-12 $\mu \mathrm{m}$ starke Knochenschnitte hergestellt, die über lediglich 24 Stunden in 0,5 M EDTA-Lösung dekalzifiziert wurden. Anschließend erfolgte die DNA-Isolation mit dem BioRobot ${ }^{\circledR} \mathrm{EZ}_{1}$ der Firma QIAGEN unter Modifikation des „Large Scale Bone-Protokolls“. Die DNA-Quantifizierung erfolgte mittels Investigator Quantiplex HYres Kit (QIAGEN) oder dem Quantifiler ${ }^{\circledR}$ Human DNA Quantification Kit (Applied Biosystems $\mathrm{s}^{\star}$ ). Nachfolgend wurde eine Typisierung mit dem PowerPlex $^{\star}$ ESX $_{17}$ Kit (Promega) auf dem ABI PRISM ${ }^{\circledR} 3130$ Genetic Analyzer durchgeführt. Alternativ wurde der Einfluss einer Dekalzifizierung über 48 Stunden auf die DNA-Ausbeute getestet.

Ergebnisse. Aus den Femurdiaphysen aller 17 Individuen wurden mit dem PowerPlex ${ }^{\circ}$ ESX17 Kit vollständige STR Profile zur Identifikation der Leichen erhalten. Selbst bei einer DNA-Ausbeute von 1-5 pg/ $\mu \mathrm{L}$ konnten gut auswertbare STR-Profile erzielt werden. Eine Dekalzifizierung über 48 Stunden führt nicht immer zu einer Steigerung der DNAAusbeute.

Schlussfolgerungen. Durch die optimierte Knochenaufarbeitung und Analytik ist es möglich, mit einem geringen Zeitaufwand für die Materialvorbereitung und DNA-Isolation einschließlich der STR-Analytik innerhalb von ca. 2,5 Tagen ein DNA-Identifizierungsmuster bei stark postmortal veränderten Leichen zu erhalten. Teilautomatisierte Prozessabläufe bei der Herstellung von Knochenschnitten und der DNAIsolation ermöglichen mit geringem Personalaufwand einen hohen Probendurchsatz.

\section{P92}

\section{Molekulargenetische Identifizierung von Pilzen aus humanem postmortalem Gewebe}

\section{J. Strien', J.A. Martínez-Ramírez',2, F.T. Peters', G. Mall', J. Sanft ${ }^{1}$}

${ }^{1}$ Rechtsmedizin Jena, Molekulargenetik, Jena, Deutschland, ${ }^{2}$ National University, Department of Pharmacy, Bogotá, Kolumbien

Einleitung. Leichen werden während der postmortalen Phase von zahlreichen Mikroorganismen besiedelt. Darunter finden sich auch verschiedenste Vertreter aus dem Reich der Pilze. Bisher ist jedoch wenig über das Auftreten der einzelnen Arten bekannt. Dies kann Aufschluss über die Lagerung der Leiche bzw. deren Umgebungsbedingungen sowie Hinweise auf die Metabolisierung bestimmter Drogen oder Medikamenten geben.

Methoden. Von uns wurde ein Verfahren zur DNA-Sequenz-basierten Identifikation von Pilzen etabliert. Postmortale Gewebeproben (Herzblut, Leber, Niere und Lunge) mäßig bis stark verwester Leichen wurden 
während der rechtsmedizinischen Sektion entnommen. Die DNA der sich daraus entwickelten Pilze wurde isoliert und mittels PCR vervielfältigt. Für jede Probe wurde ein Marker der ,internal transcribed spacer"(ITS)-Region der ribosomalen DNA amplifiziert. Die ITS-Sequenz ist in vielen Fällen geeignet um Pilzarten gegeneinander abzugrenzen. Um jedoch die genaue Gattung einiger Arten bestimmen zu können, waren weiterführende Untersuchungen mit den Markern translation elongation factor $1 \alpha$ (TEF), Calmodulin und $\beta$-Tubulin nötig. Um eine bestmögliche Amplifikation zu gewährleisten, wurden für jeden Marker ausführliche PCR-Optimierungsmaßnahmen durchgeführt. Die Methodik des Identifikationsverfahrens wird vorgestellt.

\section{P93}

The probability of spermatozoa identification in the vaginal contents of frozen cadavers

\section{A. Padure', A. Padure', M. Stratan' \\ "Universität „Nicolae Testemitanu“ Chisinau, Zentrum für Rechtsmedizin, Chisinau, Moldovien, Republik}

Introduction. It is well known that in the forensic medical examination of the dead bodies laboratory investigations play an important role. During the examination of the victims of sexual assaults committed against women vaginal content is taken, and when necessary from the mouth and rectum also. The aim is to perform biological and genetic investigations in order to find spermatozoa. The accuracy and sampling time will determine the possibility to detect spermatozoa. Detection probability is reduced by the putrefaction. In this context, we consider opportune to present a case from our experience.

Case report. In the police request for medico-legal expertise was shown that a 19-year-old woman disappeared on 07.01.2012, and her body was found on 03.04.2012 in an open field in the suburbs. The woman's cadaver was covered with twigs and dry grass. Her pants were lowered till the legs, and underwear was missing. The corpse was in a moderate state of putrefaction. After its examination it was concluded that the death occurred due to manual strangulation. No injuries were detected in the genital region and around the anus, the vaginal mucosa was autolytic process. However, whereas the body was naked, vaginal content was collected. During the microscopic research of the vaginal content smears and single spermatozoa were detected.

Conclusions. In our opinion, the possibility of sperm detection in vaginal content in this case was due to conservation of the body by freezing. The winter 2011-2012 in the Republic of Moldova was colder than usual. According to the Hydrometeorological Service of the country, the lowest temperatures were recorded in February, reaching to $-23^{\circ} \mathrm{C}$ in that region where the dead body was discovered. Thus, very low temperature caused refrigeration of both the body and its vaginal content, making it possible to detect the sperm which have not been destroyed by putrefaction process.

Conclusions. Sperm can be detected in vaginal content of frozen cadavers even after 3 months after the death. Therefore, in cases when sexual crime is suspected, collecting of its vaginal content is rational, even after its defrosting and moderate putrefaction apparition, regardless the term of freezing.

\section{P94}

Entwicklung der forensisch relevanten Schmeißfliegen Calliphora vicina und Lucilia sericata auf mit Paracetamol angereichertem Nährgewebe

\section{Komo', S. Sohre', C. Gröticke', T. Hoffmann?', W. Pogoda' ', J. Amendt ${ }^{7}$}

'Institut für Rechtsmedizin, Goethe-Universität, Forensische Entomologie, Frankfurt am Main, Deutschland, ${ }^{2}$ Institut für Rechtsmedizin, Goethe-Universität, Forensische Toxikologie, Frankfurt am Main, Deutschland

Fragestellung. Die akkurate Altersbestimmung der an einer Leiche vorgefundenen nekrophagen Insekten ist die wichtigste Aufgabe der forensischen Entomologie. In den letzten Jahren hat sich immer wieder gezeigt, dass einige Substanzen eventuell die temperaturabhängige und artspezifische Wachstumsrate der Insekten beeinträchtigen können. So hat Ethanol z. B. eine verlangsamende und Methadon eine beschleunigende Wirkung auf die Larval-Entwicklung bestimmter Schmeißfliegenarten. Das freizugängliche Analgetikum Paracetamol kann in hohen Konzentrationen $(>60 \mathrm{mg} / \mathrm{kg}$ am Tag) toxisch wirken und eine Lebernekrose auslösen, die im schlimmsten Fall den Tod herbeiführt. Aus diesem Grund findet es auch bei Suiziden immer wieder Verwendung. In der vorliegenden Arbeit wurde deshalb die Entwicklung der beiden in Deutschland forensisch wichtigsten Fliegenarten Calliphora vicina und Lucilia sericata (Diptera: Calliphoridae) in Hinblick auf den Einfluss von Paracetamol untersucht.

Methoden. Frisch geschlüpfte Larven wurden bei $20^{\circ} \mathrm{C}$ auf zwei unterschiedlichen Nährböden (Hackfleisch und Leber) mit $20 \mathrm{mg} / \mathrm{kg}$ (therapeutisch) und $250 \mathrm{mg} / \mathrm{kg}$ (toxisch) Paracetamol gezüchtet. Eine Negativkontrolle diente als Vergleich. Die Versuchsreihen wurden jeweils fünfmal wiederholt. Im Madenstadium wurden anfangs zwei und später eine Messung täglich für Gewicht und Länge dokumentiert. Bei den Puppen wurde alle 24 Stunden die Gewichtsveränderung protokolliert. Die Dauer von Larval- und Puppenphase wurde ermittelt und die jeweilige Mortalitätsrate bestimmt.

Ergebnisse. Es zeigten sich geringe Unterschiede in den Entwicklungsraten von $C$. vicina und $L$. sericata auf verschiedenen Gewebetypen und Paracetamol-Konzentrationen. Die Ergebnisse werden im Hinblick auf die Relevanz sog. entomotoxikologischer Experimente für die forensische Praxis diskutiert.

Schlussfolgerung. Die festgestellten Unterschiede scheinen nicht von forensischer Relevanz für die Altersbestimmung der untersuchten Fliegenarten zu sein. Prinzipiell stellt sich die Frage nach einer Modifikation und Standardisierung entomotoxikologischer Versuche, die bislang dem Aspekt der Verstoffwechselung der in Frage kommenden Präparate im lebenden Organismus nicht genügend Rechnung tragen. 


\section{Autorenindex}

A

$\begin{array}{ll}\text { Achenbach, J. } & \text { V62 } \\ \text { Adamec, J. } & \text { P26 } \\ \text { Ago, K. } & \text { V109 } \\ \text { Ago, M. } & \text { V109 } \\ \text { Ahlström, S. } & \text { P2 } \\ \text { Albalooshi, Y. } & \text { P12, P33 } \\ \text { Al Beraiki, H.K. } & \text { V19 } \\ \text { Albrecht, K. } & \text { V108 } \\ \text { Alm, B. } & \text { V114 } \\ \text { Amberg, R. } & \text { P11, P13, P14, P15, P16 } \\ \text { Amendt, J. } & \text { V49, V50, V51, P94 } \\ \text { Ampanozi, G. } & \text { V124, P34, P38 } \\ \text { Anders, S. } & \text { V3 } \\ \text { Andresen-Streichert, H. V61 } & \text { V83 } \\ \text { Angerer, V. } & \text { P } \\ \text { Apfelbacher, M. } & \text { V26 } \\ \text { Ast, F.-W. } & \text { V85, P59 } \\ \text { Ast, F. } & \text { V56 } \\ \text { Augustin, C. } & \text { V32 } \\ \text { Auwärter, V. } & \text { V64, V66, V89, V111, } \\ & \text { V119, P83, P85 } \\ \text { Awe, M. } & \text { V95 } \\ \text { Axmann, S. } & \text { V25 }\end{array}$

\section{B}

\begin{tabular}{ll} 
Baessmann, C. & P85 \\
Bajanowski, T. & V37, P49 \\
Balashova, I. & P31, P32 \\
Balažic, J. & P67, P73 \\
Banaschak, S. & V21, V91, V101 \\
Baqué, M. & V50 \\
Barinov, E. & P25, P31, P32 \\
Barrera, D. & V87 \\
Bartel, F. & P5 \\
Bartsch, C. & V54, V96, P70 \\
Bartschat, S. & V19 \\
Bauer, A. & P72 \\
Bechstein, L. & V9 \\
Becker, K. & P1 \\
Becker, S. & P91 \\
Belenki, L. & P39 \\
Below, E. & P55 \\
Berger, N. & P34, P38 \\
Biel, S. & V35, V36 \\
Bielefeld, L. & P61, P71 \\
Birkenbach, C. & V78, P37 \\
Birngruber, C.G. & V39, V88, V113, P7 \\
Bisharyan, M. & P45 \\
Bittner, F. & V28 \\
Bittorf, A. & P77 \\
Blaas, V. & P77 \\
Blum, S. & V123 \\
Blässer, K. & P62, P69 \\
Bockholdt, B. & P47, P55 \\
Bodendiek, S. & P85 \\
Bohnert, M. & V18, V26, V87, P39 \\
Bondarev, A. & P6 \\
Bornik, A. & V79 \\
& \\
\hline
\end{tabular}

Brandstädter, $\mathrm{K}$

Bratzke, $\mathrm{H}$.

Bregel, D.

Breitbeck, R.

Breitmeier, D.

Bremicker, $\mathrm{K}$.

Brockmann, C.

Bruchhaus, $\mathrm{H}$.

Böhm, M.

Büttner, A.

C

Catereniuc, I. P6

Cherkalina, E. P31

Chevallier, C. V76

Chowaniec, C. V22

Coolnik, M. P73

Cortis, J. V21

Costru-Tasnic, E. P6

Courts, C. V30, V46, V48

D

Daldrup, T. $\quad$ V118

Dammeier, S. V V24

Debertin, A.S. $\quad$ V91, V92, V95

Decker, $\mathrm{P}$. P85

Dedouit, F. V7

Desel, $\mathrm{H}$. P89

Dettmeyer, R. V67, V88, V113, P7, P23

Diers, V. $\quad P 60$

Dirnhofer, R. V7

Dittmann, V. V40, V106, P35

Doberentz, E. $\quad \mathrm{P} 12, \mathrm{P} 17, \mathrm{P} 33$

Dominguez, A. V72

Dreßler, J. $\quad$ V15, P1, P91

Duckwitz, D. V18

Dvorak, J. V126

Dziadosz, M. P87

E

Ebert, L.

Eckart, $\mathrm{K}$.

Edelmann, J.

Edler, C.

Egger, C.

Ehammer, $\mathrm{T}$.

Ehlert, $\mathrm{K}$.

Elakkary, S.

Eplinius, F.

Erdmann, F.

Erfurt, $C$.

Ewald, A.
V73, V81, V124, V128,

P28, P34

$\mathrm{V} 117$

V29, P91

V60

V72, V103

V12

P67

V32, V107

V7

V67

$\mathrm{V} 43, \mathrm{~V} 115, \mathrm{P} 3$

V63, V64, V120
F

Famenka, A. $\quad$ P48

Fandel, S. V34

Fangerau, M. $\quad$ V127

Fieguth, A. V95, V102

Filmann, N. V50

Fischer, F. T. V7, V9, V122

Flach, P. $\quad$ V70, V121, P34, P38

Fleischer, L. V3

Fleischmann, $\mathrm{M}$. P74

Fliss, B. V13

Flössel, U. P3

Fornaro, J. $\quad$ V123

Fracasso, T. V103

Franckenberg, S. V13, V70

Franke, B. $\quad$ V107

Franke, $\mathrm{H}$. V15, P1

Franz, A. V111

Fremdt, $\mathrm{H}$. V49

Furukawa, S. $\quad$ P8

Führer, D. V14

Fürst, M. V128

\section{G}

$\begin{array}{ll}\text { Galbavy, S. } & \text { P4 } \\ \text { Gascho, D. } & \text { P34, P38 } \\ \text { Gasse, A. } & \text { V68 } \\ \text { Gauthier, S. } & \text { V54, P70 } \\ \text { Gehl, A. } & \text { V3, V42, P27 } \\ \text { Geisenberger, D. } & \text { V47, V89, P56, P61 } \\ \text { Genneper, L. } & \text { P17 } \\ \text { Gerlach, K. } & \text { V106 } \\ \text { Germerott, T. } & \text { V56, V92, V102, V121 } \\ \text { Gilg, T. } & \text { V129, P57 } \\ \text { Gliemann, R. } & \text { V88 } \\ \text { Gonsior, M. } & \text { V42 } \\ \text { Grabherr, S. } & \text { V7, V72, V76, V77, V122, } \\ & \text { P36 } \\ \text { Grapp, M. } & \text { P89 } \\ \text { Grass, H. } & \text { V91 } \\ \text { Graw, M. } & \text { V69, V129, P20, P21, P26, } \\ & \text { P57, P64, P72 } \\ \text { Grellner, W. } & \text { P29, P63, P89 } \\ \text { Grimm, J. } & \text { V7, V9, V72, V76, V122 } \\ \text { Grohmann, M. } & \text { P1 } \\ \text { Groß, M. } & \text { V37 } \\ \text { Große Perdekamp, M. } & \text { P61, P66 } \\ \text { Gröticke, C. } & \text { P94 } \\ \text { Grünewald, S. } & \text { V40 } \\ \text { Götz, W. } & \text { P19 } \\ & \\ \text { H } & \text { P84 } \\ \text { Hammer, U. } & \text { V55, V118 } \\ \text { Hara, K. } & \text { V80 } \\ \text { Hartung, B. } & \\ \text { Hartwig, S. } & \\ \text { Hasegawa, I. } & \\ & \\ & \end{array}$




\section{Autorenindex}

\begin{tabular}{|c|c|c|c|c|c|}
\hline Hassel, T. & V52 & Kamphausen, T. & V34 & $\mathbf{L}$ & \\
\hline Hausmann, R. & V123 & Kanou, T. & P24 & Laberke, P. & V123 \\
\hline Hayashi, T. & V109 & Kashiwagi, M. & P84 & Labudde, D. & P91 \\
\hline Heide, S. & P60, P65 & Kastenholz, G. & V10, V11 & Lange-Asschenfeldt, $C$. & V55 \\
\hline Hein, M. & V129 & Kauferstein, S. & V35, V36, V118 & Langkammer, C. & V12 \\
\hline Heinemann, $A$. & & Kawaguchi, M. & & Lardi, C. & V103 \\
\hline & $\begin{array}{l}\text { V75, V77, V78, V94, } \\
\text { P36, P37 }\end{array}$ & $\begin{array}{l}\text { Kawahito, A. } \\
\text { Kawamoto, } 0 .\end{array}$ & $\begin{array}{l}\text { P30 } \\
\text { V104, P9, P10, P24 }\end{array}$ & Larribau, R. & V103 \\
\hline Heinig, B. & P47 & & P30 & Lasczkowski, G. & P23 \\
\hline Heinze, $S$. & V10, V11 & Kegler, $\mathrm{R}$. & P88, P90 & Latacz, K. & V74 \\
\hline Held, $\mathrm{H}$. & $\mathrm{V} 23$ & Keil, W. & V5, V14, V41, V53 & Lehmann, C. & P88 \\
\hline Hellen, F. & V55 & Keller, M. & V33 & Leschka, S. & V123 \\
\hline Herding, P.-M. & V99 & Kempf, J. & P85, P86 & Lessig, R. & V82, P60, P65 \\
\hline Hermanns-Clausen, $\mathrm{M}$. & V89 & Kernbach-Wighton, G. & $\mathrm{P} 11, \mathrm{P} 13, \mathrm{P} 14, \mathrm{P} 15$, & Liehr, A. & P39 \\
\hline Hettler, L. & V10, V11 & & $\mathrm{P} 16, \mathrm{P} 18, \mathrm{P} 19, \mathrm{P} 52$, & Lochner, S. & V9 \\
\hline $\mathrm{He}, \mathrm{C}$ & P15, P18, P78, P79, & & P76 & Lott, S. & P74 \\
\hline & P81, P82 & Kettner, M. & V6, V64, V120 & Lottner-Nau, S. & V69 \\
\hline Higo, E. & V109 & Kiehne, N. & V36 & Lotz, J. & P29 \\
\hline Hishmat, AM & P24 & Kimura, A. & V110 & Ludwig, K.-H. & V98 \\
\hline Hoffmann, T. & P94 & Klann, A.E. & P55 & Lunow-Linzbach, A. & V112 \\
\hline Hofmann, Y. & V46 & Klein, A. & P27 & Lupatsch, F. & V83, P5 \\
\hline Holz, F. & V39 & Klingel, K. & P63 & Lutterbach, J.M. & P26 \\
\hline Holzhausen, H.-J. & V83, P5 & Klingner, S. & P89 & Lutz-Bonengel, S. & V27, V33, P56 \\
\hline Hopf, M. & V63 & Klintschar, M. & V56, V85, V102, V108, & Lux, C. & V30 \\
\hline Huckenbeck, W. & V55 & & P59, p87 & Läer, K. & V28 \\
\hline Huppertz, L. & V66, V111, V119, P85, & Kluza, P. & V74 & Lövblad, K.-O. & V12 \\
\hline & P86 & Klöppel, A. & P49 & & \\
\hline Hutter, M. & V66 & Kneisel, S. & V64 & $\mathbf{M}$ & \\
\hline Höfig, J. & V45 & Kneubuehl, B. & V16, V25 & IVI & \\
\hline Höller, J. & V125 & Knopp, W. & V17 & Madea, B. & V30, V46, V48, V112, P11, \\
\hline Hörer, S. & V27 & Knuth, M. & P81 & & P12, P13, P14, P15, P16, \\
\hline & & Koerber, $\mathrm{F}$. & V98, V99 & & P17, P18, P19, P33, P52, \\
\hline & & Koetz, S. & V94 & & P53, P54, P74, P75, P76, \\
\hline | & & Kohlbacher, 0. & V24 & & P78, P79, P80, P81, P82 \\
\hline Idor, A. & P50 & Komatz, G. & $\mathrm{V} 12$ & Maeda, $\mathrm{H}$. & V104, P9, P10, P24, P30 \\
\hline Ishida, Y. & V110 & Komo, L. & P94 & Majcen, R. & P38 \\
\hline Ishikawa, T. & V104, P9, P10, P24, & Kondo, T. & V110 & Maksymowicz, K. & P40, P41 \\
\hline & P30 & Kosciuk, J. & P40, P41 & Mall, G. & V31, V45, P92 \\
\hline Iwersen-Bergmann, S. & V61 & Kosuhina, $\mathrm{O}$. & P32 & Maltsev, A. & P51 \\
\hline & & Kralj, E. & P67, P73 & Mangin, P. & V7, V76, V103 \\
\hline & & Kramer, F.-J. & P29 & Manhart, J. & P46 \\
\hline J & & Kraus, $\mathrm{S}$. & V5, V53 & Mark, D. & V33 \\
\hline & & Krause, $\mathrm{M}$. & V98 & Marschall, C. & P63 \\
\hline Jachau, K. & V82 & Krebs, N. & V12 & Martinez, R.M. & V96, V124, V128 \\
\hline Jackowski, C. & 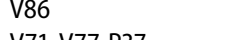 & Kreutz, K. & V39 & Martínez-Ramírez, J.A. & P92 \\
\hline Jahnke, P. & V71, V77, P37 & Kreye, C. & V4 & Mathony, U. & P65 \\
\hline Jantz, R. & V38 & Kriebel, T. & P63 & Matschke, J. & V4 \\
\hline Jarisch, A. & P55 & Krischel, R. & V90 & Matsushita, S. & V104 \\
\hline Jenewein, $\mathrm{T}$. & V35, V36 & Kröner, L. & V65 & Matsusue, A. & P84 \\
\hline Jeraufke, S. & P91 & Kubo, S. & P84 & Matzenauer, C. & V44 \\
\hline Johnke, S. & P27 & Kuczyk, M. & V108 & Meinzer, H.-P. & V127 \\
\hline Jung, $\mathrm{H}$. & P50 & Kudla, M. & P40 & Michiue, T. & V104, P9, P10, P24, P30 \\
\hline Junge, $A$. & V126 & Kuninaka, Y. & V110 & Mikulas, L. & P22 \\
\hline Jungen, $\mathrm{H}$. & V61 & Kunz, C. & V29 & Miura, M. & V84 \\
\hline Junker, J. & V24 & Kuruc, R. & P22, P58 & Miyaishi, S. & V84 \\
\hline Jurek, T. & P40, P41 & Kurz, A. & V26 & Montenarh, D. & V63 \\
\hline Jäger, A. & P19 & Kuštrin - Samba, A. & P73 & Moosmann, B. & V66 \\
\hline Jänicke, N. & V116 & Köhl, S. & V17 & Morgan, B. & V7 \\
\hline Jöster, B. & V106 & Köhler, H. & V68 & Morita, S. & V8 \\
\hline & & Köllner, R. & V31 & Moskala, A. & V74 \\
\hline$K$ & & Kölzer, S.C. & V88 & Mueller, A. & V61 \\
\hline K & & König, R. & V35 & Mueller, C. & V41 \\
\hline Kainz, S. & V57 & Köwing, A. & V8 & Musshoff, F. & V112, P75, P80, P81 \\
\hline Kaiser, C. & P26 & Kühn, M. & V17 & Märtens, A. & V82 \\
\hline Kalimo, $\mathrm{H}$. & $\mathrm{P} 2$ & Kühnel, P. & V129 & Mück, F. & V9 \\
\hline Kammal, M. & V8, V78 & & & Müller, F. & V10, V11 \\
\hline
\end{tabular}


Müller, M.

Mützel, E.

V127

V91, P21

N

Nahnsen, S. V24

Nakano, M. P30

Nasse, $\mathrm{S}$. P49

Naue, J. V33, V47

Navarro-

Crummenauer, B. $\quad$ V98, V99

Nerlich, A. $\quad$ P21

Neuhuber, F. V47

Neukamm, M.A. V89

Niederegger, $\mathrm{S}$. V45

Niederstrasser, $\mathrm{O}$. P5

Nigg Trawally, N. V54, P70

Nishi, K. P8

Nitsch, R. V58

Nofer, J.-R. V V105

Nosaka, M. V110

Nowotni, C. V27

\section{0}

Obert, M. V39

Ogata, M. V109

Ojanpera, I. P85

Okunaga, $\mathrm{H}$. $\quad \mathrm{P} 8$

Ondruschka, B. V15, P1

Opitz, F. V102

Oritani, S. P10, P24

Ormandy, L.A. P63

Ousley, S. V38

Övgüer, B. V V69

\section{P}

Padure, A. P93

Parchina, M. P15

Parzeller, M. V1, P42, P43, P44

Paul, L.D. V69

Paulke, A. V62, V116

Pelander, A. P85

Persson, A. V70

Peschel, O. P20, P21, P26, P64

Peters, B. V64

Peters, F.T. P92

Pfeiffer, H. V68, V105

Pfeiffer, J.-L. $\quad$ V97

Pflugbeil, A.-M. P91

Philipp, K.P. P47

Pietsch, K. V33

Piombino-Mascali, D. P75

Pircher, R. P61

Plenzig, S. V23, V100

Poetsch, M. V34, V37

Pogoda, W. V116, P94

Pohlemann, T. V17

Pohlers, D. V15

Pollak, S. P56, P66, P71

Potente, S. V100

Preiß, U. V56

Preuss, V. $\quad$ V85

Priester, J. $\quad$ V17

Prittwitz, C. P42
Prittwitz, S. P4

Proschak, E. V62

Ptacek, W. V128

Püschel, K.

V3, V8, V60, V78, V80, V84, V93, V94, V97, V107, P37

R

Rahlmeyer, T. V17

Ramsthaler, F. V6, V39, V42

Ratajczak, C. P39

Reckert, A. V44

Reichenspurner, $\mathrm{H}$. V75

Reichert, C. P19

Reicht, I. V127

Reimann, C. V93

Reisch, T. V54

Rentsch, D. P77, P88

Riener-Hofer, R. V57

Riepert, T. V52, V58

Rinaldi, A. V72

Rittner, C. P54

Ritz-Timme, S. V44, V118

Roewer, N. V87

Roider, G. V53, V69, P72

Roiu, I. V113

Romodanovsky, P. P25, P31, P32

Ropele, S. V12

Rosendahl, W. P75

Rosenkranz, B. V99

Ross, S.G. V13, V70, V81, V124,

P38

Rost, T. P35

Rothschild, M.A. V19, V21, V90, V101

Ruder, T.D. V73, V124, P34, P38

Rutty, G. V7

Rygol, K. V22

Rzepecka-Wozniak, E. V74

Röhrich, J. V117

\section{$S$}

Sabljic, D. V114

Sachs, H. V69, V112, P72

Sanft, J. V31, P92

Sariyar, M. V52

Sassenberg, A. V127

Sauer, E. V46, V48

Saukko, P. P2

Schermer, J. V45

Scherr, M. V9, V122

Scheurer, E. V12, V57, V79, V125

Schick, P.J. V57

Schlauderer, N. V33

Schlemmer, H.-P. V127

Schmeling, A. V105, V126

Schmidt, P.

Schmidt, S.

Schmidt, U.

Schmitter, S.

Schmüser, $\mathrm{S}$.

Schnabel, A.

Schnerr, $\mathrm{H}$.

Schober, K.

V63, V64, V120

V105

P3, V33, V47

V43

V68

V23

V29

V15
Schröder, C.
Schröder, R.-J.

Schuff, A.

Schulz, K.

Schulz, M.M.

Schulz, Y.

Schweitzer, W.

Schwerer, M.

Schyma, C.

Schäfer, N.

Schönfeldt, E.

Schöpfer, J.

Schürenkamp, J.

Sebestény, T.

Segelbacher, G.

Sehner, $\mathrm{S}$.

Seibel, 0.

Seidel, E.

Seifert, D.

Seo, T.

Sergon, M.

Shokri, D.

Sidlo, J.

Sidlova, $\mathrm{H}$.

Siegenthaler, L.

Sikuta, J.

Simons, D.

Sinicina, I.

Skopp, G.

Smith, F.

Sobanski, E.

Sogawa, N.

Sohre, $\mathrm{S}$.

Sommer, G.

Sommer, K.

Spencer, V.

Sperhake, J.

Spiridonov, V.

Spiwoks-Becker, I.

Stanislawski, N.

Sterzik, V.

Stiller, D.

Stock, J.-P.

Stoll, $\mathrm{S}$.

Stratan, M.

Strien, J.

Strohbeck-Kuehner, P.

Strohmeier, 0

Strona, M.

Sudan, S.

Sundstroem, M

Sänger, T.

P36

V10, V11

V17

V115

V129, P26

V56

V73, V124, P28, P34,

P38

P20, P21, P57, P72

V30, V46, V86, P12

V64

P27

V41, P72

V68

V58

V33

V3

V60

P91

V91, V93, V94, V97

V104

P3

$\mathrm{V} 107$

P4, P22, P58

P58

V16, V25

P4, P22, P58

$\mathrm{V} 127$

V14

V114

V72

V114

P10, P24

P94

V15

V62

V65, V67, V113, P7, P23

V4

P68

V58

P55

V87, V129, P39

V83, P5

V17

V53

P93

V31, p92

V114

V33

V74

P18

P85

V27, P61

$\mathrm{T}$

Takayama, M. P84

Taniguchi, K. V84

Tantius, B. V101

Tasnic, M.

Tatschner, $\mathrm{T}$.

Teske, J.

Teupser, D.

Thali, M.J.
P6

V87

P87

V15

V13, V70, V73, V81,

V96, V121, V124,

V128, P28, P34, P38 


\begin{tabular}{|c|c|c|c|}
\hline \multicolumn{4}{|c|}{ Autorenindex } \\
\hline Thiel, G. & V36 & Wudy, R. & V122 \\
\hline Thiele, K. & P91 & Wulff, B. & V60 \\
\hline Thieme, D. & V115 & Wunder, C. & V62, V116 \\
\hline Thierauf, A. & V111, P66 & Wölfle, J. & P80 \\
\hline Timme, M. & V126 & Wülker, M. & P39 \\
\hline Todt, M. & V95 & & \\
\hline Traber, J. & P86 & & \\
\hline Trageser, P. & V100 & $\mathbf{Y}$ & \\
\hline Trübner, K. & P48, P50 & Yen, $\mathrm{K}$. & V12, V127 \\
\hline Tschui, J. & V86 & Ten, $\mathrm{N}$ & $\sqrt{12}, \mathrm{v} 121$ \\
\hline Tsokos, M. & V107 & & \\
\hline Tunikowski, W. & P40, P41 & $\mathbf{Z}$ & \\
\hline Tzikas, A. & V71 & & \\
\hline Tönnes, S. & V62, V100, V116 & Zajac, B.K. & V51 \\
\hline Türk, E. & V2 & Zedler, B. & V1, P43, P44 \\
\hline Türk, O.M. & P7 & $\begin{array}{l}\text { Zehner, R. } \\
\text { Ziegeler, E. }\end{array}$ & $\begin{array}{l}\text { V26, V51 } \\
\text { V122 }\end{array}$ \\
\hline & & Zindler, K. & P29, P63 \\
\hline $\mathbf{U}$ & & Zinka, B. & P72 \\
\hline Uebbing, K. & V98, V99, V117 & Zummerova, A. & P22 \\
\hline Ueffing, M. & V24 & & \\
\hline Urbach, $\mathrm{H}$. & P53 & & \\
\hline Urban, R. & $\begin{array}{l}\text { V10, V11, V52, V58, } \\
\text { V98, V99, V117 }\end{array}$ & & \\
\hline Urschler, M. & V79, V125 & & \\
\hline Ückert, S. & V108 & & \\
\hline \multicolumn{4}{|l|}{$\mathbf{V}$} \\
\hline Valent, D. & P4, P58 & & \\
\hline Varlet, V. & V72 & & \\
\hline Vaucher, P. & V76 & & \\
\hline Vennemann, B. & V85, P59 & & \\
\hline Vennemann, M. & V28 & & \\
\hline Verhoff, M. A. & $\begin{array}{l}\text { V6, V39, V42, V88, } \\
\text { V113, P7 }\end{array}$ & & \\
\hline Vieth, V. & V126 & & \\
\hline Vlanic, D. & P80 & & \\
\hline Vogel, B. & V75 & & \\
\hline Vogel, $\mathrm{H}$. & $\begin{array}{l}\text { V8, V20, V71, V75, } \\
\text { V77, V78, V80, P37 }\end{array}$ & & \\
\hline Vogt, S. & V89, V119, P71 & & \\
\hline von Gerlach, S. & $\mathrm{P} 23$ & & \\
\hline von Stetten, F. & V33 & & \\
\hline Voß, H. & V83 & & \\
\hline \multicolumn{4}{|l|}{$\mathbf{W}$} \\
\hline Waters, B. & P84 & & \\
\hline Weber, M. & P1 & & \\
\hline Wehner, F. & V24, P26 & & \\
\hline Wehner, H.-D. & V24 & & \\
\hline Weisser, H.-J. & P61 & & \\
\hline Weller, J.P. & V56, P87 & & \\
\hline Wendt, K. & P85 & & \\
\hline Wildermuth, S. & V123 & & \\
\hline Wilhelm, B. & V17 & & \\
\hline Wilke, N. & V93 & & \\
\hline Windgassen, M. & V105 & & \\
\hline Wingenfeld, L. & P8, P20, P64 & & \\
\hline Wirth, S. & V122 & & \\
\hline Wittig, $\mathrm{H}$. & V7, V40, P35 & & \\
\hline Wittschieber, D. & V126 & & \\
\hline Wolff-Maras, R. & V56, V102 & & \\
\hline Wollersen, $\mathrm{H}$. & V67, V113 & & \\
\hline Wozniak, K. & V7,V74 & & \\
\hline
\end{tabular}

